\title{
Ontology of Designing
}

ISSN 2223-9537

Scientific journal

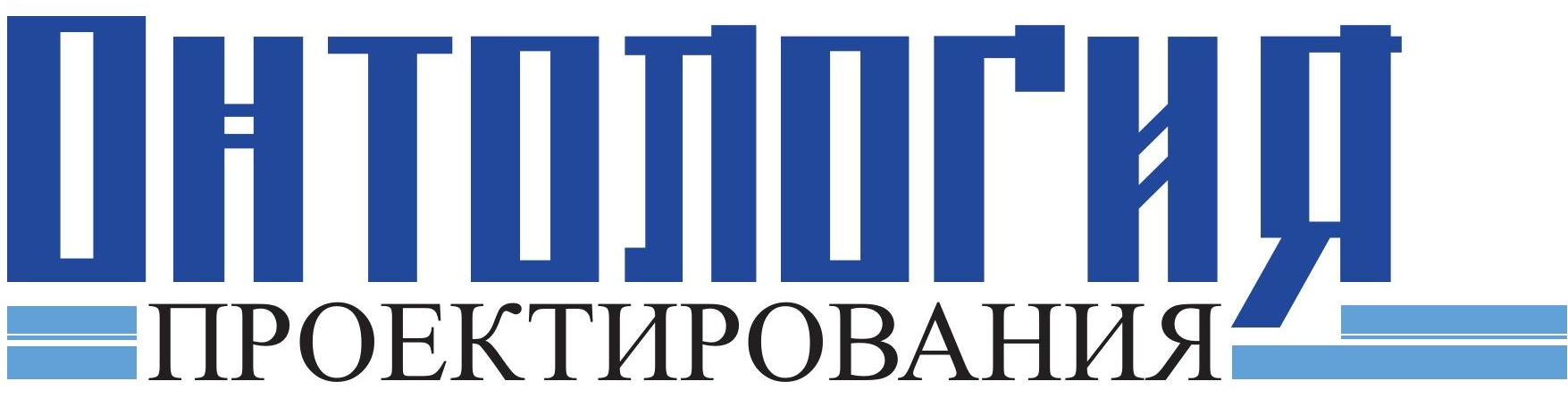

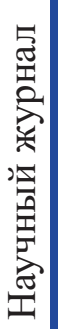

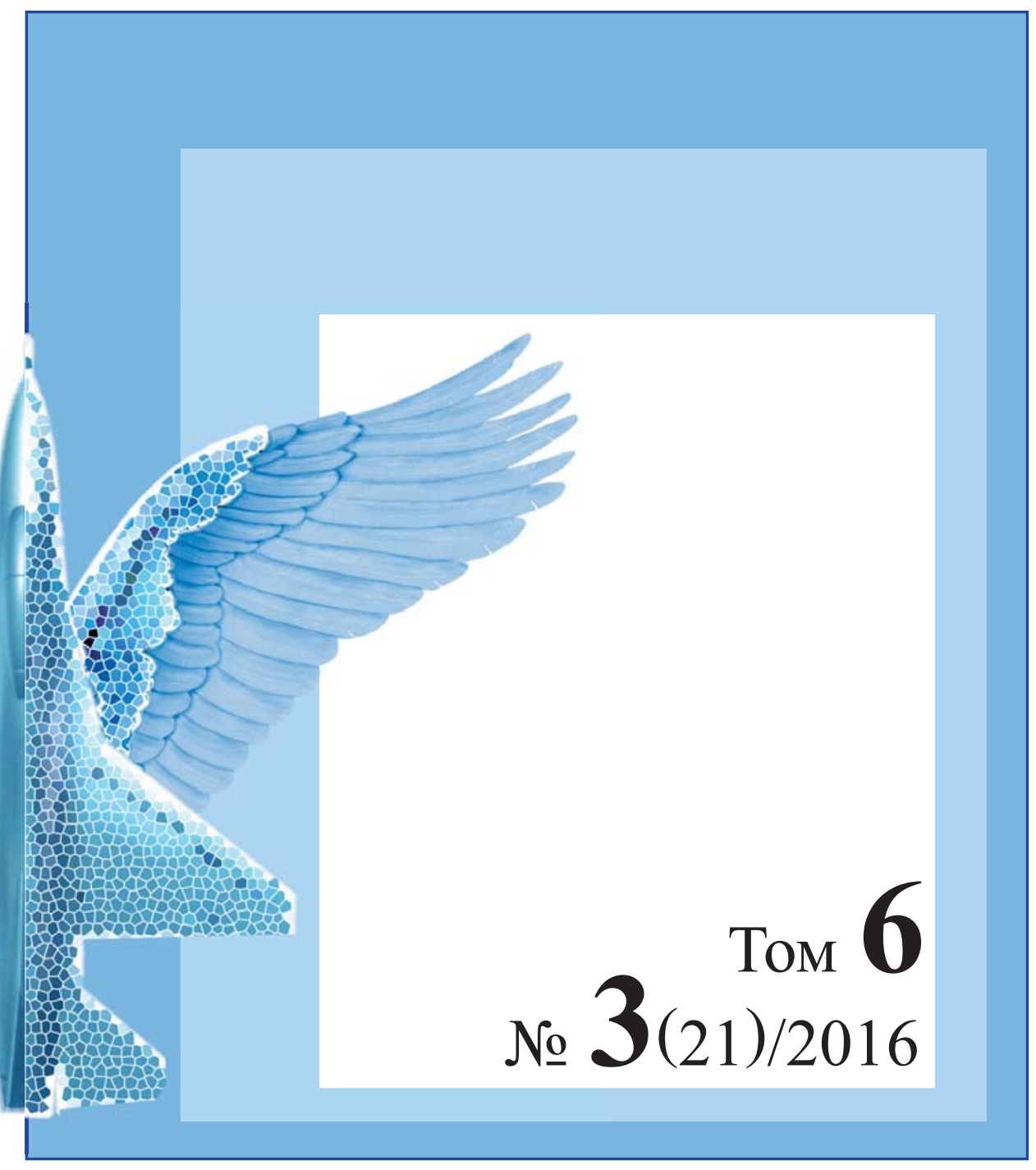




\section{Ontology of Designing}

\section{ㅁТ미대매 \\ ПРОЕКТИРОВАНИЯ}

Научный журнал

Том 6

№ 3(21)

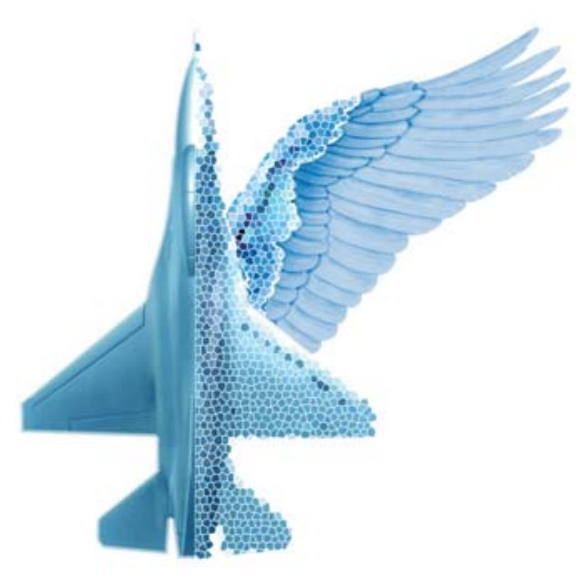


ISSN 2223-9537 (Print)

ISSN 2313-1039 (Online)
«ОНТОЛОГИЯ ПРОЕКТИРОВАНИЯ»

том 6 № 3(21)/2016

DOI:10.18287/2223-9537-2016-6-3

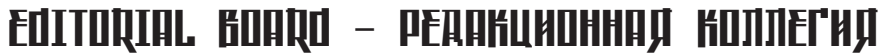

Anatoly I. Belousov

Nikolay M. Borgest Yuri R. Valkman

Stanislav N. Vasiliev

Vladimir A. Vittikh

Vladimir V. Golenkov

Vladimir I. Gorodetsky

Alexander S. Kleshchev

Valery A. Komarov

Sergey M. Krylov

Victor M. Kureichik Dmitry V. Lande

Lyudmila V. Massel

Dmitry A. Novikov

Alexander V. Palagin

Semyon A. Piyavsky

Yury M. Reznik

George Rzevski

Peter O. Skobelev

Sergey V. Smirnov

Peter I. Sosnin

Dzhavdet S. Suleymanov Robert I. Tuller

Boris E. Fedunov

Altynbek Sharipbay

Boris Ya. Shvedin
Белоусов Анатолий Иванович, д.т.н., профессор, Самарский университет, г. Самара Боргест Николай Михайлович, к.т.н., профессор Самарский университет, член IAOA, г. Самара Валькман Юрий Роландович, д.т.н., профессор, МНУЦ ИТиС НАН и МОН Украины, г. Киев Васильев Станислав Николаевич, д.т.н., профессор, академик РАН, ИПУ РАН, г. Москва Виттих Владимир Андреевич, д.т.н., профессор, ИПУСС РАН, г. Самара Голенков Владимир Васильевич, д.т.н., профессор, БГУИР, г. Минск Городецкий Владимир Иванович, д.т.н., профессор, СПИИРАН, г. Санкт-Петербург Клещёв Александр Сергеевич, д.ф.-м.н., профессор, ИАПУ ДВО РАН, г. Владивосток Комаров Валерий Андреевич, д.т.н., профессор, Самарский университет, г. Самара Крылов Сергей Михайлович, д.т.н., профессор, СамГТУ, г. Самара Курейчик Виктор Михайлович, д.т.н, профессор, Технологический институт ЮФУ, г. Таганрог Ландэ Дмитрий Владимирович, д.т.н, с.н.с., ИПРИ НАН Украины, г. Киев

Массель Людмила Васильевна, д.т.н., профессор., ИСЭМ СО РАН, г. Иркутск Новиков Дмитрий Александрович, член-корреспондент РАН, ИПУ РАН, г. Москва Палагин Александр Васильевич, д.т.н., проф., академик НАН Украины, Ин-т кибернетики, г. Киев Пиявский Семён Авраамович, д.т.Н., профессор, СГАСУ, г. Самара Резник Юрий Михайлович, д.филос.н., проф., Институт философии РАН, г. Москва Ржевский Георгий, профессор, Открытый университет, г. Лондон Скобелев Петр Олегович, д.т.н., НПК «Разумные решения», г. Самара

Смирнов Сергей Викторович, д.Т.н., ИПУСС РАН, г. Самара

Соснин Петр Иванович, д.т.н., профессор, УлГТУ, г. Ульяновск

Сулейманов Джавдет Шевкетович, академик, вице-президент АН РТ, г. Казань Таллер Роберт Израилевич, д.филос.н., профессор, Самарский университет, г. Самара Федунов Борис Евгеньевич, д.т.н., профессор, ГосНИИ авиационных систем, г. Москва Шарипбай Алтынбек, д.т.н., профессор, Институт искусственного интеллекта, г. Астана Шведин Борис Яковлевич, к.психол.н., ООО «Дан Роуз», член IАОА, г. Ростов-на-Дону

\section{Executive Editorial Board - Исполнительная редакция}

Chief Editor Smirnov S.V.

Executive Editor Borgest N.M. Editor Kozlov D.M. Editor Krylov S.M.

Technical Editor Simonova A.U. Translation Editor Korovin M.D. Secretary Shustova D.V.
Главный редактор

Выпускающий редактор

Редактор

Редактор

Технический редактор

Редактор перевода

Секретарь
Смирнов С.В.

Боргест Н.M.

Козлов Д.М.

Крылов С.М.

Симонова А.Ю

Коровин М.Д.

Шустова Д.В. зам. директора ИПУСС РАН директор изд-ва «Новая техника» профессор Самарского университета профессор СамГТУ

редактор изд-ва «Новая техника» аспирант Самарского университета инженер ИПУСС РАН

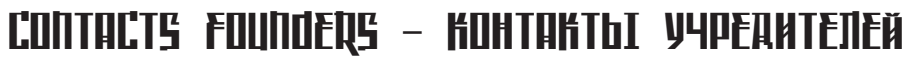

\section{ИПУСС РАН}

443020, Самара, ул. Садовая, 61

тел./факс.: +7 (846) 3332770

\section{Самарский университет}

443086, Самара, Московское шоссе 34, корп. 10, кафедра КиПЛА

тел.: +7 (846) 2674647 , факс.: +7 (846) 2674646
Смирнов С.В.

smirnov@iccs.ru

Боргест H.M.

borgest@yandex.ru

ООО «Новая техника» (издательство)

Адрес редакции: 443010, Самара, ул.Фрунзе, 145, тел.: +7 (846) 33267 84, факс: +7 (846) 3326781

The journal has entered into an electronic licensing relationship with EBSCO Publishing, the world's leading aggregator of full text journals, magazines and eBooks. The full text of JOURNAL can be found in the EBSCOhost ${ }^{\mathrm{TM}}$ databases.

The journal has been successfully evaluated in the evaluation procedure for the ICI Journals Master List 2014 and journal received the ICV (Index Copernicus Value) of $\mathbf{6 7 . 4 6}$ points.

Журнал включён в перечень рецензируемых научных изданий, в которых должны быть опубликованы основные научные результаты диссертаций на соискание учёной степени кандидата наук, на соискание учёной степени доктора наук (Письмо Департамента аттестации научных и научно-педагогических работников Минобрнауки РФ от 01.12.2015 № 13-6518).

Журнал включён в Российский индекс научного цитирования (РИНЦ). Номер контракта 64-03/2012.

Импакт-фактор РИНЦ с учётом цитирования из всех источников 0,839 (2013 г.), 1,340 (2014 г.), 2,039 (2015 г.).

Журнал зарегистрирован в Федеральной службе по надзору в сфере связи, информационных технологий и массовых коммуникаций (Роскомнадзор). Свидетельство ПИ № ФС 77-46447 от 7.09.2011 г.

\section{http://agora.guru.ru/scientific_journal/}

Отпечатано в ООО «Новая техника», г. Самара, пр.К.Маркса 24-76.

Дата выхода 19.09.2016. Тираж 300 экз. Свободная цена. (6+).
() Все права принадлежат авторам публикуемых статей

( ) Издательство «Новая техника», 2011-2016

( ) Самарский университет, 2015-2016

(c) ИПУСС РАН, 2015-2016 
[DREP米早HE

\section{ОТ РЕДАКЦИИ}

«ВСЁ СВОЁ НОШУ С СОБОЙ»

253-254

ПРИКЛАДНЫЕ ОНТОЛОГИИ ПРОЕКТИРОВАНИЯ

А.Ю. Агроник, А.А. Талалаев, В.П. Фраленко, В.М. Хачумов, О.Г. Шишкин

255-269

АНАЛИЗ СИСТЕМ ПРОЕКТИРОВАНИЯ

ТЕХНОЛОГИЧЕСКИХ ЦЕПОЧЕК И ПРОЦЕССОВ

А.И. Армер, В.С. Мошкин

ПОДХОД К ФОРМИРОВАНИЮ НАБОРОВ ЭТАЛОНОВ

РЕЧЕВЫХ КОМАНД С ИСПОЛЬЗОВАНИЕМ ОНТОЛОГИИ

В.А. Игруша, С.С. Сосинская

КОНВЕРТЕР ОНТОЛОГИЧЕСКОЙ БАЗЫ ЗНАНИЙ СТАНКОВ

И ДЕТАЛЕЙ МАШИНОСТРОИТЕЛЬНОГО ПРОИЗВОДСТВА

В ОБЪЕКТНУЮ БАЗУ ДАННЫХ НА ОСНОВЕ ANTLR

\section{ИНЖИНИРИНГ ОНТОЛОГИЙ}

$\begin{array}{lr}\text { В.Н. Кучуганов } & \mathbf{2 8 7 - 2 9 6}\end{array}$

ОНТОЛОГИЯ И АНИМАЦИЯ ПРЕЦЕДЕНТОВ

С.В. Лебедев, М.Г. Пантелеев

297-316

ОНТОЛОГИЧЕСКОЕ ПРОЕКТИРОВАНИЕ ПОДСИСТЕМЫ ОЦЕНКИ ОБСТАНОВКИ ИНТЕЛЕКТУАЛЬНЫХ АГЕНТОВ

Д.Е. Самойлов, В.А. Семёнова, С.В. Смирнов

317-339

АНАЛИЗ НЕПОЛНЫХ ДАННЫХ

В ЗАДАЧАХ ПОСТРОЕНИЯ ФОРМАЛЬНЫХ ОНТОЛОГИЙ

\section{МЕТОДЫ И ТЕХНОЛОГИИ ПРИНЯТИЯ РЕШЕНИЙ}

В.И. Левин

340-354

ДИФФЕРЕНЦИРОВАНИЕ ИНТЕРВАЛЬНЫХ

ЭЛЕМЕНТАРНЫХ ФУНКЦИЙ И ПРИНЯТИЕ РЕШЕНИЙ

\section{ФИЛОСОФСКИЕ АСПЕКТЫ ПРОЕКТНОЙ ДЕЯТЕЛЬНОСТИ}

С.Л. Подвальный, Е.М. Васильев

КОНЦЕПЦИЯ МНОГОАЛЬТЕРНАТИВНОСТИ

В ЖИВЫХ И НЕЖИВЫХ СТРУКТУРАХ

С.В. Шалагин, Г.Э. Шалагина

КОГНИТИВНЫЕ ПРОБЛЕМЫ ПРОЕКТИРОВАНИЯ НА ОСНОВЕ КОМПЬЮТЕРНЫХ МОДЕЛЕЙ: ТЕХНИЧЕСКИЙ И СОЦИО-ГУМАНИТАРНЫЙ АСПЕКТЫ

А.Ю. Нестеров

ЭПИСТЕМОЛОГИЧЕСКИЕ И ОНТОЛОГИЧЕСКИЕ ПРОБЛЕМЫ ФИЛОСОФИИ ТЕХНИКИ: «ЧЕТВЁРТОЕ ЦАРСТВО» Ф. ДЕССАУЭРА

ОРИГИНАЛЬНЫЕ ПЕРЕВОДЫ

Ф. Дессауэр. К ФИЛОСОФИИ ТЕХНИКИ. ЧТО ЕСТЬ ТЕХНИКА?

- ТЕРМИН И СУЩНОСТЬ. Пер. с нем. А.Ю. Нестерова

Рекомендуемые издания $\quad 407$

Научная конференция ACS-2016 408 


\section{FROM THE EDITORS}

ALL THAT'S MINE I CARRY WITH ME

APPLIED ONTOLOGY OF DESIGNING

A.Yu. Agronik, A.A. Talalaev, V.P. Fralenko, V.M. Khachumov, O.G. Shishkin ANALYSIS OF SYSTEMS FOR TECHNOLOGICAL CHAINS AND PROCESSES DESIGNING

A.I. Armer, V.S. Moshkin APPROACH TO CREATING A SET OF REFERENCE SPEECH COMMANDS USING ONTOLOGY

V.A. Igrusha, S.S. Sosinskaya CONVERTER FOR THE ONTOLOGIC KNOWLEDGE BASE OF MACHINE TOOLS AND PARTS OF MACHINE-BUILDING PRODUCTION PLANT INTO AN OBJECTIVE DATABASE BUIILT ON ANTLR

\section{ONTOLOGY ENGINEERING}

V.N. Kuchuganov ONTOLOGY AND ANIMATION OF PRECEDENTS

S.L. Lebedev, M.G. Panteleyev ONTOLOGY-DRIVEN DESIGN APPROACH TO DEVELOPMENT OF SITUATION AWARANESS SUBSYTEM OF INTELLIGENT AGENTS

D.E. Samoilov, V.A. Semenova, S.V. Smirnov INCOMPLETE DATA ANALYSIS FOR BUILDING FORMAL ONTOLOGIES

\section{METHODS AND TECHNOLOGIES OF DECISION MAKING}

V.I. Levin DIFFERENTIAL CALCULUS OF INTERVAL ELEMENTARY FUNCTIONS AND DECISION-MAKING

\section{PHILOSOPHICAL AND LINGUISTIC ASPECTS OF DESIGNING}

S.L. Podvalny, E.M. Vasiljev

THE CONCEPT MULTI-ALTERNATIVE

IN THE ANIMATE AND INANIMATE STRUCTURES

S.V. Shalagin, G.E. Shalagina COGNITIVE PROBLEMS OF DESIGNING BASED ON COMPUTER MODELS: TECHNICAL AND SOCIO-HUMANITARIAN ASPECTS

A.Y. Nesterov EPISTEMOLOGICAL AND ONTOLOGICAL PROBLEMS OF THE PHILOSOPHY OF TECHNOLOGY: "THE FOURTH KINGDOM" OF F. DESSAUER

\section{ORIGINAL TRANSLATION}

F. Dessauer. BY THE PHILOSOPHY OF TECHNOLOGY. WHAT IS TECHNOLOGY? - THE TERM AND NATURE. Translated from German by A.Y. Nesterov

Recommended Books

Scientific Conference ACS-2016 


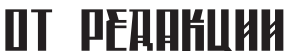

\section{«ВСЕ СВОЁ НОШУ С СОБОЙ» \\ ALL THAT'S MINE I CARRY WITH ME OMNIA MEA MECUM PORTO}

\section{Дорогой наш читатель, уважаемые авторы и члены редакционной коллегии!}

Этот номер выходит к началу работы XVIII международной конференции «Проблемы управления и моделирования в сложных системах» (ПУМСС-2016), которая пройдёт с 20 по 25 сентября 2016 г. на борту теплохода «Валерий Чкалов», следующего по маршруту Самара-Чебоксары-Нижний Новгород-Казань-Самара.

Именно на этой конференции в кругу коллег, друзей и единомышленников за «круглым столом» мы намерены обсудить пятилетние результаты молодого журнала, рождённого как раз после очередной конференции ПУМСС-2011. И уже в сентябре 2011 года, ровно пять лет тому назад, журнал был зарегистрирован в Роскомнадзоре и именно в сентябре вышел его нулевой номер, определивший формат и концепцию будущего научного продукта. Самарский университет (в ту пору СГАУ), академический институт (ИПУСС РАН) и издательство (ООО «Новая техника») объединили свои усилия в создании широкой, интернациональной и междисциплинарной площадки для научных дискуссий в области формализации знаний в проектной деятельности на основе онтологий, компьютерных наук и технологий (computer science and engineering).

Вопросы научной этики изначально для нас были определяющими. Поэтому обращение к истокам научной мысли, к ушедшим в историю гигантам, на плечах которых стоит и современное поколение исследователей, выбрано нами не случайно. В каждом номере журнала мы вспоминаем мудрецов, чтя их достижения, высказанные идеи и суждения.

В этом номере наш «гость» - Биа́нт Прие́нский (др.-греч. Вías о Прıұvє̀̀); VI век до н.э.), древнегреческий мудрец и общественный деятель, один из семи особо чтимых мудрецов. Он сочинил около 200 стихов про Ионию (область на западном побережье Малой Азии у Эгейского моря) и про то, как ей лучше достичь благоденствия, давая мудрые советы её гражданам:

Будь всем гражданам угоден, где тебе ни случится жить:

В этом - благо истинное, дерзкому же норову -

Злая сверкает судьба ${ }^{1}$.

Диоген Лаэртский в своей книге о греческих мудрецах оставил нам воззрения Бианта на жизнь, на её онтологию. «Сила человеку даётся от природы, умение говорить на благо отечества - от души и разумения, а богатство средств - у многих от простого случая». Биант говорил, что несчастен тот, кто не в силах снести несчастье; что жизнь надо размеривать так, будто жить осталось и мало, и много.

\footnotetext{
1 Диоген Лаэртский. О жизни, учениях и изречениях знаменитых философов. Пер. с древнегреч. М.Л.Гаспарова. 2-е изд., испр. - М.: Издательство "Мысль", 1986. - 576 c. - http://www.krotov.info/lib_sec/05_d/dio/gen_02.htm
} 
Биант советовал не спешить браться за дело, а взявшись, быть твёрдым. «Говори, не торопясь: спешка - знак безумия. Люби разумение. Не силой бери, а убеждением. Из молодости в старость бери мудрость, ибо нет достояния надежнее». Известно также и его «антидемократическое» и не бесспорное изречение, что «большинство - зло».

История захвата персами Приены, его родного города, «породила» ставшее знаменитым философское утверждение Бианта. Когда многие жители стали покидать город, стремясь захватить с собой как можно больше имущества, среди толпы беженцев выделялся Биант, который спокойно шёл, держа в одной руке небольшой узелок. На вопрос, почему он ничего с собой не взял, Биант ответил: «Всё своё ношу с собой». Впоследствии это изречение стало излюбленной греческой пословицей ${ }^{2}$.

Нет необходимости здесь говорить о том, что самое ценное, чем мы владеем, что действительно является нашей собственностью и что неоспоримо, и неотделяемо принадлежит лично нам - это наши знания, умения и навыки, которые всегда с нами. И только наше желание, наша добрая воля позволяет отделить их от нас.

Наши авторы искренне делятся своими знаниями и результатами своих исследований на страницах нашего журнала.

На первых этапах создания журнала мы для себя определили параметры номера по количеству статей. Решили, что их не будет более десяти в номере. Цель этого ограничения одна - стремление получить высокое качество публикаций. Сегодняшний номер вышел на границу установленного нами же максимума. Конечно, для этого потребовалась упорная работа редакции журнала, но мы счастливы порадовать авторов и читателей и вот таким образом отметить наш пятилетний юбилей.

В этом номере de facto мы констатирует открытие новой рубрики в нашем журнале «Оригинальныле переводыl». Ранее мы уже публиковали переводы с английского Коммюнике Онтологического Саммита 2014 и 2016 (№2, 2014 и № 2, 2016). В этом номере впервые публикуется перевод с немецкого языка одной из глав монографии «Спор о технике» Фридриха Дессауэра «К философии техники. Что есть техника? - термин и сущность». Впредь мы также намерены публиковать оригинальные переводы иноязычных материалов, которые актуальны для нашего читателя и нигде ранее не публиковались на русском языке.

Этот номер, также как и предыдущие, богат и на географию авторов. Наши авторы представили в нём результаты исследований, проводимых в национальных исследовательских университетах Иркутска, Казани, Самары, в университетах Воронежа, Ижевска, Пензы, Санкт-Петербурга и Ульяновска, в академических института Москвы, ПереславльЗалесского, Самары, в компаниях и предприятиях Москвы, Иркутска и других городов.

Издательский портфель журнала неуклонно растёт, и это радует.

Мы продолжаем расширять наше присутствие в медиа пространстве. Вышедшие в 2015 году печатные номера журнала проходят очередную оценку в международной базе данных Коперник (ICV 2015), а электронные версии журнала теперь можно видеть, читать и скачивать в КиберЛенинке ${ }^{3}$ и $\mathrm{EBSCO}^{4}$.

Уважаемый читатель и наш будущий автор! Присоединяйтесь и Вы к нам!

Ontologists and designers of all countries and subject areas, join us!

\footnotetext{
${ }^{2}$ Виталий Киселев. Семь мудрецов Древней Греции, вып. 4. Биант из Приены. Ворчалка № 389 от 10.09.2006 г. Ворчалки об истории или Ab hoc at ab hac - http://www.abhoc.com/arc_vr/2006_09/389/.

${ }^{3}$ КиберЛенинка - это научная электронная библиотека открытого доступа (Open Access), основными задачами которой является популяризация науки, общественный контроль качества научных публикаций, развитие института научной рецензии и повышение цитируемости российской науки. - http://cyberleninka.ru/journal/n/ontologiya-proektirovaniya.

${ }^{4}$ Полный текст журнала теперь можно найти в базах данных компании EBSCO Publishing на платформе EBSCOhost. EBSCO Publishing является ведущим мировым агрегатором научных и популярных изданий. - https://www.ebsco.com/.
} 


\title{
УДК 519.711
}

\section{АНАЛИЗ СИСТЕМ ПРОЕКТИРОВАНИЯ ТЕХНОЛОГИЧЕСКИХ ЦЕПОЧЕК И ПРОЦЕССОВ}

\author{
А.Ю. Агроник ${ }^{1}$, А.А. Талалаев ${ }^{2}$, В.П. Фраленко ${ }^{2}$, В.М. Хачумов ${ }^{3}$, О.Г. Шишкин ${ }^{2}$ \\ ${ }^{1}$ ООО «Квадросистемс», Москва, Россия \\ aleksey@agronik.im \\ ${ }^{2}$ Институт программных систем им. А.К. Айламазяна РАН, Переславль-Залесский, Россия \\ alarmod85@hotmail.com \\ ${ }^{3}$ Институт системного анализа ФИЦ ИУ РАН, Москва, Россия \\ vmh48@mail.ru
}

\begin{abstract}
Аннотация
Рассмотрено современное состояние вопроса синтеза технологических цепочек и процессов в рамках систем автоматизированного проектирования технологических процессов. Выполнен анализ публикаций по результатам современных исследований, рассмотрены особенности актуальных программных систем проектирования. Дана классификация САПР технологических процессов по отраслевому и целевому назначению с учётом нового направления в медицине, а также классификация методов, применяемых в САПР. Показано, что достигнутый современный уровень теории пока не позволяет создать универсальную технологию синтеза, единую для всех прикладных направлений. Перспективы решения вопроса связываются с построением интеллектуальных систем автоматизированного проектирования, реализующих наиболее общий подход к синтезу на основе имитации деятельности разработчиков и предназначенных для поддержки научнотехнических и технологических решений в приоритетных направлениях науки и техники. Приведена общая схема многоуровневого итерационного процесса синтеза на основе баз знаний, хранящих прецеденты, процедуры выбора, настройки и оценивания варианта. В случае отсутствия подходящего образца в базе проводится прямой синтез нового технологического процесса с применением одного из возможных формальных подходов.
\end{abstract}

Ключевые слова: автоматизированное проектирование, технологический прочесс, технологическая цеепочка, интеллектуальные системы, синтез процесса.

Цитирование: Агроник, А.Ю. Анализ систем проектирования технологических цепочек и процессов / А.Ю. Агроник, А.А. Талалаев, В.П. Фраленко, В.М. Хачумов, О.Г. Шишкин // Онтология проектирования. - 2016. - Т. 6, №3(21). - С. 255-269. - DOI: 10.18287/2223-9537-2016-6-3-255-269.

\section{Введение}

Известен ряд концептуальных подходов к решению проблемы синтеза структур технологических процессов (ТП). Однако, каждый из них обладает рядом принципиальных недостатков, которые делают невозможным создание на их основе эффективно работающих систем автоматизированного проектирования. Главными из них являются невозможность автоматического формирования ТП или его части, недостаточная универсальность и слабая интеграция в единое информационное пространство. Необходимо создание новых методов, моделей и инструментальных средств, предназначенных для построения оптимизированных технологических цепочек (ТЦ) и ТП на основе баз знаний, автоматического синтеза планов и технологий интеллектуального управления. Должен быть выполнен анализ имеющегося научного задела, дано обобщение мировых достижений в области интеллектуальных методов 
построения технологий и предложены новые механизмы синтеза научно-технических решений, основанные на создании и применении баз знаний.

В связи с нарастающей сложностью ТП становится актуальной задача автоматического построения как отдельных ТЦ, так и обобщённых схем ТП на их основе с применением различных инструментальных средств искусственного интеллекта. Создание систем автоматического синтеза ТП на основе конструктивно-технологических параметров объекта проектирования является одной из нерешённых пока проблем. Главной причиной этого является отсутствие общего решения проблемы автоматического синтеза ТП при условии инвариантности к классам объектов. Одним из перспективных путей решения этой сложной задачи является создание экспертных систем, снабжённых методами интеллектуального планирования ситуации и мощным аппаратом оптимизации. Процесс принятия решения должен опираться на математические модели соответствующих процессов и формализованные методы работы с ними, позволяющие с учётом параметров, характеризующих индивидуальность процесса, синтезировать соответствующую оптимальную стратегию.

В настоящее время отсутствуют методические работы, связанные с оптимизацией выбора ТП для конкретного приложения на основании математической модели, а также разработки единого механизма генерации и оценки ТП. К приоритетным предметным областям (ПрО) можно отнести:

- автоматическое проектирование машиностроительных изделий и приборов, в том числе проектирование оптимизированных расписаний работы технических устройств и синтез алгоритмов в системах автоматизированного проектирования специализированных устройств;

- автоматическое управление, например, управление траекторным движением роботизированной системы в целом или её механизмами в отдельности;

- формирование процесса работы интеллектуального генетически обучаемого автомата в системах защиты;

- синтез медицинских технологических процессов, оптимизированных под лечение конкретных пациентов.

\section{1 Основные понятия и определения}

Под технологической цепочкой (или траекторией) будем понимать конечную или циклическую последовательность «действий» (операций, этапов, работ, действий, перемещений и т.д.), направленную на достижение поставленной цели в исследуемой ПрО. В соответствии с ГОСТ 3.1109-82 «Термины и определения основных понятий» технологический процесс «часть производственного процесса, содержащая целенаправленные действия по изменению и (или) определению состояния предмета труда». ТП содержит не менее одной ТЦ, которые могут быть взаимосвязаны, образуя параллельные, параллельно-последовательные и конвейерные конструкции. Сложный ТП правильно рассматривать как самостоятельный процесс, состоящий из частных ТП и специфических действий, которые называются технологическими операциями. Современное содержание понятия «технология» многогранно и включает процессы обработки и переработки материалов, описание процессов, инструкции по их выполнению, всевозможные планы, графики, чертежи, изображения ТП и требования к ним, контроль за процессами (услугами) и их качеством, совокупность методов получения, обработки информации в различных областях деятельности человека. Технология как наука изучает процессы преобразования некоторых первичных сущностей в сущности, удовлетворяющие потребности человека. Она опирается на совокупность знаний о способах и средствах построения ТП. 
Полагаем, что ТЦ и ТП являются результатом автоматического планирования (генерации) дискретных «действий», осуществляемых в соответствии с набором некоторых правил с учётом темпоральных аспектов ПрО. Определение ТП может быть представлено в текстовом виде, графическим описанием, декларацией на некотором формальном языке. Для описания ТП могут быть использованы модели потоков работ (workflow) и данных (dataflow). Системы управления потоками работ обеспечивают требуемую последовательность действий с ресурсами. Каждая технологическая операция и весь ТП в целом характеризуются значениями потребляемого ресурса (объём памяти, число исполнительных ресурсов, время выполнения и другими параметрами), что позволяет проводить оценку процессов и их сравнение. Наибольший интерес представляет синтез оптимизированных по заранее установленным критериям ТЦ и ТП, получаемых в результате генерации планов интеллектуальными планировщиками, работающими с интегрированными базами знаний/данных. Отметим, что в настоящее время задача автоматического синтеза ТП является нерешённой до конца в теоретическом плане. Выполненный анализ источников позволил выявить новые или модифицированные методы и подходы, основанные на применении баз знаний и планировании.

\section{2 Систематизация и классификация систем генерации технологических цепочек и процессов}

Классификацию классических систем автоматизированного проектирования (САПР) можно считать, в основном, устоявшейся на основе англоязычных терминов, применяемых для классификации программных приложений и средств автоматизации по отраслевому и целевому назначению $[1,2]$. Здесь выделим особо такое направление как CAPP (ComputerAided Process Planning) - средства автоматизации планирования ТП, которому соответствует отечественное название САПР ТП. Многие САПР совмещают решение задач, относящихся к различным аспектам проектирования, и являются комплексными (CAD/CAM, CAD/CAE, $\mathrm{CAD} / \mathrm{CAE} / \mathrm{CAM})$. Однако, относительно недавно появилось и быстро стало получать развитие такое направление как медицинские технологические процессы (МТП) [3-5]. Анализ Интернет и библиотечных ресурсов показал, что в мире уделяется большое внимание внедрению технологий управления МТП. Отметим публикационную активность последних лет за рубежом в области синтеза МТП [6-8]. В Европе ведётся работа по внедрению систем управления лечебно-диагностическими процессами, в том числе в России развиваются онтологический и информационно-аналитические подходы к описанию МТП. Одной из основных задач, решение которой позволит существенным образом улучшить качество медицинской помощи, является построение моделей и планов индивидуального лечения пациентов с различными нозологиями [9-10]. Имеющиеся разработки пока не позволяют проводить глубокую формализацию МТП. Предполагается разработать методы и инструментальные средства, которые позволят выполнить автоматический синтез оптимизированных МТП на основе стандартов лечения и накопленных знаний об исходах лечения.

Особое место в классификации занимают интеллектуальные САПР (ИСАПР), в которых имитируется деятельность технолога. Классификация САПР с учётом новых направлений приведена на рисунке 1.

Для представления современного состояния ПрО приведём обзор некоторых работ. В работе [11] рассмотрены методы и современные САПР ТП, произведён анализ наиболее распространённых программ для проектирования ТП. В первую очередь представляют интерес методы генерации ТП, рассматриваемые в САПР ТП. Существуют три основных метода автоматизированного проектирования ТП: индивидуальное проектирование; проектирование на основе группового ТП; проектирование ТП методом синтеза (см. рисунок 2). 


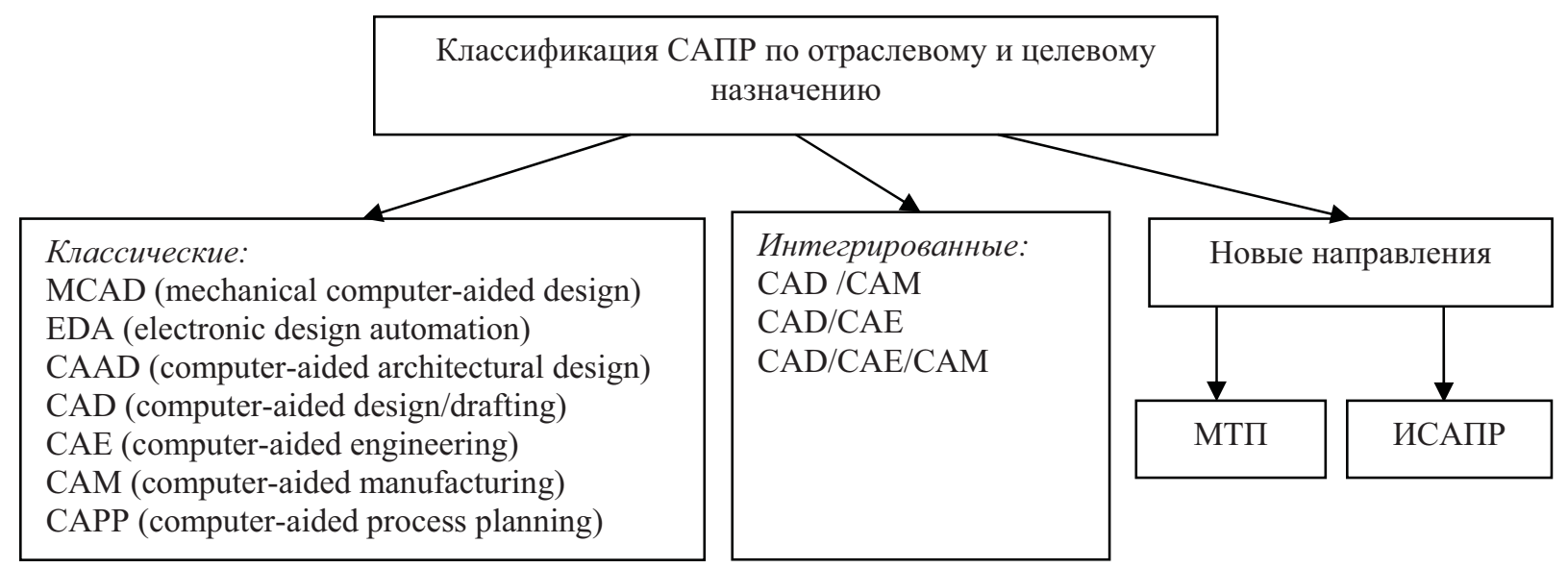

Рисунок 1 - Классификация САПР

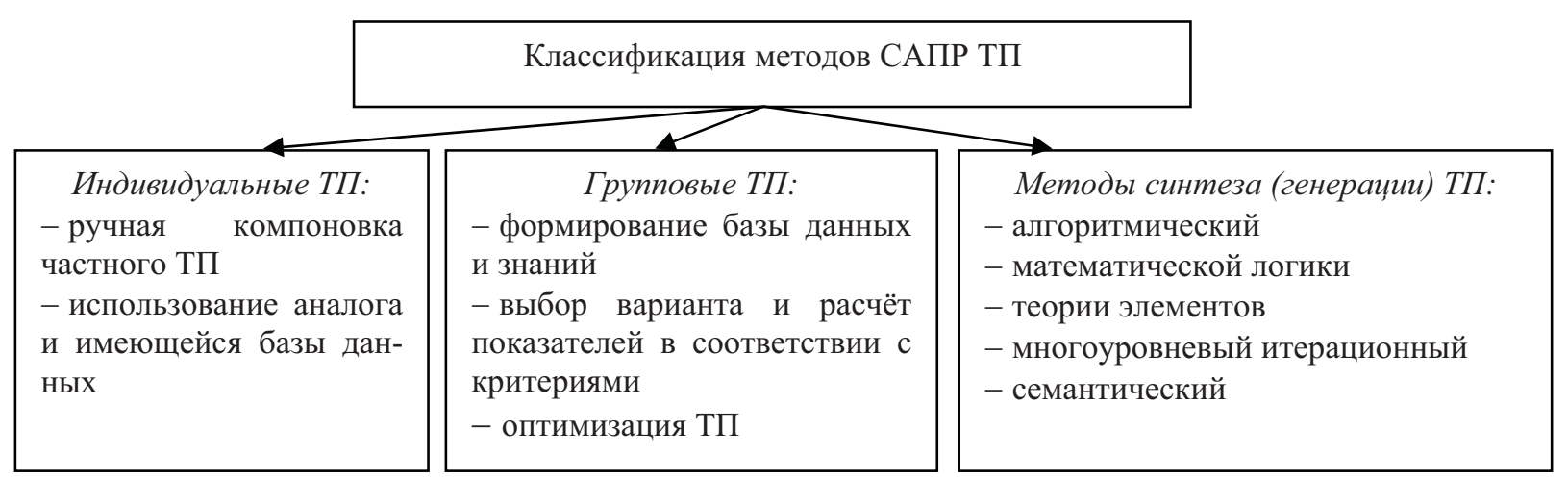

Рисунок 2 - Классификация методов проектирования ТП

Метод индивидуального проектирования заключается в компоновке необходимой последовательности операций и переходов с использованием имеющейся базы данных. Предполагается разработка ТП на основе процесса-аналога, т.е. разработанных ранее ТП-прецедентов. Проектирование на основе группового ТП, который используется в качестве настраиваемого шаблона. Метод синтеза ТП состоит в алгоритмическом формировании ТП. В настоящее время этот метод находит ограниченное применение, поскольку требует строгого математического описания формирования структуры ТП.

Индивидуальные САПР специализированы на определённые классы деталей и под конкретные предприятия. Высокая степень автоматизации в них достигается за счёт использования алгоритмов проектирования, отражающих знания технологических наук и опыт экспертов-технологов, участвующих в разработке систем и хорошо знающих конкретные предприятия. Адаптация таких систем к условиям других предприятиях оказывается весьма сложной и требует значительных трудозатрат.

Проектирование на основе группового ТП базируется на разработке группового шаблона, который настраивается на параметры конкретного ТП. Примером подобного подхода служит работа [12], в которой приведены основные методы интегрированных САПР, используемые для проектирования деталей, узлов и агрегатов конструкции космического аппарата. На основании типовых ТП формируется рабочий ТП и рассчитываются показатели. При этом выполняется оптимизация, обеспечивающая технологичность конструкции. Общим недостатком группового проектирования ТП является чрезмерное увеличение вариантов технологических решений, что делает метод громоздким, усложняя работу пользователей.

Возможности автоматизации, предоставляемые методами индивидуального и группового проектирования, практически исчерпаны. Поэтому возникает необходимость в разработке 
САПР ТП, функционирующей на основе метода синтеза ТП и комбинированных методов. Метод синтеза состоит в алгоритмическом формировании ТП на основе математических моделей, преобразований форм представления, точностей описаний и других параметров в соответствии с установленными критериями качества. Метод находится в состоянии теоретической проработки построения универсального подхода к проектированию ТП.

Особенностью синтеза схемы ТП является формирование последовательности преобразования изделия от начального состояния до конечного. Преобразование производится по уровням, и каждый уровень представляет собой многовариантную систему. Результатом процесса синтеза является построение дерева вариантов, которое отвечает заданным технологическим ограничениям [13].

Многоуровневый итерационный метод является универсальным методом, т.к. с его помощью можно спроектировать ТП практически для любой детали или сборочной единицы. На первом этапе принимается наиболее общее решение, которое уточняется на последующих этапах. Окончательный вариант определяется на последнем этапе, на промежуточных этапах выбирается комплекс решений, наиболее полно отвечающих заданным критериям. От этапа к этапу круг поиска сужается. Схема процесса синтеза представлена на рисунке 3.

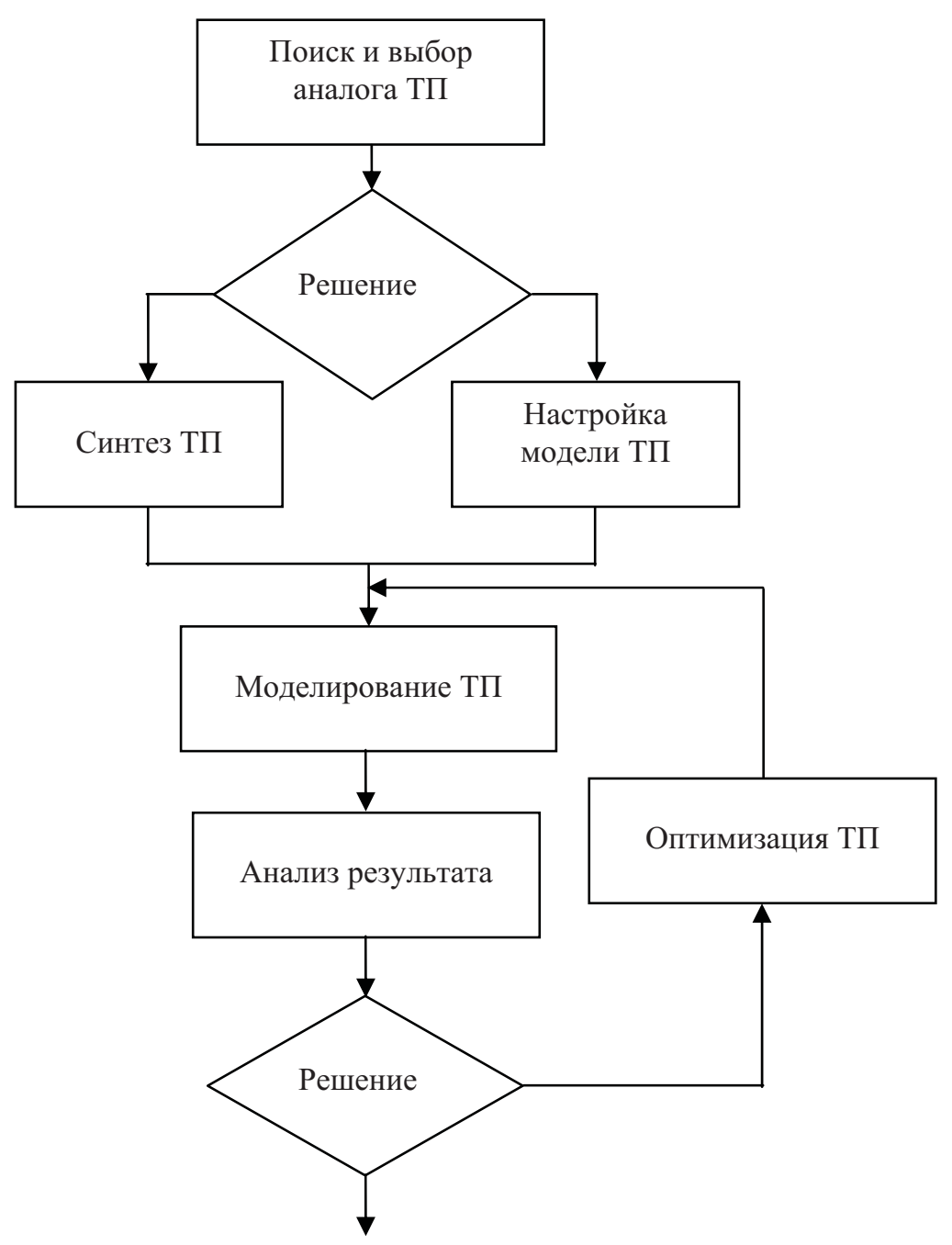

Рисунок 3 - Схема процесса синтеза ТП 
По результатам поиска принимается решение. Если аналог существует, то блоком решения производится настройка процесса-аналога на проектируемую деталь. Затем анализируется результат на соответствие техническому заданию и производится моделирование полученного процесса. Если аналог не найден в базе данных, то переходят к варианту синтеза ТП. Проектировщик создаёт первоначальное решение и производится моделирование процесса. Результаты моделирования анализируются и принимается решение о выборе рационального варианта. Этот вариант оптимизируется, цикл повторяется, в результате нескольких итераций выбирается оптимальный вариант по критериям ТП.

Примером метода синтеза ТП может служить подход, описанный в [14]. Необходимым условием является предварительное заполнение базы данных, когда становится возможным автоматизированное принятие сложных логических решений, связанных, например, с выбором структуры процесса и операций, назначением технологических баз и другими подобными задачами. В работе [15] изложены основы разработки методов анализа и синтеза систем управления, учитывающих наличие обратных связей, сложную динамику процессов управления, физическую разнородность устройств и элементов, многокритериальность, неопределённость задаваемых параметров и возмущающих воздействий. Примером алгоритмического подхода к синтезу служит работа [16], в которой рассмотрена методика и процесс автоматического построения (генерации) схем электрической системы.

В работе [17] рассмотрено новое поколение САПР. Основная идея - перенос логики взаимосвязи технологических объектов из модели ТП в семантическую модель справочных данных. Это позволяет, с одной стороны, упростить настройку и конфигурирование объектной модели технологии, с другой, расширяет возможности системы управления за счёт консолидации знаний о поведении и взаимодействии технологических объектов. Ключевым сервисом организации данных является семантический поиск, при котором в качестве критериев отбора объектов можно задавать не только их атрибуты, но и взаимосвязи с другими объектами.

В [18] представлен обзор САПР ТП (методы проектирования, современные системы автоматического проектирования и др.), рассмотрены два метода проектирования ТП: метод синтеза и метод процессации. Метод синтеза (многоуровневый, итерационный метод проектирования) является универсальным методом, позволяющим проектировать достаточно сложные ТП, основан на аксиоматическом подходе и реализован как система проектирования в классе систем «искусственный интеллект». Проектирование операций ведётся от последней к первой операции (метод «обратного планировщика»). Метод процессации основывается на создании рабочих ТП путём настройки унифицированных (типовых или групповых) ТП на конкретные детали. Метод позволяет использовать все преимущества групповой технологии. В настоящее время оба метода из-за их высокой сложности не реализованы в полной мере. В частности, не решены задачи автоматического формирования маршрута процесса, определения структуры операции, базирования заготовок, поиска приспособлений и ряд других интеллектуальных задач.

Отдельно отметим теоретически проработанную САПР [19, 20], в которой были сделаны первые попытки автоматического синтеза ТП применительно к машиностроительным, радиоэлектронным, строительным и другим изделиям, сформулирована общая теория формального синтеза структур интерактивных систем. Основная идея синтеза структур заключалась в создании сетевой модели интерактивных систем на основе алгоритма функционирования и возможных взаимосвязей форматов данных с различными реализациями отдельных блоков, а также последующего формального выбора лучшей реализации в виде определения кратчайшего пути на сетевой модели. 
Пример практической САПР, работающей на стыке групповых технологий и технологий синтеза, описан в работе [21], в которой представлена полнофункциональная система технологического проектирования, обладающая гибкими современными средствами разработки технологических проектов любой сложности. Система позволяет синтезировать варианты системы из компонентов (блоков) и оценивать варианты при их частичном переборе с предварительным прогнозированием характеристик компонентов. Блочно-иерархический подход к проектированию основан на декомпозиции сложных описаний объектов и средств их создания на иерархические уровни, вводит понятие стиля проектирования, устанавливает связь между параметрами соседних иерархических уровней. Вся информация, необходимая для проектирования ТП, хранится в справочниках комплекса T-FLEX. Создаётся библиотека технологических решений, в которую заносятся профессиональные знания (операции с переходами, оснащением, инструкциями и т.п.). Сформированная таким образом база знаний становится важным информационным ресурсом предприятия. По выбранным критериям можно найти аналогичный ТП и на его основе спроектировать новый. При использовании на предприятии типовых или групповых ТП обеспечивается возможность их параметризации. В таких параметрических ТП могут автоматически пересчитываться значения параметров по всему ТП, а затем производиться автоматический подбор оснащения.

Примерами современных зарубежных программных решений, направленных на подготовку ТП, являются: программа Allplan компании Nemetschek [22], предназначенная для поддержки всех фаз жизненного цикла проекта; программа CADdy компании ZIEGLERInformatics $\mathrm{GmbH}$ [23], предназначенная для автоматизации комплексных интегрированных технологий от стадии проектирования до стадии производства; система автоматизированного проектирования, инженерного анализа и подготовки производства SolidWorks компании SolidWorks Corporation [24]. Примерами отечественных программ для проектирования ТП в машиностроении являются «Т-Flex Технология» [21], «Вертикаль» [25] и «ТехноПро» [26]. Даже в этой наиболее развитой области вопрос полностью автоматической генерации технологии изготовления объекта пока остаётся открытым.

Ввиду недостатков перечисленных выше методов САПР ТП всё большее развитие получают интеллектуальные системы - ИСАПР. Основные концепции ИСАПР представлены в работе [27].

Интеллектуализация САПР возможна тремя способами [28].

1. Внешняя универсальная интеллектуализация с помощью подключения инструментальных средств, настроенных на соответствующую ПрО (конструирование, технология и т.д.). В качестве таких средств могут выступать оболочки экспертных, диалоговых и обучающих систем.

2. Внешняя специализированная интеллектуализация с помощью специальных программных дополнений, работающих на принципах искусственного интеллекта. Способ целесообразно применять как развитие предыдущего в тех случаях, когда предъявляются повышенные требования к качеству работы САПР. Этот способ не требует существенного изменения внутренней структуры и алгоритмов ИСАПР, поскольку сводится, как правило, к улучшению сервисных характеристик, возможности формулировки типовой задачи проектирования на предметно-ориентированном языке, более близком к естественному. Совокупность средств общения пользователя с САПР на предметно-ориентированном языке называется интеллектуальным интерфейсом.

3. Внутренняя интеллектуализация с помощью встроенных технологий искусственного интеллекта. Способ затрагивает глубинные свойства САПР, включая её функциональные возможности проектирования, возможности синтеза, адаптации, самоорганизации, работы с нечёткой формулировкой задачи. 
Типовая структура ИСАПР представлена на рисунке 4.

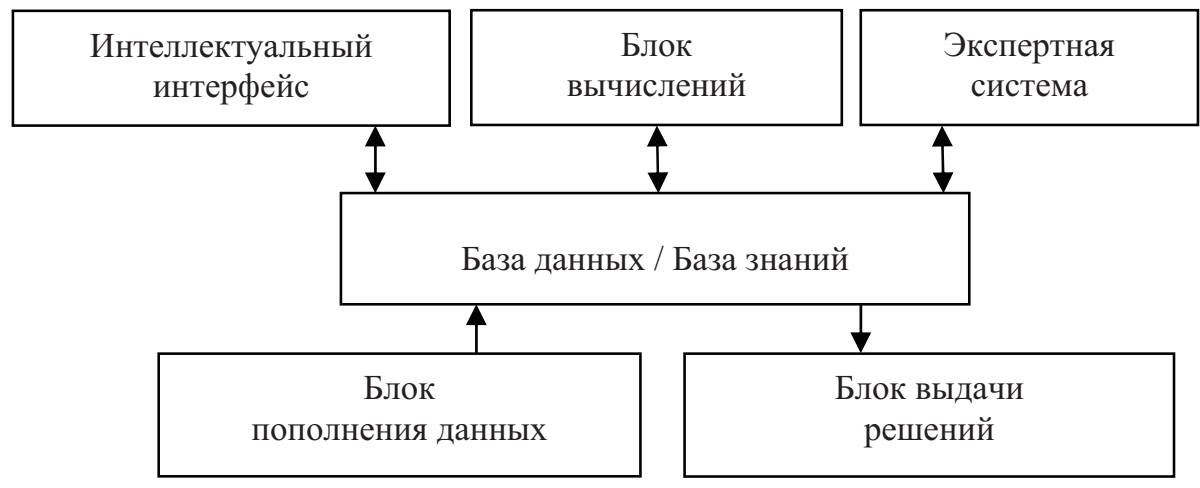

Рисунок 4 - Структура ИСАПР

Структурный синтез ТП в ИСАПР реализуется с помощью экспертных систем [29]. База знаний ИСАПР содержит необходимую информацию о ПрО, в которой решается задача проектирования, а также экспертную информацию о предполагаемых путях проектирования. Проектирование опирается на методы моделирования и опыт, накопленный проектировщиками и хранящийся в базе знаний. Задание на проектирование формируется с помощью интеллектуального интерфейса и переводится в специальное внутреннее представление (базу данных). Затем задача передаётся на вход экспертной системы ПрО, которая инициализирует вычисления и производит поиск решения. Представленные в базе знаний модели оперируют набором правил и утверждений, следуя которым можно прийти от начальных условий к логическим выводам.

При использовании ИСАПР повышается качество проектируемых объектов благодаря увеличению числа просматриваемых вариантов и детальности проработки, уменьшается время проектирования за счёт применения средств имитационного моделирования и численных методов, повышается эффективность благодаря планированию вычислений и контролю результатов. ИСАПР на данный момент не получили широкого распространения, поскольку отсутствует универсальность подобных систем, разработка ведётся с привязкой к определённой ПрО и носит фрагментарный характер.

\section{3 Универсальные методы автоматической генерации технологических процессов}

Базовая концепция алгоритмического выполнения систем операций над абстрактными и физическими объектами однородного и неоднородного характера, позиционируемая как «Общая формальная технология» (ОФТ), получила своё развитие в серии работ [30-32]. Основные её положения были обобщены в монографии [33]. Важно, что концепция может быть применена в теории автоматического построения универсальных технологических систем и процессов различного назначения. ОФТ опирается на фундаментальную алгебраическую систему вида $\mathrm{U}=\left\langle A, \Omega_{F}, \Omega_{P}\right\rangle$, где $A$ - основное множество системы; $\Omega_{F}$ - множество операций, определённых на $A ; \Omega_{P}$ - множество предикатов, заданных на множестве $A$ [34]. Утверждается [33], что все другие практически важные модели являются её частными случаями. В ОФТ приняты аналогичные алгоритмические системы (называемые «технологиями») $\mathrm{T}=\left\langle B, F_{T}, F_{A}\right\rangle$, где $B$ - множество некоторых физических объектов, являющихся исходными и конечными объектами-результатами операций множества $F_{T}$, называемых «конструкция- 
ми»; $F_{T}$ и $F_{A}$ - конечные множества конечноместных технологических (типа синтеза и декомпозиции) и аналитических операций над объектами из $B$, причём ни одна из операций в $F_{T}$ и $F_{A}$ не может быть выражена через другие.

ОФТ позволяет сравнивать потенциальные возможности различных технологий. В таких метаматематических структурах легко строятся модели программируемых технологических систем примерно на тех же формальных базовых принципах. В свою очередь, эти модели позволяют использовать их в качестве базовых при построении практических универсальных программируемых технологических систем в самых различных областях. В соответствии с ОФТ сформулированы основные этапы разработки конкретных многоцелевых программно управляемых технологических систем:

- на основе анализа различных процессов обработки (преобразования) объектов в заданной технологической области выделяются наиболее часто используемые типы технологических операций; получающиеся при этом наборы технологических и аналитических операций должны образовывать совокупности операций, отвечающих критерию полноты;

- анализируются потенциальные возможности вариантов максимально широкого класса объектов в заданной технологической области; выбирается вариант полной технологии, который позволяет синтезировать и анализировать максимально широкий класс объектов и достаточно просто реализуется технически;

- выбирается конкретный вариант структуры для технической реализации, который корректируется с учётом реального состава технологических операций.

Перечисленным принципам ОФТ соответствует, например, универсальный метод $[19,20]$, нашедший применение в САПР радиоэлектроники, машиностроения, приборостроения. Он устанавливает взаимосвязи между характеристиками алгоритмов функционирования систем и реализациями (аппаратными, программными) алгоритмов, формализует процесс генерации вариантов структурной организации проектируемых систем. Источниками синтеза являются: операции со структурами алгоритмов, декомпозиция алгоритмов на части и их объединение, базы программной или аппаратной реализаций частей алгоритмов, способы преобразования характеристик объектов информации и систематизация реализаций, критерии оценки вариантов построения систем. Декомпозицию структур алгоритмов предлагается проводить по принципу связности операций в алгоритмах. Предполагается, что проектируемая система работает по заданному алгоритму функционирования $\mathrm{E}$, который характеризуется следующей тройкой параметров: $\mathrm{E}=\langle\mathrm{P}, \mathrm{O}, \Gamma\rangle$, где $\mathrm{P}-$ множество объектов системы, $\mathrm{O}$ - множество операций над объектами (операндами), Г - множество связей между операциями. Применительно к синтезу информационно-вычислительных систем [20] объекты в свою очередь характеризуется двойкой $\mathrm{P}=\langle C, \Delta\rangle$, где $C$ - множество способов кодирования операндов, $\Delta-$ множество точностей их представления. Действия над заданным алгоритмом выполняются по определённым правилам.

Правило 1. Первоначальное разделение алгоритма на локальные алгоритмы (ЛА) для их независимой реализации на локальных структурах (ЛС) выполняется при наличии хотя бы одного из следующих условий: 1) отсутствие информационной связи между ЛА, 2) наличие разной точности и/или разных способов кодирования операндов.

После операций разделения структуры алгоритма на ЛА и их покрытия ЛС образуется первый вариант структуры алгоритмов системы, характеризуемый определёнными показателями качества, который может быть подвергнут дальнейшему преобразованию путём объединения ЛА в более крупные с целью образования новых вариантов реализации системы. Операции объединения ЛА производятся многократно. При этом каждому ЛА соответствует в общем случае множество ЛС из соответствующей базы данных. По мере укрупнения ЛА 
уменьшается количество блоков структуры и увеличивается их сложность. Операции объединения проводятся по следующему правилу.

Правило 2. При объединении локальных алгоритмов способы кодирования информации должны быть приведены к единой форме, причём точность представления данных в обобщённом алгоритме выбирается как $\delta=\min \left\{\delta_{i}\right\}, \forall i \in\{1, \ldots, n\}$, где $n$ - число объединяемых ЛА.

При объединении возникает новый ЛА, которому соответствует новая ЛС, имеющая в общем случае увеличенный объём памяти по отношению к первоначальным ЛС. Таким образом, за счёт операций с алгоритмами генерируется множество вариантов структурной организации проектируемой системы.

На рисунке 5 в качестве примера показаны последовательно этапы синтеза вариантов структур измерительной системы [20]. Система предназначена для высокоточного измерения, нормализации и визуализации в десятичном коде четырёх параметров ТП. При решении задачи оптимального перехода к структуре системы можно ограничиться наиболее общими показателями качества, определяющими характеристики устройства, реализующего систему ЛА. К ним относятся показатели сложности реализации, быстродействия и надёжности.

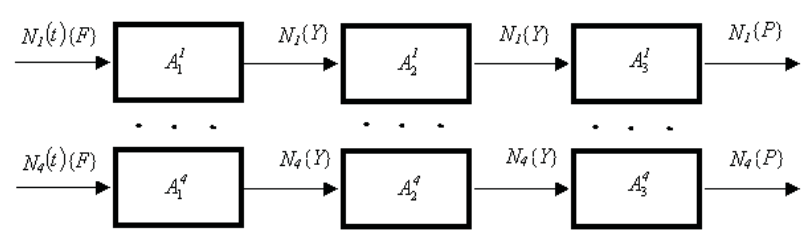

a)

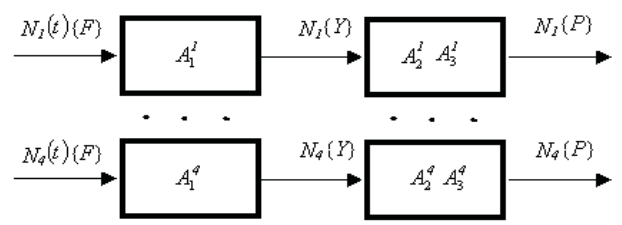

B)

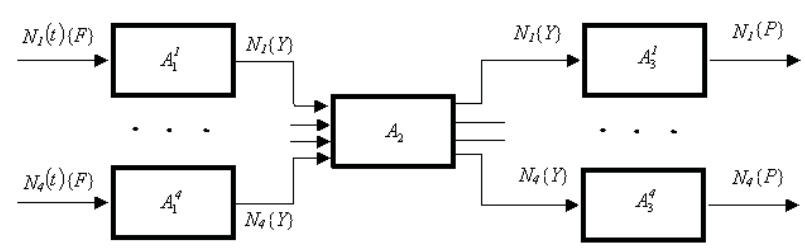

б)

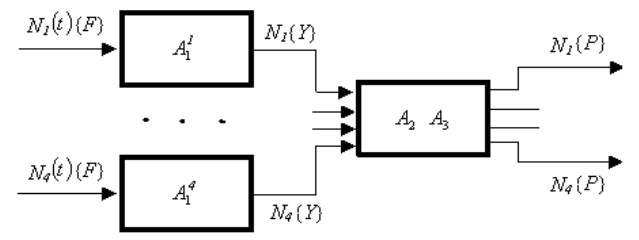

Г)

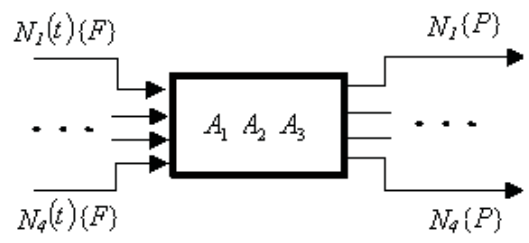

Д)

Рисунок 5 - Некоторые варианты синтезируемой измерительной системы

Вариант (a) соответствует первоначальному разбиению общего алгоритма функционирования системы на ЛА и их покрытие ЛС. Он содержит четыре независимых канала измерения и визуализации частотных сигналов. Каждый канал содержит следующие блоки: преобразователь частотного сигнала $\{F\}$ в унитарный $\{Y\}$-код алгоритма $\mathrm{A}_{1}$; реверсивный счётчик импульсов $\{Y\}$-кода с преобразованием параллельного $\{P\}$-кода в унитарный $\{Y\}$-код, для реализации $\mathrm{A}_{2}$; двоично-десятичный счётчик с выводом числа в $\{P\}$-коде для последующего преобразования в десятичный код с целью визуализации измеряемого параметра (для реализации $\mathrm{A}_{3}$ ). Канал разделён на три части в соответствии с алгоритмами: $A_{1}^{i}, A_{2}^{i}, A_{3}^{i}$, поскольку они отличаются способами кодирования. В алгоритме $A_{1}^{i}$ используется аналоговый ча- 
стотный сигнал, в $A_{2}^{i}$ - двоичный код, в $A_{3}^{i}$ - десятичный код. Форма передачи промежуточной информации между локальными алгоритмами выбрана в виде унитарного двоичного $\{Y\}$-кода. Все последующие варианты показаны фрагментарно, и в них может применяться как двоичное кодирование, так и десятичный код $\{P\}$-код. Последний вариант (д) соответствует объединению всех ЛА $A_{1}^{i}, A_{2}^{i}, A_{3}^{i}$ по всем каналам. Он характеризуется параллельным измерением частотного сигнала по всем каналам за короткие промежутки времени, для чего используется блок временного разделения импульсов от каждого датчика, один двоичнодесятичный счётчик и четыре регистра. Накопленная в регистрах информация (за общее время измерения) преобразуется в десятичный код и визуализируется.

В другой работе этого направления [35] была рассмотрена задача оптимизации структурной организации программного обеспечения интерактивных средств 3D-систем геометрического моделирования, используемых для тренажеров и обучающих систем, средств автоматизированной настройки станков с ЧПУ и роботов. Проектирование сложного изделия осуществлялось универсальным методом путём генерации вариантов с помощью операций со структурами алгоритмов в соответствии с правилами, закладываемыми в базу знаний и последующим выбором оптимального по заданным критериям варианта.

\section{Заключение}

Анализ современного состояния показывает, что, несмотря на обилие публикаций по отдельным направлениям синтеза ТЦ и ТП, теоретические исследования, объединяющие различные подходы в единую интеллектуальную технологию, достаточную для создания систем поддержки принятия научно-технических решений в приоритетных направлениях составляют их малую часть. Среди них выделяется так называемая «Общая формальная технология», которая создаёт теоретические предпосылки для полностью автоматического проектирования. Определённые перспективы связываются также с внедрением в САПР методов и технологий искусственного интеллекта. Внедрение указанных подходов позволит построить универсальные САПР, пригодные для различных ПрО. В этом случае ТП генерируется с помощью правил, хранящихся в базе знаний интеллектуальных систем при нечётких критериях.

\section{Благодарности}

Работа выполнена при финансовой поддержке проекта РФФИ № 16-29-12839-офи_м «Разработка моделей, методов и инструментальных средств для синтеза оптимизированных технологических цепочек и технологических процессов на основе интегрированных баз знаний и интеллектуальных технологий автоматической генерации и оценки планов».

\section{Список источников}

[1] Обзор современных систем автоматизированного проектирования. -

URL: http://bourabai.ru/graphics/dir.htm (дата обращения 19.07.2016).

[2] Валов, А.В. Методы автоматизированного проектирования электропривода. - Ч.1. / А.В. Валов, А.Е. Бычков // Учебное пособие. - Челябинск: Издательский центр ЮУрГУ, 2015. - 73 с.

[3] Назаренко, Г.И. Основы теории медицинских технологических процессов. - Ч.1 / Г.И. Назаренко, Г.С. Осипов. - М.: Физматлит, 2005. - 144 с.

[4] Назаренко, Г.И. Основы теории медицинских технологических процессов. - Ч.2. / Г.И. Назаренко, Г.С. Осипов. - М.: Физматлит, 2006. - 144 с.

[5] Осипов, Г.С. Методы искусственного интеллекта / Г.С. Осипов. - М.: Физматлит, 2011. - 296 с. 
[6] Partington, A. Process Mining for Clinical Processes: a Comparative Analysis of Four Australian Hospitals / A. Partington, B. Valdivieso, V. Traver, J.M. Benedi // ACM Transactions on Management Information Systems (TMIS) 5.4, 2015. - 19 p.

[7] Mans, R.S. Healthcare Processes / R.S. Mans, W. van der Aalst, R.J.B. Vanwersch // Process Mining in Healthcare. - Springer International Publishing, 2015. - P. 11-15.

[8] Fernandez-Llatas, $\boldsymbol{C}$. Using Process Mining for Automatic Support of Clinical Pathways Design / C. FernandezLlatas, B. Valdivieso, V. Traver, J.M. Benedi // Data Mining in Clinical Medicine. - Springer New York, 2015. P. 79-88.

[9] Maльх, В.Л. Управление и принятие решений в лечебно-диагностическом процессе / В.Л. Малых, Я.И. Гулиев, А.В. Еремин, С.В. Рудецкий // Труды ХІІ Всероссийского совещания по проблемам управления (ВСПУ-2014) (16-19 июня, 2014 г., Москва), 2014, с.6518-6528.

[10] Malykh, V.L. Estimation of Accuracy of Recommended Diagnostic and Treatment Actions Based on Precedent Approach / V.L. Malykh, I.N. Kononenko, S.V. Rudetskiy // Proceedings of the International Conference e-Health 2016 (1-4 July 2016, Madeira, Portugal); 2016. - P. 52-58.

[11] Фролова, И.Н. Анализ современных систем автоматизированного проектирования технологических процессов (САПР ТП) / И.Н. Фролова, О.И. Кутилова // Труды Нижегородского государственного технического университета им. Р.Е. Алексеева № 1(80), Машиностроение и автоматизация, 2010, с.91-94. URL: http://www.nntu.ru/trudy/2010/01_/91-94.pdf (дата обращения 19.07.2016).

[12] Анисин, Д.А. Автоматизация проектирования технологического процесса изготовления / Д.А. Анисин, И.В. Морозов // Электронный журнал «Труды МАИ». - 2012. - № 51. -

URL: http://www.mai.ru/upload/iblock/a59/avtomatizatsiya-proektirovaniya-tekhnologicheskogo-protsessa.pdf.

[13] Методы автоматизированного проектирования ТП, 2011. URL: http://bittu.org.ru/umkd/sites/default/files/2.pdf (дата обращения 19.07.2016).

[14] Аверченков, В.И. Автоматизация проектирования технологических процессов / В.И. Аверченков, Ю.М. Казаков // Учеб. пособие для вузов. - 2-е изд., стереотип. - М.: Флинта, 2011. - 229 с.

[15] Носкова, E.E. Автоматизированное проектирование средств и систем управления / Е.Е. Носкова, Д.В. Капулин, Ю.В. Краснобаев, С.В. Ченцов // Курс лекций. - Красноярск: ИПК СФУ, 2009. - 266 с.

[16] Лученков, В.В. Автоматическое проектирование схем системы ЭЦ-12-03 с использованием типовых проектных решений / В.В. Лученков // Известия Петербургского университета путей сообщения. - 2010. - № 3. - C. 147-157.

[17] Андриченко, $\boldsymbol{A . H}$. Тенденции и состояние в области управления справочными данными в машиностроении / А.Н. Андриченко // Онтология проектирования. - 2012. -№2(4). - С. 25-35.

[18] Куликов, Д.Д. Интеллектуальные программные комплексы для технической и технологической подготовки производства / Часть 7. Системы проектирования технологических процессов / Д.Д. Куликов, Е.И. Яблочников, В.С. Бабанин // Учебно-методическое пособие. - СПб: СПбГУ ИТМО, 2011. - 136 с.

[19] Артамонов, Е.И. Синтез структур специальных средств машинной графики / Е.И. Артамонов, В.М. Хачумов. - М.: Институт проблем управления, 1991. - 145 с.

[20] Артамонов, Е.И. Интерактивные системы. Синтез структур / Е.И. Артамонов. - М.: Инсвязьиздат, 2010. $185 \mathrm{c}$.

[21] Ковалев, $\boldsymbol{A}$. T-FLEX Технология 10 - ваша профессиональная система проектирования технологических процессов / А. Ковалев // САПР и графика. - 2006. - № 9. - URL: http://www.sapr.ru/Article.aspx?id=16671 (дата обращения 19.07.2016).

[22] Allplan - BIM - CAD - BCM - FM Software. - URL: https://www.allplan.com/ (дата обращения: 19.07.2016).

[23] Das CADdy Forum. - URL: http://www.caddy.de/ (дата обращения 19.07.2016).

[24] SolidWorks Russia. - URL: http://www.solidworks.ru/ (дата обращения 19.07.2016).

[25] Система автоматизированного проектирования технологических процессов ВЕРТИКАЛЬ [Электронный pecypc]. - URL: http://machinery.ascon.ru/software/developers/items/?prpid=420 (дата обращения 19.07.2016).

[26] Комплекс автоматизации подготовки, планирования и управления производства «ТехноПро» [Электронный pecypc]. - URL: http://www.tehnopro.com/ (дата обращения 19.07.2016).

[27] Организация процесса автоматизированного проектирования | Архитектура интеллектуальных САПР. URL: http://3ys.ru/organizatsiya-protsessa-avtomatizirovannogo-proektirovaniya/arkhitektura-intellektualnykhsapr.html (дата обращения 19.07.2016).

[28] Романова, И.В. Интеллектуальные подсистемы САПР / И.В. Романова // Конспект лекций. - Омск: Изд-во ОмГТУ, 2008. - 64 с.

[29] Семенов, В.С. Системы автоматизации проектных работ / В.С. Семенов, В.П. Золотов // Курс лекций. - Самара: Самарский государственный технический университет, 2012. - 134 с.

[30] Крылов, С.М. Формальная технология и эволюция. - Самара: СамГТУ, 2012. - 324 с. 
[31] Крылов, С.M. Онтология метанауки. Аксиомы, технологии, алгоритмы, эволюция. - LAP Lambert Academic Publishing, Saarbrücken, Deutchland, 2012. - 404 c.

[32] Крылов, С.М. Перспективы метаматематических структур в науке // Вестник Самар. гос. техн. ун-та. Сер. Физ.-мат. науки. - 2013. - № 2(31). - С. 101-110.

[33] Крылов, С.М. Метаматематические основы науки будущего: монография. - Самара: Самар. гос. техн. ун-т, 2014. -247 c.

[34] Мальцев, А.И. Алгебраические системы. - М.: Наука, 1970. - 392 с.

[35] Артамонов, Е.И. Специализированные интерактивные системы в виртуальных производственных корпорациях / Е.И. Артамонов, А.В. Балабанов, С.Н. Григорьев, В.А. Ромакин // Информационные технологии и вычислительные системы. - 2012. - № 1. - С. 69-75.

\title{
ANALYSIS OF SYSTEMS FOR TECHNOLOGICAL CHAINS AND PROCESSES DESIGNING
}

\author{
A.Yu. Agronik ${ }^{1}$, A.A. Talalaev², V.P. Fralenko ${ }^{2}$, V.M. Khachumov ${ }^{3}$, O.G. Shishkin ${ }^{2}$ \\ ${ }^{I}$ Kvadrosystems Ltd, Moscow, Russia \\ aleksey@agronik.im \\ ${ }^{2}$ Ailamazyan Program Systems Institute of Russian Academy of Sciences, Pereslavl-Zalessky, Russia \\ alarmod85@hotmail.com \\ ${ }^{3}$ Institute for Systems Analysis of Russian Academy of Sciences, Moscow, Russia \\ vmh48@mail.ru
}

\begin{abstract}
The current state of the problem of synthesis of technological chains and processes of the computer-aided systems for technological processes designing was reviewed. Some publications on the results of modern research were analyzed; features of modern system's program design were described. A classification of CAD for the technological processes of industrial and specific purpose was presented, taking into account new trends in medicine, as well as the classification methods, utilized in CAD. It is shown that the achieved level of modern theory does not allow us to create a universal synthesis technology that may be common to all subject areas. Prospects to solve the problem are associated with the construction of intelligent computer-aided design systems that implement the most common approach to synthesis, based on simulation and development activities, designed to support scientific, technical and technological solutions in the priority areas of science and technology. A general circuit of multilevel iterative synthesis process built on knowledge bases intended for storing precedents, select, configure, and options evaluating is presented. In case of absence of a suitable sample in the base, a direct synthesis of a new process is performed, using one of the possible formal approaches.
\end{abstract}

Key words: computer-aided design, technology process, process chain, intelligent systems, process synthesis.

Citation: Agronik AYu, Talalaev AA, Fralenko VP, Khachumov VM, Shishkin OG. Analysis of systems for technological chains and processes designing [In Russian]. Ontology of designing. 2016; 6(21): 255-269. DOI: 10.18287/22239537-2016-6-3-255-269.

\section{References}

[1] Review of Modern Computer-aided Design Systems [In Russian]. Source: 〈http://bourabai.ru/graphics/dir.htm〉.

[2] Valov AV, Bychkov AE. Methods of Computer-aided Design of Electric Drive [In Russian]. P.1. Uchebnoe posobie. - Chelyabinsk: South Ural State University Publishing Center; 2015.

[3] Nazarenko GI, Osipov GS. Fundamentals of the Medical Processes Theory. P.1 [In Russian]. - Moscow: Fizmatlit; 2005.

[4] Nazarenko GI, Osipov GS. Fundamentals of the Medical Processes Theory. P.2 [In Russian]. - Moscow: Fizmatlit; 2006.

[5] Osipov GS. Methods of Artificial Intelligence [In Russian]. - Moscow: Fizmatlit; 2011.

[6] Partington A, Valdivieso B, Traver V, Benedi JM. Process Mining for Clinical Processes: a Comparative Analysis of Four Australian Hospitals. ACM Transactions on Management Information Systems (TMIS) 5.4; 2015. 
[7] Mans RS, Aalst van der W, Vanwersch RJB. Healthcare Processes. Process Mining in Healthcare. Springer International Publishing; 2015. - P. 11-15.

[8] Fernandez-Llatas C, Valdivieso B, Traver V, Benedi JM. Using Process Mining for Automatic Support of Clinical Pathways Design. Data Mining in Clinical Medicine. Springer New York; 2015. - P. 79-88.

[9] Malykh VL, Guliyev YaI, Eremin AV, Rudetskiy SV. Management and Decision-making in Medical Diagnostic Process [In Russian]. Trudy XII Vserossijskogo soveshhanija po problemam upravlenija (VSPU-2014) (16-19 June 2014, Moscow); 2014. - P. 6518-6528.

[10] Malykh VL, Kononenko IN, Rudetskiy SV. Estimation of Accuracy of Recommended Diagnostic and Treatment Actions Based on Precedent Approach. Proceedings of the International Conference e-Health 2016 (1-4 July 2016, Madeira, Portugal); 2016. - P. 52-58.

[11] Frolova IN, Kutilova OI. The Analysis of Modern Systems of the Automation Design of Technological Processes [In Russian]. Trudy Nizhegorodskogo gosudarstvennogo tehnicheskogo universiteta im. R.E. Alekseeva № 1(80), Mashinostroenie i avtomatizacija; 2010. - P. 91-94. Source: 〈http://www.nntu.ru/trudy/2010/01_/91-94.pdf $\rangle$.

[12] Anisin DA, Morozov IV. Design Automation of Technological Production Processes [In Russian]. Jelektronnyj zhurnal "Trudy MAI"; 2012; 51. Source: 〈http://www.mai.ru/upload/iblock/a59/avtomatizatsiya-proektirovaniyatekhnologicheskogo-protsessa.pdf $\rangle$.

[13] Methods of Computer-aided Design of TP [In Russian]; 2011. Source: 〈http://bittu.org.ru/umkd/sites/default/files/2.pdf $\rangle$.

[14] Averchenkov VI, Kazakov JuM. Design Automation of Technological Processes [In Russian]. Ucheb. posobie dlja vuzov. - 2-e izd., stereotip. - Moscow: Flinta; 2011.

[15] Noskova EE, Kapulin DV, Krasnobaev JuV, Chencov SV. Computer-aided Design Tools and Control Systems [In Russian]. Kurs lekcij. - Krasnojarsk: IPK SFU; 2009.

[16] Luchenkov VV. Automatic Design of ETs-12-03 System Schemes by Using Model Design Solutions [In Russian]. Proceedings of Petersburg Transport University; 2010; 3: 147-157.

[17] Andrichenko AN. Tendencies and condition in the field of reference data management in the engineering industry [In Russian]. Ontology of designing. - 2012. -№2(4): 25-35.

[18] Kulikov DD, Jablochnikov EI, Babanin VS. Intelligent Software Packages for Technical and Technological Preparation of Production. Part 7: System Engineering Processes [In Russian]. Textbook. - St. Petersburg: SPbSU ITMO; 2011.

[19] Artamonov EI, Khachumov VM. Synthesis of Structures of Special Means of Computer Graphics [In Russian]. Moscow: Institute of Control Problems; 1991.

[20] Artamonov EI. Interactive Systems. Synthesis of Structures [In Russian]. - Moscow: Insvjazizdat; 2010.

[21] Kovalev A. T-FLEX Technology 10 - Your Professional System Design Processes [In Russian]. CAD and Graphics; 2006; 9. Source: 〈http://www.sapr.ru/Article.aspx?id=16671〉.

[22] Allplan - BIM - CAD - BCM - FM Software. Source: 〈https://www.allplan.com/〉.

[23] Das CADdy Forum. Source: 〈http://www.caddy.de/ $\rangle$.

[24] SolidWorks Russia [In Russian]. Source: 〈http://www.solidworks.ru/〉.

[25] Computer-aided Design of Technological Processes VERTICAL [In Russian]. Source: $\langle$ http://machinery.ascon.ru/software/developers/items/?prpid=420 $\rangle$.

[26] The Complex of "TekhnoPro" Company for Automation of Preparation, Planning and Management [In Russian]. Source: 〈http://www.tehnopro.com/ $\rangle$.

[27] Organization of the Process of the Automated Designing | Architecture of Intelligent CAD [In Russian]. Source: $\langle$ http://3ys.ru/organizatsiya-protsessa-avtomatizirovannogo-proektirovaniya/arkhitektura-intellektualnykhsapr.html $\rangle$.

[28] Romanova EV. Intelligent CAD subsystems [In Russian]. Konspekt lekcij. - Omsk: Izd-vo OmGTU; 2008.

[29] Semenov VS, Zolotov VP. Systems for the Automation of Design Work [In Russian]. Kurs lekcij. - Samara: Samara State Technical University; 2012.

[30] Krylov SM. Formal Technology and Evolution. Ed. second, revised. and ext. [In Russian]. - Samara: Samara State Technical University; 2012.

[31] Krylov SM. Ontology of Metascience. Axioms, Technology, Algorithms, 241 Evolutions [In Russian]. - LAP Lambert Academic Publishing, Saarbrücken, Deutchland; 2012.

[32] Krylov SM. Prospects of the Metamathematical Structures in Science [In Russian] // Bulletin of the Samara State Technical University. Physics and mathematics; 2013; 2: 101-110.

[33] Krylov SM. Metamathematical Foundations of Science of the Future: a Monograph [In Russian]. - Samara: Samara State Technical University, 2014. - 247 c.

[34] Maltsev AI. Algebraic Systems [In Russian]. - Moscow: Nauka, 1970. - 392 c. 
[35] Artamonov EI, Balabanov AV, Grigoryev SN, Romakin VA. Specialized Interactive Systems in Virtual Manufacturing Corporations [In Russian]. Information Technology and Computer Systems; 2012; 1: 69-75.

\section{Сведения об авторах}
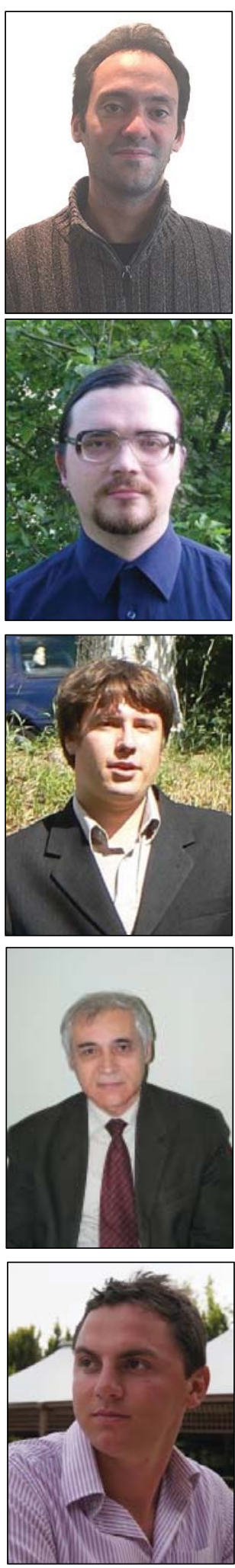

Агроник Алексей Юрьевич, 1986 г. рождения. Окончил Московский государственный университет приборостроения и информатики в 2008 г. Инженер-исследователь ООО «Квадросистемс». Область научных интересов: автоматизация бизнес-процессов, повышение эффективности хранения и обработки данных, управление разработкой программного обеспечения, проектирование интерфейсов.

Alexey Yurevich Agronik (b. 1986) graduated from the Moscow State University of Instrument Engineering and Computer Science in 2008. Research engineer of "Kvadrosystems". Fields of research interest: automation of business processes, improving the efficiency of data storage and processing, software project management, interface designing.

Талалаев Александр Анатольевич, 1981 г. рождения. Окончил ЧОУ ВО «УГП имени А.К. Айламазяна» в 2006 г., к.т.н. (2013). Старший научный сотрудник Институт программных систем им. А.К. Айламазяна РАН. Область научных интересов: искусственный интеллект, машинная графика, высокопроизводительные вычисления.

Alexander Anatolevich Talalaev (b. 1981) graduated from the Ailamazyan Pereslavl University in 2006, PhD (2013). Senior Researcher of Ailamazyan Program Systems Institute of Russian Academy of Sciences. Fields of research interest: artificial intelligence, computer graphics, high performance computing.

Фраленко Виталий Петрович, 1985 г. рождения. Окончил ЧОУ ВО «УГП имени А.К. Айламазяна» в 2007 г., к.т.н. (2012). Старший научный сотрудник ИПС им. А.К. Айламазяна РАН. Область научных интересов: искусственные нейронные сети, параллельные вычисления, защита компьютерных сетей, диагностика сложных технических систем, обработка изображений, графические интерфейсы.

Vitaly Petrovich Fralenko (b. 1985) graduated from the Ailamazyan Pereslavl University in 2006, PhD (2012). Senior Researcher of Ailamazyan Program Systems Institute of Russian Academy of Sciences. Fields of research interest: artificial neural networks, parallel computing, protection of computer networks, diagnostics of complex technical systems, image processing, graphical interfaces.

Хачумов Вячеслав Михайлович, 1948 г. рождения. Окончил Ленинградский кораблестроительный институт в 1971 г., д.т.н. (1997). Зав. лабораторией интеллектуального управления ИПС им. А.К. Айламазяна РАН, зав. лабораторией методов интеллектуального управления ИСА ФИЦ ИУ РАН, профессор кафедры информационных технологий Российского университета дружбы народов, действительный член Академии космонавтики им. К.Э. Циолковского. В списке научных трудов более 200 работ в области искусственного интеллекта, машинной графики, вычислительной техники и управления.

Vyacheslav Mikhailovich Khachumov (b. 1948) graduated from the Leningrad Shipbuilding Institute in 1971, D. Sc. Eng. (1997). Head of the Laboratory of Intelligent control at Ailamazyan Program Systems Institute of Russian Academy of Sciences, head of the Laboratory of Intelligent Control Methods at ISA FRC CSC RAS, professor at the People's Friendship University (Information Technologies sub-department), member of the Tsiolkovsky Russian Academy of Cosmonautics. Hi is co-author more than 200 papers in the field of artificial intelligence, computer graphics, computer science and management.

Шишкин Олег Гарриевич, 1988 г. рождения. Окончил ЧОУ ВО «УГП имени А.К. Айламазяна» в 2015 г. Аспирант ИПС им. А.К. Айламазяна РАН. Область научных интересов: искусственные нейронные сети, диагностика сложных технических систем. Oleg Garrievich Shishkin (b. 1988) graduated from the Ailamazyan Pereslavl University in 2015. Postgraduate at Ailamazyan Program Systems Institute of Russian Academy of Sciences. Fields of research interest: artificial neural networks, diagnosis of complex technical systems. 
УДК 004.82

\title{
ПОДХОД К ФОРМИРОВАНИЮ НАБОРОВ ЭТАЛОНОВ РЕЧЕВЫХ КОМАНД С ИСПОЛЬЗОВАНИЕМ ОНТОЛОГИИ
}

\author{
А.И. Армер ${ }^{1}$, В.С. Мошкин ${ }^{2}$ \\ Ульяновский государственный технический университет, Ульяновск, Россия \\ 1a.armer@mail.ru, ${ }^{2}$ PostForVadim@ya.ru
}

\begin{abstract}
Аннотация
В работе приводится метод формирования библиотеки эталонов речевых команд с использованием предметной онтологии с целью повышения их дальнейшего распознавания. Представлена формальная модель предметной OWL-онтологии, используемой в качестве базы знаний в процессе формирования и расширения библиотеки эталонных команд в процессе распознавания речевых команд, а также описан алгоритм извлечения списка синонимов входных речевых команд на основе предметной OWL-онтологии. Статья содержит описание методики проведения, а также результаты экспериментов по формированию вариантов библиотеки эталонов и выбора библиотеки с наиболее различимыми командами с использованием OWL-онтологии предметной области управления гражданского самолета с помощью речевых команд. Приводятся результаты экспериментов, доказывающие эффективность подхода.
\end{abstract}

Ключевые слова: речевые команды, онтология, эталоны, распознавание речи.

Цитирование: Армер, А.И. Подход к формированию наборов эталонов речевых команд с использованием онтологии /А.И. Армер, В.С. Мошкин // Онтология проектирования. - 2016. - Т. 6, №3(21). - C. 270-277. - DOI: 10.18287/2223-9537-2016-6-3-270-277.

\section{Введение}

При распознавании речевых команд (РК) из ограниченного словаря в ряде алгоритмов используется сравнение наблюдаемой РК с каждой эталонной РК, и из эталонных находится наиболее близкая к наблюдаемой. С этой эталонной РК наблюдаемая РК признаётся идентичной. В силу различных причин от состава библиотеки эталонных команд в значительной степени зависит вероятность правильного распознавания РК $[1,2]$.

При распознавании РК большое влияние на вероятность правильного распознавания оказывает различимость команд по длительности произнесения. Обычно по длительности произнесения производится предварительная сортировка эталонных команд, в результате которой в дальнейшем сравнении с наблюдаемой РК могут участвовать не все эталонные [3-5]. Однако, из-за изменчивости длительности произнесения РК даже при идентификации по длительности возможны ошибки первого и второго рода.

Ошибка первого рода возникает тогда, когда после предварительной идентификации в дальнейшей идентификации не участвует эталон, в действительности идентичный наблюдаемой РК. Предварительная идентификация целесообразна, если в результате вероятность ошибки первого рода близка к нулю.

Ошибки второго рода возникают, если в дальнейшей идентификации помимо действительно соответствующего эталона участвуют и другие эталонные РК, и сколько их, столько и ошибок второго рода. Поэтому при сохранении близкой к нулю вероятности ошибки первого рода снижение количества ошибок второго рода приводит к увеличению вероятности правильного распознавания речи $[6,7]$. 
Целью настоящей работы является формирование библиотеки эталонных команд, в которой команды были бы максимально различимы по длительности произнесения, то есть в процессе распознавания давали минимальное количество ошибок второго рода при близкой к нулю вероятности ошибки первого рода, и при этом не терялся тематический и практический смысл библиотеки. Например, если библиотека используется для распознавания команд управления транспортным средством, то команды должны сохранять смысловую связь с вызываемыми ими автоматическими действиями бортового оборудования. Для достижения поставленной цели необходимо использовать некую базу знаний, определяющую семантику каждой РК из библиотеки эталонных команд и расширяющую её за счет формирования выражений, синонимичных РК. Одним из наиболее эффективных подходов при решении данной задачи является использование онтологии.

\section{OWL-онтология формирования наборов эталонов PK}

Онтология представляет собой систему, состоящую из множества понятий, их определений и аксиом, необходимых для ограничения интерпретации и использования понятий. Любая онтология основана на математическом аппарате - дескрипционной логике (ДЛ) определенного типа.

OWL (Ontology Web Language) - язык описания онтологий, позволяющий описывать классы и отношения между ними. В основе языка - представление действительности в модели данных «объект - свойство». OWL является переформулировкой ДЛ с использованием синтаксиса XML.

Онтология предметной области (ПрО) представляет собой совокупность RDF-троек: subject - predicate - object (субъект - отношение - объект). В рамках решения поставленной задачи использовалась OWL-онтология [8].

Онтологический подход к хранению знаний в рамках решения задачи получения полной библиотеки аналогов возможных РК предполагает представление их в виде

$$
O=<T, R, F>\text {, }
$$

где:

- $\quad T$ - термины прикладной области, которую описывает онтология, при этом

$$
T \subset\left\{T_{O B J}, T_{A C T}, T_{C H A R}\right\},
$$

где $T_{O B J}-$ множество классов, описывающих иерархию объектов затрагиваемой ПрО;

$T_{A C T}-$ множество классов, описывающих возможные действия, совершаемые над элементами множества $T_{O B J}$;

$T_{C H A R}-$ множество классов характеристик объектов ПрО или действий над ними.

- $R$ - отношения между терминами заданной ПрО:

$$
R \subset\left\{R_{C M N}, R_{\text {OBJ }}, R_{D A T A}, R_{A N N O T}\right\},
$$

где $R_{C M N}$ - множество встроенных отношений синонимии и иерархии классов онтологии. Пример определения встроенного отношения идентичности (sameAs) разработанной OWLонтологии:

$<$ NamedIndividual rdf:about="\&www;связь">

$<$ rdf:type rdf:resource $=" \& w w w ;$ Объект">>

$<$ sameAs rdf:resource $=" \& w w w ;$;оединение" $>>$

$<$ sameAs rdf:resource $=" \& w w w ;$ сообщение"/>

$</$ NamedIndividual $>$

$R_{O B J}-$ множество отношений объектов (Object Properties). Пример определения отношения объектов «частьВыражения»:

$<$ NamedIndividual rdf:about="\&www;больше" $>$ 
$<$ rdf:type rdf:resource="\&www;Действие" $>>$

$<$ www:частьBыражения rdf:resource="\&www;мошнее" $>>$

$<$ sameAs rdf:resource $=" \& w w w ; n o в b l c u m b " />$

$<$ NamedIndividual $>$

$R_{D A T A}-$ множество отношений типа данных (Datatype Properties);

$R_{A N N O T}-$ множество отношений аннотации (Annotation Properties).

- $F$ - множество функций интерпретации (аксиоматизации), заданных на терминах и/или отношениях онтологии.

Для решения задачи получения максимального количества вариантов синонимичных РК в библиотеке эталонов была разработана OWL-онтология, включающая команды системы речевого управления режимами работы двигателя самолёта.

OWL-онтология состоит из 3 классов: «Действие», «Объект» и «Характеристика», объекты которых связаны между собой отношениями $R_{C M N}$ и $R_{O B J}$. Благодаря наличию этих отношений, онтология позволяет получать различные вариации написания команд, синонимичных анализируемым. Фрагмент онтологии, иллюстрирующий данный процесс, представлен на рисунке 1 .

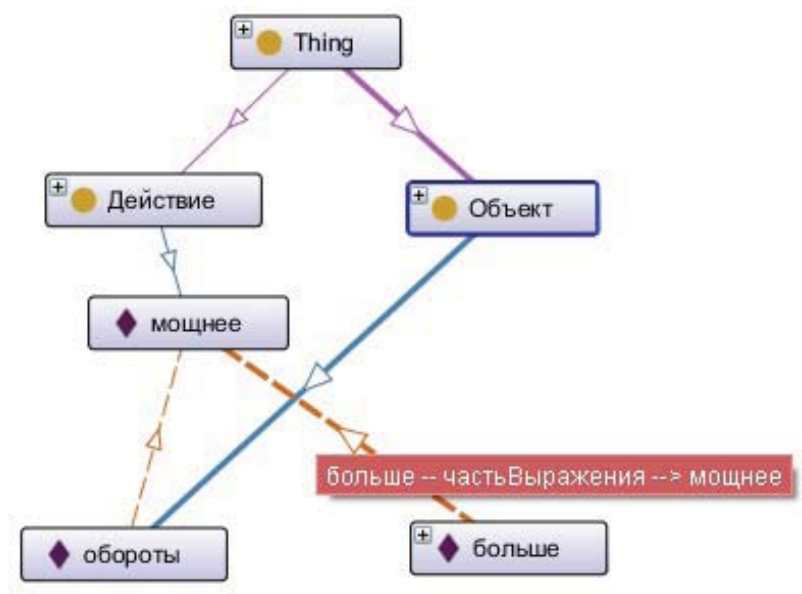

Рисунок 1 - Пример применения отношения «частьВыражения» OWL-онтологии

Как видно из рисунка 1 , два объекта онтологии «обороты» и «больше» связаны с объектом «мощнее» класса «Действие» посредством отношения (Object Property) «частьВыражения», благодаря чему при формировании набора эталонов РК «обороты слева (справа) больше» можно заменить на семантически синонимичную РК «мощнее слева (справа)».

Аналогичным образом используются при формировании набора эталонов РК отношение «включает», являющееся обратным (свойство отношения «Inverse Of») отношению «частьВыражения», а также встроенное отношение идентичности «sameAs», которое определяет синонимию непосредственно между двумя объектами онтологии. На данный момент разработанная OWL-онтология содержит 89 объектов классов.

\section{2 Алгоритм извлечения списка синонимов входных речевых команд на ос- нове предметной OWL-онтологии}

OWL-онтология позволяет, помимо непосредственного описания основных объектов рассматриваемой ПрО, связывать их между собой, благодаря чему в процессе обработки какого-либо семантически значимого выражения (в нашем случае им является РК), появляется возможность извлечения синонимичных выражений, необходимых при решении задачи определения и наполнения библиотеки эталонных команд. 
Таким образом, алгоритм получения списка синонимов выражения на основе предметной OWL-онтологии включает в себя следующие этапы.

1) разбиение входного выражения на семантически значимые сочетания - синтагмы (с учётом употребления предлогов): $\mathrm{P}: \mathrm{a} \rightarrow \mathrm{B}$, где а - входное выражение, В - множество семантически значимых единиц, на которое данное выражение разбивается.

2) поиск полученных объектов в предметной OWL-онтологии.

3) генерация набора выражений посредством смены порядка слов в сочетаниях $\mathrm{G}_{1}: \mathrm{B} \rightarrow \mathrm{B}^{\prime}, B^{\prime} \subseteq\left\{\mathrm{B}_{1}^{\prime}, \mathrm{B}_{2}^{\prime} \ldots \mathrm{B}_{\mathrm{n}}^{\prime}\right\}$, где $\mathrm{B}^{\prime}$ - множество выражений, полученных из входного путём смены порядка семантически значимых единиц.

4) поиск синонимов для каждого слова входного сочетания: $\mathrm{S}_{1}$ : B $\rightarrow \mathrm{B}_{\mathrm{S}}$, где $\mathrm{B}_{\mathrm{S}}$ - множество синонимов для каждой семантически значимой единицы входного выражения.

5) генерация набора выражений посредством смены порядка слов и с учётом их замены на синонимы: $\mathrm{G}_{2}: \mathrm{B} \rightarrow \mathrm{B}_{\mathrm{s}}{ }^{\prime}, B_{s}{ }^{\prime} \subseteq\left\{\mathrm{B}_{\mathrm{S}^{\prime}}{ }_{1}, \mathrm{~B}_{\mathrm{S}_{2}}{ }^{\prime} \ldots \mathrm{B}_{\mathrm{s}_{\mathrm{m}}{ }_{\mathrm{m}}}\right\}$, где $\mathrm{B}_{\mathrm{s}}{ }^{\prime}-$ множество выражений, полученных из входного путём смены порядка слов с учётом их замены на синонимы.

6) поиск синонимов устойчивых выражений во входном выражении (количество слов может не совпадать): $\mathrm{S}_{2}: \mathrm{B} \rightarrow \mathrm{B}_{\mathrm{EXP}}$, где $\mathrm{B}_{\mathrm{EXP}}$ - множество синонимов устойчивых выражений, содержащихся во входном выражении.

7) генерация набора выражений посредством смены порядка слов и с использованием си-

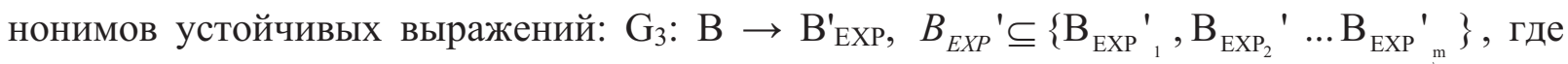

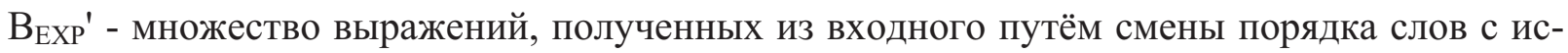
пользованием найденных синонимов устойчивых выражений.

8) построение полного списка полученных синонимов: $B_{A L L} \subseteq\left\{B^{\prime}, B^{\prime}{ }_{S}, B^{\prime}{ }_{E X P}\right\}$.

Схематично данный алгоритм представлен на рисунке 2.

Таким образом, в результате анализа входного выражения, являющегося прототипом некоторой речевой команды, алгоритм формирует на основе анализа отношений в предметной онтологии список всех возможных синонимов данного выражения, тем самым расширяя возможность правильного выбора команды на этапе распознавания.

\section{3 Создание вариантов библиотеки эталонов и выбор библиотеки с наиболее различимыми командами}

Схема эксперимента по выявлению наиболее различимых по длительности команд, составляющих библиотеку эталонов, с использованием предметной OWL-онтологии выглядит следующим образом.

1) выбирается набор команд, рассматриваемый в качестве исходной библиотеки.

2) разрабатывается предметная OWL-онтология, позволяющая получать синонимы для команд из этой библиотеки.

3) для каждой команды из этой библиотеки с помощью OWL-онтологии создаётся максимально возможное количество синонимов так, что каждая команда из исходной библиотеки образует набор команд - синонимичных вариантов. Всевозможные сочетания без повторений команд из образованных наборов дают новые библиотеки эталонных команд.

4) для каждой новой библиотеки подготавливаются наборы тестовых команд для распознавания по длительности произнесения.

5) проводится эксперимент, в котором тестовые команды идентифицируются по длительности. 
6) выявляется библиотека, для которой в результате идентификации получено минимальное количество ошибок второго рода при отсутствии ошибок первого рода.

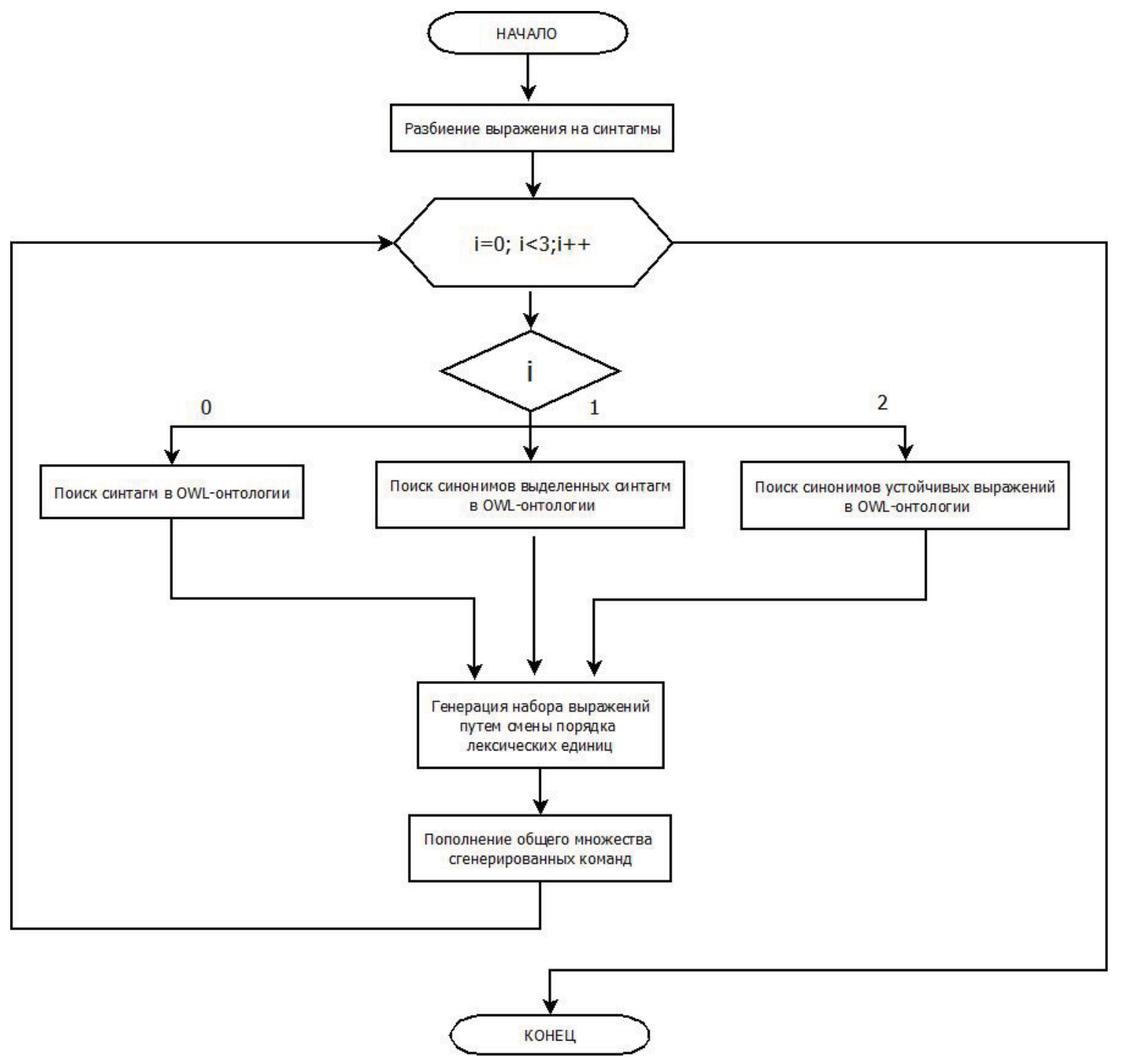

Рисунок 2 - Схема алгоритма расширения библиотеки эталонных команд

Для проведения испытаний взята библиотека из восьми команд, предназначенных для системы речевого управления режимами работы двигателя самолёта (см. таблицу 1). Для каждой команды с использованием алгоритма получения синонимов эталонных команд сгенерировано своё количество синонимов. Например, для команды «обороты слева меньше» сгенерировано 24 синонима, группа этих синонимов приведена в таблице 2.

Если из каждой группы брать по одному синониму, то получится 897122304 различных комбинаций синонимов, называемых сочетаниями. Каждое сочетание рассматривалось как библиотека эталонных РК. Для каждой из 897122304 библиотек определено количество ошибок идентификации по длительности произнесения. Та библиотека, для которой определено наименьшее количество ошибок второго рода, была признана «оптимальной». Идентификация производилась путём сравнения длины распознаваемой РК с длинами эталонных команд. 
Таблица 1 - Формирование наборов эталонов речевых команд

\begin{tabular}{|c|l|c|c|}
\hline № & \multicolumn{1}{|c|}{ Команда } & $\begin{array}{c}\text { Количество } \\
\text { синонимов }\end{array}$ & $\begin{array}{c}\text { Номер синонима в } \\
\text { «оптимальной» библиотеке }\end{array}$ \\
\hline 1. & обороты слева меньше & 24 & 1 \\
\hline 2. & обороты слева больше & 26 & 25 \\
\hline 3. & обороты справа меньше & 24 & 25 \\
\hline 4. & обороты справа больше & 26 & 4 \\
\hline 5. & турбостартер слева & 4 & 3 \\
\hline 6. & турбостартер слева выключить & 12 & 3 \\
\hline 7. & турбостартер справа & 4 & 5 \\
\hline 8. & турбостартер справа выключить & 12 & \\
\hline
\end{tabular}

Таблица 2 - Перечень синонимов команды «обороты слева меньше»

\begin{tabular}{|c|l|l|l|}
\hline № & \multicolumn{1}{|c|}{ Синонимы } & № & \multicolumn{1}{|c|}{ Синонимы } \\
\hline 1. & обороты слева меньше & 13. & мощность слева меньше \\
\hline 2. & обороты меньше слева & 14. & мощность меньше слева \\
\hline 3. & слева обороты меньше & 15. & слева мощность меньше \\
\hline 4. & слева меньше обороты & 16. & слева меньше мощность \\
\hline 5. & меньше обороты слева & 17. & меньше мощность слева \\
\hline 6. & меньше слева обороты & 18. & меньше слева мощность \\
\hline 7. & обороты слева снизить & 19. & мощность слева снизить \\
\hline 8. & обороты снизить слева & 20. & мощность снизить слева \\
\hline 9. & слева обороты снизить & 21. & слева мощность снизить \\
\hline 10. & слева снизить обороты & 22. & слева снизить мощность \\
\hline 11. & снизить обороты слева & 23. & снизить мощность слева \\
\hline 12. & снизить слева обороты & 24. & снизить слева мощность \\
\hline
\end{tabular}

В результате сравнения, если длина распознаваемой команды попадает в интервал $\left[\frac{1}{a} L_{i} ; a L_{i}\right],(i=1 . .8)$, где $L_{i},(i=1 . .8)$ - длина $i-\check{u}$ эталонной команды; $a$ - коэффициент, подбираемый экспериментально, команда признаётся идентичной заданному эталону. Коэффициент a подбирался в процессе идентификации РК таким образом, чтобы при отсутствии ошибок первого рода количество ошибок второго рода было минимальным.

В результате эксперимента при идентификации восьми тестовых РК минимальное количество ошибок второго рода составило 46 при отсутствии ошибок первого рода, что говорит о хорошей эффективности разработанного алгоритма. Выявленная «оптимальная» библиотека РК приведена в таблице 3.

\section{Заключение}

Использование OWL-онтологии, позволяющей получать наборы синонимов для каждой речевой команды из библиотеки эталонов, позволило определить лучшую библиотеку эталонов, в которой команды в большей степени различимы по длительности произнесения, то 
Таблица 3 - «Оптимальная» библиотека РК

\begin{tabular}{|l|l|}
\hline \multicolumn{1}{|c|}{$№$} & \multicolumn{1}{|c|}{ Команда } \\
\hline 1. & обороты слева меньше \\
\hline 2. & мощнее слева \\
\hline 3. & обороты справа меньше \\
\hline 4. & мощнее справа \\
\hline 5. & слева стартер \\
\hline 6. & слева турбостартер выключить \\
\hline 7. & стартер справа \\
\hline 8. & выключить турбостартер справа \\
\hline
\end{tabular}

есть в процессе идентификации РК с использованием этой библиотеки произошло минимальное количество ошибок второго рода при отсутствии ошибок первого рода. При этом не потерялся тематический и практический смысл библиотеки.

\section{Благодарности}

Работа выполнена при финансовой поддержке РФФИ (проект № 16-48-730305 «Разработка метода распознавания слитной речи по двумерным автокорреляционным изображениям с использованием онтологии, извлекаемой из текстов определённой предметной области»).

\title{
Список источников
}

[1] Крашенинников, В.P. Модели изменчивости речевых команд / В.Р. Крашенинников, А.И. Армер, И.Н. Синицин // Наукоемкие технологии. - М.: Радиотехника, 2007. - С 56-64.

[2] Крашенинников, B.P. Алгоритм выбора эталонов речевых команд при распознавании речи / В.Р. Крашенинников, Н.А. Крашенинникова, В.В. Кузнецов // Труды Российского научно-технического общества радиотехники, электроники и связи им. А.С. Попова. 2007. - № LXII. C. 158-159.

[3] Pienado A., Segura J.C. Speech recognition over digital channels: robustness and standards / John Wiley \& Sons Ltd., 2006. 257 P.

[4] Keshet J., Bengio S. Automatic Speech and Speaker Recognition: Large Margin and Kernel Methods / John Wiley \& Sons Ltd., 2009. 253 P.

[5] Gelbart D. Ensemble Feature Selection for Multi-Stream Automatic Speech Recognition / Technical Report No. UCB/EECS-2008-160, University of California at Berkeley, 2008, 117 P.

[6] Галунов В.И. Современные проблемы в области распознавания речи / В.И. Галунов, А.Н. Соловьев // Информационные технологии и вычислительные системы. Под. ред. С. В. Емельянова, Вып. 2. М.: «Рохос», 2004. - C.41-45.

[7] Rabiner L., Juang B.-H. Fundamentals of speech recognition / Prentice-Hall International Inc., USA, 1993, 497 P.

[8] Гаврилова T.A. Базы знаний интеллектуальных систем: [учеб. пособие для студентов вузов]/ Т.А. Гаврилова, В.Ф. Хорошевский. - СПб: Изд-во «Питер», 2001. - 384 с.

\section{APPROACH TO CREATING SETS OF REFERENCE SPEECH COMMANDS USING ONTOLOGY}

\author{
A.I. Armer ${ }^{1}$, V.S. Moshkin ${ }^{2}$ \\ Ulyanovsk State Technical University, Ulyanovsk, Russia \\ 1a.armer@mail.ru, ${ }^{2}$ PostForVadim@ya.ru
}

\begin{abstract}
This article describes the method of formation of speech commands reference library using ontology to increase their further recognition. The article presents the formal model of a subject OWL-ontology, used as a base of knowledge in the process of formation and expansion of the library of reference teams in the process of recognition of voice commands. An algorithm for retrieval of the list of synonyms of input speech commands, based on the subject of OWLontology is also described. The article describes the research methodology, as well as the results of experiments on the formation of variants of the reference library and selection of a library with the most recognizable commands using
\end{abstract}


OWL-ontology of civil aircraft voice command control. In conclusion, the results of experiments demonstrating the effectiveness of this approach are presented.

Key words: speech commands, ontology, model, speech recognition.

Citation: Armer AI, Moshkin VS. Approach to creating set of reference speech commands using ontology [In Russian]. Ontology of designing. 2016; v.6, 3(21): 270-277. - DOI: 10.18287/2223-9537-2016-6-3-270-277.

\section{References}

[1] Krasheninnikov VR, Armer AI, Sinicin IN. Models variability voice commands [In Russian]. High Tech. - M.: Radiotekhnika, 2007. - pp. 56-64.

[2] Krasheninnikov VR, Krasheninnikova NA., Kuznecov VV. The selection algorithm standards of voice commands at the speech recognition [In Russian]. Proceedings of the Russian Scientific and Technical Society of Radio Engineering, Electronics and Communication named after AS Popov. 2007. № LXII. pp. 158-159.

[3] Pienado A, Segura JC. Speech recognition over digital channels: robustness and standards / John Wiley \& Sons Ltd., 2006. 257 P.

[4] Keshet J., Bengio S. Automatic Speech and Speaker Recognition: Large Margin and Kernel Methods / John Wiley \& Sons Ltd., 2009. 253 P.

[5] Gelbart D. Ensemble Feature Selection for Multi-Stream Automatic Speech Recognition / Technical Report No. UCB/EECS-2008-160, University of California at Berkeley, 2008, P. 117

[6] Galunov VI., Solov'ev AN. Contemporary Issues in Speech Recognition [In Russian]. Information technology and computer systems. Ed. SV Emelyanov, 2004, Is.2. - Moscow: «Rojos», 2004. pp.41-45.

[7] Rabiner L, Juang BH. Fundamentals of speech recognition / Prentice-Hall International Inc., USA, 1993,497 P.

[8] Gavrilova TA, Horoshevskiy VF. Knowledge Base of Intelligent Systems [In Russian]. - SPb: Pbl.«Piter», 2001. $384 \mathrm{p}$.

\section{Сведения об авторах}

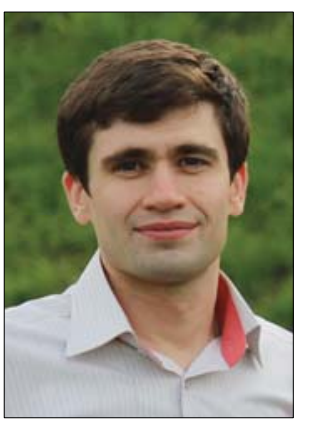

Армер Андрей Игоревич, 1982 г. рождения, окончил Ульяновский государственный технический университет (2004) г., к.т.н. (2006 г.), доцент кафедры прикладной математики и информатики Ульяновского государственного технического университета (2011 г.), круг научных интересов: обработка и анализ речевых сигналов, распознавание образов. Имеет более 60 публикаций.

Armer Andrey Igorevich, (b.1982), education: Ulyanovsk State Technical University, 2004, $\mathrm{PhD}$ (modeling and recognition of speech signals against the background of high noise), 2006, main work: Ulyanovsk State Technical University, Associate professor (Dpt. of Applied Mathematics and Computer Science), 2011, Expert in modeling and recognition of speech signals against the background of high noise. He has more then 60 articles.

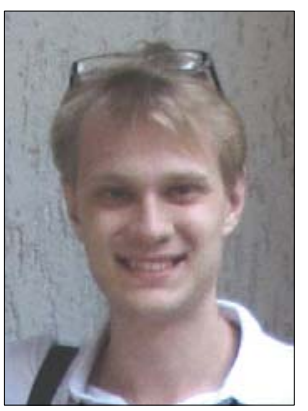

Моикин Вадим Сергеевич, 1990 г. рождения. Окончил Ульяновский государственный технический университет (УлГТУ) в 2012 г., аспирант, ассистент кафедры информационных систем УлГТУ. Ведущий разработчик Центра разработки электронных мультимедиа технологий УлГТУ. Член Российской ассоциации искусственного интеллекта. В списке научных трудов более 30 статей в области интеллектуальной обработки знаний, автоматизации проектирования, а также построения прикладных интеллектуальных систем.

Moshkin Vadim Sergeevich (b. 1990) graduated from the Ulyanovsk State Technical University (U1STU) in 2012, post-graduate student at the Chair 'Information Systems' of Ulyanovsk State Technical University. A lead developer of Center of Multimedia Technologies of U1STU. He is Russian Association of Artificial Intelligence member. He is co-author of more than 30 publications in the field of intellectual knowledge processing, automation of design and construction of intelligent systems applied. 


\title{
КОНВЕРТЕР ОНТОЛОГИЧЕСКОЙ БАЗЫ ЗНАНИЙ СТАНКОВ И ДЕТАЛЕЙ МАШИНОСТРОИТЕЛЬНОГО ПРОИЗВОДСТВА В ОБЪЕКТНУЮ БАЗУ ДАННЫХ НА ОСНОВЕ ANTLR
}

\author{
В.А. Игруша ${ }^{1}$, С.С. Сосинская ${ }^{2}$ \\ Иркутский национальный исследовательский технический университет, Иркутск, Россия \\ 'xoy-90@mail.ru, ${ }^{2}$ sosinskaya@mail.ru
}

\begin{abstract}
Аннотация
Статья посвящена разработке автоматизированного конвертера, преобразующего базу знаний в виде онтологии, представленной в одном из форматов, допустимых редактором онтологий OntoStudio (OWL или RDF), в объектно-ориентированную базу данных (ООБД) db4o. Впервые предложен подход, основанный на использовании компилятора компиляторов ANTLR (ANother Tool for Language Recognition). Это позволяет сократить трудозатраты и применить программное средство ANTLR для других онтологий, так как разработана грамматика языка описания онтологий, которая не зависит от предметной области базы знаний. Грамматика содержит не только лексические и синтаксические правила для проверки правильности текста, но и правила действий для преобразования элементов онтологии в изоморфные им элементы объектной базы данных.
\end{abstract}

Ключевье слова: онтология, OntoStudio, ANTLR, Protégé, конвертер, ООБД, db4o, проект, база знаний, класс.

Цитирование: Игруша, В.А. Конвертер онтологической базы знаний станков и деталей машиностроительного производства в объектную базу данных на основе ANTRL / B.A. Игруша, С.C. Сосинская // Онтология проектирования. - 2016. - Т. 6, №3(21). - С. 278-286. - DOI: 10.18287/2223-9537-2016-6-3-278-286.

\section{Введение}

Существует множество обстоятельств, которые затрудняют распространение и обмен между людьми знаниями, столь необходимыми для их систематического пополнения и накопления.

Это связано с быстрым ростом численности населения и вовлечением новых поколений в различные сферы деятельности, требующие постоянно растущего уровня знаний, умений и навыков. Особым обстоятельством являются фундаментальные отличия и множественность национальных языков.

Многие проблемы в создании знаний и обмене ими обусловлены неоднозначным восприятием смысла знаний различными участниками процесса, которые могут пользоваться различной терминологией и понятийным аппаратом и руководствоваться различными моделями деятельности.

Вследствие этих объективных обстоятельств весьма желательно, чтобы информация и знания были структурированы таким образом, чтобы пользователь, в том числе и компьютер, понимал и текст, и смысл документа и обрабатывал его посредством использования известных ему правил с помощью некоторого логического языка, а также был способен вывести новые факты и знания из документа [1]. 
Онтология - один из способов структурирования знаний путём создания иерархии понятий с их свойствами, правилами и запросами. Понятия вместе с их экземплярами создают объектную базу знаний [2]. Правила позволяют выводить новые экземпляры [3].

С другой стороны, объектно-ориентированные базы данных (ООБД) представляют собой набор классов, образующих иерархию и содержащих свойства, методы, запросы и объекты (экземпляры) классов [4].

Информационная модель данных в области машиностроения требует перехода от неструктурированных данных к таким структурам, которые позволяют получить ответы на нужные запросы за наименьшее время. Для решения этой проблемы был предложен новый подход, сочетающий формирование онтологии, содержащей информацию о технологических возможностях станков и обрабатываемых на них деталей [5], и параллельно с этим проектирование и реализацию хранения той же информации в виде ООБД [6].

Разработка онтологии даёт возможность автоматизировать процедуру выбора станков, наиболее подходящих для обработки тех или иных деталей. Применение онтологии как гибкой системы знаний, в которую могут быть включены самые различные характеристики оборудования, позволяет создать технологический процесс, обеспечивающий минимальные простои оборудования и снижение расходов на его техническое обслуживание.

Рассмотрение ООБД является существенно более эффективным подходом к разработке баз данных по сравнению с широко используемыми реляционными базами данных.

Разработка различных структур представления данных позволит в будущем сравнивать оба способа по скорости обработки запросов и объёму необходимой памяти и переходить от одного к другому для выбора наиболее эффективного в тот или иной период времени.

\section{1 Цель разработки конвертера}

Как показано в [6], онтология и ООБД для одной предметной области изоморфны.

Если представить онтологию $\mathrm{N}=\{\mathrm{C}, \mathrm{A}, \mathrm{E}, \mathrm{Q}, \mathrm{R}, \mathrm{P}\}$, а объектно-ориентированную базу данных $\mathrm{B}=\{\mathrm{C}, \mathrm{S}, \mathrm{O}, \mathrm{Z}, \mathrm{M}, \mathrm{D}\}$, где

C- классы;

А - атрибуты;

Е - экземпляры классов;

Q - запросы;

$\mathrm{R}$ - правила;

P - отчеты;

$\mathrm{S}$ - свойства классов;

O - объекты, то есть экземпляры классов;

$\mathrm{Z}$ - результаты запросов;

M - методы;

D - отчетные документы,

то утверждается, что $\mathrm{N} \equiv \mathrm{B}$, так как $\mathrm{A} \equiv \mathrm{S}, \mathrm{E} \equiv \mathrm{O}, \mathrm{Q} \equiv \mathrm{Z}, \mathrm{R} \equiv \mathrm{M}, \mathrm{P} \equiv \mathrm{D}$.

В связи с этим необходимо иметь программное средство для преобразования из одной формы в другую.

Авторами было разработано приложение для сканирования онтологии [6], представленной в формате RDF-файла; этот формат описан в [7]. Такой файл является результатом совместной обработки редакторами онтологий OntoStudio и Protégé.

Результатом работы приложения является ООБД db4o.

Однако написание подобного приложения является очень трудоёмкой задачей и потребует больших затрат времени программиста при внесении хотя бы небольших 
изменений в онтологию, а тем более при разработке расширенной онтологии, что является необходимым, например, при рассмотрении технологии изготовления деталей на станках.

На основании изложенного было принято решение разработать конвертер с использованием ANTLR (от ANother Tool for Language Recognition) - инструментария для создания компилятора языков программирования, который не только проверяет правильность текста на входном языке с точки зрения лексики и синтаксиса, но и преобразует описание с языка описания онтологий в язык ООБД [8].

\section{2 Состав и назначение ANTLR}

ANTLR - генератор парсеров, позволяющий автоматически создавать программы лексического и синтаксического анализа на одном из целевых языков программирования (C++, Java, C\#, Python, Ruby) по описанию LL - грамматики в расширенной нотации Бэкуса Наура [8]. В общем случае грамматика относится к классу $\operatorname{LL}(\mathrm{K})$ грамматик, если для неё можно построить анализатор, учитывающий K входных символов, расположенных справа от текущей входной позиции. Название LL произошло от слова Left, поскольку анализатор просматривает входную цепочку слева направо и слова Leftmost, поскольку он обнаруживает появление правила по одному или группе символов, образующих левый край цепочки. На практике наибольшее применение имеет класс LL(1) грамматик, для которых анализатор рассматривает только один входной символ, расположенный справа от текущей позиции. Создатели ANTLR утверждают, что многие преимущества при определении действий для правил грамматики являются следствием того, что ANTLR осуществляет разбор сверху вниз. Кроме того, ANTLR выгодно отличается от других подобных программ наличием визуальной среды разработки ANTLRWorks, позволяющей удобно создавать и редактировать грамматики.

ANTLR представляет собой набор, состоящий из двух частей.

- Генератора анализаторов - приложения, которое получает на вход описание грамматики и генерирует код для лексического и синтаксического анализатора.

- Библиотеки времени выполнения, которая используется для создания конечной программы. Эта библиотека содержит базовые классы для анализаторов, а также классы, управляющие потоками символов, обрабатывающие ошибки разбора, генерирующие выходной код на основе шаблонов и многое другое.

Одна из основных задач, при решении которых используется ANTLR, - разработка трансляторов с языков DSL (Domain Specific Language - язык, специфичный для предметной области), которые генерируют код на языке высокого уровня [9].

В отличие от многих других инструментов создания компиляторов, ANTLR имеет средства для создания не только frontend-части (лексического и синтаксического анализатора), но и возможности backend (генератора кода).

При этом backend может быть организован по-разному, в зависимости от желания пользователя. В статье используется вызов действий (семантических правил, actions) в синтаксическом анализаторе. Действия вызываются синтаксическим анализатором, когда он заканчивает разбирать какую-то грамматическую конструкцию или её часть (см. рисунок 1).

На этом рисунке изображено:

- Поток символов - текст программы на исходном языке;

- Lexer - лексический анализатор, разбивающий исходный поток символов на отдельные лексемы. На выходе лексический анализатор порождает поток лексем;

- Parser - синтаксический анализатор. Просматривает поток лексем и анализирует структуру предложений языка; 
- Actions - действия (код). Эти действия позволяют генерировать код на языке описания Java [10] который используется в ООБД db4o;

- Output Text-окончательный текст на предметном языке.

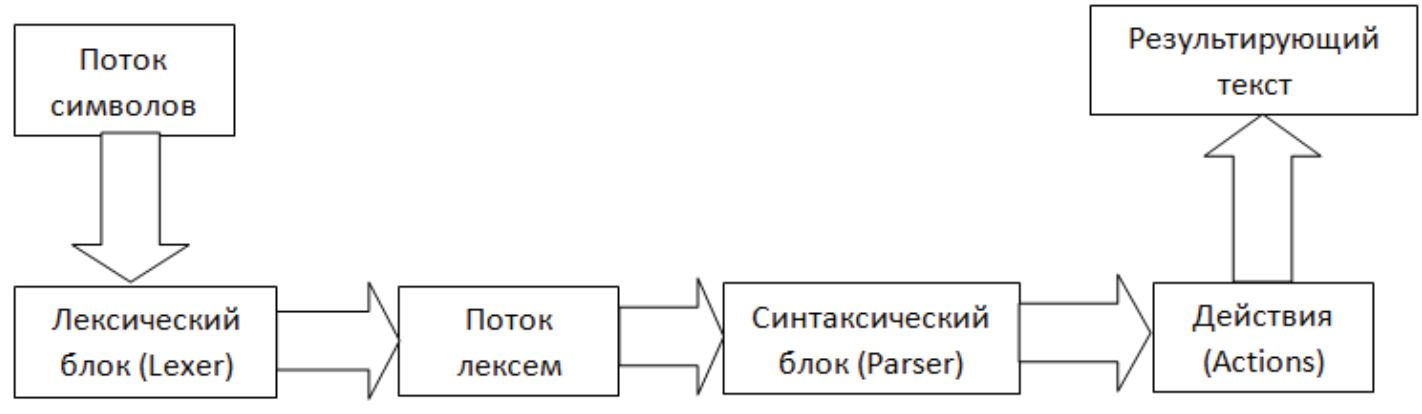

Рисунок 1 - Организация элементов ANTLR

\section{3 Представление онтологии станков и деталей машиностроительного производства в редакторе OntoStudio}

На основе анализа информации, необходимой для описания станков и деталей [11-14], при построении онтологии в редакторе OntoStudio были выделены следующие классы: Станок, Деталь, Материал, Инструмент, Марка материала, Марка инструмента, Нормативные документы.

Каждый класс имеет некоторые свойства. Например, свойства класса Деталь показаны на рисунке 2. Взаимосвязи класса Деталь показаны на рисунке 3.

\begin{tabular}{|c|c|c|c|c|}
\hline Local name: Деталь & & & & \\
\hline Properties & & & & \\
\hline Properties & Range & Min & Max & \\
\hline РГГабариты детали & 이 string & 0 & $\mathrm{~N}$ & $x$ \\
\hline геом.точность обрабатываемых поверхностей & decimal & 0 & $\mathrm{~N}$ & $x$ \\
\hline Pия детали & 이 string & 0 & $\mathrm{~N}$ & $x$ \\
\hline Pacca (гр.) & 미 integer & 0 & $\mathrm{~N}$ & $x$ \\
\hline P:метод изготовления & 이 string & 0 & $\mathrm{~N}$ & $x$ \\
\hline P Наименование детали & 이 string & 0 & $\mathrm{~N}$ & $x$ \\
\hline PНеобходимость приспособлений & 마 integer & 0 & $\mathrm{~N}$ & $x$ \\
\hline РОбозначение детали & 미 string & 0 & $\mathrm{~N}$ & $x$ \\
\hline P:Трудоемкость & 미 decimal & 0 & $\mathrm{~N}$ & $x$ \\
\hline P्:шеховатость поверхностей & 이 decimal & 0 & $\mathrm{~N}$ & $x$ \\
\hline Pероховатость радиусных переходов & 이 decimal & 0 & $\mathrm{~N}$ & $x$ \\
\hline P: материал & С Материал & 0 & $\mathrm{~N}$ & $x$ \\
\hline РОбрабатывается & C Станок & 0 & $\mathrm{~N}$ & $x$ \\
\hline
\end{tabular}

Рисунок 2 - Свойства класса Деталь

Свойства, перечисленные на рисунке 2 , могут иметь различные типы - как строка, так и целое число. Свойство «Имя детали» хранит имя детали, свойство «Наименование детали» хранит описание детали, свойство «Габариты детали» хранит габариты детали, измеренные в различных единицах измерения, поэтому было решено выбрать тип String, который в дальнейшем программным путём будет преобразовываться в нужный числовой формат. 


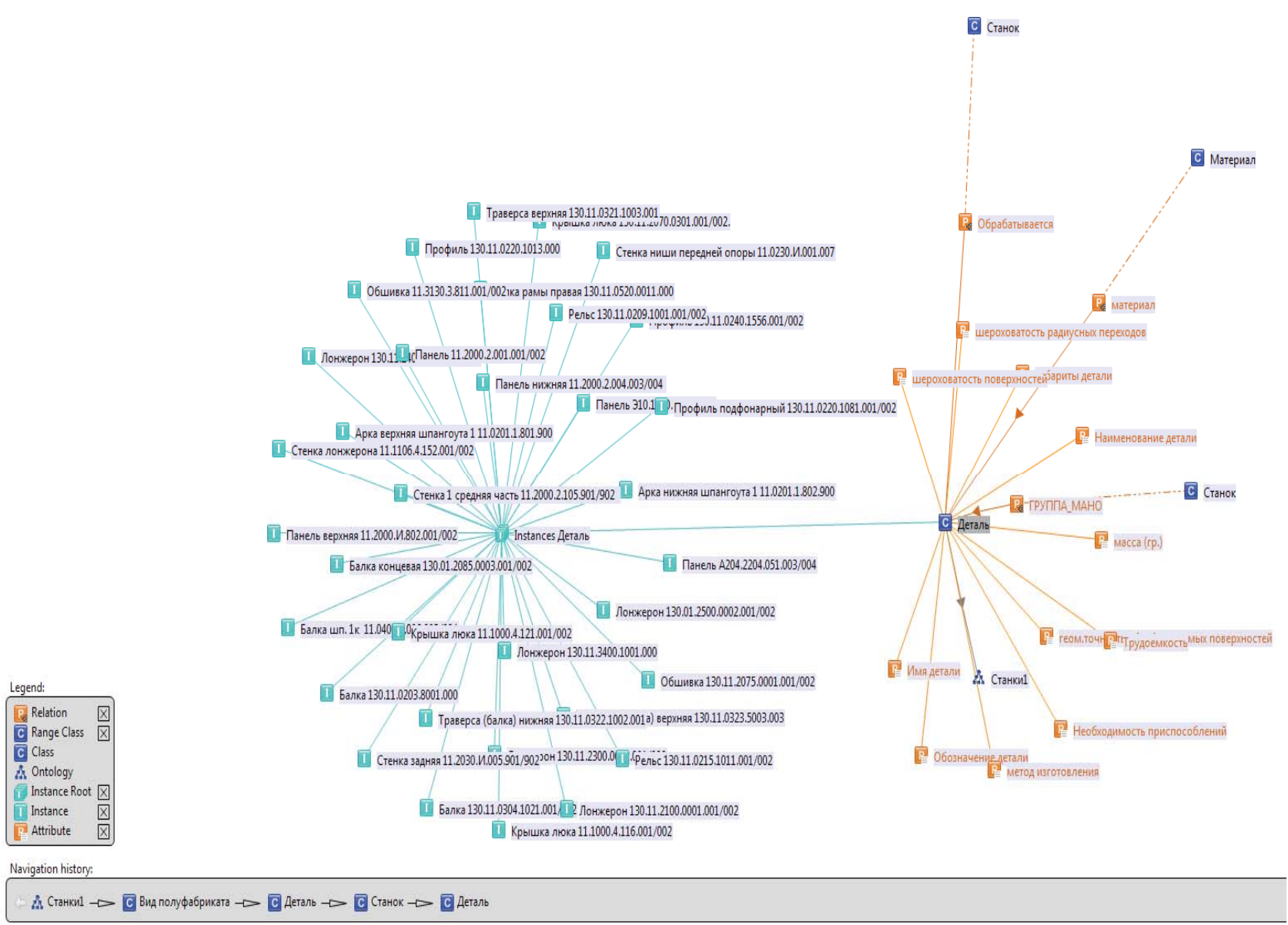

Рисунок 3 - Взаимосвязи класса Деталь

На рисунке 3 показано, как в OntoStudio можно визуально показать взаимосвязи свойств одного класса, которые являются экземплярами другого класса. В левой части рисунка изображены экземпляры класса «Деталь», а в правой части можно увидеть, какие свойства класса «Деталь» являются экземплярами других классов.

\section{4 Структура проекта}

Рассмотрим, как будет взаимодействовать ANTLR с разработками [5] и [6]. Грамматика описания онтологии на языке Object Logic приведена ниже.

grammar ont_db4o;

beginprog :((name_conc '[(concept $\{$ emitter.AddConc(\$name_conc.text $) ;\} \mid$

schema $\{$ emitter.AddSchema( $\$$ scema.text $) ;\})$

(name_conc concept_nasl\{emitter.AddConc_Child(\$name_conc.text); $\}$ )|

name_inst(props $\left\{-\quad\right.$ emitter.AddProp $\left(\$\right.$ name_ist.text $\left.^{-}\right) ; \quad$ |instance \{

emitter.AdddIns(\$name_ins.text);\})|

query $\{$ emitter.Add̄SQL(\$query ); $\} \mid$

rule $\{$ emitter.AddMethod(\$rul.text $) ;\}$ )'.')+ ;

query : '?-' usls ;

tip : TIP|name_conc ;

usls : $\quad$ ((uslo|uslp)'and'?)+;'

uslo : NP ':' name_conc; 


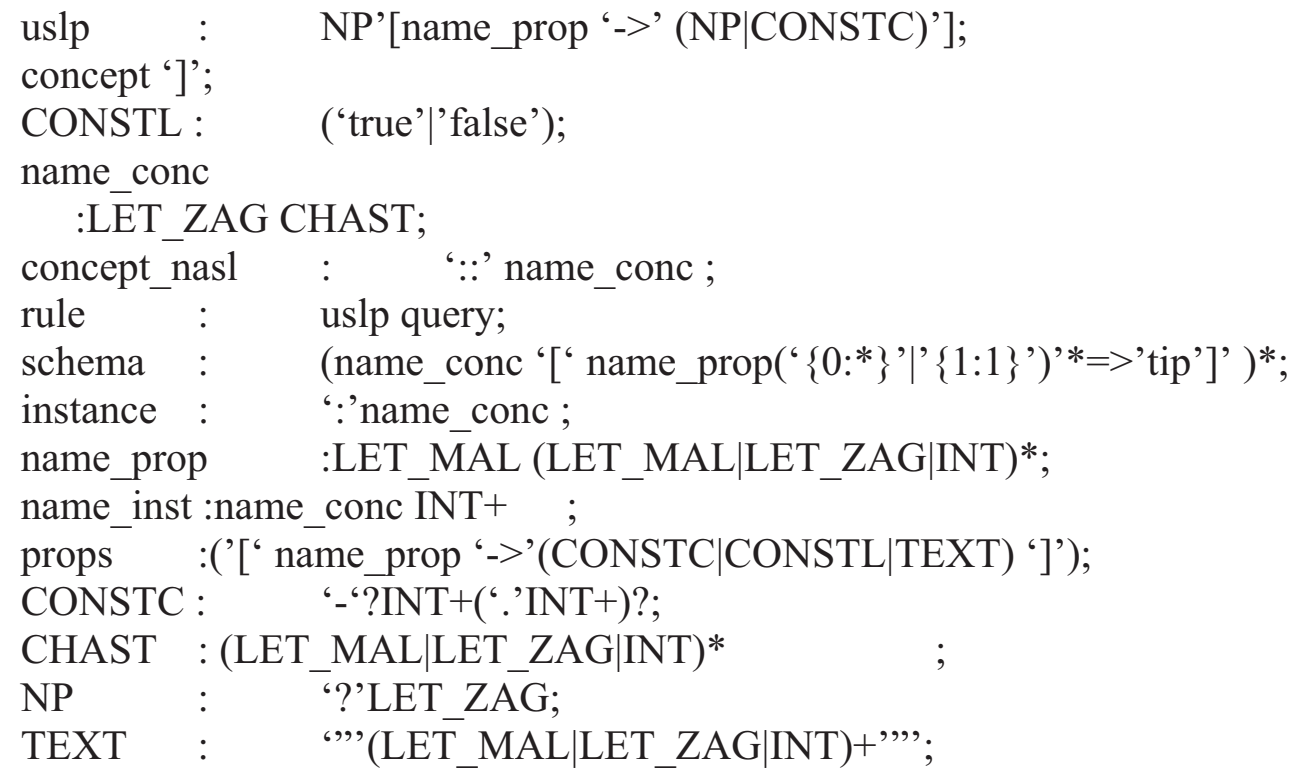

Грамматика состоит из правил. Все правила делятся на лексические и синтаксические.

Лексические правила используются для описания лексем и служат основой для генерации лексического анализатора. Синтаксические правила описывают грамматику языка.

Лексические правила (и соответствующие им имена лексем) должны начинаться с заглавной буквы, а синтаксические - со строчной.

В грамматику вставлены Action - символы действия, позволяющие сгенерировать код на языке јava.

По грамматике были сгенерированы классы:

- Lexer - лексический блок;

- Parser - синтаксический блок;

- Emitter - блок генерации классов db4o на языке Java.

Все эти классы экспортируются в среду разработки Eclipse [15], с помощью которой создаётся программный продукт «Конвертер Онтология - db4o». Взаимодействие всех блоков проекта Конвертер Онтология - db4o показано на рисунке 4.

Грамматика онтологии обрабатывается программой ANTLRWorks, с помощью которой генерируются классы Lexer, Parser и Emitter. Эти классы включаются в состав проекта приложения Конвертер Онтология - db4o на языке Java.

Файлы с онтологией в форматах OWL и RDF поступают на вход приложения. В случае наличия лексических или синтаксических ошибок выдаются сообщения. Например,

- token recognition error at: " at 3:5

- mismatched input '4' expecting \{'as', 'is', '[', '(', '.', ';', '+', '-', '*', '/, '\%', '\&', '|', '^, '<', '>', '?', '??', '++', '--', '\&\&', '||', '->', '==', '!=', '<=', '>=', '<<'\} at 8:19

- extraneous input '5' expecting \{'as', 'is', '[', '(', '., ',', '+', '-', '*', '1', 1\%', '\&', '|', '^, '<', '>', '?',

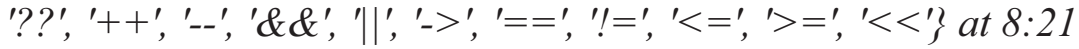

- $\quad$ no viable alternative at input 'c\}' at 15:5

- missing '\}' at 'EOF' at 15:6.

Если ошибок нет, то генерируются классы ООБД db4o, которые можно включать в любой проект, созданный в среде разработки Eclipse. 


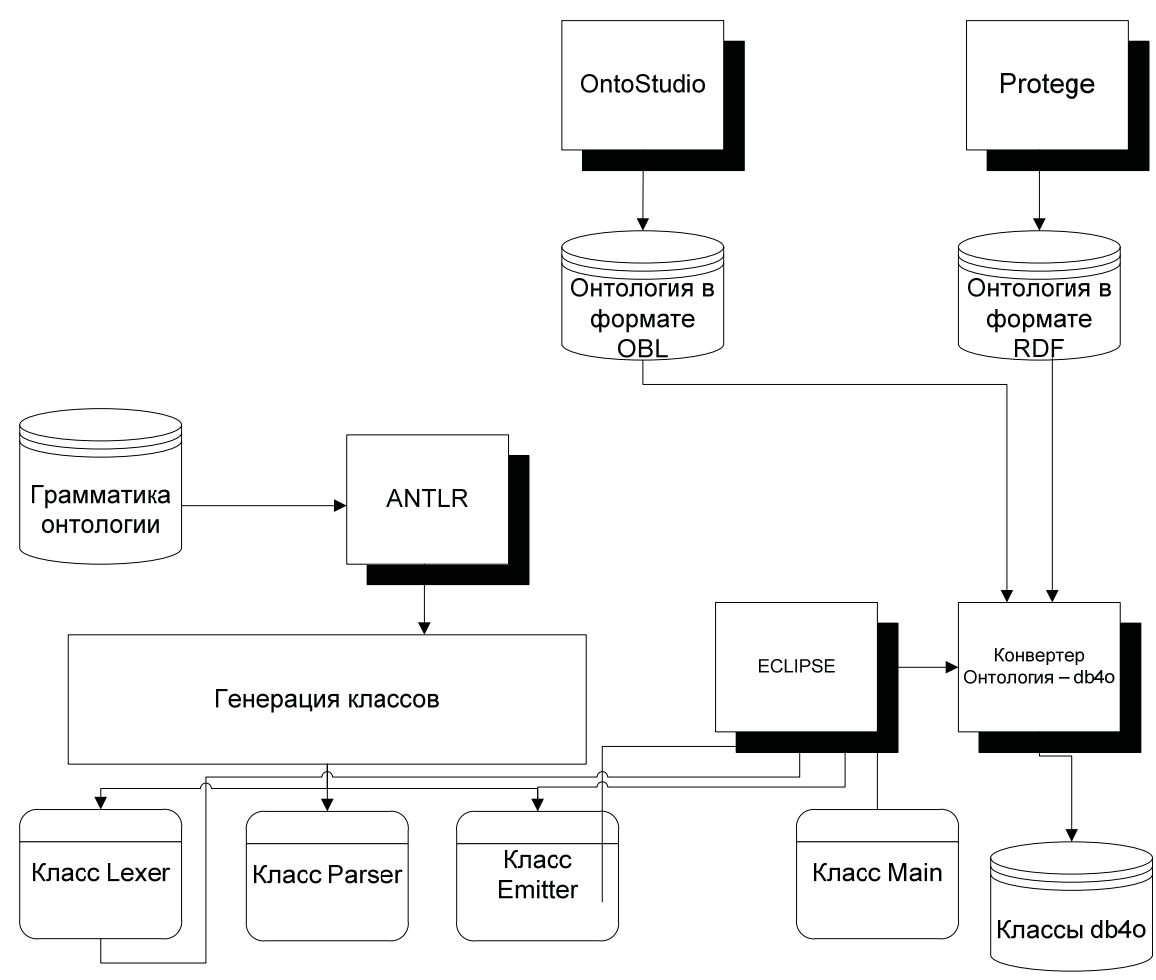

Рисунок 4 - Взаимодействие блоков проекта Конвертер Онтология - db4o

\section{Заключение}

В статье рассмотрены принципы разработки конвертера для преобразования онтологии в ООБД с использованием программного продукта ANTLR. Это позволило сократить трудозатраты при написании программного кода. Предлагаемая технология может быть распространена на случай расширения описанной онтологии, а также для обратного конвертирования из ООБД в онтологию. Для этого потребуется скорректировать грамматику ANTLR, возможно, включая класс Emitter.

\section{Список источников}

[1] Хорафас, Д.Н. Системы и моделирование / Д.Н. Хорафас - пер. с англ. Е. Г. Коваленко, В. Я. Алтаева, Б. А. Квасова. - М.: Мир , 1967. - 420 с. - Пер. изд.: Systems and simulation / Dimitris N Chorafas. - New York, 1965. - $240 \mathrm{p}$

[2] Scott $\boldsymbol{W}$. Ambler. Mapping objects to relational databases. What you need to know and why. - developerWorks ${ }^{\circledR}$ IBM Corporation 2000. Отображение объектов в реляционных базах данных. - URL: http://www.ibm.com/developerworks/library/ws-mapping-to-rdb/ (дата обращения 10.05.2016).

[3] Боргест, Н.M. Онтология проектирования: теоретические основы. Часть 1. Понятия и принципы / Н.М. Боргест // Учеб. пособие. - Самара: Изд-во СГАУ, 2010. - 91 с.

[4] Рабчевский, E. Автоматическое построение онтологий. - URL: http://shcherbak.net/avtomaticheskoepostroenie-ontologij/ (дата обращения 02.06.2016).

[5] Сосинская, С.C. Сравнение возможностей программных продуктов OntoStudio и Protege для анализа станочных систем машиностроительного производства / В.А. Игруша, С.С. Сосинская, С.А. Орсоева // Вестник ИрГТУ. - 2015. - № 3. - С. 17-23.

[6] Игруша, В.A. Изоморфизм онтологии и объектной базы данных для деталей механообработки / В.А. Игруша, С.С. Сосинская// Винеровские чтения. - 2015. - С. 51-55.

[7] Безруков, В. RDF - инструмент для неструктурированных данных. / В. Безруков, Ю. Конов, И. Стечкин // Открытые системы, № 9, 2012. - C.42-71.

[8] Программный продукт ANTLR. - URL: http://www.antlr.org/ (дата обращения 05.05.2016). 
[9] Разработка парсеров в программной среде ANTLR3. https://theantlrguy.atlassian.net/wiki/display/ANTLR3/FAQ+-+Getting+Started (дата обращения 05.05.2016).

[10] Руководство разработки Java при использовании db4o. - URL: http://supportservices.actian.com/versant/default.html (дата обращения 10.05.2016).

[11] Соснин, П.И. Структурное проектирование конфигурируемых шаблонов авиационных деталей / П.И. Соснин, О.Э. Чоракаев // Автоматизация процессов управления. - 2014. - №2 (36). - С. 99-107.

[12] Шустова, Д.В. Подход к разработке семантических основ информационных систем для проектирования и производства авиационной техники / Д.В. Шустова // Онтология проектирования. - 2015. - №1 (15). - С.7082.

[13] Нитипанова, Г.П. Онтологический анализ предметной области задачи базирования детали / Г.П. Нитипанова, С.В. Смирнов // Проблемы управления и моделирования в сложных системах: Труды ХІІІ международной конф. (15-17 июня 2011 г., Самара, Россия). - Самара: СамНЦ РАН, 2011. - С. 85-94.

[14] Шведин, Б.Я. Онтология предприятия: экспириентологический подход. Технология построения онтологической модели предприятия / Б.Я. Шведин. - М.: Ленанд. 2010. - 240 с.

[15] Программный продукт Eclipse. - https://eclipse.org/ (дата обращения 05.05.2016)

\title{
CONVERTER FOR THE ONTOLOGIC KNOWLEDGE BASE OF MACHINE TOOLS AND PARTS OF MACHINE-BUILDING PRODUCTION PLANT INTO AN OBJECTIVE DATABASE BUIILT ON ANTLR
}

\author{
V.A. Igrusha ${ }^{1}$, S.S. Sosinskaya ${ }^{2}$ \\ Irkutsk National Research Technical University, Irkutsk, Russia \\ ${ }^{1}$ xoy-90@mail.ru, ${ }^{2}$ sosinskaya@mail.ru
}

\begin{abstract}
The article is devoted to developing an automated converter for the knowledge base in the form of ontologies represented in one of the formats, acceptable for ontology editor OntoStudio (OWL or RDF), into an object-oriented database (OODB) db4o. The proposed approach is based on the ANTLR compiler (ANother Tool for Language Recognition). This approach is implemented for the first time. It reduces labor costs and applies the ANTLR software tool to other ontologies as the developed grammar ontology for the description language is independent from the subject area. Grammar contains not only lexical and syntactical rules to verify the text, but also the rules of action for the transformation of ontology elements into elements of isomorphic object database.
\end{abstract}

Key words: Ontology, OntoStudio, ANTLR, Protégé, converter, OODB, db4o, project, knowledge base, class.

Citation: Igrusha VA, Sosinskaya SS. Converter for the ontologic knowledge base of machine tools and parts of machine-building production plant into an objective database built on ANTLR [In Russian]. Ontology of designing. 2016; 3(21): 278-286. DOI: 10.18287/2223-9537-2016-6-3-278-286.

\section{References}

[1] Chorafas DN. Systems and Simulation. - New York, 1965. - 240 p.

[2] Scott WA. Mapping objects to relational databases. What you need to know and why. - developerWorks ${ }^{\circledR}$ IBM Corporation 2000. http://www.ibm.com/developerworks/library/ws-mapping-to-rdb/.

[3] Borgest NM. Ontology designing: theoretical bases. A part 1: Concepts and Principles Studies [In Russian]. Samara: Samara State Aerospace University Publishing House, 2010. - P. 91-93.

[4] Rabchevsky E. Automatic construction of ontologies [In Russian]. Source: 〈http://shcherbak.net/avtomaticheskoepostroenie-ontologij/>.

[5] Sosinskaya SS, IgrushaVA, Orsoeva SA. Comparison of possibilities of software products OntoStudio and Protege for the analysis of machine systems of machine-building manufacture [In Russian]. The Bulletin of Irkutsk National Research Technical University. - 2015; 3:17-23. 
[6] Igrusha VA, Sosinskaya SS. Isomorphism of ontology and objective database for details mechanical engineering [In Russian]. Vinerovsky readings. - 2015. - P. 51-55.

[7] Bezrukov V, Konov Yu, Stechkin I. RDF - the tool for not structured data [In Russian]. Open systems. - 2012; 9: 4271.

[8] The software ANTLR. Source: 〈http://www.antlr.org/〉.

[9] The development of parsers in ANTLR3 software environment. Source: $\langle\mathrm{http}: / / \mathrm{www}$. antlr3.org/ $\rangle$.

[10] Guide Java development using db40. Source: 〈http://supportservices.actian.com/versant/default.html/ $>$.

[11] Sosnin PI, Chorakaev OE. Structural designing of configured templates of aviation parts [In Russian]. Automation of management processes. - 2014; 2(36): 99-107.

[12] Shustova $D V$. The approach to the working out of semantic bases of information systems for the designing and manufacture of aviation technics [In Russian]. Ontology of designing. - 2015; 1(15): 70-82.

[13] Nitipanova GP, Smirnov SV. The ontologic analysis of a subject domain of a problem of basing of a detail [In Russian]. Problems of management and modeling in difficult systems: Work of XIII International Conf. (15 June 17, 2011, Samara, Russia). - Samara: SamNTs RAS, 2011. - P. 85-94.

[14] Shvedin BYa. The ontology the enterprise: experientalogical approach. Technology of construction of ontological model of the enterprise [In Russian]. - M.: LENAND. 2010. - P. 240.

[15] Eclipse. Source: 〈https://eclipse.org/〉.

\section{Сведения об авторах}

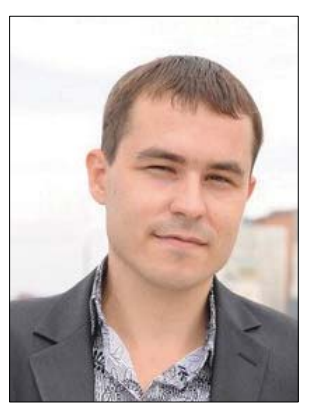

Игруша Владимир Андреевич, 1990 г. рождения. Окончил Иркутский национальный исследовательский технический университет. (2013). Аспирант кафедры технологии и оборудования машиностроительных производств. Область научных интересов онтологии, базы данных. Имеет около 10 публикаций. Инженер-программист 2 категории на Иркутском авиационном заводе - филиал ПАО "Корпорация "Иркут".

Igrusha Vladimir Andreevich, (b 1990) He graduated from Irkutsk national research technical University. (2013). Post-graduate student of department of technology and the equipment of machine-building manufactures. Research interests - ontology, database. He has about 10 publications. The Engineer-programmer of 2 categories on Irkutsk Aviation Factory - branch PAO "Corporation "Irkut".

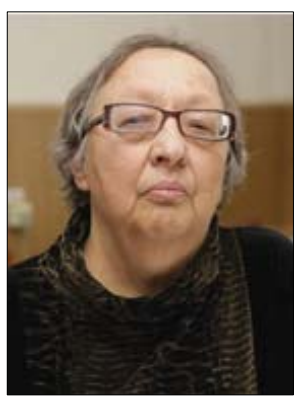

Сосинская Софья Семеновна, окончила Иркутский государственный университет по специальности «Математик-вычислитель». Кандидат технических наук, профессор кафедры технологии и оборудования машиностроительных производств. Область научных интересов - искусственный интеллект, трансляторы. Имеет свыше 70 публикаций.

Sosinskaya Sofya Semenovna, graduated from Irkutsk state university with the "Mathematician-calculator" speciality. PhD in Technical Science, Professor of department of technology and the equipment of machine-building manufactures. Research interests - artificial intelligence, translators. She has over 70 publications. 


\title{
УДК 519.7
}

\section{ОНТОЛОГИЯ И АНИМАЦИЯ ПРЕЦЕДЕНТОВ}

\author{
В.Н. Кучуганов \\ Ижевский государственный технический университет имени М.Т. Калашникова, Ижевск, Россия \\ kuchuganov@istu.ru
}

\begin{abstract}
Аннотация
В работе описана мета-онтология, предназначенная для накопления, классификации, контроля и поиска прецедентов, представляющих экземпляры конкретных ситуаций и сценариев, которые возникают при практической деятельности в той или иной предметной области. Особенностью онтологий, создаваемых на её основе, является наличие прагматических - алгоритмических, геометрических, предикатных, графовых - моделей понятий, с помощью которых, дополнительно к средствам логического вывода, можно осуществлять «анимацию» прецедентов для визуального контроля и поддержки принятия решений. Алгоритмические модели могут быть заданы формулой, программой, анимационным файлом в формате GIF. Геометрические модели задаются файлами в форматах XML, SVG, JPG и др. Графы также могут быть заданы в формате XML и ему подобных. Предикатные модели - это логические выражения, задаваемые в строковом виде. В результате синтаксического и семантического анализа текста формируется прагматическая семантическая модель, которая отображает атрибутивный граф ситуации или сценария. В этом графе вершинами являются предметы, процессы и отношения, а рёбрами - связи между ними. Описаны эксперименты с использованием системы Protege для разработки онтологий.
\end{abstract}

Ключевые слова: онтология, прецедент, прагматика, исполняемая модель, анимаџия.

Цитирование: Кучуганов, В.Н. Онтология и анимация прецедентов / В.Н Кучуганов // Онтология проектирования. - 2016. - Т.6, №3(21). - С. 287-296. - DOI: 10.18287/2223-9537-2016-6-3-287-296.

\section{Введение}

Онтологии прецедентов используются в различных предметных областях (ПрО) для информационного обеспечения систем поддержки принятия решений (СППР). Ризонеры (reasoners) - «рассуждатели», основанные на дескрипционных (описательных) логиках, осуществляют контроль корректности определений, классификацию понятий, поиск экземпляров и прочие контрольные функции.

Одной из мощных стратегий поиска решений в системах искусственного интеллекта является моделирование рассуждений на основе опыта, накопленного системой. Это могут быть решения, модели, экспертные правила. Наиболее простым и понятным путём кажется поиск в базе знаний подходящих прецедентов и использование их в текущих ситуациях Case-based Reasoning (CBR). Это позволяет ускорить решение, избавиться от предыдущих ошибок. К недостаткам подхода, основанного на CBR, относят [1] необходимость большой базы данных прецедентов, что снижает производительность системы, а также проблемы с определением критериев идентификации и сравнения случаев.

В существующих системах рассуждений на прецедентах ситуация представлена в виде совокупности атрибутов. В процессе их сопоставления сравниваются значения всех атрибутов и вычисляется вероятностная либо нечёткая мера подобия. После этого формируется решение [2]. К недостаткам такого подхода следует отнести слабую структурированность описаний ситуаций, что ведёт к потере выразительности для анализа семантики отношений и 
недостаточной конкретности решений. Во многих задачах требуется учитывать различные виды и значения отношений между участниками ситуации.

L.K. Branting [3] для моделирования рассуждений по аналогии в юридической практике предлагает редукционно-графовую модель юридического прецедента, в которой вершинами служат предикаты (высказывания), а ребрами - семантические связи между ними. Описанная система GREBE отыскивает в базе структурно-конгруэнтные прецеденты, выполняя поиск отображения с помощью «жадного» алгоритма. Предикаты считаются частично совпавшими, если имеют ближайшего общего предка в таксономической иерархии.

В работе [4] описывается онтология для правовой ПрО. Онтология основывается на текстовом контенте юридических документов. Автоматизация процесса пополнения онтологии является весьма актуальной задачей, способной устранить часть проблем формализации знаний и снизить вероятность появления ошибок, неоднозначностей и противоречий. Авторы применяют обработку естественного языка для построения онтологии документов и нечёткую логику для вычисления сходства между документами и их классификации. Основу предложенного метода составляет набор заданных шаблонов - конструкций, описывающих документы и их содержание. Недостатком метода, на наш взгляд, следует считать узкую предметную специализацию шаблонов.

Важность проблемы визуального представления понятий, хранимых в онтологиях, показывает, например, работа [5], где описывается метод полуавтоматического представления семантики концептов с помощью языка иконок VCM (Visualization of Concept in Medicine) для медицинской онтологии SNOMED CT. Очевидно, языки иконок и другие средства когнитивной графики, применяемые в СППР, существенно повышают наглядность и воспринимаемость терминов и определений в ПрО. С другой стороны, в них как в естественных иероглифических языках постоянно возникает потребность в новых символах.

В данной работе описана мета-онтология, ориентированная на создание баз знаний о процессах и их участниках. Особенностью онтологий, создаваемых на её основе, является наличие прагматических - алгоритмических, геометрических, предикатных, графовых - моделей понятий, с помощью которых, дополнительно к средствам логического вывода ризонеров, можно осуществлять «анимацию» прецедентов для визуального контроля. Первый раздел посвящен описанию подхода, во втором разделе предлагается мета-онтология прецедентов, в третьем - описаны эксперименты с использованием системы Protege [6] для разработки онтологий.

\section{1 Описание подхода}

Процессные онтологии описывают процесс как совокупность, включающую связанные между собой: сценарий (script), сцену, участников, условия, свойства. Достоинством дескрипционных логик, на которых основываются все онтологические системы, является удобство описания структурированной информации.

Предлагаемая мета-онтология предназначена для накопления, классификации, контроля и поиска прецедентов, представляющих экземпляры конкретных ситуаций и сценариев, которые возникают при практической деятельности в той или иной ПрО.

В нашей онтологии понятия содержат дополнительно геометрические, алгоритмические, предикатные, графовые модели, которые представляют прагматическую компоненту понятий, связывая их с системой воспроизведения (анимации) - исполнительным механизмом так же, как обычный конкретный атрибут связывает понятие с конкретным значением в базе фактов Abox ${ }^{1}$.

\footnotetext{
${ }^{1}$ Часть базы знаний, которая называется системой фактов об индивидах или АВох (от англ. assertional box). Прим. peд. 
Алгоритмические модели могут быть заданы формулой, программой, анимационным файлом в формате GIF. Геометрические модели задаются файлами в форматах XML, SVG, JPG и др. Графы также могут быть заданы в формате XML и ему подобных. Предикатные модели - это логические выражения, задаваемые в строковом виде. Естественно, такие прагматические модели понятий (ПМП) не могут отобразить всего того, что содержат реальные ситуации и события, например, психологические, эмоциональные и прочие аспекты.

ПМП относятся к категории исполняемых моделей. Они позволяют воспроизводить структуру ситуаций и сценариев, вычислять эффект действий и истинность отношений, а также служат средством визуального контроля прецедентов, правильности их понимания машиной, что очень важно для СППР.

\section{2 Мета-онтология прецедентов}

Для описания синтаксиса и семантики ситуаций воспользуемся дескрипционной логикой $A L C(D)$, созданной на основе логики $A L C$ (Attributive Language with Compliments) [7-9]. Логика $A L C(D)$ расширена для моделирования рассуждений не только на «абстрактных» объектах, таких как люди, животные, компании вообще, но и на «конкретных» объектах и их качествах, какие обычно содержатся в базах данных.

Пусть задана некоторая конкретная область $D$ с множеством $P N$ предикатных символов (предикатов, выражений), связывающих абстрактные элементы с конкретными областями значений, например, веса, температуры, скорости.

Пусть также имеются конечные множества символов:

- $C N=\{A 1, \ldots, A n\}-$ атомарные концепты;

- $R N=\{R 1, \ldots, R n\}$ - атомарные роли;

- $A F \subseteq R N$ - атомарные абстрактные атрибуты (концептуальные роли);

- $C F$ - атомарные конкретные атрибуты, связывающие абстрактные атрибуты с конкретными областями существования с помощью предикатов из $P N$.

Правила конструирования составных концептов задаются индуктивной грамматикой:

- $\quad$ Т,$\perp$ - концепты истина и ложь;

- $A \in C N$ - атомарный концепт $A$ является концептом;

- $\quad$ если $C$ - концепт, то $\neg C$ (дополнение $C$ ) является концептом;

- если $C$ и $D$ - концепты, то $C \sqcap D, C \sqcup D$ (пересечение и объединение) являются концептами;

- если $C$ - концепт, $R \in R N$ - роль, то $\exists R . C, \quad \forall R . C$ - концепты;

- $\exists\left[u_{1}, \ldots, u_{n}\right] . P$ - концепт, в котором составные конкретные атрибуты $u_{1}, \ldots, u_{n}$ связаны $n-$ местным предикатом $P \in P N$ в конкретной области $D$.

Здесь $u=f_{1} \ldots f_{k} h, k \geq 1$ - составной конкретный атрибут, представляющий собой цепочку длиной $k+1$ из атомарных абстрактных атрибутов $f_{i} \in A F$ и одного конкретного атрибута $h$ $\in C F$.

Для удобства работы с экспертом ПрО разобьём множество $A F$ атомарных абстрактных атрибутов на два подмножества:

где $P A F$ - собственные качества (Private);

$$
A F=P A F \cup E A F,
$$

$E A F$ - внешние, ситуативные атрибуты (External).

Собственные качества присущи всякому объекту от природы. По областям науки - это физические, химические и т.П. свойства. Например: иметьВес, иметьПлотность, иметьСкорость, иметьДлительность, иметьСтоимость. 
Ситуативные атрибуты дают дополнительные характеристики объекту, описывая его отношения с внешним окружением, изменяющимся от ситуации к ситуации. Например, иметьДиплом, иметьДом, иметьЖену, иметьСоседей.

Мета-концепты процессно-ориентированной онтологии прецедентов задают синтаксис и семантику конструкторов концептов, которые будут входить в классы составных понятий онтологии, опирающейся на прагматику ПрО.

В качестве базового концепта введём абстрактное непустое конечное (в общем случае бесконечное) множество Thing сущностей, охватывающее все атомарные концепты $C N$ :

$$
C N \subseteq \text { Thing. }
$$

Mета-концепт Предмет выделяет из всевозможных индивидов множество индивидов, отображаемых геометрической моделью (чертеж, изображение, кинематическая схема, карта, трёхмерная геометрическая модель, экранная форма, бланк, и т.п.), имеющих собственные качества и внешние ситуативные атрибуты и обладающих способностью (для искусственных предметов можно считать назначением) принимать участие в каких-либо определённых действиях:

$$
\begin{gathered}
\text { Subject } \equiv \text { Thing } \sqcap \exists \text { hasModel.GModel } \sqcap \exists \text { hasQuality.PAF } \sqcap \text { ヨhasAttribute.EAF } \\
\sqcap \text { GhasAppointment.Action. }
\end{gathered}
$$

Замечание 1. Здесь только геометрические модели и собственные качества предмета ограничены конкретными областями. Ситуативные атрибуты могут быть ограничены количеством существующих связей соответствующего типа.

Между собой предметы различаются геометрическими моделями, собственными качествами и внешними атрибутами, зависящими от назначения (искусственные предметы), либо наоборот, они находят то или иное применение благодаря присущим им качествам (природные объекты).

Типичные аксиомы вложенности для предметов:

$$
\text { КухонныйСтол } 匚 \text { Стол, Стол } 匚 \text { Мебель. }
$$

Концепт-предмет описывает категорию таких объектов, которые существуют в статике, т.е. не изменяются (в определённых пределах) на протяжении отрезка времени, рассматриваемого в задаче, в отличие от ниже описываемых процессов, которые существуют в динамике.

Mета-концепт Процесс. Как уже сказано, процессы существуют в динамике. В ходе процесса всегда что-то изменяется. А именно, меняются качества, в том числе, пространственные характеристики объектов. Например, старение, нагревание, перемещение.

В отличие от предметов, процессы имеют алгоритмическую модель (формула, алгоритм, программа). Назначением процесса является изменение чего-либо, т.е. собственно процесс как таковой:

$$
\text { Process } \equiv \text { Thing } \sqcap \text { } \exists \text { hasModel.AModel } \sqcap \text { } \exists \text { hasQuality.PAF. }
$$

Мета-концепт Отношение. В логике ALC определяют двуместные и $n$ - местные отношения как роли двух или более понятий в некоторых связках. Для наглядности онтологии и удобства работы с ней полезно предопределить типовые семантические категории отношений между экземплярами в исследуемой ПрО.

Определим метаконцепт отношения следующим образом:

$$
\begin{gathered}
\text { Relation } \equiv \text { Thing } \sqcap \text { GhasModel.PModel } \sqcap \text { GhasType.Type } \sqcap \text { } \sqcap \text { hasQuality.PAF } \\
\sqcap \exists(\geq 2 \text { hasAttribute.EAF }) .
\end{gathered}
$$

В интерпретации это означает существование отношения TypeR между экземплярами, указанными в ситуативных атрибутах hasAttribute, которое (отношение) имеет конкретное значение hasQuality. Отношение имеет предикатную модель - высказывание, записанное на естественном языке или в терминах логики предикатов 1-го порядка. 
Выделим следующие категории отношений, актуальные (на наш взгляд) для моделирования в СППР [10].

\section{Бинарные:}

- принадлежность ( $\epsilon$ ) предмету, процессу, классу, множеству;

- положение ( $\uparrow$ ) экземпляра в пространстве предмета, сцены относительно другого экземпляра;

- следование $(\rightarrow)$ во времени относительно события, процесса;

- каузальность $(\Rightarrow)$ - причинно-следственные связи;

- сравнение $(<,=,>)$ значений свойств;

- толерантность (//);

- conymствие (@)- сосуществование (accompanies) экземпляров, принадлежащих разным классам, например, стул@стол;

- проиессуально-ролевые (?) - кто? кому? что? для чего? где? когда? как? и т.д..

\section{Отночения на графах:}

- $\quad$ родство $(\boldsymbol{T})$ - степень удалённости друг от друга двух экземпляров в родовидовом дереве;

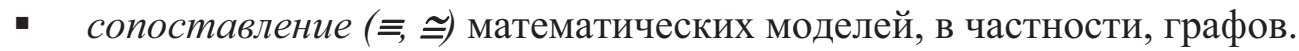

Унарные отношения преобразования $R \rightarrow R^{\prime}:$

- отрицание (ᄀ);

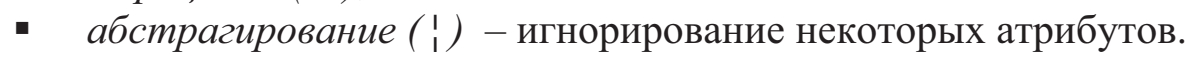

В свою очередь, классы отношений могут быть разбиты на подклассы. Например, процессуально-ролевые: бытьИсполнителем, бытьИнструментом, бытьСубъектомВоздействия.

Таким образом, сущности-отношения Relation $\sqsubseteq$ Thing, как и другие категории сущностей, обладают моделью и свойствами.

Замечание 2. Мета-концепт Relation не заменяет собой традиционный способ описания отношений. С одной стороны, логики с операциями над ролями и аксиомами для ролей, образующих базу RBox, позволяют осуществлять логический анализ и моделирование рассуждений на отношениях, с другой - мета-концепт Отношение, рассматривая отношения как разновидность сущностей реального мира, даёт возможность хранить и обрабатывать их так же, как и другие сущности.

Составной объект - предмет или процесс - имеет состав (дерево вложенности) и схему соединений (пространственный граф):

CompositionSubj $\equiv$ Subject $\sqcap$ ヨhasTreeCompos.TreeCompos $\sqcap$ ヨhasScheme.Graph

$$
\sqcap \text { ヨhasQuality.PAF } \sqcap \text { ヨhasAttribute.EAF; }
$$

CompositionProc $\equiv$ Process $\sqcap \quad \exists$ hasTreeCompos.TreeCompos $\sqcap$ ヨhasScheme.Graph $\sqcap$ $\exists$ hasQuality.PAF $\sqcap$ ヨhasAttribute.EAF.

Мета-концепт Действие связывает процесс и систему процессуально-ролевых отношений с участниками:

Action $\equiv$ Process $\sqcap$ $\exists$ hasPrecondition.Relation $\sqcap$ $\exists$ hasPostcondition.Relation $\sqcap \exists$ hasActor. Subject $\Pi$ $\exists$ hasRecipient.Subject $\sqcap$ $\exists$ hasObject.Subject $\Pi \exists$ hasTool.Subject $\sqcap$... .

Здесь моделью действия служит алгоритмическая модель процесса. Участниками действия являются:

- актор (исполнитель);

- бенефициант - заказчик, в чьих интересах выполняется действие, работа;

- $\quad$ реципиент - приемник действия (например, "Вася даёт яблоко Кате", реципиент - Катя);

- предмет воздействия: исходный/результирующий (в приведённом примере - яблоко); 
- сцена действия;

- инструмент;

- коагент (соисполнитель);

- эффект и т.д.

На рисунке 1 показана начальная онтология процессных прецедентов, созданная в системе для разработки онтологий Protege.

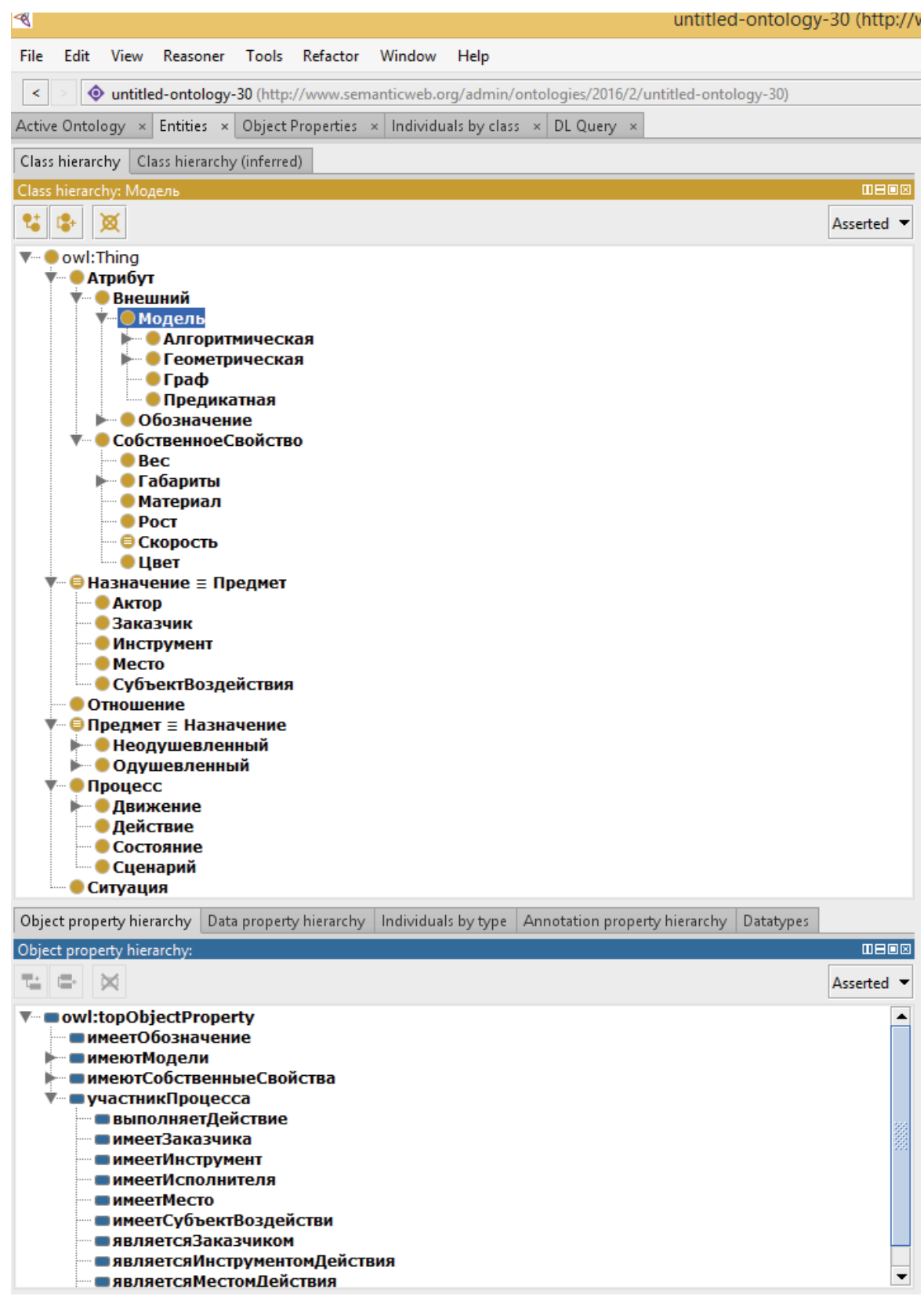

Рисунок 1 - Начальная онтология процессных прецедентов в системе Protege

Интерпретация действия как системы зависимостей показывает, что результат и эффективность процесса существенным образом зависят от участников действия. Например: «Измеряй микрометром, отмечай мелом, руби топором» ${ }^{2}$. В упрощённой естественной интерпре-

\footnotetext{
${ }^{2}$ Физики шутят. Под общей редакцией В.Турчина: Мир. - М., 1966.
} 
тации в результате действия где-то что-то убывает, где-то что-то прибывает (почти по М. Ломоносову).

Ситуация рассматривается как совокупность состояний предметов, процессов, отношений, где состояние - это совокупность значений их параметров в некоторый момент или отрезок времени.

Мета-концепт Ситуация задаёт конструкцию концептов, определяющих множества конкретных ситуаций как сущность, моделью которой может служить атрибутивный граф, а общими характеристиками - атрибуты:

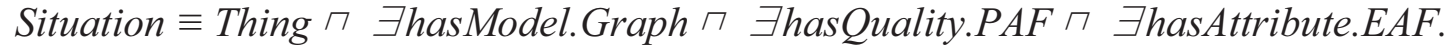

Мета-концепт Сценарий - это упорядоченная во времени совокупность ситуаций, пересекающихся по составу участников:

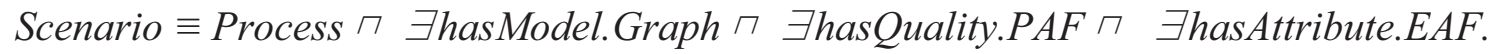

Для удобства поиска в список атрибутов рекомендуется выносить основных участников (исполнители, место).

\section{3 Эксперимент}

Рассмотрим высказывание «Маленький мальчик медленно шёл по лесу и увидел девочку, которая собирала грибы».

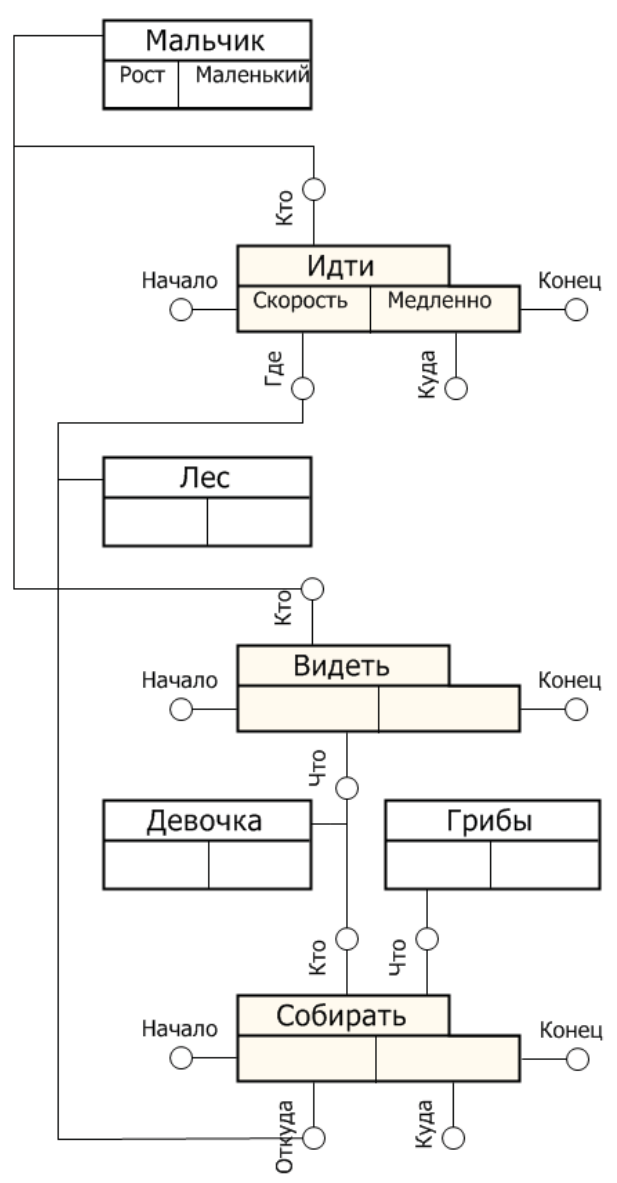

Рисунок 2 - Прагматическая семантическая модель высказывания
В результате синтаксического и семантического анализа мы получаем прагматическую семантическую модель сценария (рисунок 2) в нотации СеМС [10], которая визуально отображает атрибутивный граф сценария. В этом графе вершинами являются предметы, процессы и отношения (с их атрибутами) в соответствии с вышеописанной мета-онтологией, а рёбрами - связи между ними.

При передаче информации о высказывании в онтологию прецедентов рассуждатель системы отыскивает в таксономии классов экземпляр прагматической модели ближайшего общего предка и показывает его пользователю. Если нет релевантных экземпляров, то их нужно создать и записать в раздел фактов онтологии в качестве экземпляров соответствующих понятий - предметов, действий, сценариев, либо удовлетвориться теми, которые найдены. Для действий и сценариев наиболее адекватны GIF анимации, но их создание более затратно. Требуемая степень визуальной релевантности зависит от назначения онтологии прецедентов. Если нужно лишь убедиться, что прецедент воспринят машиной правильно, достаточно иметь изображения и анимации только на старших уровнях иерархий.

На первых этапах жизненного цикла прецедентной онтологии при визуализации прецедента система может показать лишь изображения абстрактных предметов, например, мальчика, девочку, лес, грибы и действий идти, собирать. По мере накопления информации, система показывает сочетания, состоящие из большего количества компонентов в соответствии с содержанием прецедента. В общем случае, мы получаем но- 
вые экземпляры сценария, действий, участников. В данном примере, какими бывают мальчик, девочка, что они могут делать.

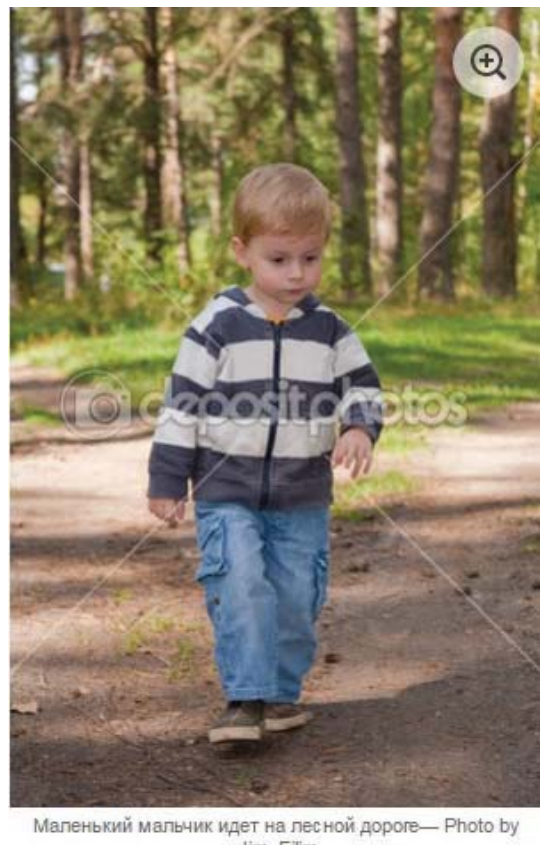

Jim_Flilim

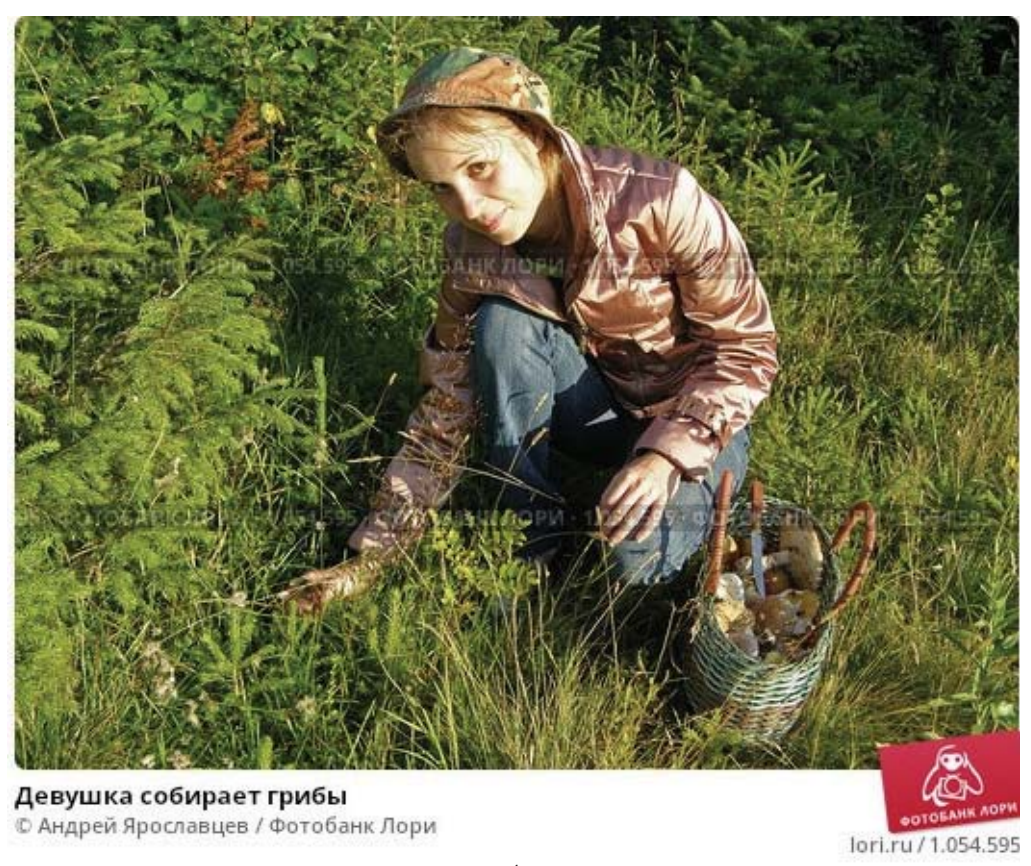

б) $)^{4}$

Рисунок 3 - Визуализация прецедента автоматически найденными изображениями
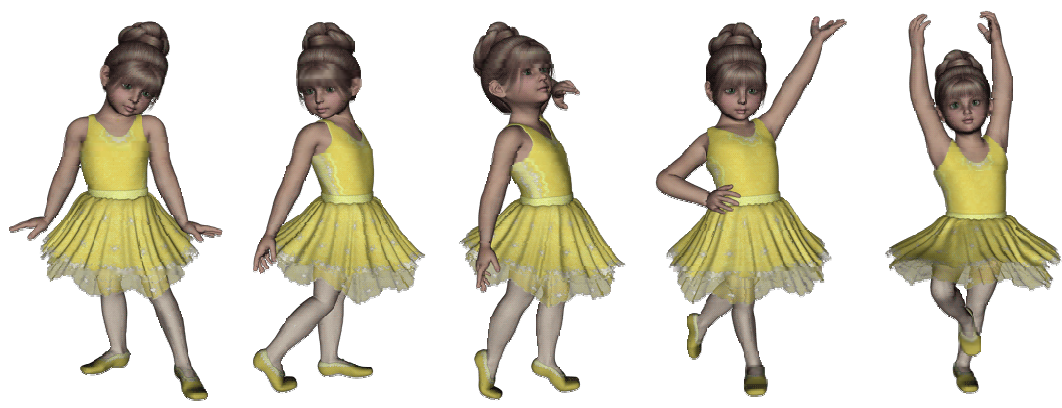

Рисунок 4 - Анимация прецедента «Девочка танцует» (*.gif, источник: http://umors.net/photo/26-0-1864)

На рисунках 3, 4 показаны найденные в базе знаний изображения «Мальчик идёт по лесу», «Девушка собирает грибы» и GIF анимация «Девочка танцует».

\section{Заключение}

В отличие от задачи поиска картинок по ключевым словам, где изображения аннотируются при их записи в базу данных, здесь представлен один из возможных подходов к организации визуального контроля прецедентов, предназначенных для задач моделирования рассуждений на основе прецедентов, выявления сходства и отличий в ситуациях и сценариях, извлечения знаний о действиях и участниках.

Способы визуализации понятий и прецедентов включают диаграммы, графические схемы, рисунки, фотографии, фильмы, анимации. Это важно для понимания и человеко-

\footnotetext{
${ }^{3}$ Яков Филимонов, Фотобанк Лори, https://lori.ru/1370884

${ }^{4}$ Андрей Ярославцев, Фотобанк Лори, https://lori.ru/1054980
} 
машинного общения. Распространение терминологических онтологий в различных областях образования, науки, бизнеса вновь привлекло внимание исследователей к технологиям пиктограмм, иконок, визуализации, которые благодаря сети Интернет позволяют в глобальном масштабе обмениваться информацией в наглядной, легко воспринимаемой форме.

Предложенный подход, основывающийся на прагматических моделях понятий, в том числе представляющих ситуации и сценарии, даёт возможность интерпретировать их в исполняемые коды, визуально и формально оценивать корректность и эффект.

В дальнейшем планируется повысить степень автоматизации при автозаполнении онтологий прецедентов, попытаться генерировать анимационные файлы, основываясь на прагматических моделях понятий и экземпляров.

\title{
Благодарности
}

Исследование выполнено при частичной поддержке Госзадания Минобрнауки РФ, Проект № 625.

\section{Список источников}

[1] Luger, G.F. Artificial Intelligence: Structures and Strategies for Complex Problem Solving, 6th edn, AddisonWesley, New York, 2008.

[2] Recio-García J.A., González-Calero P.A., Díaz-Agudo B. jcolibri2: A framework for building Case-based reasoning systems. Science of Computer Programming 79, 1, 2014, pp.126-145.

[3] Branting, L.K. A reduction-graph model of precedent in legal analysis // Artificial Intelligence 150, 1-2, 2003, pp.59-95.

[4] Валькман, Ю.P. Проектирование онтологии для правовой предметной области на основе текстового контента с использованием нечеткой логики / Ю.Р. Валькман, Е.А. Хала // Онтология проектирования. - 2014. - №2(12). C. 19-39.

[5] Lamy J.B., Tsopra R., Venot A., Duclos C. A semi-automatic semantic method for mapping SNOMED CT concepts to VCM Icons. Stud Health Technol Inform, 2013, 192:42-6.

[6] Protégé. URL:http://protege.stanford.edu/ products.php (Дата обращения: 10.05.2016).

[7] Baader F., Calvanese D., McGuinness D., Nardi D., Patel-Schneider P.F. (editors), The Description Logic. Handbook, Cambridge University Press, 2003.

[8] Lutz C., Description Logics with Concrete Domains - A Survey, In P. Balbiani, N.-Y. Suzuki, F. Wolter, M. Zakharyaschev (editors), Advances in Modal Logics, 4, King's College Publications, 2003.

[9] Золин, E. Дескрипционная логика (лекции). http://lpcs.math.msu.su/ zolin/dl/

[10] Кучуганов, В.Н. Элементы теории ассоциативной семантики / В.Н. Кучуганов // Управление большими системами. Выпуск 40. - М.: ИПУ РАН, 2012. С. 30-48.

\section{ONTOLOGY AND ANIMATION OF PRECEDENTS}

\author{
V.N. Kuchuganov \\ Kalashnikov Izhevsk State Technical University, Izhevsk, Russia \\ kuchuganov@istu.ru
}

\begin{abstract}
The paper describes a meta-ontology, designed for accumulating, classifying, controlling and retrieving precedents, representing instances of specific situations and scenarios, which arise in practical activity in a particular domain. A feature of ontologies, created on its basis, is the presence of pragmatic - algorithmical, geometrical, predicate, graph models of concepts, with help of which, in addition to logical inference means, it is possible to carry out "animation" of cases for visual control and decision making support. Algorithmical models can be specified by a formula, a program or
\end{abstract}


an animation file in the GIF format. Geometrical models are specified by files in the formats XML, SVG, JPG, etc. Graphs are also can be specified in the format XML and similar ones. Predicate models are logical expressions, specified in a string form. In the result of syntactic and semantic analysis of a text we get a pragmatic semantic model, which represents an attributed graph of a situation or a scenario. In this graph vertices are things, processes and relations, while edges are connections between them. Experiments with the use of the system Protégé for developing ontologies are provided.

Key words: ontology, precedent, pragmatics, executable model, animation.

Citation: Kuchuganov VN. Ontology and animation of precedents [In Russian]. Ontology of designing. 2016; 6(21): 287-296. DOI: 10.18287/2223-9537-2016-6-3-287-296.

\section{References}

[1] Luger GF. Artificial Intelligence: Structures and Strategies for Complex Problem Solving, 6th edn, AddisonWesley, New York, 2008.

[2] Recio-García JA, González-Calero PA, Díaz-Agudo B. jcolibri2: A framework for building Case-based reasoning systems. Science of Computer Programming 79, 1, 2014, 126-145.

[3] Branting LK. A reduction-graph model of precedent in legal analysis, Artificial Intelligence 150, 1-2, 2003, 59-95.

[4] Valkman IR, Hala CA. Ontology design based on the text content with fuzzy logic for legal domain [In Russian], Ontology of Designing. 2014; 2(12): 19-39.

[5] Lamy JB, Tsopra R, Venot A, Duclos C. A semi-automatic semantic method for mapping SNOMED CT concepts to VCM Icons. Stud Health Technol Inform, 2013, 192:42-6.

[6] Protégé. Source: 〈http://protege.stanford.edu/products.php $\rangle$.

[7] Baader F, Calvanese D, McGuinness D, Nardi D, Patel-Schneider PF. (editors), The Description Logic. Handbook, Cambridge University Press, 2003.

[8] Lutz C. Description Logics with Concrete Domains - A Survey, In P. Balbiani, N.-Y. Suzuki, F. Wolter, M. Zakharyaschev (editors), Advances in Modal Logics, 4, King's College Publications, 2003.

[9] Zolin E., Description Logic (lectures) [In Russian]. Source: 〈http://pcs.math.msu.su/ zolin/dl/ $\rangle$.

[10] Kuchuganov VN. Elements of associative semantic theory [In Russian], Large-Scale Systems Control 40, 2012, 30 48.

\section{Сведения об авторе}

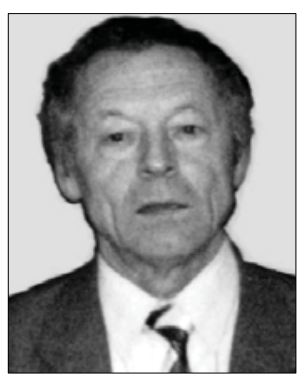

Кучуганов Валерий Никонорович, 1942 г. рождения. ФГБОУ ВО Ижевский государственный технический университет имени имени М.Т. Калашникова, д.т.н. (1993), профессор кафедры «Автоматизированные системы обработки информации и управления». Область научных интересов: онтологии и инженерия знаний, моделирование рассуждений на основе прецедентов, контекстный поиск изображений.

Valery Nikonorovich Kuchuganov (b. 1942), Kalashnikov Izhevsk State Technical University, Department of Automated Data Processing and Control Systems, Doctor of Engineering Sciences, Professor. His research interests include ontologies and knowledge engineering, modeling of reasoning on the base of precedents, and content-based image retrieval. 


\title{
ОНТОЛОГИЧЕСКОЕ ПРОЕКТИРОВАНИЕ ПОДСИСТЕМЫ ОЦЕНКИ ОБСТАНОВКИ ИНТЕЛЛЕКТУАЛЬНЫХ АГЕНТОВ
}

\author{
С.В. Лебедев ${ }^{1}$, М.Г. Пантелеев ${ }^{2}$ \\ Санкт-Петербургский государственньй электротехнический университет «ЛЭТИ» \\ им. В.И. Ульянова (Ленина), Санкт-Петербург, Россия \\ ${ }^{1}$ lebedev.sv.etu@gmail.com \\ ${ }^{2}$ mpanteleyev@gmail.com
}

\begin{abstract}
Аннотация
Рассматривается онтологический подход к проектированию подсистем оценки обстановки (ПОО) интеллектуальных агентов (ИА), функционирующих в динамических многоагентных средах, в том числе в условиях группового противодействия. Подход основан на выделении аспектов построения ПОО, инвариантных конкретным областям применения агентов и решаемым ими задачам. В качестве теоретического базиса процесса проектирования предложено семейство моделей, формализующих различные аспекты построения и функционирования ПОО, с учётом представления разных компонентов внутренней модели мира агента, особенностей организации процесса вычислений и этапов проектирования ПОО. Предложенные модели позволяют с единых позиций проектировать ПОО для разных ИА с использованием онтологий. Выделены два класса онтологий, поддерживающих процесс проектирования: онтология ПОО и онтологии конкретных предметных областей. Онтология ПОО обеспечивает интеграцию в инвариантный каркас программного кода, реализующего функции оценки обстановки для конкретного агента. Онтология предметной области расширяет онтологию ПОО и поддерживает автоматическую генерацию программного кода и его интеграцию в инвариантный каркас ПОО. Генерация программного кода ПОО для конкретного ИА обеспечивается предложенными отображениями онтологических классов и свойств в программные структуры. Рассмотрен прототип инструментальной платформы разработки ПОО, реализованный с использованием языков представления и обработки онтологий OWL, SPARQL, SPIN и языка программирования Јava. Подход иллюстрируется построением ПОО агента, функционирующего в среде виртуального футбола.
\end{abstract}

Ключевые слова: интеллектуальный агент, подсистема оченки обстановки, онтология проектирования, инструментальная платформа.

Цитирование: Лебедев, С.В. Онтологическое проектирование подсистемы оценки обстановки интеллектуальных агентов / С.В. Лебедев, М.Г. Пантелеев // Онтология проектирования. - 2016. T. 6, №3(21). - C. 297-316. - DOI: 10.18287/2223-9537-2016-6-3-297-316.

\section{Введение}

В последние годы онтологии все шире используются при проектировании различных классов технических систем в качестве формализованных моделей представления концептуальных знаний об этих системах [1-3]. Одним из наиболее динамично развивающихся классов систем в области искусственного интеллекта являются в настоящее время интеллектуальные агенты (ИА) и основанные на них многоагентные системы (MAC) $[4,5]$. Использованию онтологий при проектировании агентных систем различного назначения посвящено достаточно много исследований, в частности $[6,7]$. Однако, вследствие широкого разнообразия и сложности таких систем, проблема их онтологического проектирования ещё далека от окончательного решения и весьма актуальна в настоящее время. 
В статье рассмотрен онтологический подход к автоматизации разработки программного обеспечения подсистем оченки обстановки (ПОО) ИА, функционирующих в открытых динамических многоагентных (ОДМ) мирах.

Интеллектуального агента определим как систему, способную планировать свои действия и осуществлять автономное целенаправленное поведение в ОДМ-мирах.

В процессе проектирования агентных систем при выборе архитектуры ИА одним из ключевых аспектов является тип взаимодействия агентов в МАС: кооперация в рамках априори заданной организационной структуры; поиск партнеров в открытой многоагентой среде (включая переговоры и заключение контрактов об условиях сотрудничества); конкуренция (в том числе, в рамках аукционов); антагонистическое противодействие (например, в военных приложениях).

Одним из наиболее сложных для проектирования подклассов ИА являются агенты, предназначенные для решения целевых задач в условиях группового (командного) противодействия. При построении таких ИА в настоящее время используются делиберативные архитектуры, предполагающие формирование и поддержание в памяти агента явной символьной модели мира (ММ). Обобщённая делиберативная архитектура ИА представлена на рисунке 1.

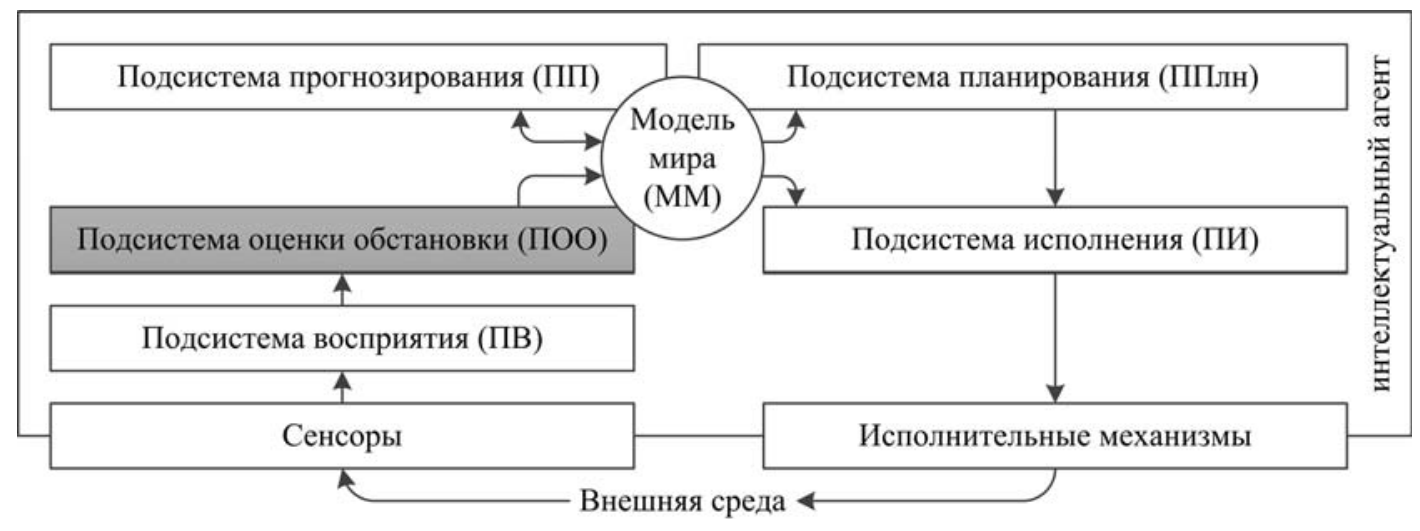

Рисунок 1 - Архитектура ИА

Важной особенностью данного класса систем является отсутствие коммуникации между агентами противодействующих групп и, как правило, ограниченная коммуникация (в некоторых случаях - отсутствие) между агентами своей группы. В таких системах агент обновляет свою ММ по результатам наблюдений за состоянием и поведением внешних объектов на основе сенсорных данных, поступающих от подсистемы восприятия.

Сенсорные данные от подсистемы восприятия являются низкоуровневыми и требуют обработки для представления ММ на более высоком уровне абстракции, необходимом для планирования агентом своих действий (принятия решений). Такая обработка выполняется ПОО.

Основными особенностями сред функиионирования ИА рассматриваемого класса ОДМмиров являются:

- открытость - состав агентов, находящихся в определённый момент времени в окружающей рассматриваемого агента среде, априори неизвестен и может меняться в процессе его функционирования как количественно, так и качественно (по типам агентов);

- динамичность - в результате целенаправленных действий агентов состояние мира меняется достаточно быстро и недетерминировано, т.к. намерения других агентов неизвестны (относительно этих намерений могут строиться лишь гипотезы на основе наблюдаемого поведения); в определённые моменты времени разные агенты способны в 
различной степени влиять на цели и планы рассматриваемого агента, т.е. имеют для него различную прагматическую значимость;

- реализачия групповых действий в $M A C$ - в процессе функционирования агенты противодействующих группировок могут действовать скоординированно, динамически формируя группы различного состава на разных уровнях организационной иерархии.

Анализ указанных особенностей позволяет выделить следующие основные задачи ПОО агентов рассматриваемого класса, решение которых необходимо для поддержания ММ в актуальном состоянии:

- обнаружение в окружающей среде новых (вновь появившихся) агентов и фиксация выбывания отдельных агентов (например, вследствие их убытия или физического уничтожения);

- $\quad$ классификация типов агентов, определение (построение гипотез) по наблюдаемому поведению их намерений (распознавание планов) и, как следствие, определение (оценка) прагматической значимости этих агентов с точки зрения рассматриваемого агента;

- обнаружение фактов формирования из отдельных агентов (или групп более низкого уровня иерархии) групп скоординированно действующих агентов, изменения состава таких групп или их расформирования;

- определение (построение гипотез относительно) тактики групповых действий на разных уровнях иерархии по наблюдаемому скоординированному поведению агентов противодействующей группировки;

- формирование ситуаций как множества индивидуальных агентов и их групп, имеющих прагматическую значимость при планировании действий $[8,9]$.

\section{1 Краткий анализ состояния проблемной области}

В статье термины «оценка обстановки» и «оценка ситуации» (Situation Assessment) используются как синонимы, а содержание соответствующего понятия трактуется в смысле решения перечисленных выше задач по обновлению и поддержанию в актуальном состоянии ММ агента. Подробный анализ публикаций, рассматривающих различные аспекты этих понятий, выходит за рамки статьи. Ниже представлен краткий обзор работ, наиболее значимых и близких к предлагаемому в статье подходу.

Круг проблем, связанных с оценкой обстановки в сложных динамических средах, достаточно широк и исследуется в рамках концепций ситуационной осведомленности (Situation Awareness) и слияния данных (Data Fusion) [10].

Согласно наиболее известному определению, предложенному Эндсли (Endsley), ситуационная осведомлённость понимается как «восприятие элементов среды в рамках некоторого пространства и времени, осознание её смысла и проецирование её состояния на ближайшее будущее» [11]. В соответствии с данным определением в модели ситуационной осведомлённости выделены три уровня: восприятие элементов среды (их состояния, свойств и динамики); осмысление текущей ситуащии на основе синтеза всех элементов уровня 1 (включая фокусировку внимания, интеграцию различных частей информации и определение их значимости для целей агента); проекиия будущих состояний, т.е. способность прогнозировать события и динамику будущих ситуаций.

Среди моделей слияния данных наибольшее распространение получила JDL Data Fusion Model [12], разработанная Группой слияния данных (Data Fusion Group) Объединенной дирекции лабораторий (Joint Directors of Laboratories) Министерства Обороны США. Подходы к оценке ситуаций с использованием модели JDL рассмотрены, в частности, в [13, 14]. Представленные в этих работах модели достаточно абстрактны, не ориентированы на практиче- 
ские вопросы проектирования ИА, в частности, на повышение эффективности программной реализации агентов.

Наиболее близким к рассмотренному в настоящей статье подходу, является онтологоориентированное построение систем оценки ситуации с использованием модели Эндсли и ситуационной теории [15]. Предложенная в этой работе модель позиционируется как общий формализованный теоретический каркас, позволяющий с единых позиций проектировать ПОО для разных областей применения. В $[16,17]$ рассмотрено использование модели Эндсли в системах поддержки операторов крупных центров данных. Основные идеи: повторное использование артефактов, имеющих точки расширения (за счёт применения ядерных онтологий и мета-сущностей), широкая поддержка пространственно-временных отношений, формальное описание развития отношений и ситуаций. Применение известных подходов при построении ПОО агентов, функционирующих в ОДМ-мирах, ограничено недостаточно гибкими возможностями управления процессом вычислений. Это обусловлено недостаточным уровнем гранулярности таких моделей и, как следствие, отсутствием возможности адаптации вычислительного процесса к доступному времени принятия решений.

\section{2 Уточнение постановки задачи}

Рассмотрим функционирование ПОО в составе базовой архитектуры ИА при решении выделенных выше её основных задач на концептуальном уровне, абстрагируясь от особенностей конкретных агентов и средств функционирования.

Сенсоры и средства низкоуровневой обработки поступающих от них сигналов и изображений в рассматриваемой архитектуре ИА отнесены к подсистеме восприятия (ПВ). Учитывая практическую направленность настоящей работы на создание инструментальной платформы, обеспечивающей быстрое прототипирование программного обеспечения данного класса систем, примем объектно-ориентированное представление ММ агента (см. рисунок 2).

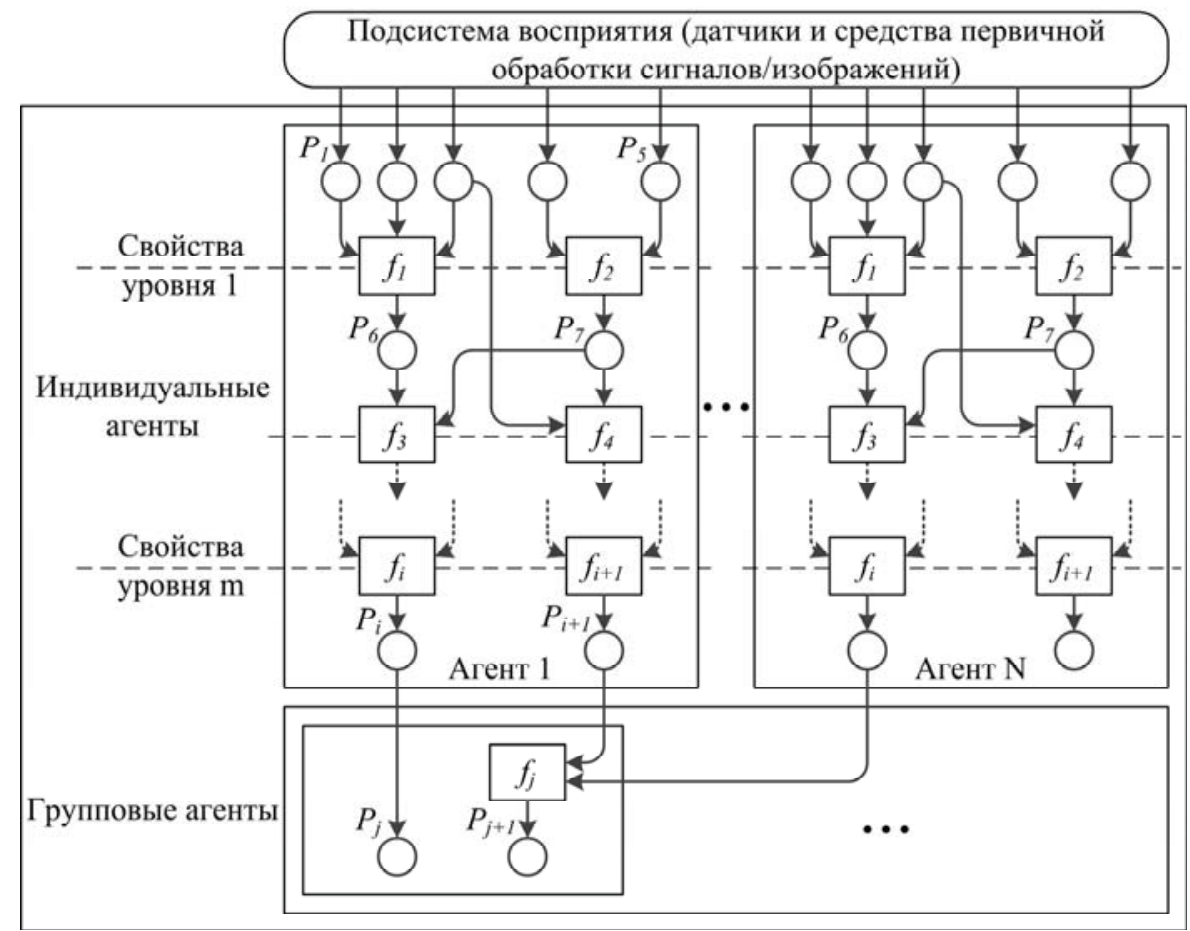

Рисунок 2 - Объектное представление внутренней модели мира ИА и уровней обработки данных 
В структуре ММ выделим уровень индивидуальных агентов и, в общем случае, произвольное число уровней иерархии групп агентов (на рисунке 2 показан один такой уровень). Индивидуальные агенты и их группы в объектном представлении ММ характеризуются определённым набором свойств, состав которых зависит от типа соответствующих сущностей (на рисунке 2 показаны кружками).

Введём понятие уровня вычисления свойства (далее для краткости - уровня свойства). К первому уровню отнесём свойства индивидуальных агентов, значения которых поступают непосредственно от ПВ (на рисунке $2-P_{1}-P_{5}$ ). Свойство относится к $k$-му уровню, если для вычисления его значения используется хотя бы одно свойство $(k-1)$-го уровня. Значения свойств в общем случае вычисляются некоторыми функциями $f_{i}$, зависящими от семантики свойства и метода его вычисления в конкретном приложении.

Поскольку состав агентов в открытой среде может динамически меняться, предусмотрены функции порождения нового агента в ММ (конструктор) и удаления агента из ММ (деструктор).

Порождение в ММ новых сущностей на уровне групп агентов и их удаление (расформирование) определяется на основе выделения соответствующих отношений между индивидуальными агентами (или группами более низкого уровня иерархии). Например, групповая сущность «линия нападения» в виртуальном футболе [18] выделяется (формируется в ММ), если соответствующие игроки в течение определённого интервала времени находятся ближе всего к воротам соперника и действуют примерно на одной линии.

Приведённое на рисунке 2 объектное представление ММ инвариантно предметным областям (ПрО). Выделенные уровни индивидуальных агентов, их групп, свойств и отношений, а также абстрактных функций для их вычисления, составляют абстракцию ПОО, не зависящую от среды функционирования агента и решаемых им задач. С точки зрения инструментария разработки программного обеспечения ИА данному объектному представлению соответствует инвариантный каркас ПОО.

Проектирование агентов для конкретных приложений предполагает конкретизацию данной абстракции путём задания конкретных типов объектов, функционирующих в среде, состав свойств для каждого типа, функиий для вычисления значений свойств индивидуальных агентов и отношений между агентами, позволяюших выделить скоординированно действующие груnпь и т.п. Эти сущности на этапе проектирования могут быть взяты из онтологий соответствующих ПрО.

Исходя из изложенного, задача проектирования ПОО для ИА, функционирующих в различных средах, в статье ставится и решается в двух аспектах. В теоретическом плане необходимо разработать множество моделей, составляющих основу процесса проектирования ПОО, включая создание средств быстрого прототипирования ИА. В практическом плане рассматриваются вопросы создания инструментальной платформы для автоматизации проектирования и разработки ИА.

Традиционными подходами к решению задачи автоматизации проектирования программного обеспечения являются разработка на основе моделей и повторное использование кода. Использование онтологий в рамках модельно-ориентированной парадигмы [19] является перспективным направлением, т.к. позволяет строить (в том числе, используя графические редакторы), визуализировать и автоматически выводить элементы моделей.

\section{3 Базовые формальные модели онтологического проектирования ПОО ИА}

Общая концепция предлагаемого подхода к автоматизации проектирования и разработки программного обеспечения ПОО ИА иллюстрируется рисунком 3. 


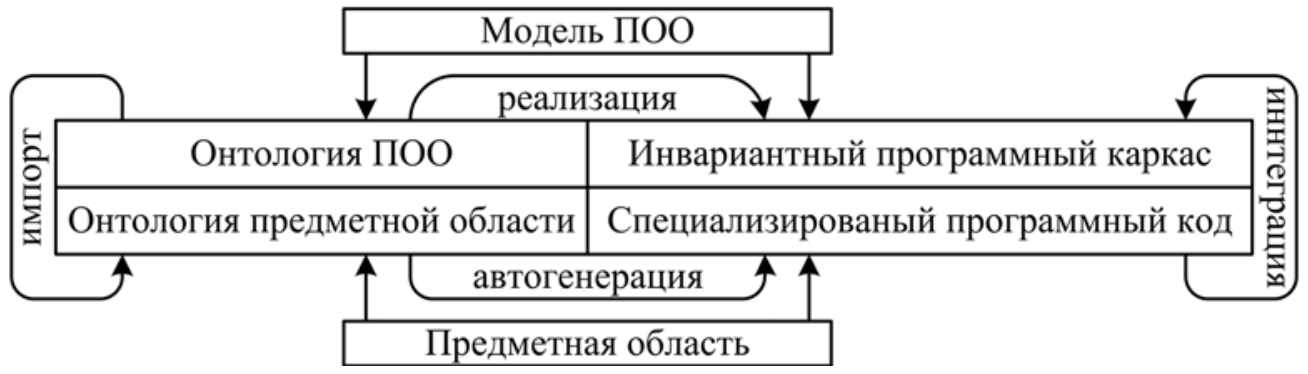

Рисунок 3 - Концепция автоматизации проектирования ПОО

Рассмотрим базовые формальные модели, лежащие в основе предлагаемого подхода.

На самом общем уровне решаемая проблема декомпозируется на две базовые задачи: построение формализованного описания рассматриваемой ПрО; проектирование ПОО агента, предназначенного для решения определённых задач в данной ПрО.

Соответственно, базовая модель проблемной области содержит два компонента: < MMM, $M П p$ >, где $M M M$ - метамодель ММ; $М П р$ - модель проектирования.

\section{1 Метамодель модели мира}

Анализ особенностей взаимодействия агента со средой позволяет выделить три обобщённых компоненты, независящие от ПрО. С одной стороны, в процессе функционирования агент на основе воспринимаемых данных и априорных знаний должен формировать в своей памяти (и в каждом цикле обновлять) внутреннюю модель мира (BнMM). Эта модель содержит знания агента об объектах внешней среды, их свойствах и отношениях, представленные на различных уровнях абстракции.

С другой стороны, ИА, обладая свойством проактивности, в каждый момент времени хранит в памяти свои текущие планы, варианты возможных будущих действий, оценки их полезности и другую информацию, влияющую на оценку текущей ситуации. Соответствующий компонент $M M M$ назовём проактивным компонентом (ПК).

ПК задаёт контекст, определяющий сущности внешней среды (объекты, свойства, отношения), которые являются прагматически значимыми для агента в данный момент времени, т.е. могут влиять на его решения. Совокупность этих сущностей соответствует понятию сиmуащии и образует верхний уровень представлений агента о текущем состоянии мира. Именно этот уровень ПОО используется для идентификации классов проблемных ситуаций. Соответствующий компонент представлений агента назовём ситуаџионной моделью мира (CMM).

Таким образом, метамодель включает три рассмотренных выше компонента:

$$
M M M=<B н M M, \Pi К, C M M>\text {. }
$$

\section{2 Модель проектирования}

Проектирование ПОО предполагает решение двух взаимосвязанных задач: выбор формализованного представления $M M M$ и реализацию процесса вычисления её элементов в процессе решения задачи оценки обстановки. Для описания этих задач будем использовать соответственно модель представления (MП) и модель вычисления (MB). Для формализации связи между этими моделями введём в рассмотрение модель вычислимости (MBч).

Таким образом, модель проектирования может быть представлена кортежем:

$$
M \Pi p=<M \Pi, M B ч, M B>.
$$




\subsection{1 Модель представления}

МП включает совокупность элементов, используемых для внутреннего представления воспринимаемой среды:

$$
M \Pi=E=O \bigcup R,
$$

где $E$ - множество элементов; $O$ - множество объектов; $R$ - множество отношений между объектами.

Без потери общности можно ограничить рассмотрение бинарными отношениями:

$$
r\left(o_{1}, o_{2}\right) \text {. }
$$

Элемент представляет собой совокупность свойств: $e=\left\{p_{1}, \ldots, p_{n}\right\}$. Объект представлен множеством свойств и отношений с другими объектами:

$$
o=\left\{p_{1}, \ldots, p_{n} ; r_{1}, \ldots, r_{m}\right\} .
$$

В зависимости от особенностей среды функционирования и физической организации подсистемы восприятия агента, объекты и их свойства могут быть либо непосредственно воспринимаемыми, либо вычисляемыми. Например, в виртуальном футболе непосредственно воспринимаемыми объектами являются игроки, мяч, линии и флаги [20], а непосредственно воспринимаемыми свойствами - координаты и скорости движения игроков в полярной системе координат. Примером вычисляемого свойства является «владение мячом», а вычисляемого объекта - групповой объект «линия нападения». Вычисляемыми отношениями являются: «находится в одной линии», «быть партнером для паса» и т. п.

\subsection{2 Модель вычисления}

$M B$ описывает компоненты (модули) вычислительного процесса, позволяющие установить факт существования элементов модели мира на основе воспринятых, ранее вычисленных и априорно известных элементов. Таким образом, множество элементов МП (см. формулу (1)) можно определить так:

$$
E=\left\{e_{\text {known }}\right\} \bigcup\left\{e_{\text {percepted }}\right\} \bigcup\left\{e_{\text {calculated }}\right\},
$$

где $\left\{e_{k n o w n}\right\}-$ множество априорно известных элементов, $\left\{e_{\text {percepted }}\right\}-$ множество воспринимаемых элементов, $\left\{e_{\text {calculated }}\right\}-$ множество вычисляемых элементов.

Вычисление базируется на допущении наличия между объектами отношений, заданных формулой (2). Если установлено существование части элементов этой конфигурации (например, объект $o_{1}$ воспринят и представлен в $M M$ агента), то может быть вычислен факт существования других элементов - объект $o_{2}$ и отношение $r$. Таким образом, вычислительные зависимости определены через предметные отношения.

В соответствии с принятым допущением введём в рассмотрение две базовые функции вычисления (ФВ):

$$
\begin{aligned}
& f_{a}\left(\dot{o}_{1}, \dot{o}_{2}, r\left(o_{1}, o_{2}\right)\right)=\dot{r}\left(\dot{o}_{1}, \dot{o}_{2}\right), \\
& f_{c}\left(\dot{o}_{1}, r\left(o_{1}, o_{2}\right)\right)=<\dot{r}\left(\dot{o}_{1}, \dot{o}_{2}\right), \dot{o}_{2}>.
\end{aligned}
$$

Здесь $f_{a}$ - ассоциирующая функиия, связывает два известных объекта некоторым отношением; $f_{c}$ - порождающая функция, создаёт новый объект по известному объекту и отношению, связывающему данные объекты. Символы без точки соответствуют априорно известным элементам, символы с точкой - воспринятым или вычисленным элементам. Отметим, что типы отношений включены в отображения. 
Примером ассоциирующей функции является вычисление отношения «владеть мячом» на основе воспринятой информации об игроке и мяче. Вычисление же объекта «владелец мяча» реализуется порождающей функцией на основе той же информации.

С учётом вышеизложенного, в реализации оценки обстановки можно выделить два ключевых аспекта:

- установление факта существования объектов - расширение $M M$;

- установление отношений между существующими объектами - связывание ММ.

Процесс вычисления в ПОО состоит из множества функций вычисления и, в соответствии с требованиями к ИА, должен обладать свойствами гранулярности и иерархичности. Иерархичность представлена деревом вычислительных зависимостей, в котором вычисляемое значение зависит от известных (воспринятых и/или ранее вычисленных) значений.

Свойства гранулярности и иерархичности позволяют реализовать оценку обстановки как процесс с итеративным уточнением результата в пределах выделенного времени. Одним из фрагментов такой иерархии в виртуальном футболе может быть, например, определение владельца мяча на основе воспринятого множества игроков и мяча.

В соответствии с принципом иерархичности и гранулярности процесс делится на уровни вычисления (далее просто уровни) и узлы вычисления (далее узлы):

$$
M B=<l_{1}, l_{2}, \ldots, l_{n}>, l_{i} \in L,
$$

где $l_{i}-i$-ый уровень; $\mathrm{L}-$ множество уровней.

Каждый уровень может быть представлен кортежем:

$$
l_{i}=<\{e\}_{i},\{c n\}_{i}, g_{i}>,
$$

где $\{e\}_{i}-$ множество элементов $M M i$-ого уровня; $\{c n\}_{i}-$ множество узлов $i$-ого уровня, каждый из которых реализует функцию вычисления; $g_{i}-$ функция вычисления $(i+1)$-ого уровня, такая что $g_{i} \circ f_{i}=l_{i+1}$. Таким образом, уровни, в общем случае, порождаются динамически на основе значений функций вычисления нижележащего уровня.

Например, в виртуальном футболе элементами первого уровня являются непосредственно воспринимаемые элементы: линии, флаги, ворота, игроки, мяч. При этом один из узлов может реализовывать порождающую функцию вычисления владельца мяча. Вычисленный владелец мяча будет являться элементом второго уровня иерархии.

Множество $\{e\}_{i}$ элементов каждого $i$-го уровня представляет собой фрагмент $M M$. Таким образом, можно записать:

$$
M M=\{e\}_{1} \cup\{e\}_{2} \cup \ldots \cup\{e\}_{n}:\{e\}_{i} \cap\{e\}_{j}=\varnothing, i \neq j .
$$

При этом множество элементов каждого уровня формируется динамически в результате восприятия (для 1-го уровня) или вычисления (для остальных уровней).

Каждый узел может быть представлен кортежем:

$$
c n=<\{e\}_{p r},\{e\}_{p r}^{\text {in }},\{e\}_{p r}^{\text {out }}, p r, l_{i}>,
$$

где $p r$ - процедура вычисления элементов, реализующая функцию вычисления; $\{e\}_{p r}$ обязательное множество аргументов процедуры $p r$, такое что $\{e\}_{p r} \subseteq\{e\}_{i} ;\{e\}_{p r}^{i n}-$ необязательно множество аргументов процедуры $p r$, такое что $\{e\}_{p r}^{i n} \subseteq\{e\}_{1} \cup\{e\}_{2} \cup \ldots \cup\{e\}_{i-1} ;\{e\}_{p r}^{\text {out }}-$ множество результирующих элементов процедуры $p r$, такое что $\{e\}_{p r}^{\text {out }} \subseteq\{e\}_{i+1} ; l_{i}-i$-ый уровень, к которому относится данный узел.

Для рассматриваемого в данном примере узла множество обязательных аргументов процедуры включает игроков и мяч, элементом результирующего множества является «владелец мяча». 
Структура вычислительного процесса, соответствующая описанной модели, представлена рисунке 4.

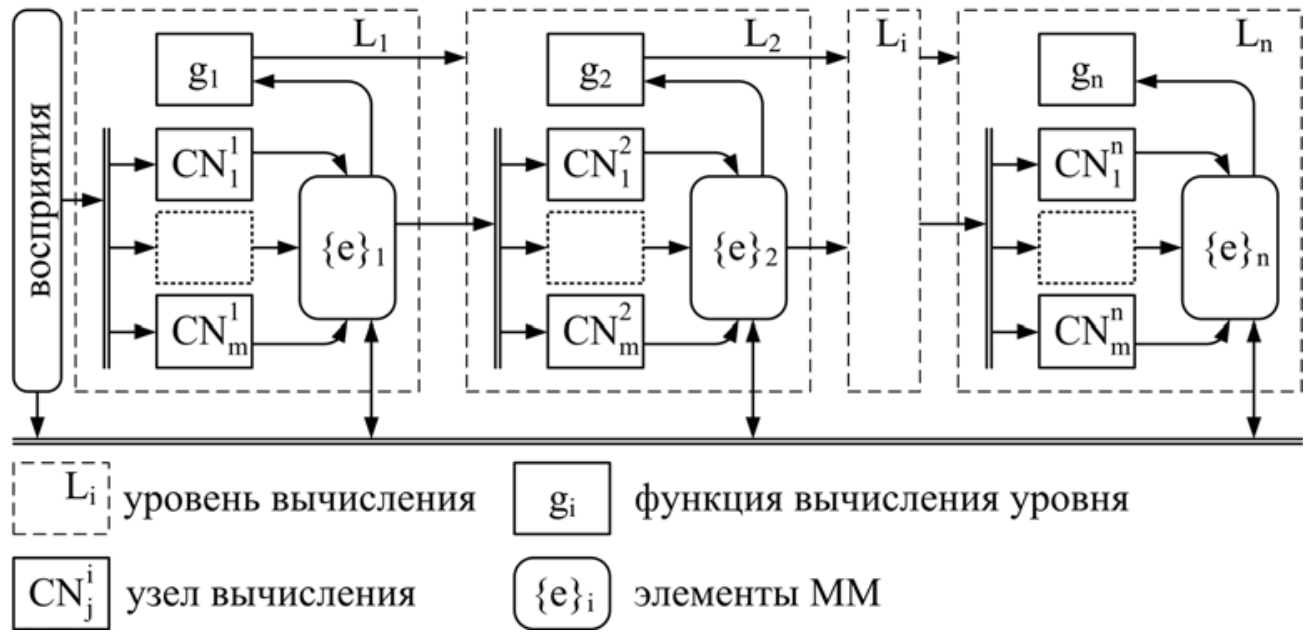

Рисунок 4 - Структура вычислительного процесса, соответствующая МВ

Важным свойством предлагаемой модели является динамическое порождение уровней и узлов, что обеспечивает гибкость в организации процесса вычислений и позволяет выделять ресурсы только по мере необходимости.

\subsection{3 Модель вычислимости}

$M B ч$ представляет собой отображение $M П$ в $M B$, в основе которого лежит использование функций вычисления, как связующего звена между элементами указанных моделей. Данная модель позволяет переходить от $M П$ к $M B$ на основе описываемых далее отображений.

Отображение $M П$ в $M B ч$ задаётся через ассоциирующие и порождающие вычислительные отношения:

$$
r_{a}, r_{c} \in R_{f}: \text { Domain } \rightarrow \text { Range } .
$$

Введём отображение предметных отношений в функции вычисления:

$$
R \rightarrow R_{f} .
$$

Тогда функции вычисления (3) и (4) могут быть записаны в виде:

- для $r \rightarrow r_{a}, f_{a}:<$ Domain, Range $>\rightarrow r_{a}$;

- для $r \rightarrow r_{c}, f_{c}$ : Domain $\rightarrow<$ Range, $r_{c}>$.

Для представления отображения $M B ч$ в $M B$ введём понятие звена вычисления (далее просто звено) $C U$ :

$$
C U=<\left\{e_{b}\right\},\left\{e_{d}\right\}, f>,
$$

где $f \in F_{a} \cup F_{c},\left\{e_{b}\right\}$ - множество базовых элементов звена; $\left\{e_{d}\right\}-$ множество производных элементов звена.

Каждое вычислительное отношение может быть преобразовано в звено следующим образом:

- для $r \rightarrow r_{a}:\left\{e_{b}\right\}=$ Range UDomain , $\left\{e_{\mathrm{d}}\right\}=r$;

- для $r \rightarrow r_{c}:\left\{e_{b}\right\}=$ Domain, $\left\{e_{\mathrm{d}}\right\}=r \bigcup$ Range .

Отображение $C U \rightarrow C N$, множества звеньев вычисления $C U$ во множество узлов вычисления $C N$, должно удовлетворять следующим условиям: 


$$
\left\{\begin{array}{l}
\{e\}_{p r} \cup\{e\}_{p r}^{i n}=\left\{e_{b}\right\}, \\
\{e\}_{p r}^{\text {out }}=\left\{e_{d}\right\}, \\
p r \text { является реализацией } f, \\
l_{i} \text { устанавливается динамически. }
\end{array}\right.
$$

Рассмотренные отображения обеспечивают реализацию принципа соответствия одного представления множеству вариантов организации вычислений. Отображение (5) позволяет связать с одним предметным отношением вычислительные отношения двух разных типов ассоциирующее или порождающее. Отображение (6) позволяет динамически определять уровень, на котором в ПОО будет реализована данная функция и, кроме того, сопоставлять одной функции вычисления несколько программных реализаций (отличающихся, например, языком программирования).

\section{3 Подход к проектированию}

Предлагаемый подход к проектированию ПОО предполагает дополнение рассмотренных базовых моделей моделями конкретной ПрО, для которой проектируются ИА. Собственно процесс проектирования ПОО включает последовательные отображения, заданные формулами (5) и (6), и состоит из трёх этапов:

1) построение $M П$ для $B н M M$, ПК и $C M M$, путём расширения базовой $М П$ объектами и отношениями выбранной ПрО;

2) отображение полученных $M П$ в $M B ч$ в соответствии с отображением, представленным формулой (5);

3) отображение полученной $M B ч$, а соответственно и $M \Pi$, в $M B$ в соответствии с отображением, представленным формулой (6).

\section{4 Пример}

Проиллюстрируем предлагаемый подход к проектированию ПОО на примере агента, функционирующего в среде виртуального футбола. В этой среде состояние многоагентного мира моделирует сервер, обновляя это состояние на основе команд, получаемых в каждом такте от всех игроков, и генерируя им неполные и неточные сенсорные данные.

Подсистема восприятия агента в каждом такте получает от сервера следующие данные: координаты статических (линии, флаги, ворота) и динамических (другие игроки, мяч) объектов в полярных координатах относительно себя. Статические объекты используются в качестве навигационных привязок для определения собственных координат.

Необходимо построить модель ПОО агента, обеспечивающую:

- вычисление собственных абсолютных координат агента на основе относительных координат навигационных объектов;

- $\quad$ определение владельца мяча на основе абсолютных координат мяча и игроков.

В соответствии с предложенным подходом для решения задачи проектирования ПОО агента разработаны:

- инвариантные онтологии и программный каркас ПОО, реализующие представленные модели;

- онтология и программная структура, соответствующая ПрО; каждый из этих артефактов в качестве основы использует соответствующую онтологию;

- способ автоматизированной интеграции онтологии и программного кода.

При решении поставленной задачи использовались следующие языки и инструменты:

- Java - основной язык программирования при реализации платформы проектирования; 
- OWL [21], SPIN [22], SPARQL [23] - языки представления и обработки онтологических знаний;

- TopBraid Composer Free Edition [24] - среда разработки, поддерживающая работу со всеми указанными выше языками.

При разработке сквозного сценария проектирования для апробации предлагаемого подхода были приняты следующие упрощающие допущения, не влияющие на общность подхода:

- формируемая на основе онтологической модели структура вычислений в ПОО является статической (на уровне модели это означает отождествление понятий узла и звена);

- рассматриваются достаточно простые конфигурачии отношений между объектами;

- проактивный контекст оценки обстановки предполагается статичным и не учитывается (СММ и ПК исключены из рассмотрения).

\subsection{1 Онтология ПОО}

В инвариантной онтологии ПОО (core.rdf) формализованы модели проектирования - МП, $M B ч, M B$. На рисунке 5 представлена иерархия классов данной онтологии.

owl:Thing

$\triangle$ CalculationEntity

Level

Node

4 ComputabilityEntity

ComputationUnit

4 DevelopmentStage

CUGeneration

LevelGeneration

4 DomainEntity

Object

Percepted

Рисунок 5 - Иерархия классов онтологии ПОО

Базовыми онтологическими классами MПр являются: DomainEntity, ComputabilityEntity, CalculationEntity.

Класс DomainEntity является суперклассом всех классов, используемых для построения МП. Класс Percepted соответствует элементам, поступающим от ПВ. Отношения между объектами записываются с помощью стандартной конструкции языка OWL - Object Property.

Для класса ComputabilityEntity определён подкласс ComputationUnit, используемый для представления звена.

Класс CalculationEntity имеет подклассы, представляющие элементы процесса вычисления - узлы и уровни вычисления.

Кроме рассмотренных классов в онтологии определён ряд свойств, представленных ниже в формате имя свойства (область определений $\rightarrow$ область значений):

- hasBase (ComputationUnit $\rightarrow$ DomainEntity) - описывает

базовые элементы звена;

- hasDerivative(ComputationUnit $\rightarrow$ DomainEntity) - описывает

производные элементы звена;

- computable и его дочерние свойства associative и generative - представляют ассоциирующие и порождающие вычислительные отношения (для этих свойств области определения и значения не заданы);

- level(ComputationUnit $\rightarrow$ Level) - описывает уровень вычисления данного звена;

- $\quad$ number (Level $\rightarrow$ xsd:integer) - номер («высота») уровня вычисления.

\subsection{2 Автоматизация процесса проектирования}

Процесс проектирования предполагает расширение базовой онтологии элементами ПрО. В рамках рассматриваемого примера разработана онтология ПрО (soccer.rdf), в которую импортирована базовая онтология ПОО.

Процесс проектирования в соответствии с п. 3.3 включает:

1) определение объектов и отношений (свойств) ПрО;

2) отображение предметных отношений в вычислительные отношения;

3) формирование звеньев и структуры процесса вычисления. 


\subsection{3 Онтология виртуального футбола}

В результате первых двух этапов процесса проектирования разработана онтология ПрО, фрагмент которой представлен на рисунке 6. Кроме классов, определён ряд отношений (свойств), перечисленных ниже в функциональном формате (ассоциативные отношения отмечены признаком «а», порождающие - признаком «g»):

- beBase4Ego(BodyState $\rightarrow E g o ; g)$ - порождает внутреннее представление собственного состояния агента-футболиста на основе восприятия;

- $\operatorname{seeLandmark(Ego~} \rightarrow$ Flag, Goal, Line; a) - фиксирует множество видимых агентом статических объектов, которые могут использоваться для навигации на футбольном поле;

- identifiedAs(Player $\rightarrow$ IdentifiedPlayer; g) - порождает внутреннее представление об игроке на основе соответствующего восприятия (в виртуальном футболе данная операция включает идентификацию игрока и отнесение его к определённой команде);

- subClassOfEgo(seeLandmark $\rightarrow$ EgoAbsolute; g) - порождает внутреннее представление абсолютных координат, вычисляемых на основе видимых навигационных объектов;

- ownsBall(EgoAbsolute, IdentifiedPlayer $\rightarrow$ Ball; a) - определяет владельца мяча.

\begin{tabular}{|c|c|}
\hline : Classes $\mathbb{Z}$ & Properties \&3 \\
\hline $\begin{array}{l}4 \text { core:DomainEntity } \\
\text { core:Object } \\
\text { Ego } \\
\text { IdentifiedPlayer } \\
\text { Perception } \\
\text { core:Percepted } \\
\text { Ball } \\
\text { BodyState } \\
\text { Flag } \\
\text { Goal } \\
\text { Line } \\
\text { Player }\end{array}$ & $\begin{array}{l}\Delta \square \text { core:computable } \\
\square \text { core:associative } \\
\square \text { ownsBall } \\
\square \text { seeLandmark } \\
\square \text { core:generative } \\
\square \text { beBase4Ego } \\
\square \text { identifiedAs } \\
\square \text { subClassOfEgo } \\
\square \text { subClassOfIdentifiedPlayer } \\
\square \text { core:hasBase } \\
\square \text { core:hasDerivative } \\
\square \text { core:level } \\
\text { core:number }\end{array}$ \\
\hline
\end{tabular}

Рисунок 6 - Фрагменты онтологии предметной области (классы и свойства)

Отображение предметных отношений в вычислительные выполняется через наследование соответствующего ассоциирующего или порождающего свойства (см. рисунок 6).

\subsection{4 Автоматизация процесса проектирования}

На заключительном этапе проектирования в качестве средства автоматизации используется редактор TopBraid Composer Free Edition, поддерживающий язык SPIN. Данный язык позволяет связывать SPARQL-запросы с онтологическими классами. Запросы выполняются встроенным модулем вывода на экземплярах соответствующих классов. В частности, для порождения новых сущностей (классов, экземпляров, свойств) используются SPARQL-запросы CONSTRUCT. Другой особенностью языка SPIN является возможность определения пользовательских функций, представляющих собой запросы на языке SPARQL, которые можно вызывать из других SPARQL-запросов.

Запуск правил на экземплярах класса позволил построить небольшую иерархию классовэтапов процесса проектирования (см. рисунок 5) - DevelopmentStages: CUGeneration и LevelGeneration. Создание экземпляров данных классов позволяет запускать правила, порождающие элементы онтологии на соответствующем этапе проектирования.

Класс CUGeneration включает правила порождения звеньев: 
- звеньев первого уровня, играющих роль объектов-посредников с ПВ (такие звеньяпосредники не имеют базовых элементов);

- звеньев, реализующих ассоциирующие или порождающие функции.

Кроме того, класс CUGeneration включает правило для привязки звеньев-посредников к первому уровню.

Класс LevelGeneration включает правило порождения первого уровня и правило привязки звена к уровню, которое является наиболее сложным. При построении правила привязки используются понятия звена-реципиента и звена-донора: базовые элементы первого являются производными элементами второго. Правило реализует следующий алгоритм.

1) фиксируются базовые элементы реципиента, при этом реципиент не должен быть привязан к какому-либо уровню.

2) ищутся доноры, у которых в качестве производных элементов выступают базовые элементы. Эти доноры должны быть привязаны к некоторому уровню.

3) выбирается донор, привязанный к наиболее высокому уровню, по которому определяется уровень реципиента. Все базовые элементы должны быть поддержаны донорами.

Соответствующее правило представлено на рисунке 7.

\section{CONSTRUCT \{}

?recipient :level ?nextLevel .

\}

WHERE \{

?recipient a :ComputationUnit .

MINUS \{

\{

SELECT DISTINCT ?recipient WHERE \{

\{

?recipient a :ComputationUnit .

BIND (:CountBases(?recipient) AS ?cb) .

BIND (:CountDonors(?recipient) AS ?cd). FILTER $(((? \mathrm{~cd}=0) \|(? \mathrm{~cd}=0)) \|(? \mathrm{cb} !=? \mathrm{~cd}))$. \} .

\}

\} .

\} .

MINUS \{

?recipient :level ?anyLevel.

\} .

BIND (:FindMaxLevel(?recipient) AS ?level) .

BIND (:FindNextLevel(?level) AS ?nextLevel). \}

Рисунок 7 - Правило связывания звена вычисления и уровня вычисления

Данное правило использует следующие пользовательские функции:

- FindMaxLevel - реализует поиск максимального уровня, к которому привязан донор;

- FindNextLevel - вычисляет уровень реципиента;

- CountBases - подсчитывает количество базовых элементов звена;

- CountDonors - подсчитывает количество доноров звена.

Класс ComputationUnit также содержит правило для порождения нового уровня: при добавлении нового звена на самый высокий среди имеющихся уровень, порождается следующий уровень.

На рисунке 8 представлены звенья, их взаимозависимость и принадлежность к уровню, полученные автоматически в результате обработки SPARQL-запроса.

Логика порождаемой иерархии звена заключается в следующем. Часть восприятий переводится во внутреннее представление, что позволяет, например, сохранять историю. Это относится к состоянию агента (cd_beBas4Ego) и видимым игрокам (cd_idetifiedAs). Навигационные объекты связываются с внутренним представлением агента ( $c d$ seeLandmark), что позволят в явном виде использовать полученное отношение для вычисления абсолютных координат (cd_subClassOfEgo). В соответствии с протоколом работы футбольного сервера воспринятое собственное состояние не включает абсолютных координат. Но эти координаты могут быть вычислены на основе расстояния и угла относительно навигационных объектов. Абсолютные координаты навигационных объектов относятся к априорным знаниям. Последний шаг - это вычисление владельца мяча 
(cd_ownBall), исходя из собственного положения, положения видимых игроков и положения мяча.

\begin{tabular}{lll}
\hline donor & recipient & level \\
& cd_perception & level_1 \\
- cd_perception & cd_beBase4Ego & lidentifiedAs
\end{tabular}

Рисунок 8 - Вычислительные зависимости между звеньями вычисления и их привязка к уровням вычисления

На рисунке 9 с некоторыми упрощениями представлена схема автоматизированного порождения элементов $M B$. В ручном режиме описываются классы, отношения и определяется тип отношений. После этого автоматически с использованием запроса CONSTRUCT выводятся элементы процесса вычислений.

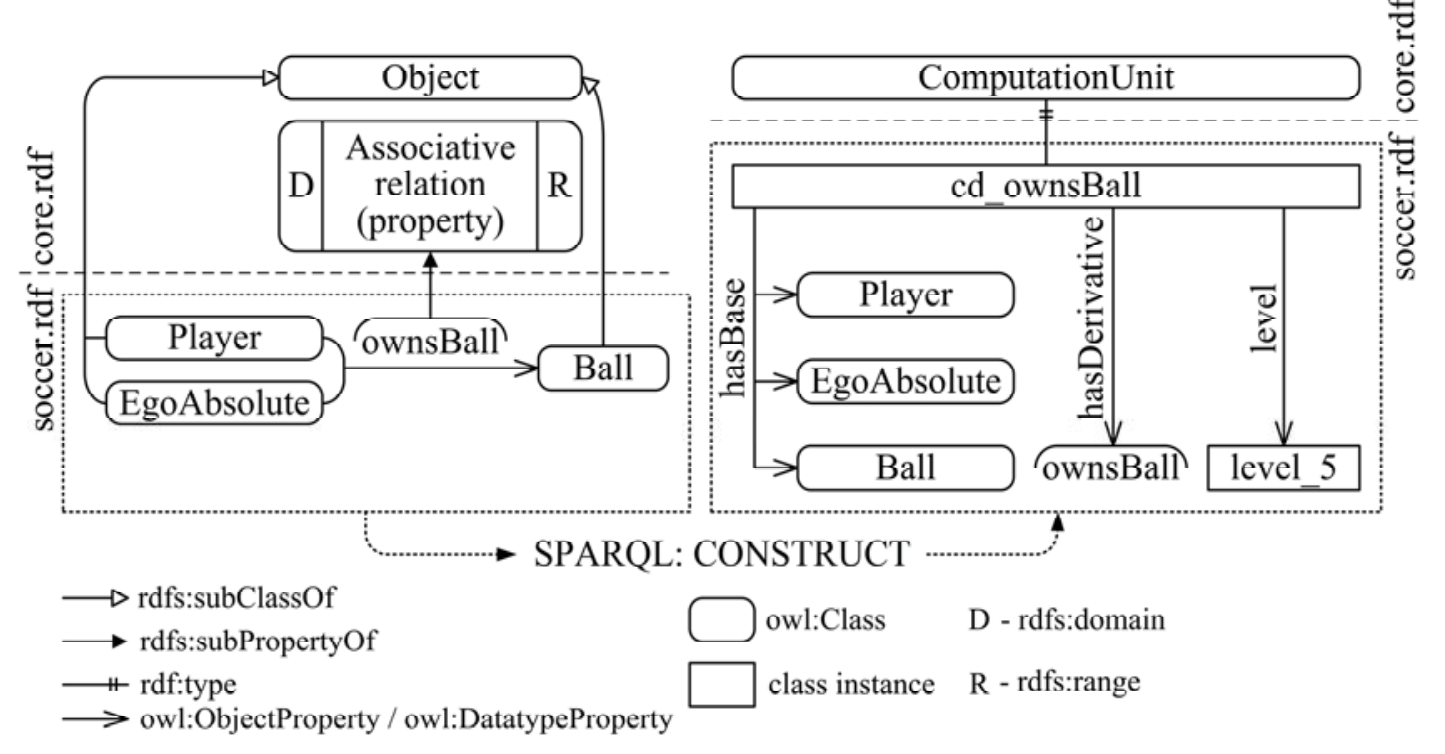

Рисунок 9 - Автоматизация генерации элементов $M B$ на уровне онтологии

\subsection{5 Программный каркас}

Программный каркас реализован на языке Java версии 1.8. В настоящее время каркас включает две подсистемы - восприятия и оценки обстановки. Подсистема восприятия предназначена для взаимодействия с сервером виртуального футбола и работает в отдельном вычислительном потоке. Данная подсистема реализует обмен сообщениями и преобразование полученных текстовых сообщений из текстового формата S-expression в объекты.

Главный класс приложения инициализирует каждую из подсистем, после чего запускает их в бесконечном цикле. Цикл начинается с ожидания сенсорных данных. После их получения они передаются ПОО (push-подход). После этого управление передается ПОО.

Программный каркас ПОО представлен тремя базовыми классами: 
- LevelHolder - класс-контейнер, содержащий все уровни обработки информации в ПОО;

- LightweightLevel - класс-контейнер уровней, содержащий все узлы данного уровня;

- LightweightNode - абстрактный класс, представляющий узел.

Классы LevelHolder и LightweightLevel реализуют метод process(), в теле которого вызываются одноименные методы внутренних объектов.

Класс LightweightNode также содержит абстрактный метод process(), который должен быть реализован пользователем в соответствии с логикой ПрО (например, вычисление абсолютных координат объекта в виртуальном футболе). Кроме того, в класce LightweightNode определён абстрактный метод pullBases() для получения данных от узлов-поставщиков (доноров), т.е. используется рull-подход.

Процесс вычисления организован следующим образом (см. рисунок 10). При получении управления каждый узел (кроме узла 1-го уровня) пытается получить информацию от узловдоноров. Если информация доступна, выполняются необходимые вычисления и результат сохраняется в полях объекта, доступных узлам-потребителям вышележащих уровней. Для упрощения взаимодействия программных компонентов между узлами всегда передаются списки объектов.

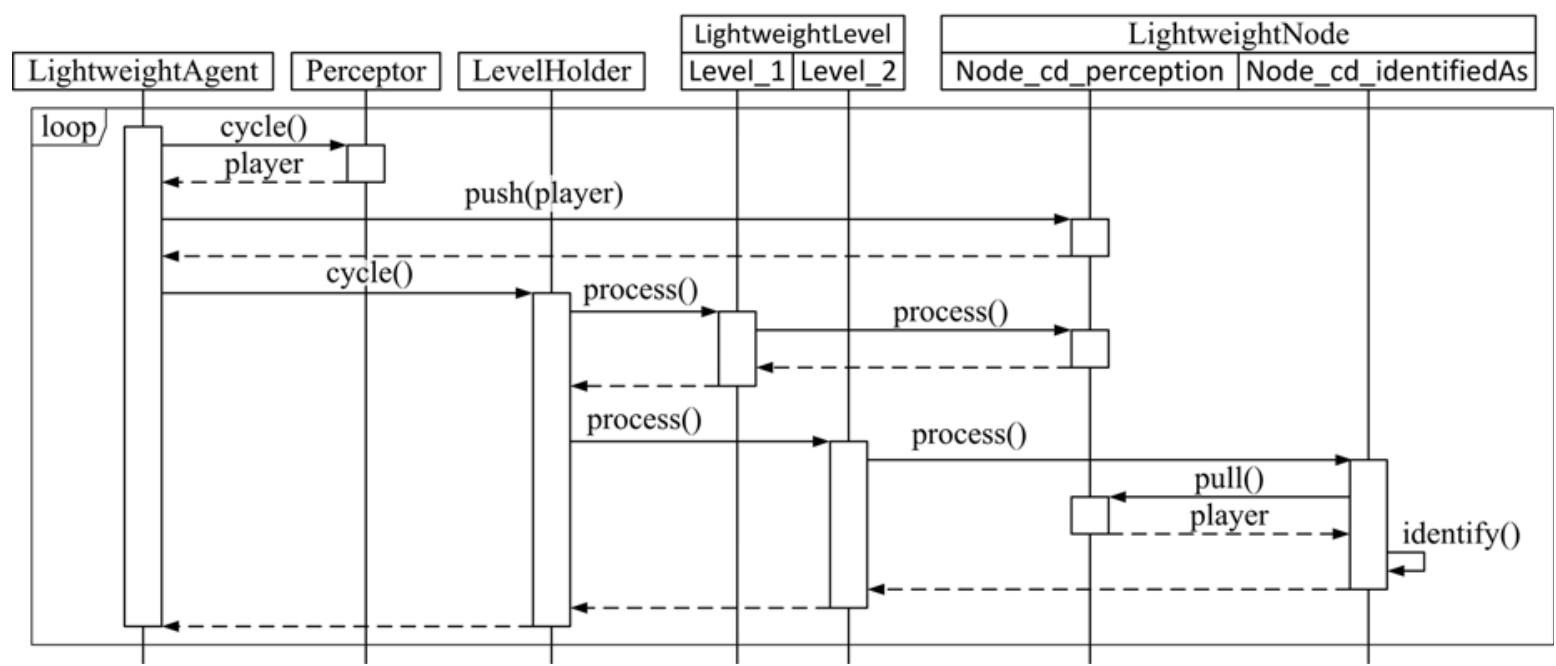

Рисунок 10 - Фрагмент цикла вычисления

\subsection{6 Генерация программного кода}

Для генерации программного кода использовалась библиотека CodeModel [25], позволяющая компоновать программный код Јava-классов. Библиотека представляет собой набор вызовов, каждый из которых создаёт заданную структуру программного класса (поля, методы, конструкторы). Над этими функциями был надстроен функционал преобразования онтологических данных в программный код, реализованный в классе Translator. Для доступа к онтологии использовались средства TорBraid API [26] и Jena [27].

Для получения данных из онтологии использовались следующие SPARQL запросы:

- получение всех звеньев с номерами уровней, к которым они привязаны, для генерации уровней и узлов;

- получение базовых и производных элементов для заданного звена для генерации полей класса узла, представляющих собой списки базовых и порождаемых элементов;

- получение узлов доноров совместно с уровнями, к которым они привязаны, для уточнения конструктора класс узла таким образом, чтобы в него передавались уровни, включающие узлы-доноры (при инициализации извлекаются по имени класса узла- 
донора). Узлы-доноры используются в методе pullBases(), который также порождается автоматически. Также добавляются поля класса, представляющие узлы-доноры.

Перед выполнением запросов необходимо запустить логический вывод для формирования структуры вычислительного процесса в рамках онтологии.

Кроме порождения классов для уровней и узлов порождается класс LevelNodeInitializer, инициализирующий структуры процесса вычисления: создание экземпляров классов уровней и узлов, с передачей последним уровней, от которых они зависят.

После порождения кода требуется его интеграция в каркас и определение методов process() каждого из узлов вычисления. В будущем эти методы могут быть специфицированы на этапе создания онтологии, если соответствующие функции будут доступны из готовых библиотек.

\subsection{7 Результаты апробации подхода}

Разработанный прототип продемонстрировал возможность построения онтологии выбранной ПрО на базе инвариантной онтологии и возможность генерации программного кода по построенной онтологии ПрО. Достоинствами предлагаемого подхода являются:

- Возможность использования графических средств для построения онтологии ПрО. Выбранный редактор имеет встроенные средства, позволяющие на этапе построения онтологии просматривать структуру формируемого в ПОО вычислительного процесса и контролировать её правильность уже на ранних этапах проектирования.

- Поддержка автоматической генерации онтологических сущностей (в реализованном прототипе автоматически сгенерировано 55 троек).

- Поддержка автоматической генерации программного кода. В реализованном прототипе было автоматически сгенерировано 12 классов, общий объём сгенерированного кода составил 291 строку.

Вместе с тем, разработанный прототип выявил ряд требующих решения проблем.

- Поддержка на онтологическом и программном уровне групповых объектов, порождаемых на основе множества других (более простых) объектов, связанных специфическим отношением. Примером является определение тактического построения команды на основе ранее вычисленных линий обороны, полузащиты и нападения. При этом для каждого из специфических отношений будет создано своё звено, тогда как по логике вычисления звено должно быть одно. Т.е. вместо одного звена, вычисляющего формацию на основе трёх объектов, будет создано три отдельных звена, каждое из которых будет вычислять формацию на основе одной линии.

- Переход от отношений-свойств к отношениям-классам, обусловленный, например, необходимостью расширения отношений специфическими свойствами.

- Реализация динамического свойства МВ (динамическое порождение уровней и узлов). В качестве базовых вариантов можно назвать централизованное порождение и распределённое порождение, на каждом уровне вычисления отдельно.

- В рамках изложенного подхода предлагается переходить от предметных отношений к вычислительным зависимостям. С этим переходом связана проблема вычисления на уровне свойств отдельного объекта, когда одни свойства объекта вычисляются на основе других свойств и отношений, в которых участвует данный объект. В предложенном примере это решено вводом специфического отношения наследования, например, subClassOfEgo, область определения которого включает свойство seeLandmark. Иным вариантом может стать выделение подмодели, формализующей зависимости между свойствами и отношениями одного класса. 
Эта проблема может быть рассмотрена в контексте более общей проблемы общеприменимости принципа порождения вычислительных зависимостей на основе предметных отношений;

- Сложные задачи трудно решить на едином уровне концептуализации, когда эффективней ввести различные интерпретации для сущностей, например, как пространственно-временных и структурно-организационных. Под каждую такую интерпретацию необходимо строить свою онтологию и обеспечивать их взаимное отображение.

\section{4 Будущие направления исследований}

Перспективы практического развития данной работы связаны с реализацией полнофункциональной среды проектирования, поддерживающей сквозные сценарии проектирования ПОО для ИА различного назначения. Эти сценарии должны включать генерацию программных классов объектов и отношений по онтологическим сущностям, а также реализацию и подключение специфических функций вычисления. Механизм подключения предполагается реализовать через специфицирование библиотек и функций в онтологии ПрО. В теоретическом плане требуют дальнейшего анализа проблемы, сформулированные в п. 3.4.7.

Конечной целью проекта является создание интегрированной системы проектирования ИА РВ, обеспечивающей совместное проектирование программного обеспечения всех подсистем ИА, включая ПОО и подсистемы планирования.

\section{Заключение}

Разработан и апробирован онтологический подход к автоматизации проектирования и разработки ПОО ИА, основанный на повторном использовании кода и модельноориентированном проектировании. Онтологии позволяют применять методы автоматической генерации программного кода, который затем интегрируется в инвариантный вычислительный каркас ПОО.

В процессе апробации подхода разработаны инвариантные предметной области базовая онтология и программный каркас ПОО. При проектировании агента для среды виртуального футбола построена доменная онтология и апробирована технология автоматической генерации программного кода.

Результаты апробации подтвердили работоспособность и эффективность предложенного онтологического подхода к автоматизации проектирования программного обеспечения ПОО ИА. Вместе с тем, апробация позволила уточнить проблемы, требующие дальнейшей разработки.

\section{Список источников}

[1] Боргест, Н.М. Онтология проектирования: теоретические основы. Ч. 1. Понятия и принципы / Н.М. Боргест // уч. пособ. - Самара: Изд-во Самар. гос. аэрокосм. ун-та, 2010. - 88 с.

[2] Мордвинов, В.A. Онтология моделирования и проектирования семантических информационных систем и порталов / В.А. Мордвинов // Справочное пособие. - М.: МИРЭА, 2005. - 237 с.

[3] Скобелев П.О. Онтологии деятельности для ситуационного управления предприятиями в реальном времени / П.О. Скобелев // Онтология проектирования. - 2012.- № 1(3). - С. 6-38.

[4] Russell S. J., Norvig P. Artificial Intelligence. A modern approach // Artificial Intelligence. - 3rd edition. - Prentice-Hall, 2010. - $1152 \mathrm{p}$. 
[5] Пузанков, Д.В. Интеллектуальные агенты, многоагентные системы и семантический Web: концепции, технологии, приложения / Д.В. Пузанков, В.И. Мирошников, М.Г. Пантелеев, А.В. Серегин - СПб.: Изд-во «Технолит», 2008. - 292 с.

[6] Ed. Hadzic, M., Chang, E. J., Wongthongtham, P. Ontology-Based Multi-Agent Systems // Studies in Computational Intelligence. - Berlin: Springer-Verlag, 2009. - T. 219. - XIV. - 274 p.

[7] Лахин, О.И. Подход к разработке прототипа интеллектуальной системы поддержки принятия согласованных решений при проектировании малоразмерных космических аппаратов на основе мультиагентных технологий / О.И. Лахин, Е.В. Симонова, П.О. Скобелев // Информационно-управляющие системы. - 2015. - № 2. - С. 43-48.

[8] Пантелеев, М.Г. Концепция построения интеллектуальных агентов реального времени на основе модели опережающего итеративного планирования / М.Г. Пантелеев // Труды 12-ой национальной конф. по искусственному интеллекту с международным участием КИИ-2012. - Белгород: Изд-во БГТУ, 2012. - Т 3. C.25-33.

[9] Пантелеев, М.Г. Формальная модель опережающего итеративного планирования действий интеллектуальных агентов реального времени / М.Г. Пантелеев // //Труды 14-ой национальной конф. по искусственному интеллекту с международным участием КИИ-2014. - Казань: Физматлит, 2014. - Т 1. - С.323-334.

[10] Foo P.H., Ng G.W. High-level Information Fusion: An Overview // J. Adv. Inf. Fusion. - 2013. - V. 8. - №. 1. pp. 33-72.

[11] Endsley M.R. Toward a theory of situation awareness in dynamic systems // Human Factors: The Journal of the Human Factors and Ergonomics Society. - 1995. - V. 37. - №. 1. - pp. 32-64.

[12] Bowman C.L., Steinberg A.N. Systems Engineering Approach for Implementing Data Fusion Systems/ Llinas J., Hall D. L., Liggins M. E. (ed.). Handbook of Multisensor Data Fusion: Theory and Practice. - CRC Press, 2009. pp. 561-596.

[13] Steinberg A.N., Bowman C.L. Revisions to the JDL Data Fusion Model / Llinas J., Hall D. L., Liggins M. E. (ed.). Handbook of Multisensor Data Fusion: Theory and Practice. - CRC Press, 2009. - pp. 44-67.

[14] Steinberg, A.N. Foundations of Situation and Threat Assessment / Llinas J., Hall D. L., Liggins M. E. (ed.). Handbook of Multisensor Data Fusion: Theory and Practice. - CRC Press, 2009. - pp. 437-501.

[15] Kokar, M.M., Matheus, C.J., Baclawski K. Ontology-based situation awareness //Information fusion. - 2009. V.10. - № 1. - pp. 83-98.

[16] Baumgartner N., Gottesheim W., Mitsch S., Retschitzegger W., Schwinger W. BeAware!-situation awareness, the ontology-driven way // Data \& Knowledge Engineering. - Elsevier, 2010. - V. 69. - №. 11. - pp. 1181-1193.

[17] Baumgartner N., Mitschb S., Muller A., Retschitzegger W., Salfinger A., Schwinger W. A tour of BeAware-A situation awareness framework for control centers //Information Fusion. - 2014. - V. 20. - pp. 155-173.

[18] RoboCup Soccer Server for Soccer Server Version 7.07. Users Manual / Mao Chen, Klaus Dorer, Ehsan Foroughi, Fredrik Heintz, ZhanXiang Huang, Spiros Kapetanakis, Kostas Kostiadis, Johan Kummeneje, Jan Murray, Itsuki Noda, Oliver Obst, Pat Riley, Timo Steffens, Yi Wang and Xiang Yin. February 11, 2003. - 140 p. https://sourceforge.net/projects/sserver/files/rcssmanual/9-20030211/manual-20030211.pdf/download (Valid on 26.02.2016).

[19] Pan J. Z., Staab S., Abmann U., Ebert J., Zhao Y. Ontology-driven software development. - Berlin: SpringerVerlag, 2013. - 344 p.

[20] Robocup Soccer Server. User manual. -

URL: https://sourceforge.net/projects/sserver/files/rcssmanual/9-20030211/manual-20030211.pdf/download (дата обращения 26.02.2016).

[21] OWL 2 Web Ontology Language Primer (Second edition). -

URL: https://www.w3.org/TR/owl2-primer (дата обращения 26.02.2016).

[22] SPIN - Overview and Motivation. -

URL: https://www.w3.org/Submission/spin-overview (дата обращения 26.02.2016).

[23] SPARQL 1.1 Query Language. -

URL: https://www.w3.org/TR/sparql11-query (дата обращения 26.02.2016).

[24] TopBraid Composer. Getting Started Guide. -

URL: http://www.topquadrant.com/resources/products/docs/TBC-Getting-Started-Guide.pdf (дата обращения 26.02.2016).

[25] CodeModel project. - URL: https://codemodel.java.net (дата обращения 26.02.2016).

[26] The TopBraid SPIN API. - URL: http://topbraid.org/spin/api (дата обращения 26.02.2016).

[27] Apache Jena. - URL:https://jena.apache.org (дата обращения 26.02.2016). 


\title{
ONTOLOGY-DRIVEN DESIGN APPROACH TO DEVELOPMENT OF SITUATION AWARENESS SUBSYSTEM OF INTELLIGENT AGENTS
}

\author{
S.L. Lebedev ${ }^{1}$, M.G. Panteleyev ${ }^{2}$ \\ Saint Petersburg Electrotechnical University "LETI", St. Petersburg, Russia \\ ${ }^{1}$ lebedev.sv.etu@gmail.com, ${ }^{2}$ mpanteleyev@gmail.com
}

\begin{abstract}
An ontology-driven design approach to development of situation awareness subsystem (SAS) of intelligent agents is discussed. It is supposed that agents act in multi-agent competitive environments. The approach is based on the separation of domain independent and domain specific aspects. A set of domain independent models is proposed as a theoretical underpinning of the approach. Those models formalize different aspects of design and development of SAS including internal agent's representation of an environment, situation awareness calculation stages and SAS design stages. The models are used to build ontological and program components, used for SAS design and development. Two classes of ontologies are defined: SAS ontology and ontologies of specific domains. SAS ontology is used to provide domain specific program code integration into the domain independent SAS framework. Domain specific ontology is used to represent domain specific concepts on the base of SAS ontology concepts. SAS development process includes the following stages: domain specific ontology construction, automatized generation of domain specific code, integration of domain specific code into the SAS framework and implementation of domain specific functions within the framework. Automatized code generation is based on the proposed mappings of ontological classes and properties to the program structures. A toolset is proposed for building domain specific SAS. The toolset utilizes such languages from the Semantic Web stack as OWL, SPARQL and SPIN. The toolset is written in Java language. The approach is illustrated and evaluated on the simplified virtual soccer scenario.
\end{abstract}

Key words: intelligent agent, situation assessment, ontology-driven development, toolset.

Citation: Lebedev SL, Panteleyev MG. Ontology-driven design approach to development of situation awareness subsystem of intelligent agents [In Russian]. Ontology of designing. 2016; 6(21): 297-316. DOI: 10.18287/2223-9537-2016-63-297-316.

\section{References}

[1] Borgest NM. Ontology of Designing: theoretical foundations. Part 1. Concepts and definitions: textbook [In Russian]. - Samara: Samara airspace university publ., 2010. - 88 p.

[2] Mordvinov VA. Ontology of modeling and designing of semantic information systems and portals. Reference guide [In Russian]. - Moscow: MIREA, 2005. - 237 p.

[3] Skobelev PO. An activity ontology for enterprise real-time situation management [In Russian]. Ontology of Designing. 2012; 1(3): 6-38.

[4] Russell SJ, Norvig P. Artificial Intelligence. A modern approach. - 3rd edition. - Prentice-Hall, 2010. - 1152 p.

[5] Puzankov DV, Miroshnikov VI, Panteleev MG, Seregin AB. Intelligent agents, multiagent systems and Semantic Web: concepts, technologies and applications [In Russian]. - SPb.: "Tekhnolit" publ., 2008. - $292 \mathrm{p}$.

[6] Hadzic EdM, Chang EJ, Wongthongtham P. Ontology-Based Multi-Agent Systems. Studies in Computational Intelligence. - Berlin: Springer-Verlag, 2009. - V. 219. - XIV. - 274 p.

[7] Lahin OI, Simonova IB, Skobelev PO. Prototype intelligent system of coordinated decision-making support for small spacecraft design on the basis of multi-agent technologies [In Russian]. Information and Control Systems. 2015; 2: 43-48.

[8] Panteleev MG. A conception of a real-time intelligent agents development on the basis of proactive iterative planning [In Russian]. Proc. of the 12 National Conference on Artificial Intelligence with International Participation KII-2012. - Belgorod: BGTU, 2012. - V 3. - pp. 25-33.

[9] Panteleev MG. A formal model of proactive iterative action planning for real-time intelligent agents [In Russian]. Proc. of the 14 National Conference on Artificial Intelligence with International Participation KII-2014. - Kazan: Fizmatlit, 2014. - V 1. - pp.323-334. 
[10] Foo PH, Ng GW. High-level Information Fusion: An Overview. J. Adv. Inf. Fusion. - 2013; 8(1): 33-72.

[11] Endsley MR. Toward a theory of situation awareness in dynamic systems. Human Factors: The Journal of the Human Factors and Ergonomics Society. - 1995; 37(1): 32-64.

[12] Bowman CL, Steinberg AN. Systems Engineering Approach for Implementing Data Fusion Systems. Llinas J., Hall D. L., Liggins M. E. (ed.). Handbook of Multisensor Data Fusion: Theory and Practice. - CRC Press, 2009. pp. 561-596.

[13] Steinberg AN, Bowman CL. Revisions to the JDL Data Fusion Model. Llinas J., Hall D. L., Liggins M. E. (ed.). Handbook of Multisensor Data Fusion: Theory and Practice. - CRC Press, 2009. - pp. 44-67.

[14] Steinberg AN. Foundations of Situation and Threat Assessment. Llinas J., Hall D. L., Liggins M. E. (ed.). Handbook of Multisensor Data Fusion: Theory and Practice. - CRC Press, 2009. - pp. 437-501.

[15] Kokar MM, Matheus CJ, Baclawski K. Ontology-based situation awareness. Information fusion. - 2009. - V. 10. № 1. - pp. 83-98.

[16] Baumgartner N., Gottesheim W., Mitsch S., Retschitzegger W., Schwinger W. BeAware!-situation awareness, the ontology-driven way. Data \& Knowledge Engineering. - Elsevier, 2010; 69(11): 1181-1193.

[17] Baumgartner N, Mitschb S, Muller A, Retschitzegger W, Salfinger A, Schwinger W. A tour of BeAware-A situation awareness framework for control centers. Information Fusion. - 2014. - V. 20. - pp. 155-173.

[18] RoboCup Soccer Server for Soccer Server Version 7.07. Users Manual / Mao Chen, Klaus Dorer, Ehsan Foroughi, Fredrik Heintz, ZhanXiang Huang, Spiros Kapetanakis, Kostas Kostiadis, Johan Kummeneje, Jan Murray, Itsuki Noda, Oliver Obst, Pat Riley, Timo Steffens, Yi Wang and Xiang Yin. February 11, 2003. - 140 p. http://www.robocup.org/robocup-soccer/simulation/ (Valid on 26.02.2016).

[19] Pan J. Z., Staab S., Abmann U., Ebert J., Zhao Y. Ontology-driven software development. - Springer-Verlag, 2013. $-344 \mathrm{p}$.

[20] Robocup Soccer Server. User manual.

Source: 〈https://sourceforge.net/projects/sserver/files/rcssmanual/9-20030211/manual-20030211.pdf/download .

[21] OWL 2 Web Ontology Language Primer (Second edition). Source: 〈https://www.w3.org/TR/owl2-primer $\rangle.$

[22] SPIN - Overview and Motivation. Source: 〈https://www.w3.org/Submission/spin-overview $\rangle$.

[23] SPARQL 1.1 Query Language. Source: 〈https://www.w3.org/TR/sparql11-query $\rangle.$

[24] TopBraid Composer. Getting Started Guide.

Source: 〈http://www.topquadrant.com/resources/products/docs/TBC-Getting-Started-Guide.pdf〉.

[25] CodeModel project. Source: 〈https://codemodel.java.net $\rangle$.

[26] The TopBraid SPIN AP. Source: 〈http://topbraid.org/spin/api $\rangle$.

[27] Apache Jena. Source: 〈URL:https://jena.apache.org〉.

\section{Сведения об авторах}

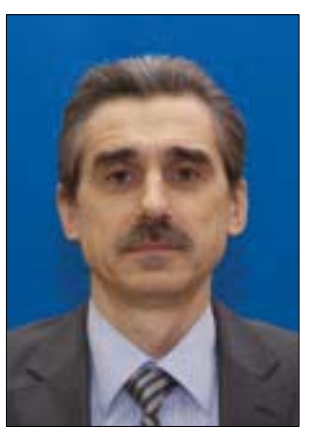

Пантелеев Михаил Георгиевич, 1960 г. рождения. Окончил Пензенский политехнический институт в 1982 г. Кандидат техн. наук (1988), доцент кафедры вычислительной техники СПбГЭТУ «ЛЭТИ». В списке научных трудов более 100 работ в области искусственного интеллекта, многоагентных систем и технологий семантического Web.

Panteleyev Michail Georgievich (b. 1960) graduated from Penza Polytechnical Institute in 1982. Ph.D (1988), Associate Professor, Saint Petersburg Electrotechnical University "LETI" (Department of Computer Science and Engineering). He is co-author of more than 100 publications in the field of artificial intelligence, multi-agent systems and semantic web technologies.

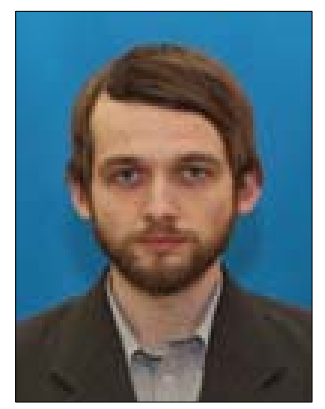

Лебедев Сергей Вячеславович, 1984 г. рождения. Окончил Санкт-Петербургский государственный электротехнический университет «ЛЭТИ» им. В.И. Ульянова (Ленина) (СПбГЭТУ ЛЭТИ) в 2010 году. Ассистент кафедры Вычислительной техники СПбГЭТУ ЛЭТИ. В списке научных трудов более 10 работ в области многоагентных систем и технологий семантического Web.

Lebedev Sergey Vyacheslavovich (b. 1984) graduated from Saint Petersburg Electrotechnical University "LETI" in 2010. He is an assistant at Saint Petersburg Electrotechnical University "LETI" (Department of Computer Science and Engineering). He is co-author of more than 10 publications in the field of multi-agent systems and semantic web technologies. 


\title{
УДК 519.711.3
}

\section{АНАЛИЗ НЕПОЛНЫХ ДАННЫХ В ЗАДАЧАХ ПОСТРОЕНИЯ ФОРМАЛЬНЫХ ОНТОЛОГИЙ*}

\author{
Д.Е. Самойлов ${ }^{1,2}$, В.А. Семенова ${ }^{1,2}$, С.В. Смирнов ${ }^{2}$ \\ ${ }^{1}$ Самарский национальный исследовательский университет им. академика С.П. Королева, Самара, Россия \\ dmitrysam3@gmail.com,queenbfjr@gmail.com \\ ${ }^{2}$ Институт проблем управления сложными системами РАН, Самара, Россия \\ smirnov@iccs.ru
}

\begin{abstract}
Аннотация
В статье рассматривается проблема автоматизации формирования онтологических спецификаций предметных областей на основе измерений - стержневая проблема онтологического анализа данных. Представлены модели и методы, направленные на выявление понятийной структуры и, в конечном счете, формальной онтологии исследуемой предметной области. Фундаментальные реалии накопления эмпирической информации: многократные независимые измерения каждого свойства объекта обучающей выборки; конгруэнтность части процедур измерения; дифференциация доверия к различным источникам данных - отражены в модели обобщенной таблицы «объектысвойства». Неполнота (неточность, противоречивость, неопределенность) этой информации влечет необходимость использования для её первичной обработки моделей многозначной логики. Результат такой обработки - нестрогий формальный контекст - должен быть аппроксимирован однозначным контекстом, из которого возможен вывод формальных понятий в рамках прикладной ветви теории решёток, известной как «анализ формальных понятий». Исследуется генезис «ограничений существования свойств», которые влияют на корректность аппроксимации нестрогого формального контекста. Предлагаются модели и метод учета этой дополнительной информации. Формулируются прагматически обоснованные принципы преобразования решетки формальных понятий в формальную онтологию. Приводится модельный пример использования разработанных моделей и методов онтологического анализа данных.
\end{abstract}

Ключевые слова: онтологический анализ данных, формальная онтология, анализ формальных понятий, многозначная векторная логика, ограничения существования свойств.

Цитирование: Анализ неполных данных в задачах построения формальных онтологий / Д.Е. Самойлов, В.А. Семенова, С.В. Смирнов // Онтология проектирования. - 2016. - Т. 6, №3(21). - C. 317-339. - DOI: 10.18287/2223-9537-2016-6-3-317-339.

\section{Введение}

Сложные информационные системы результативны лишь при надежном и согласованном (в разных смыслах) представлении их предмета. Систематизация, разработка и использование соответствующих информационных моделей составляют современное содержание онтологического подхода в вычислительных науках.

В отличие от философии онтология в информатике описывает некоторую ограниченную сферу знания, предметную область (ПрО). Поэтому в силу множественности наук и ПрО, когда каждая из них имеет свою собственную или даже несколько конкурирующих терминологий, здесь в противоположность философии приобретает смысл употребление множественного числа для термина, т.е. говорят об «онтологиях». Более того, различают лингви-

\footnotetext{
* Журнальный вариант докладов на Международной конференции и молодежной школе «Информационные технологии и нанотехнологии» ИТНТ-2015, 2016. Рекомендован к опубликованию Программным комитетом ИТНТ.
} 
стические и формальные онтологии, где последние наследуют парадигму моделей и методов представления знаний, разработанных в искусственном интеллекте $[1,2]$.

Формальная онтология описывает ПрО с помощью стандартизирующей терминологии словаря, а также неоднородных связей между определенными в нём понятиями. Моделирующими примитивами онтологической спецификации обычно служат классы, отношения, функции и аксиомы, что в некотором смысле сближает эти структуры представления знаний и соответствующие компьютерные ресурсы с алгебраическими системами А.И. Мальцева [3].

Сегодня можно указать три основных пути разработки онтологий [4]:

- наиболее используемый связан с прямой формализацией опыта и знаний экспертов, которые с помощью компьютерных языковых средств либо автоформализуют свои представления о ПрО, либо фиксируют их с помощью инженера по знаниям [5];

- при наличии развитой инфраструктуры работы со знаниями актуальные онтологии могут синтезироваться в результате человеко-машинных процедур конкретизации, композиции/декомпозиции апробированных формальных онтологий, их прототипов (паттернов) разного уровня и направленности [6-8];

- третий путь связан с автоматическим «выводом» формальных онтологий из доступных данных. Эти данные рассматриваются как результат измерений свойств объектов исследуемой ПрО и сводятся в стандартизованные таблицы «объекты-свойства» (ТОС) $[9,10]$, анализ которых приводит к выявлению понятийной структуры ПрО. Наиболее результативные методы этого направления опираются на ветвь теории решёток - анализ формальных понятий (АФП) [11-15]. В исходном варианте АФП доставляет лишь «скелет» онтологии [16], т.е. множество формальных понятий и существующее на этом множестве отношение обобщения (is-A). Методика выявления с помощью АФП произвольных семантических отношений между формальными понятиями предложена в [17] на основе интерпретации нетаксономических связей между объектами ПрО как проявления особых свойств-валентностей.

Рассматривая третий путь построения формальных онтологий - онтологический анализ данных (ОАД), - важно подчеркнуть иную, чем в других случаях роль субъекта онтологического инжиниринга («онтолога»). Фактически его основной задачей становится выдвижение гипотез о свойствах объектов исследуемой ПрО и затем априорное комплектование арсенала измерительных процедур (органов чувств, вербальных возможностей экспертов, искусственных сенсоров, приборов, систем и т.д.), с помощью которых интересующая его ПрО будет зондироваться.

В предлагаемой статье внимание сосредоточено на двух аспектах ОАД. Во-первых, это отражение реалий сбора данных о ПрО, приводящее к необходимости использования для представления эмпирической информации моделей многозначной логики, а, во-вторых (и в связи с первым), на моделировании и методе учета в работе априори известных исследователю зависимостей между измеряемыми свойствами.

\section{1 Формирование эмпирических данных о предметной области}

\section{1 Отправные тезисы}

В контраст с общепринятой точкой зрения в анализе данных ОАД исходит из положения, что всякое измерение свойства объекта может дать специальный результат «None», который может свидетельствовать о семантическом несоответствии исследуемого объекта и измерительной процедуры, о нахождении значения измеряемого свойства за порогами чувствительности, вне динамического диапазона средства измерений [18]. 
В классическом АФП подобные эффекты достигаются в результате выполнения когнитивной процедуры, именуемой концептуальным шкалированием [11, 19]. Здесь ТОС именуется многозначным формальным контекстом и описывается кортежем

$$
\left(G^{*}, M, V, I\right) \text {, }
$$

где:

- $G^{*}=\left\{g_{i}\right\}_{i=1, \ldots, r}, r=\left|G^{*}\right| \geq 1$ - набор объектов исследуемой ПрО, попавших в поле зрения онтолога; иначе говоря, это множество объектов обучающей выборки: $G^{*} \subseteq G$, где $G$ - всё мыслимое множество объектов ПрО;

- $M=\left\{m_{j}\right\}_{j=1, \ldots, s}, s=|M| \geq 1$ - множество измеряемых у объектов свойств;

- $V$ - множество значений свойств;

- $\boldsymbol{I}$ - тернарное отношение между $G^{*}, M$ и $V\left(\boldsymbol{I} \subseteq G^{*} \times M \times V\right)$, определённое для всех пар из $G^{*} \times M$.

Неформально концептуальное шкалирование измеряемого свойства представляет собой субъективное конструирование «покрытия» динамического диапазона (домена доставляемых значений) соответствующей процедуры измерения с образованием новых измеряемых свойств у объектов ПрО. Такое покрытие именуется концептуальной шкалой. Пример концептуальной шкалы с дизъюнктным «расщеплением» динамического диапазона процедуры измерения даёт таблица 1. После шкалирования вновь введенные свойства фактически измеряются в бинарной шкале наименований $\{\mathbf{X}$, None $\}$, где $\mathbf{X}$ - лингвистическая константа, собирательно обозначающая любой символ шкалы динамического диапазона измерительной процедуры.

Таблица 1 - Концептуальная шкала для свойства «Рост» объектов-мужчин («х» - Истина, пробел - Ложь)

\begin{tabular}{|l|c|c|c|}
\hline Рост мужчины, см & Низкий & Средний & Высокий \\
\hline$<168$ & $\times$ & & \\
\hline $168-175$ & & $\times$ & $\times$ \\
\hline$>175$ & & & \\
\hline
\end{tabular}

Так или иначе, подобная «None-концепция» позволяет изменить парадигму анализа экспериментального материала о ПрО и, прежде всего, естественным образом преобразовать ТОС в совокупность оценок истинности базовых семантических суждений (БСС) о ПрО вида $b_{i j}=$ «объект $g_{i}$ обладает свойством $m_{j} »$ :

$$
\left\|b_{i j}\right\|=\left\{\begin{array}{l}
\text { Истина, если результат измерения свойства } m_{j} \text { у объекта } g_{i} \text { есть } \mathbf{X} ; \\
\text { Ложь, в противоположном случае. }
\end{array}\right\}
$$

Именно на обработку таких данных ориентирован АФП, в котором используются следующие обозначения и модели [11]:

- $\boldsymbol{K}=\left(G^{*}, M, I\right)$ - формальный контекст, где $G^{*}$ и $M$ имеют уже указывавшийся смысл, $I-$ бинарное соответствие «объекты-свойства», т.е. совокупность оценок вида (1);

- операторы Галуа $\varphi, \omega$ (общая нотация «'») для контекста $\boldsymbol{K}$ :

$\varphi(X)=X^{\prime}=\left\{m_{j} \mid m_{j} \in M, \forall g_{i} \in X:\left(g_{i}, m_{j}\right) \in I\right\}$ - общие свойства объектов, составляющих $X \subseteq G^{*}$, или Галуа-проекция $X$ на $M$;

$\omega(Y)=Y^{\prime}=\left\{g_{i} \mid g_{i} \in G^{*}, \forall m_{j} \in Y:\left(g_{i}, m_{j}\right) \in I\right\}$ - объекты, которые обладают всеми свойствами из $Y \subseteq M$, или Галуа-проекция $Y$ на $G^{*}$;

- $(X, Y)$ - формальное понятие, у которого $X \subseteq G^{*}$ - объем, $Y \subseteq M$ - содержание, причем $X=Y^{\prime}, Y=X^{\prime}$

- $\boldsymbol{B}(\boldsymbol{K})$ - множество формальных понятий контекста $\boldsymbol{K}$; 
- $(\boldsymbol{B}(\boldsymbol{K}), \leq)$ - замкнутая решетка понятий, отражающая бинарное отношение частичного порядка на множестве формальных понятий: $\left(X_{1}, Y_{1}\right) \leq\left(X_{2}, Y_{2}\right)$, если $X_{1} \subseteq X_{2}$, или эквивалентно $Y_{1} \supseteq Y_{2}$, - известное как отношение обобщения понятий, или наследования свойств.

ОАД в полной мере опирается на модели АФП.

\section{2 Обобщенная таблица «объекты-свойства»}

На практике качество исходного эмпирического материала таково, что, по крайней мере, для части БСС оценка истинности расплывчата (например, формируется экспертом на основе опыта или интуиции), и для оценивания таких суждений естественнее употреблять истинностные значения, вводимые многозначнылми логиками. Однако тогда возникает вопрос о модели, объясняющей происхождение и определяющей способ вычисления подобных оценок.

В общем плане ясно, что многозначность оценок истинности БСС вызывает неполнота данных о ПрО (неточность, противоречивость, неопределённость и т.п.), которая не находит отражения в стандартной структуре ТОС. Причины неполноты вызываются реалиями накопления эмпирической информации. Фундаментальными факторами здесь являются:

- выполнение, как правило, многократных независимых измерений свойства $m_{j} \in M$ у объекта $g_{i} \in G^{*}$;

- использование для измерения одного и того же свойства $m_{j}$ нескольких различных процедур (конгруэнтных источников информации);

- дифференциация доверия к различным процедурам измерения.

Поэтому в качестве адекватной модели исходных данных предлагается обобщенная ТОС, описываемая кортежем

$$
\left(G^{*}, M, \operatorname{Se}, \operatorname{Pr}, A\right)
$$

где (см. рисунок 1):

- $S e=\bigcup_{i=1}^{r} S e_{(i)}$ - множество всех выполненных при зондировании ПрО серий измерений, $|S e|=\sum_{i=1}^{r}\left|S e_{(i)}\right|=m$, и $S e_{(i)}=\left\{s e_{(i) k}\right\}_{k=1, \ldots q_{(i)}}, q_{(i)} \geq 1, i=1, \ldots, r$ - множество серий измерений, которым подвергнут объект $g_{i} \in G^{*}$;

- $\operatorname{Pr}=\bigcup_{j=1}^{s} \operatorname{Pr}_{(i)}$ - арсенал всех используемых при зондировании ПрО процедур измерения, $|\operatorname{Pr}|=\sum_{j=1}^{s}\left|\operatorname{Pr}_{(j)}\right|=n$, и $\operatorname{Pr}_{(j)}=\left\{p r_{(j) k}\right\}_{k=1, \ldots p_{(j)}}, p_{(j)} \geq 1, j=1, \ldots, s$ - множество конгруэнтных процедур измерения свойства $m_{j} \in M$, причем всякая процедура $p r_{(j) k}$ характеризуется степенью доверия к её результатам $t_{(j) k}$;

- $A=\left(a_{i j}\right)_{i=1, \ldots, *^{*}} m ; j=1, \ldots, n-$ матрица результатов серий измерений $S e$ свойств $M$ у объектов из выборки $G^{*}$, выполненных с помощью процедур измерения $\operatorname{Pr}$. Элементами этой матрицы могут быть константы $\mathbf{X}$ и None, а также ещё две лингвистические константы. Константа Failure фиксирует отказ, сбой измерительного средства, воздержание при голосовании и т.п., т.е. тот нередко наблюдаемый на практике «результат» работы измерительной процедуры, который собирательно можно квалифицировать как «отказ от выполнения измерения». Константа NM (not measured) указывает, что в действительности в рассматриваемой серии измерений отдельная процедура измерения не использовалась (введение этого формального результата необходимо, помимо прочего, для сохранения двумерного характера обобщённой таблицы «объекты-свойства»). 


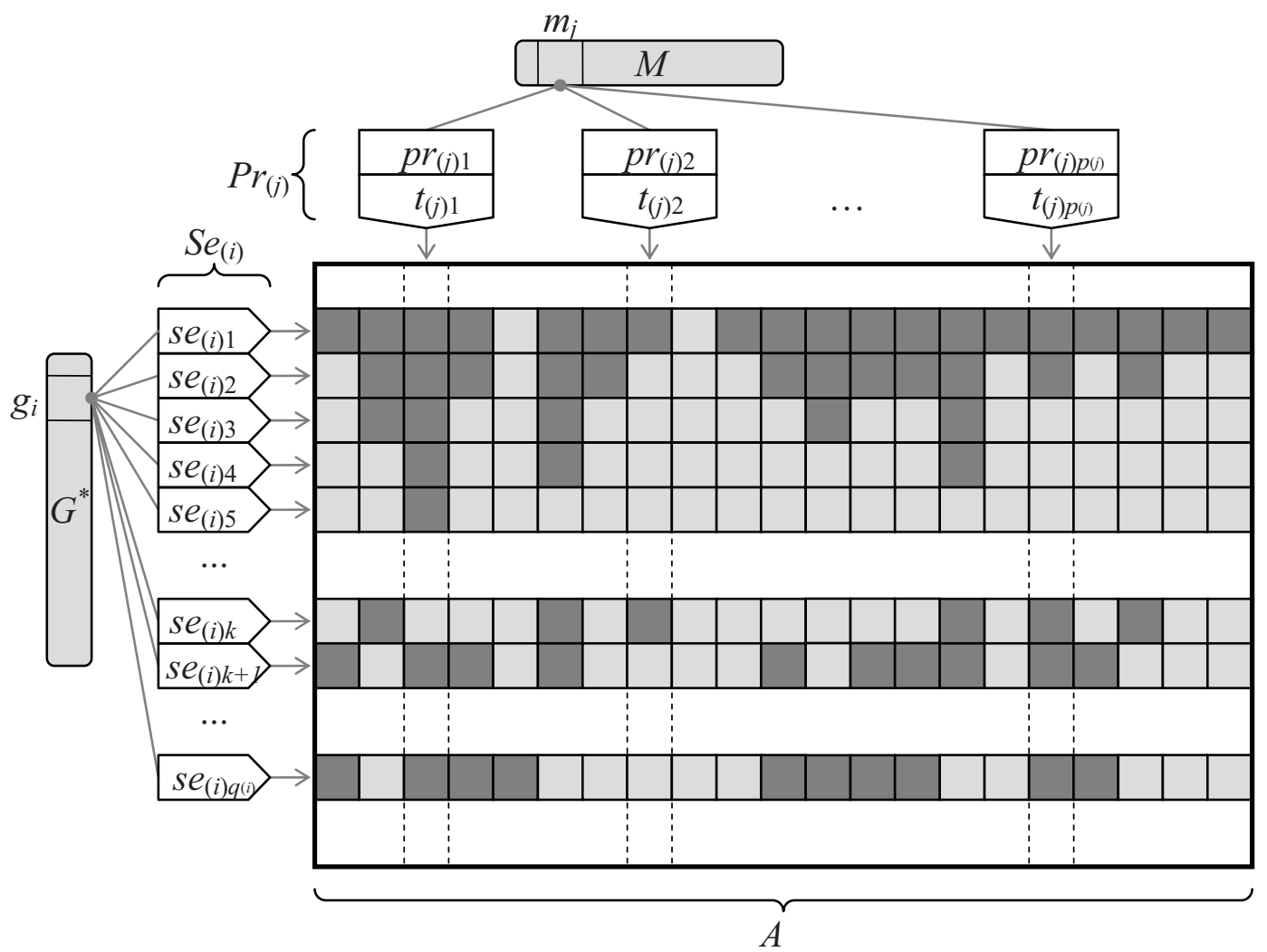

Рисунок 1 - Структура обобщенной таблицы «объекты-свойства» на основе двумерной матрицы (темные ячейки матрицы соответствуют результатам измерения X, None и Failure, a светлые - результату NM)

\section{3 Построение нестрогого формального контекста и задача его однозначной аппроксимации}

Модель (2) позволяет вычислять «мягкие», многозначные оценки истинности БСС о ПрО.

Например, это вычисление можно осуществить на основе нечёткой логики. Однако на сегодня большей мощностью моделирования «человеческого подхода» к подобным оценкам обладают векторные логики, для которых хорошо развит понятийный и аналитический аппарат, обобщающий положения и классической, и нечеткой, и различных многозначных логик [20]. В частности, в логике класса $V^{T F}$ истинность БСС будет оцениваться вектором $\langle$ Истина, Ложь (рисунок 2):

$$
\left\|b_{i j}\right\|=\left\langle b_{i j}^{+}, b_{i j}^{-}\right\rangle ; b_{i j}^{+}, b_{i j}^{-} \in[0,1],
$$

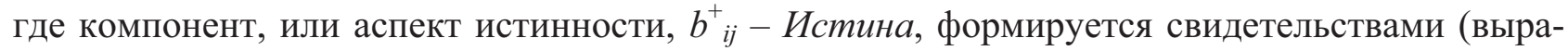
жающими личный опыт и знания онтолога, поступающими к нему от экспертов, находимыми им в литературе, приобретаемыми им в специально поставленных экспериментах и т.п.), подтверждающими БСС, а компонент (аспект) $b_{i j}^{-}$- Ложь, - отрицающими БСС. Ожидание большей адекватности нестрогого [20] соответствия $I$, заданного матрицей векторов (3), реальному процессу осмысления ПрО может быть объяснено тем, что традиционные константы Истина и Ложь, которыми онтолог интуитивно стремится оценить истинность БСС, зачастую определяется для него независимым комплексом свидетельств так, что Ложь не выводима из отсутствия (дефицита) Истины, а Истина - из отсутствия (недостачи) Лжи. 
Этапы построения нестрогого формального контекста $\boldsymbol{K}$ - формального контекста с нестрогим соответствием $I$ - сводятся к следующему.

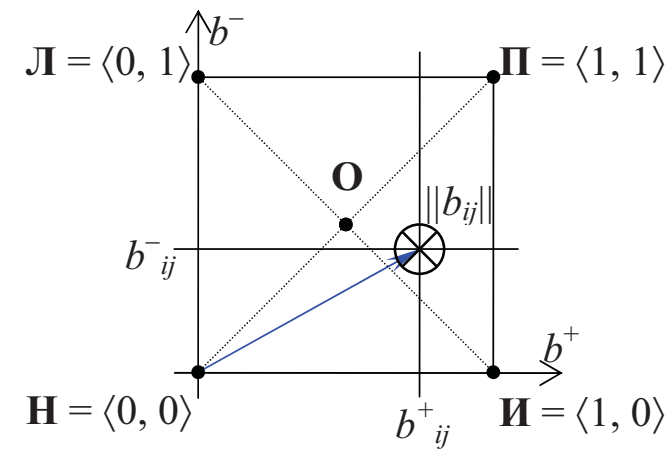

$\bigotimes$ - вектор истинности $\left\|b_{i j}\right\|=\left\langle b_{i j}^{+}, b^{-}{ }_{i j}\right\rangle, b_{i j}^{+}, b_{i j}^{-} \in[0,1]$ базового семантического суждения $b_{i j}$;

- - истинностные константы $V^{T F}$-логики:

Н - «Неопределённость», Л - «Ложь», И - «Истина», П - «Противоречие»;

$\mathbf{O}=\langle 0.5,0.5\rangle-«$ Жжидание [оценки]» (дополнительная константа)

Рисунок 2 - Оценка истинности базового семантического суждения в векторной $V^{T F}$-логике

Первым шагом является переход от первичных данных, структурированных в виде матрицы $A$, к их смысловой интерпретации в виде нестрогого соответствия «серии измерений процедуры измерений» $I$ :

$$
\left\|b_{i j}\right\|_{i=1, \ldots, m ; j=1, \ldots, n}=\left\{\begin{array}{ll}
\mathbf{U}=\langle 1,0\rangle, & \text { если } a_{i j}=\mathbf{X} \\
\boldsymbol{I}=\langle 0,1\rangle, & \text { если } a_{i j}=\text { None } \\
\mathbf{O}=\langle 0.5,0.5\rangle, & \text { если } a_{i j} \in\{\text { Failure, } \mathbf{N M}\} .
\end{array}\right\},
$$

где И, Л и О - истинностные константы $V^{T F}$-логики (см. рисунок 2).

Учёт значений Failure потребовал введения в анализ истинностной константы «Ожидание [оченки]» $\mathbf{O}=\langle 0.5,0.5\rangle$, которая имеет аналоги в прагматически ориентированных многозначных логиках (см., например, дополнительное значение истинности «круглый информационный ноль» Крин в [21]) и равноудалена от известных в $V^{T F}$-логике истинностных констант «Истина» И, «Ложь» $\mathbf{I}$, «Неопределённость» $\mathbf{H}=\langle 0,0\rangle$ и «Противоречие» $\boldsymbol{\Pi}=\langle 1,1\rangle$ (см. рисунок 2). Пожалуй, «Ожидание» - наиболее адекватная оценка БСС и в случае, когда необходимое измерение не проводилось.

Далее нестрогое соответствие $I$ трансформируется в следующем порядке.

Bo-nepвblx, каждая оценка истинности БСС в $I$ совмещается со степенью доверия к источнику данных, которые были положены в основу этой оценки. Используется простейшая модель учета степени доверия к измерительным процедурам в виде скалярных мер $t_{(j)} \in[0,1]$ и элементарная формула пересчета вектора истинности БСС $b_{i j}:\left\|b_{i j}\right\|:=t_{j} \cdot\left\|b_{i j}\right\|$ (фактически это соответствует применению для моделирования дифференциации доверия онтолога к источникам информации вектора истинности $V^{T F}$-логики $\left(t_{j}^{+}, t_{j}^{-}\right)$, где $t_{j}^{+}=t_{j}^{-}=t_{j}$, и объединению свидетельств об истинности каждого БСС и уровня доверия к источнику этого БСС по схеме так называемого «00-композищионного совмещения» на основе композиционного умножения согласно $t$-норме $x \bullet y=x y[20])$.

Bo-вторых, согласно полученному соответствию $I$ определяются оценки истинности БСС по результатам всех серий измерений, выполненных для отдельно взятого объекта каждой измерительной процедурой. Когда для объекта $g_{i} \in G^{*}$ произведена лишь одна серия измерений, т.е. $\left|S e_{(i)}\right|=1$, то требуемая оценка де-факто уже имеется. Иначе оценки истинности во всех строках соответствия $I$, соответствующих элементам серии $S e_{(i)}$, должны быть совмеще- 
Hbl. Другими словами, обработка данных многократного измерения свойства объекта приводит к необходимости интеграции независимых свидетельств истинности отдельного БСС.

Для совмещения истинностных значений в векторной логике имеется несколько допустимых схем. Наиболее адекватной смысловой деятельности онтолога следует признать схему «усиления-усреднения» - частный случай так называемого «11-композищионного совмещения〉 на основе композиционного сложения согласно триангулированной $s$-норме $x \oplus y=\min (1, x+y)[20]$.

Важно отметить, что совмещая оценки, полученные на основе работы отдельно взятой измерительной процедуры применительно к определённому объекту, следует безусловно отбрасывать оценки, которые были помещены в $I$ на основе «не-измерений» $\mathbf{N M}$, т.к. их появление вызвано исключительно формальными потребностями структуризации обобщенной ТОС, поэтому их учёт приведёт к некорректному результату совмещения. Единственным изъятием из этого правила будет случай, когда результат NM был «получен» во всех без исключения сериях измерений $S e_{(i)}$.

Наконец, в-третьих, для каждого свойства $m_{j} \in M$ в формируемом соответствии $I$ «свертывается» информация столбцов, соответствующих конгруэнтным процедурам $\operatorname{Pr}_{(j)}$. И эту интегрирующую операцию для онтолога естественно производить по схеме «усиленияусреднения» при совмещении свидетельств векторной логики.

В результате получаем нестрогий формальный контекст $\left(G^{*}, M, I\right)$, где итоговое нестрогое соответствие $I$ имеет размерность $r \times s$, а его элемент вида (3) можно рассматривать как векторный показатель принадлежности свойства $m_{j}$ априори неизвестному множеству $M_{i}$ свойств объекта $g_{i}$. В терминах $V^{T F}$-логики $M_{i}$ есть нестрогое подмножество универсума $M$.

На сегодня не существует эффективных методов вывода понятийной структуры ПрО непосредственно из «мягких» формальных контекстов. Например, сложный в теоретическом и вычислительном плане метод, использующий оператор замыкания нечёткого множества [22], представляет лишь академический интерес, поскольку генерирует гигантское количество нечетких понятий даже для малоразмерных «разреженных» нечётких контекстов. Поэтому результативные методы основаны на формально возможном разложении логически многозначного соответствия «объекты-свойства» по его однозначным (с элементами инцидентности, определёнными в бинарной шкале наименований \{Истина, Ложь $\})$ альфaсечениям с установлением онтологом порога доверия к исходным данным (см., например $[23,24])$.

Применительно к нестрогому соответствию $I$ имеем [20]:

$$
\begin{gathered}
I=\bigcup_{\alpha^{+}, \alpha^{-} \in[0,1]}\left\langle\alpha^{+}, \alpha^{-}\right\rangle \cdot I^{(\alpha)}, \\
I^{(\alpha)}=\left(\left\|b_{i j}^{(\alpha)}\right\|\right)_{i=1, \ldots, r ; j=1, \ldots, s}, \quad\left\|b_{i j}^{(\alpha)}\right\|=\left\{\begin{array}{ll}
\text { Истина, } & \text { если } b_{i j}^{+} \geq \alpha^{+} \wedge b_{i j}^{-} \leq \alpha^{-} ; \\
\text {Ложь } & \text { в противоположном случае }
\end{array}\right\},
\end{gathered}
$$

где альфа-сечение $I^{(\alpha)}$ - обычное бинарное отношение «объекты-свойства» векторного уровня $\alpha=\left\langle\alpha^{+}, \alpha^{-}\right\rangle$.

На практике при задании онтологом порога доверия $\alpha$ к исходным данным сечение $I^{(\alpha)}$ используют в качестве приближения, так называемой « $\alpha$-аппроксимации» исходного «мягкого» соответствия $I$. Затем к полученной аппроксимации применяются (с различными дополнениями) апробированные методы вывода понятий.

Тем не менее, и этот подход в общем случае оказывается некорректнылм. Например, рост конкретного мужчины в однозначном формальном контексте, полученном путём альфасечения, может быть оценён и как низкий, и как высокий, поскольку приём $\alpha$-аппроксимации не учитывает зависимости между измеряемыми свойствами. 


\section{2 Ограничения существования свойств}

\section{1 Зависимости между свойствами}

Действительно, стандартная процедура альфа-сечения не учитывает какие бы то ни было связи между элементами множеств-носителей нестрогого отношения «объекты-свойства».

Поскольку об объектах ПрО согласно общей парадигме анализа данных нам ничего неизвестно (кроме предположения о возможности выделить объект в ПрО и осуществить измерения его свойств), то рассматриваемая «слепота» процедуры альфа-сечения индифферентна по отношению к обучающей выборке объектов.

Иначе дело обстоит с множеством измеряемых свойств. Однозначная аппроксимация нестрогого соответствия «объекты-свойства» способна «обнажить» противоречия между БСС, которые проявляются для онтолога как априори недопустимые сочетания свойств объектов. В общем случае эти противоречия не могут быть обнаружены в формальном контексте с мягкими оценками истинности БСС.

В концептуальном плане источником проблемы является присущая ОАД когнитивная асимметрия «объектов» и «свойств». Формально «объекты» независимы от онтолога, описывающего ПрО. Напротив «свойства» - результат продуцирования онтологом гипотез о ПрО на основе достигнутого им ранее миропонимания или, точнее говоря, имеющейся у него совокупности априорных знаний. Онтолог является «владельцем» арсенала процедур измерения свойств, обладая достаточно полной информацией об этих инструментах. В частности, он может (и должен) знать об определённых зависимостях между результатами выполнения различных процедур измерения применительно к одному и тому же объекту, т.е. о зависимостях между свойствами объектов.

Общие модели характерных типов связей между свойствами предложены в [25] в форме бинарных отношений «ограничений существования» свойств (ОСС). Пара свойств $m_{j}, m_{k} \in M, j \neq k$ для любого объекта ПрО (и, следовательно, для $\forall g_{i} \in G^{*}$ ) может обладать:

- обусловленностью, если, обладая свойством $m_{j}$, объект $g_{i}$ непреложно обладает свойством

$m_{k}$ (хотя обратное может быть неверно), т.е. $C\left(m_{j}, m_{k}\right) \leftrightarrow \forall g_{i} \in G^{*}: m_{j} \in\left\{g_{i}\right\}^{\prime} \rightarrow m_{k} \in\left\{g_{i}\right\}^{\prime}$, где $\left\{g_{i}\right\}^{\prime}-$ множество свойств объекта $g_{i}$ (см. подраздел 1.1$)$;

- несовместимостью, если, обладая свойством $m_{j}$, объект $g_{i}$ заведомо не обладает свойством $m_{k}$, и наоборот, т.е. $E\left(m_{j}, m_{k}\right) \leftrightarrow \forall g_{i} \in G^{*}: m_{j} \in\left\{g_{i}\right\}^{\prime} \rightarrow m_{k} \notin\left\{g_{i}\right\}^{\prime}$.

При таких зависимостях объект обучающей выборки может обладать лишь нормальным подмножеством множества измеряемых свойств [16, 25]. Подмножество измеряемых свойств $Z \subseteq M$ нормально тогда и только тогда, когда оно замкнуто и совместимо: $Z$ замкнуто, если оно содержит все свойства, обусловленные любым элементом $Z$, т.е. $\forall m_{j} \in Z$ $\left(\exists m_{k} \in M: C\left(m_{j}, m_{k}\right) \rightarrow m_{k} \in Z\right) ; Z$ совместимо, если любые два элемента $Z$ не связаны отношением несовместимости, т.е. $\forall m_{j} \in Z\left(\exists m_{k} \in M: E\left(m_{j}, m_{k}\right) \rightarrow m_{k} \notin Z\right)$.

Свойства симметрии бинарных отношений $E$ и $C$ вполне очевидны как и то, что пара несовместимых свойств не может принадлежать множеству пар свойств с обусловленностью. Более важным в модельном и методическом обеспечении ОАД оказывается условная транзитивность несовместимости относительно обусловленности свойств (рисунок $3 \mathrm{a})$ :

$$
\forall m_{j}, m_{k}, m_{l} \in M, j \neq k, j \neq l, k \neq l: C\left(m_{j}, m_{k}\right) \& E\left(m_{k}, m_{l}\right) \rightarrow E\left(m_{j}, m_{l}\right) .
$$

\section{2 Генезис ограничений существования свойств}

Как уже отмечалось, в общем плане источником ОСС являются априорные знания субъекта онтологического анализа, релевантные исследуемой ПрО. Очевидно, что исследование такого «источника» ограничений весьма проблематично. 


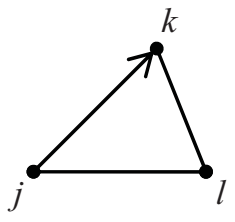

a)

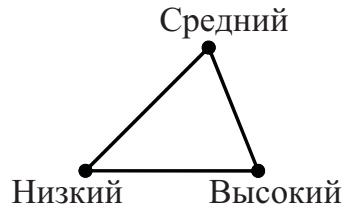

б)

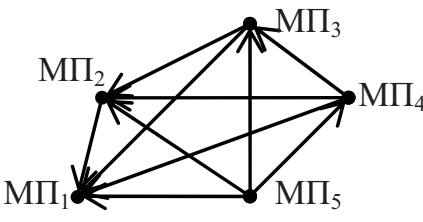

в)

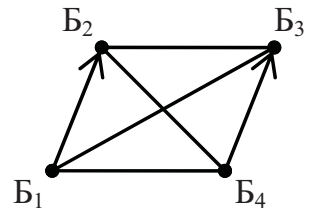

г)

Рисунок 3 - Примеры отношений несовместимости и обусловленности измеряемых свойств:

- - свойство; - несовместимость; $\nearrow$ - обусловленность

Однако в рассматриваемом методическом комплексе анализа данных упоминалась фундаментальная когнитивная процедура - концептуальное шкалирование, - где онтолог фактически вводит качественно новую информацию о ПрО, прямо формирующую ОСС.

Так, таблица 1 является примером номинальной шкальы, или шкалы наименований [9], устанавливающей строго дизъюнктивно покрытие исходного домена значений шкалируемого свойства «Рост мужчины, см»; образцом более тонкого подхода здесь могло бы быть использование нечёткой шкалы наименований. В любом варианте ясно, что вводимым номинальной шкалой свойствам объектов ПрО присуща парная несовместимость E. В этом смысле результат номинального шкалирования согласно таблице 1 иллюстрирует рисунок $3 б$.

Эффекты применения других типов шкал можно показать на примерах из [26], разумеется, не исчерпывающих способы выражения исследователем своего субъективного восприятия ПрО.

Порядковую шкалу целесообразно использовать для сохранения упорядоченности значений в домене значений измеряемого свойства.

Домен свойства «Материальное положение (МП)» может быть описан следующими выражениями (от тяжелого до благополучного) [26]:

1) денег не хватает даже на питание;

2) на питание денег хватает, но не хватает на покупку одежды и обуви;

3) на одежду и обувь денег хватает, но приобретение бытовой техники позволить не можем;

4) денег вполне хватает на приобретение бытовой техники, но не можем купить новый автомобиль;

5) денег хватает на всё, кроме таких дорогих приобретений как квартира, дом;

6) материальных затруднений не испытываем, при необходимости могли бы приобрести квартиру, дом.

Для онтолога естественной шкалой для такого свойства будет таблица 2, которая устанавливает между вновь введёнными свойствами бинарное отношение обусловленности $C$ : $i<k \leftrightarrow C\left(\mathrm{M}_{k}, \mathrm{M \Pi}_{i}\right)-$ см. рисунок 3в.

Таблица 2 - Шкала материального положения

\begin{tabular}{|c|c|c|c|c|c|c|}
\hline$\leq$ & $\mathrm{M \Pi}_{1}$ & $\mathrm{M \Pi}_{2}$ & $\mathrm{M \Pi}_{3}$ & $\mathrm{M \Pi}_{4}$ & $\mathrm{M \Pi}_{5}$ & $\mathrm{M \Pi}_{6}$ \\
\hline 1 & $\times$ & & & & & \\
\hline 2 & $\times$ & $\times$ & & & & \\
\hline 3 & $\times$ & $\times$ & $\times$ & & & \\
\hline 4 & $\times$ & $\times$ & $\times$ & $\times$ & & \\
\hline 5 & $\times$ & $\times$ & $\times$ & $\times$ & $\times$ & \\
\hline 6 & $\times$ & $\times$ & $\times$ & $\times$ & $\times$ & $\times$ \\
\hline
\end{tabular}


В настоящее время весьма популярны шкалы с разделением и порядком, описанные в [26] на примере закрытого вопроса «Чувствуете ли Вы себя в безопасности? (Б)» с вариантами ответа:

1) безусловно да;

2) скорее да;

3) скорее нет;

4) безусловно нет.

Субъективное понимание значений этого домена значений может быть выражено двупорядковой шкалой, доставляемой таблицей 3.

Таблица 3 - Шкала безопасности

\begin{tabular}{|c|c|c|c|c|}
\hline & $5_{1}$ & $5_{2}$ & $Б_{3}$ & $5_{4}$ \\
\hline 1 & $\times$ & $\times$ & & \\
\hline 2 & & $\times$ & $\times$ & \\
\hline 3 & & & $\times$ & $\times$ \\
\hline 4 & & & & \\
\hline
\end{tabular}

В этом примере онтолог субъективно расширяет имеющиеся данные о ПрО, вводя следующие бинарные отношения между вновь вводимыми свойствами (рисунок 3г):

- $E=\left\{\left(Б_{1}, Б_{3}\right),\left(Б_{1}, Б_{4}\right),\left(Б_{2}, Б_{3}\right),\left(Б_{2}, Б_{4}\right)\right\}$;

- $C=\left\{\left(Б_{1}, Б_{2}\right),\left(Б_{4}, Б_{3}\right)\right\}$.

\section{3 Двухуровневая модель ограничений существования свойств}

Различные задачи онтологического инжиниринга побуждают рассматривать характерные группы зависимых свойств.

Например, в [25] при построении онтологий лишь на основе знания свойств объектов ПрО и зависимостей между свойствами отправным пунктом анализа являются взаимообусловленные пары свойств. В [16] при расширении существующих онтологий в центре внимания оказываются нормальные подмножества учитываемых свойств объектов.

В [27] исследовалась проблема вывода формальных понятий из противоречивых данных с учётом зависимости между свойствами, возникающей в результате их номинального шкалирования. Как уже отмечалось, этот наиболее распространенный когнитивный приём порождает во множестве измеряемых свойств объектов группы свойств с парной несовместимостью. Назовем такие группы свойств сопряжёнными (ГСС). Фактически, каждая такая группа в целом представляет некоторое протосвойство, домен значений которого дизъюнктивно расщеплён в результате шкалирования.

Каждая ГСС предопределяет одну из двух возможностей: либо все измеряемые свойства, входящие в группу, у объекта обучающей выборки должны отсутствовать, либо объект обучающей выборки должен обладать каким-либо одним и только одним свойством из данной группы.

Условимся, что всякое измеряемое свойство, не входящее ни в одну из ГСС, понимается как «нерасщепленное» протосвойство, или одиночная ГСС (ОдГСС в противоположность множественным ГСС - МнГСС). Отсюда естественно принять, что ОСС задаются на множестве протосвойств. Тем самым формируется двухуровневая модель ОСС, которую, как будет пояснено в следующем разделе, целесообразно использовать в ОАД.

Укрупнённо эта модель определяется кортежем

$$
\left(M_{P}, E_{P}, C_{P}\right),
$$

где: 
- $M_{P}$ - множество актуальных для онтолога протосвойств объектов ПрО, $1 \leq\left|M_{P}\right| \leq \mid M$, $M_{P}=M_{P 1} \cup M_{P 2}, M_{P 1} \cap M_{P 2}=\varnothing ; M_{P 1}-$ подмножество нерасщеплённых протосвойств, т.е. множество ОдГСС; $M_{P 2}-$ подмножество расщепленных протосвойств, т.е. множество МнГСС: $M_{P 2}=\left\{G r_{1}, \ldots, G r_{M_{P 2} \mid}\right\}$, - причем в каждой МнГСС $G r_{i}$ составляющие ее измеряемые свойства несовместимы, т.е. $\left(\forall m_{j}, m_{k} \in G r_{i}, j \neq k\right) \rightarrow E\left(m_{j}, m_{k}\right)=$ Истина;

- $E_{P}$ - пары несовместимых протосвойств, $E_{P} \subseteq M_{P} \times M_{P},\left|E_{P}\right| \leq C_{\left|M_{P}\right|}^{2}$ (число сочетаний);

- $C_{P}$ - пары обусловленных протосвойств, $C_{P} \subseteq M_{P} \times M_{P},\left|C_{P}\right| \leq A_{\left|M_{P}\right|}^{2}$ (число размещений).

\section{3 Рациональная аппроксимация нестрого формального контекста}

Итак, с целью применения эффективных методов вывода понятийной структуры ПрО из нестрогого формального контекста необходимо обеспечить его корректную $\alpha$-аппроксимацию при наличии ОСС.

Формально эту задачу можно свести к построению одноместного предиката «Альфасечение корректно» с векторным аргументом $\alpha=\left\langle\alpha^{+}, \alpha^{-}\right\rangle, \alpha^{+}, \alpha^{-} \in[0,1]$, где условие подтверждения истинности каждого эмпирического БСС $b_{i j}$

$$
\left\|b_{i j}\right\| \geq \alpha^{+} \wedge\left\|b_{i j}\right\| \leq \alpha^{-}
$$

(или, напротив, необходимой ложности этого БСС) должно быть совмещено с выполнением всех актуальных ОСС. И далее найти область (возможно, она окажется пустой) существования порогов доверия $\alpha$, доставляющих такому предикату значение Истина.

Разумеется, в общем случае построить такой предикат и выявить указанную область весьма непросто; пример построения такого предиката для случая, когда ОСС вызваны номинальным шкалированием некоторой части измеряемых свойств, можно найти в [27]. Однако, даже допуская возможность такого решения, связать онтолога необходимостью выбирать порог только из ограниченной области весьма непрактично. Например, при таком подходе для онтолога в общем случае не будут выполняться интуитивные ожидания на смягчение и ужесточение порога доверия к исходным данным.

Взамен предлагается следующая эвристика: онтолог свободен в выборе порога, а соответствующее порогу и в общем случае недопустимое множество свойств у каждого объекта обучающей выборки последовательно сокращается за счёт локального ужесточения порога доверия для отсечения на каждом шаге свойства, нарушающего ограничения существования. Основным критерием выбора свойства для отсечения служит минимальное ужесточение порога доверия к данным, установленного онтологом.

Предлагаемый эвристический метод получения корректной бинарной аппроксимации нестрогого формального контекста результативен.

Действительно, метод реализуется для каждого объекта обучающей выборки сепарабельно, и на некотором шаге возникнет одно из следующих условий:

- либо множество свойств объекта станет удовлетворять ограничениям существования (заметим, что пустое множество свойств им удовлетворяет, правда тогда объект с таким «набором» свойств приходится квалифицировать как неопознанный);

- либо будет констатировано, что в исходных «мягких» оценках истинности БСС имеется неустранимое противоречие: относительно объекта имеются изначально истинные в классической логике БСС, нарушающие априорные ОСС.

Выполнять предлагаемый метод целесообразно как двухэтапную процедуру, укрупнённо представленную на рисунке 4. 


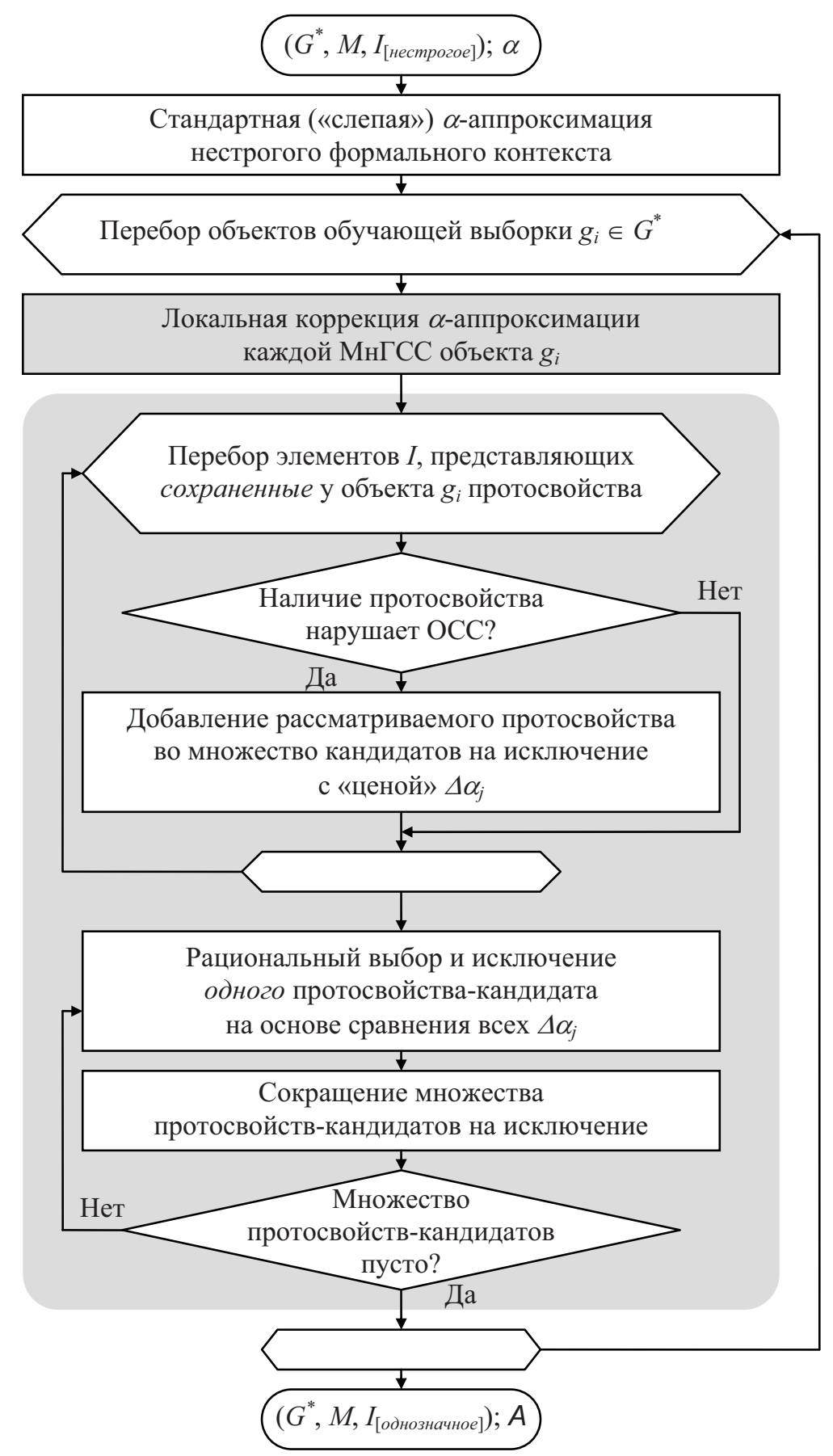

Рисунок 4 - Схема построения рациональной $\alpha$-аппроксимации нестрогого формального контекста $(A$ - множество реально использованных порогов доверия для аппроксимации различных фрагментов контекста)

Сначала предлагаемым способом обрабатываются все МнГСС с принципиальным условием сохранения у каждого объекта обучающей выборки не более одного свойства из каждой группы (соответствующий блок выделен на рисунке 4 тёмной заливкой). Затем результаты первой стадии обрабатываются тем же способом совместно с исходными данными о «нерасщеплённых» протосвойствах (на рисунке 4 этот фрагмент схемы размещён на тёмном фоне).

Основанием для такой организации процедуры коррекции являются два момента: 
- во-первых, упомянутая в подразделе 2.1 «транзитивность несовместимости относительно обусловленности». Конкретно реализации предлагаемого метода в один этап препятствует уникальная ситуация, когда согласно ограничениям существования некоторые из протосвойств являются обусловленными и в то же время «расщеплёнными». Каждое такое сочетание порождает $n$ оригинальных вариантов бинарного отношения обусловленности на множестве измеряемых свойств, где $n$ - количество измеряемых свойств, на которые «расщеплено» обусловленное протосвойство. Поэтому одноэтапная стратегия реализации предложенного метода по необходимости должна предусматривать конструирование и обработку прямого произведения всех вариантов ограничений существования измеряемых свойств с последующим сопоставлением получаемых результатов, что нельзя признать рациональным;

- во-вторых, обособленная локальная коррекция $\alpha$-аппроксимации каждой МнГСС имеет резервы эффективной реализации предлагаемого метода за счёт «однородности» ОСС отсутствие каких-либо сложных схем ограничений кроме парной несовместимости измеряемых свойств (подробности можно найти в [28]).

\section{4 Построение формальной онтологии предметной области}

Заключительным этапом ОАД является трансформация решётки формальных понятий, полученной с помощью базовых алгоритмов АФП, в формальную онтологию, понимаемую здесь как таксономия классов объектов ПрО с заданными на классах нетаксономическими отношениями. При этом таксономию определяет отношение обобщения на множестве формальных понятий, зафиксированной решёткой, а все нетаксономические структурные отношения между понятиями-классами будут описаны, как уже упоминалось во введении, благодаря свойствам-валентностям [17].

Вместе с тем это преобразование становится нетривиальной задачей, если учитывать перспективу генерации на основе формальной онтологии баз данных для хранения денотативных объектных моделей ПрО.

Дело в том, что найденные формальные понятия в зависимости от структуры своих объёмов имеют три разновидности:

- понятия первого вида описывают объекты, действительно существующие в анализируемой ПрО (разумеется, насколько её представляет обучающая выборка). Эти понятия определят классы объектов, которые заслуживают именование сущностные, или фундаментальные;

- понятия второго вида лишь обобщают другие понятия. В программировании такие классы известны как виртуальные;

- третий вид понятий характеризуется совмещением указанных черт понятий первого и второго видов.

Прагматические соображения обычно требуют ограничиться при построении формальной онтологии лишь фундаментальными и виртуальными классами объектов, и в целом опираться на следующие принципы преобразования решётки формальных понятий в таксономию классов:

- все понятия решётки являются кандидатами в фундаментальные классы таксономии;

- в фундаментальный класс превращается минимальное (в терминологии решёток) понятие, содержащее объект в своем объеме;

- свойство сохраняется в максимальном понятии, содержащем это свойство в своём содержании; 
- наибольшее понятие решётки (его признак - мощность объёма равна мощности множества объектов обучающей выборки) заведомо исключается из таксономии, если его содержание пусто;

- наименьшее понятие решётки (его признак - мощность содержания равна мощности множества свойств) заведомо исключается из таксономии, если его объём пуст;

- анализ понятий-кандидатов в фундаментальные классы ведётся по ярусам ближайших надпонятий («родителей»), начиная с наименьшего понятия.

Метод, обладающий описанным качеством и результативностью, подробно описан в [29].

\section{5 Пример}

Элементы представленного подхода использовались в различных случаях, связанных с необходимостью структурированного описания ПрО в задачах поддержки принятия решений, в частности:

- при проектировании цветового оформления элементов пользовательского интерфейса инструментальных программных комплексов с целью улучшения удобства использования;

- при проектировании базирующихся на онтологиях субъективно-ориентированных интерфейсов к реляционным базам данных;

- при выделении целевых групп населения при формировании региональных государственных программ социальной поддержки;

- для описания типов внешности групп людей на основе экспертизы согласно габитоскопии - теории идентификации внешности людей, разработанной в криминалистике;

- при изучении товарных рынков.

Эти применения объединял вполне определённо выраженный характер исходных данных. Мнение о свойствах объектов столь разных ПрО выражали группы экспертов, пользователей, граждан, и соответствующие данные как дополняли друг друга, так и нередко противоречили один другому. Данных из одного источника могло оказаться значительно больше, чем из конкурирующего, а доверие заказчика исследования к различным источникам часто было не одинаковым. Для консолидации такой информации и были использованы модели и методы, представленные в статье.

Как правило, упомянутые примеры громоздки, и за редким исключением (см., например, $[27,30])$ остаются в малодоступных отчетах о НИР. Здесь для иллюстрации ограничимся искусственным модельным примером.

На рисунке 5 представлена обобщённая ТОС, где имитированы данные измерений свойств $M=\{\mathrm{a}, \sigma, \ldots, \phi\}$ у объектов ПрО, из которой в обучающую выборку попали объекты, условно поименованные прописными буквами, а именно: $G^{*}=\{\mathrm{A}$, Б,.., К $\}$. Повторяющиеся имена объекта в первом столбце ТОС идентифицируют различные серии измерений, выполненные для данного объекта, а повторяющиеся имена измеряемого свойства в первой строке TOC - конгруэнтные процедуры, измеряющие это свойство. Во второй строке ТОС в процентах зафиксирована степень доверия к процедурам измерения. Незаполненные ячейки результатов работы процедур измерения в различных сериях означают, что в соответствующей серии измерение не производилось (ср. с рисунком 1).

Рисунок 6 демонстрирует эту таблицу не только с упорядоченными сериями измерений для объектов, но, прежде всего, с уточнением незаполненных элементов соответствия: одни из них получили значение $\mathbf{N M}$ и будут учитываться при построении нестрогого формального контекста, согласно формуле (4), другие при построении нестрогого формального контекста использованы не будут (см. подраздел 1.3). 


\begin{tabular}{|c|c|c|c|c|c|c|c|c|c|c|c|c|c|c|c|c|}
\hline & a & a & 6 & B & $B$ & $B$ & r & д & e & ë & * & * & 3 & n & й & K \\
\hline & 70 & 50 & 75 & 25 & 80 & 60 & 75 & 90 & 80 & 85 & 85 & 95 & 60 & 95 & 85 & 70 \\
\hline $\mathrm{A}$ & $\mathrm{X}$ & $X$ & None & Failure & & None & Failure & None & None & & & Failure & $X$ & None & $\mathrm{X}$ & None \\
\hline B & & X & $x$ & None & $\mathrm{X}$ & & Failure & & None & None & $x$ & $x$ & & Failure & $x$ & None \\
\hline C & $x$ & None & $\mathrm{X}$ & $x$ & & $\mathrm{X}$ & None & None & None & None & None & None & & & 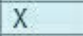 & $x$ \\
\hline D & $x$ & None & $\mathrm{X}$ & & & & $\mathrm{X}$ & $\mathrm{x}$ & None & & $\mathrm{X}$ & $\mathrm{X}$ & $\mathrm{x}$ & $\mathrm{X}$ & None & $\mathrm{X}$ \\
\hline D & $X$ & & $\mathrm{X}$ & None & & $\mathrm{X}$ & X & X & None & None & None & & None & & None & $\mathrm{X}$ \\
\hline D & $x$ & $\mathrm{X}$ & $X$ & None & $\mathrm{X}$ & & $X$ & $x$ & None & None & & & $x$ & & None & $x$ \\
\hline$E$ & $X$ & & None & & & & None & $\mathrm{X}$ & & None & None & Failure & & None & X & 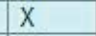 \\
\hline$E$ & & None & & Failure & & $\mathrm{X}$ & Failure & & Failure & $X$ & & $X$ & & Failure & None & None \\
\hline $\mathrm{F}$ & & & X & & None & X & Failure & & $x$ & & $x$ & & Failure & $x$ & & \\
\hline$E$ & & $\mathrm{X}$ & & $\mathrm{X}$ & None & & None & $\mathrm{X}$ & $x$ & None & None & & & X & $x$ & None \\
\hline C & & & & $x$ & Failure & & & $x$ & None & Failure & & Failure & None & None & & \\
\hline $\mathrm{G}$ & & $x$ & Failure & & $\mathrm{X}$ & X & & $x$ & & None & X & & & X & $x$ & \\
\hline $\mathrm{H}$ & $X$ & & & None & & None & & $\mathrm{X}$ & & & & Failure & $X$ & & & \\
\hline 1 & X & & None & & X & X & $X$ & & X & None & & X & None & $\mathrm{X}$ & None & \\
\hline $\mathrm{J}$ & & & None & & None & & & None & $x$ & $x$ & $\mathrm{X}$ & None & $\mathrm{X}$ & $\mathrm{x}$ & $\mathrm{x}$ & $x$ \\
\hline $\mathrm{K}$ & None & None & & None & None & $X$ & None & $X$ & $x$ & None & $x$ & & $X$ & $x$ & & $x$ \\
\hline $\mathrm{L}$ & $x$ & X & None & $x$ & $x$ & $X$ & None & None & None & None & None & None & $x$ & $x$ & $x$ & \\
\hline L & $x$ & None & $\mathrm{X}$ & None & $\mathrm{X}$ & & & None & & & X & None & X & $\mathrm{X}$ & & None \\
\hline M & None & None & None & & None & $\mathrm{X}$ & & 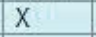 & & Failure & & Failure & & $\mathrm{x}$ & & \\
\hline $\mathrm{N}$ & $x$ & & & $x$ & $\mathrm{X}$ & $\mathrm{X}$ & None & & None & $x$ & None & None & Failure & $\mathrm{x}$ & None & \\
\hline 0 & None & & None & None & None & $\mathrm{X}$ & & & None & $x$ & & & Failure & $\mathrm{X}$ & $x$ & None \\
\hline $\mathrm{P}$ & X & None & & & & None & $x$ & & None & $x$ & $X$ & & & $\mathrm{X}$ & None & None \\
\hline$Q$ & $x$ & $\mathrm{X}$ & None & $\mathrm{X}$ & $x$ & $\mathrm{X}$ & Failure & & & $x$ & None & $x$ & None & $x$ & & $\mathrm{X}$ \\
\hline $\mathrm{R}$ & & & & $X$ & $x$ & $\mathrm{X}$ & $X$ & & None & $X$ & & None & & & & \\
\hline $\mathrm{R}$ & None & None & $\mathrm{X}$ & & $\mathrm{X}$ & None & None & & Failure & & & None & $\mathrm{X}$ & & & \\
\hline$R$ & None & X & & Failure & X & & & None & $x$ & & X & $x$ & & None & None & \\
\hline B & & & $x$ & $\mathrm{x}$ & None & $x$ & & None & & None & $x$ & $x$ & & & $x$ & None \\
\hline $\mathrm{N}$ & & $\mathrm{x}$ & & $x$ & $x$ & X & & & & $x$ & None & $x$ & & $\mathrm{X}$ & None & $x$ \\
\hline$E$ & $x$ & & $\mathrm{X}$ & Failure & $X$ & $\mathrm{X}$ & X & & X & Failure & X & & Failure & $\mathrm{X}$ & None & None \\
\hline $\mathrm{H}$ & None & None & None & & Failure & & & & $\mathrm{X}$ & & X & None & $X$ & & None & \\
\hline$S$ & & None & $x$ & $x$ & $x$ & None & $x$ & & $\mathrm{X}$ & & $x$ & None & & None & None & $x$ \\
\hline D & None & None & X & X & $x$ & $\mathrm{X}$ & None & None & Failure & & None & Failure & None & $x$ & & $X$ \\
\hline$B$ & $x$ & $\mathrm{x}$ & None & None & $x$ & $\mathrm{X}$ & & None & & $x$ & $x$ & None & $x$ & & $x$ & $x$ \\
\hline D & None & $x$ & $\mathrm{X}$ & $x$ & $X$ & 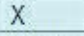 & & & None & $x$ & None & & & & None & $X$ \\
\hline $\mathrm{S}$ & None & & Failure & None & $\mathrm{X}$ & None & & $\mathrm{x}$ & & & None & $x$ & None & & & \\
\hline$B$ & $x$ & None & None & None & None & 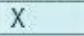 & $x$ & None & & $x$ & $X$ & None & & & None & $x$ \\
\hline D & & $\mathrm{X}$ & Failure & Failure & & & Failure & None & & & None & X & None & & None & $X$ \\
\hline D & & & Failure & & & & $X$ & None & Failure & & None & $\mathrm{X}$ & & None & & $x$ \\
\hline$M$ & & X & $\mathrm{X}$ & $x$ & & None & None & $\mathrm{X}$ & $X$ & $\mathrm{X}$ & None & None & & $\mathrm{x}$ & & \\
\hline $\mathrm{H}$ & $x$ & None & $\mathrm{X}$ & & None & None & $X$ & & None & $x$ & $X$ & $X$ & & & None & \\
\hline$S$ & None & $x$ & None & None & & None & $X$ & & None & & & & Failure & & & None \\
\hline C & None & & $\mathrm{X}$ & $\mathrm{X}$ & Failure & & $X$ & & & $x$ & & & Failure & None & None & \\
\hline$S$ & $x$ & $\mathrm{X}$ & & & $x$ & $x$ & & None & & & & None & None & None & $x$ & \\
\hline
\end{tabular}

Рисунок 5 - Обобщенная таблица «объекты-свойства»

Рисунок 7 показывает табличную схему ОСС, априори фиксируемую онтологом. Первая строка схемы содержит идентификаторы измеряемых свойств и «расщеплённых» протосвойств. В первом столбце схемы перечисляются идентификаторы «связок» свойств, префиксы которых указывают вид отношения между свойствами: ОдГСС; МнГСС; ПССВ - пара сопряжённых свойств-валентностей; ПСО - пара свойств с обусловленностью; ПСН - пара свойств с несовместимостью. Соответствие «связки-свойства» представлено в схеме горизонтальными «лентами» и знаками инцидентности «Х» и «О». Последний знак указывает обусловленное свойство в ПСО и свойство-ковалентность в ПССВ (т.е. схема ограничивает описание нетаксономических семантических связей между понятиями в выводимых онтологиях бинарными асимметричными отношениями [15]).

Нестрогий формальный контекст, полученный из рассматриваемой обобщённой ТОС приведён на рисунке 8. Его стандартную, «слепую» к ОСС $\alpha$-аппроксимацию при пороге доверия $\langle 0,55 ; 0,5\rangle$ представляет рисунок 9, где сохранённые элементы соответствия «объектысвойства» следует понимать как свидетельства об истинности соответствующих БСС; иные БСС полагаются ложными. 


\begin{tabular}{|c|c|c|c|c|c|c|c|c|c|c|c|c|c|c|c|c|}
\hline & $a$ & a & 6 & B & B & B & r & A & e & ë & ж & ж & 3 & n & й & k \\
\hline & 70 & 50 & 75 & 25 & 80 & 60 & 75 & 90 & 80 & 85 & 85 & 95 & 60 & 95 & 85 & 70 \\
\hline A & $X$ & X & None & Failure & NM & None & Failure & None & None & NM & NM & Failure & X & None & X & None \\
\hline B & & $x$ & $X$ & None & $x$ & & Failure & & None & None & $x$ & $\mathrm{X}$ & & Failure & $\mathrm{X}$ & None \\
\hline B & & & $X$ & $\mathrm{X}$ & None & $X$ & & None & & None & $x$ & $x$ & & & $X$ & None \\
\hline B & $X$ & X & None & None & X & $\mathrm{X}$ & & None & & $\mathrm{x}$ & X & None & $\mathrm{X}$ & & $x$ & $x$ \\
\hline B & X & None & None & None & None & X & $X$ & None & & $x$ & X & None & & & None & $x$ \\
\hline C & $x$ & None & $x$ & $x$ & & $X$ & None & None & None & None & None & None & & & $X$ & $x$ \\
\hline C & & & & $x$ & Failure & & & $\mathrm{X}$ & None & Failure & & Failure & None & None & & \\
\hline C & None & & X & $x$ & Failure & & $x$ & & & $X$ & & & Failure & None & None & \\
\hline D & $X$ & None & $X$ & & & & $X$ & $\mathrm{X}$ & None & & X & $X$ & $\mathrm{X}$ & X & None & $\mathrm{X}$ \\
\hline D & $X$ & & $X$ & None & & $\mathrm{X}$ & X & $x$ & None & None & None & & None & & None & $x$ \\
\hline D & X & X & X & None & X & & $X$ & $x$ & None & None & & & $x$ & & None & $x$ \\
\hline D & None & None & $X$ & $x$ & X & X & None & None & Failure & & None & Failure & None & X & & $\mathrm{X}$ \\
\hline D & None & $X$ & $X$ & $x$ & $x$ & X & & & None & $x$ & None & & & & None & $x$ \\
\hline D & & $x$ & Failure & Failure & & & Failure & None & & & None & $x$ & None & & None & $x$ \\
\hline D & & & Failure & & & & $X$ & None & Failure & & None & $X$ & & None & & $x$ \\
\hline$E$ & X & & None & & & & None & $X$ & & None & None & Failure & & None & $x$ & $x$ \\
\hline$E$ & & None & & Failure & & X & Failure & & Failure & $x$ & & $x$ & & Failure & None & None \\
\hline$E$ & & $X$ & & $X$ & None & & None & $x$ & $X$ & None & None & & & $x$ & $x$ & None \\
\hline$E$ & $X$ & & $\mathrm{X}$ & Failure & $x$ & $X$ & $X$ & & $\mathrm{X}$ & Failure & $x$ & & Failure & $x$ & None & None \\
\hline$F$ & NM & NM & $X$ & NM & None & $x$ & Failure & NM & $x$ & NM & 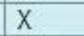 & NM & Failure & $\mathrm{X}$ & NM & NM \\
\hline $\mathrm{G}$ & NM & X & Failure & NM & $\mathrm{X}$ & X & NM & $\mathrm{X}$ & NM & None & X & NM & NM & $\mathrm{X}$ & $x$ & NM \\
\hline $\mathrm{H}$ & $x$ & & & None & & None & & $\mathrm{X}$ & & & & Failure & $X$ & NM & & NM \\
\hline $\mathrm{H}$ & None & None & None & & Failure & & & & $\mathrm{X}$ & & $X$ & None & $\mathrm{x}$ & NM & None & NM \\
\hline $\mathrm{H}$ & X & None & X & & None & None & $X$ & & None & $x$ & $X$ & 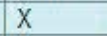 & & NM & None & NM \\
\hline 1 & $X$ & NM & None & NM & $x$ & $X$ & $x$ & NM & $x$ & None & NM & $x$ & None & X & None & NM \\
\hline $\mathrm{J}$ & NM & NM & None & NM & None & NM & NM & None & $\mathrm{X}$ & $\mathrm{X}$ & X & None & $X$ & $X$ & $x$ & $\mathrm{X}$ \\
\hline $\mathrm{K}$ & None & None & NM & None & None & $x$ & None & 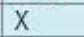 & $x$ & None & $x$ & NM & $X$ & $x$ & NM & $X$ \\
\hline L & X & X & None & $\mathrm{X}$ & X & $x$ & None & None & None & None & None & None & X & X & $x$ & \\
\hline L & 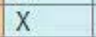 & None & $X$ & None & X & & & None & & & X & None & $x$ & $\mathrm{X}$ & & None \\
\hline$M$ & None & None & None & & None & $X$ & & $x$ & & Failure & & Failure & NM & $x$ & NM & NM \\
\hline$M$ & & $X$ & $X$ & $\mathrm{X}$ & & None & None & X & $\mathrm{X}$ & $x$ & None & None & NM & $X$ & NM & NM \\
\hline $\mathrm{N}$ & X & & NM & $x$ & X & $X$ & None & NM & None & $x$ & None & None & Failure & $X$ & None & \\
\hline $\mathrm{N}$ & & X & NM & $x$ & $x$ & $X$ & & NM & & $x$ & None & X & & X & None & $x$ \\
\hline 0 & None & NM & None & None & None & $x$ & NM & NM & None & $X$ & NM & NM & Failure & $x$ & $X$ & None \\
\hline $\mathrm{P}$ & X & None & NM & NM & NM & None & X & NM & None & $\mathrm{X}$ & $\mathrm{X}$ & NM & NM & $x$ & None & None \\
\hline $\mathrm{Q}$ & X & X & None & $x$ & $x$ & $x$ & Failure & NM & NM & $x$ & None & $x$ & None & X & NM & $x$ \\
\hline $\mathrm{R}$ & & & & $x$ & $x$ & X & $X$ & & None & $x$ & & None & & & & NM \\
\hline$R$ & None & None & $x$ & & $x$ & None & None & & Failure & & & None & $x$ & & & NM \\
\hline $\mathrm{R}$ & None & X & & Failure & $X$ & & & None & $x$ & & $X$ & $X$ & & None & None & NM \\
\hline$S$ & & None & X & $\mathrm{X}$ & X & None & X & & $\mathrm{X}$ & NM & X & None & & None & None & $\mathrm{X}$ \\
\hline$S$ & None & & Failure & None & X & None & & $\mathrm{X}$ & & NM & None & $X$ & None & & & \\
\hline$S$ & None & $x$ & None & None & & None & $X$ & & None & NM & & & Failure & & & None \\
\hline$S$ & $X$ & X & & & $\mathrm{X}$ & $X$ & & None & & NM & & None & None & None & $X$ & \\
\hline
\end{tabular}

Рисунок 6 - Уточнённая обобщенная таблица «объекты-свойства»

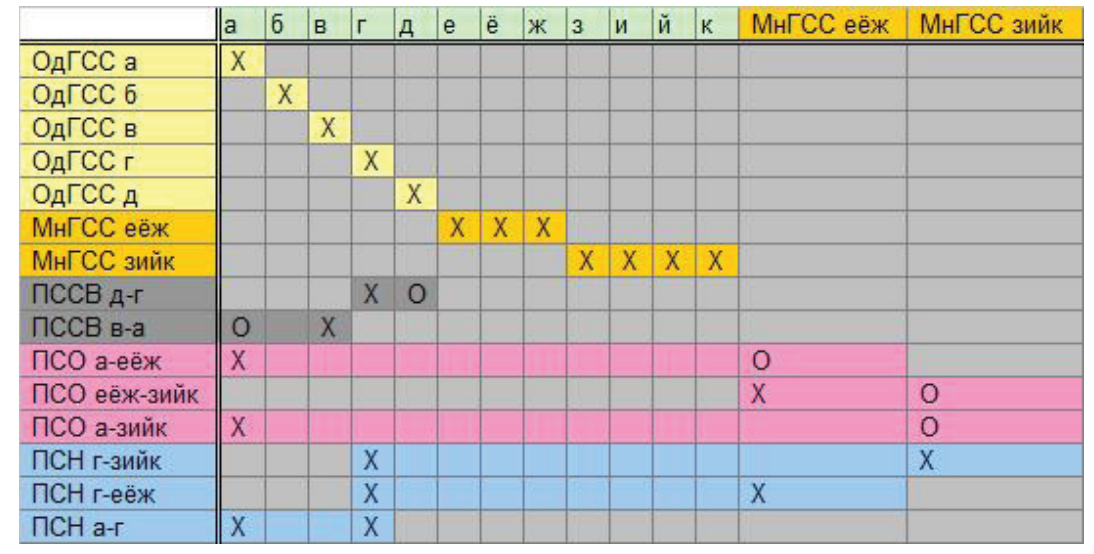

Рисунок 7 - Табличная схема ограничений существования свойств 


\begin{tabular}{|c|c|c|c|c|c|c|c|c|c|c|c|c|}
\hline & $a$ & 6 & $B$ & r & A & e & $\ddot{\mathrm{e}}$ & * & 3 & n & й & k \\
\hline A & $\langle 0,6 ; 0\rangle$ & $\langle 0 ; 0,75\rangle$ & $\langle 0,17 ; 0,37\rangle$ & $\langle 0,38 ; 0,38\rangle$ & $\langle 0 ; 0,9\rangle$ & $\langle 0 ; 0,8\rangle$ & $\langle 0,43 ; 0,43\rangle$ & $\langle 0,45 ; 0,45\rangle$ & $\langle 0,6 ; 0\rangle$ & $\langle 0 ; 0,95\rangle$ & $\langle 0,85 ; 0\rangle$ & $\langle 0 ; 0,7\rangle$ \\
\hline$B$ & $\langle 0,51 ; 0,09\rangle$ & $\langle 0,38 ; 0,38\rangle$ & $\langle 0,35 ; 0,2\rangle$ & $\langle 0,56 ; 0,19\rangle$ & $\langle 0 ; 0,9\rangle$ & $\langle 0 ; 0,8\rangle$ & $\langle 0,43 ; 0,43\rangle$ & $\langle 0,66 ; 0,23\rangle$ & $\langle 0,6 ; 0\rangle$ & $\langle 0,47 ; 0,47\rangle$ & $\langle 0,64 ; 0,21\rangle$ & $\langle 0,35 ; 0,35\rangle$ \\
\hline $\mathrm{c}$ & $\langle 0,17 ; 0,43\rangle$ & $\langle 0,75 ; 0\rangle$ & $\langle 0,42 ; 0,13\rangle$ & $\langle 0,38 ; 0,38\rangle$ & $\langle 0,45 ; 0,45\rangle$ & $\langle 0 ; 0,8\rangle$ & $\langle 0,43 ; 0,43\rangle$ & $\langle 0,12 ; 0,78\rangle$ & $\langle 0,15 ; 0,45\rangle$ & $\langle 0 ; 0,95\rangle$ & $\langle 0,43 ; 0.43\rangle$ & $\langle 0,7 ; 0\rangle$ \\
\hline D & $\langle 0,36 ; 0,24\rangle$ & $\langle 0,64 ; 0,11\rangle$ & $\langle 0,51 ; 0,04\rangle$ & $\langle 0,56 ; 0,19\rangle$ & $\langle 0,45 ; 0,45\rangle$ & $\langle 0,13 ; 0,67\rangle$ & $\langle 0,28 ; 0,57\rangle$ & $\langle 0,48 ; 0,41\rangle$ & $\langle 0,24 ; 0,36\rangle$ & $\langle 0,63 ; 0,32\rangle$ & $\langle 0 ; 0,85\rangle$ & $\langle 0,7 ; 0\rangle$ \\
\hline $\mathrm{E}$ & $\langle 0,47 ; 0,12\rangle$ & $\langle 0,38 ; 0,38\rangle$ & $\langle 0,39 ; 0,16\rangle$ & $\langle 0,28 ; 0,47\rangle$ & $\langle 0,9 ; 0\rangle$ & $\langle 0,67 ; 0,13\rangle$ & $\langle 0,32 ; 0,53\rangle$ & $\langle 0,5 ; 0,4\rangle$ & $\langle 0,3 ; 0,3\rangle$ & $\langle 0,59 ; 0,35\rangle$ & $\langle 0,43 ; 0,43\rangle$ & $\langle 0,17 ; 0,52\rangle$ \\
\hline $\mathrm{F}$ & $\langle 0,3 ; 0,3\rangle$ & $\langle 0,75 ; 0\rangle$ & $\langle 0,24 ; 0,31\rangle$ & $\langle 0,38 ; 0,38\rangle$ & $\langle 0,45 ; 0,45\rangle$ & $\langle 0,8 ; 0\rangle$ & $\langle 0,43 ; 0,43\rangle$ & $\langle 0,66 ; 0,23\rangle$ & $\langle 0,3 ; 0,3\rangle$ & $\langle 0,95 ; 0\rangle$ & $\langle 0,43 ; 0,43\rangle$ & $\langle 0,35 ; 0,35\rangle$ \\
\hline G & $\langle 0,43 ; 0,17\rangle$ & $\langle 0,38 ; 0,38\rangle$ & $\langle 0,51 ; 0,04\rangle$ & $\langle 0,38 ; 0,38\rangle$ & $\langle 0,9 ; 0\rangle$ & $\langle 0,4 ; 0,4\rangle$ & $\langle 0 ; 0,85\rangle$ & $\langle 0,66 ; 0,23\rangle$ & $\langle 0,3 ; 0,3\rangle$ & $\langle 0,95 ; 0\rangle$ & $\langle 0,85 ; 0\rangle$ & $\langle 0,35 ; 0,35\rangle$ \\
\hline $\mathrm{H}$ & $\langle 0,23 ; 0,37\rangle$ & $\langle 0,38 ; 0,38\rangle$ & $\langle 0,07 ; 0,48\rangle$ & $\langle 0,75 ; 0\rangle$ & $\langle 0,9 ; 0\rangle$ & $\langle 0,4 ; 0,4\rangle$ & $\langle 0,85 ; 0\rangle$ & $\langle 0,66 ; 0,23\rangle$ & $\langle 0,6 ; 0\rangle$ & $\langle 0,47 ; 0,47\rangle$ & $\langle 0 ; 0,85\rangle$ & $\langle 0,35 ; 0,35\rangle$ \\
\hline 1 & $\langle 0,47 ; 0,12\rangle$ & $\langle 0 ; 0,75\rangle$ & $\langle 0,51 ; 0,04\rangle$ & $\langle 0,75 ; 0\rangle$ & $\langle 0,45 ; 0,45\rangle$ & $\langle 0,8 ; 0\rangle$ & $\langle 0 ; 0,85\rangle$ & $\langle 0,69 ; 0,22\rangle$ & $\langle 0 ; 0,6\rangle$ & $\langle 0,95 ; 0\rangle$ & $\langle 0 ; 0,85\rangle$ & $\langle 0,35 ; 0,35\rangle$ \\
\hline $\mathrm{J}$ & $\langle 0,3 ; 0,3\rangle$ & $\langle 0 ; 0,75\rangle$ & $\langle 0,14 ; 0,41\rangle$ & $\langle 0,38 ; 0,38\rangle$ & $\langle 0 ; 0,9\rangle$ & $\langle 0,8 ; 0\rangle$ & $\langle 0,85 ; 0\rangle$ & $\langle 0,43 ; 0,47\rangle$ & $\langle 0,6 ; 0\rangle$ & $\langle 0,95 ; 0\rangle$ & $\langle 0,85 ; 0\rangle$ & $\langle 0,7 ; 0\rangle$ \\
\hline K & $\langle 0 ; 0,6\rangle$ & $\langle 0,38 ; 0,38\rangle$ & $\langle 0,2 ; 0,35\rangle$ & $\langle 0 ; 0,75\rangle$ & $\langle 0,9 ; 0\rangle$ & $\langle 0,8 ; 0\rangle$ & $\langle 0 ; 0,85\rangle$ & $\langle 0,66 ; 0,23\rangle$ & $\langle 0,6 ; 0\rangle$ & $\langle 0,95 ; 0\rangle$ & $\langle 0,43 ; 0,43\rangle$ & $\langle 0,7 ; 0\rangle$ \\
\hline $\mathrm{L}$ & $\langle 0,47 ; 0,12\rangle$ & $\langle 0,38 ; 0,38\rangle$ & $\langle 0,51 ; 0,04\rangle$ & $\langle 0 ; 0,75\rangle$ & $\langle 0 ; 0,9\rangle$ & $\langle 0 ; 0,8\rangle$ & $\langle 0 ; 0,85\rangle$ & $\langle 0,22 ; 0,69\rangle$ & $\langle 0,6 ; 0\rangle$ & $\langle 0,95 ; 0\rangle$ & $\langle 0,85 ; 0\rangle$ & $\langle 0 ; 0,7\rangle$ \\
\hline M & $\langle 0,12 ; 0,47\rangle$ & $\langle 0,38 ; 0,38\rangle$ & $\langle 0,18 ; 0,37\rangle$ & $\langle 0 ; 0,75\rangle$ & $\langle 0,9 ; 0\rangle$ & $\langle 0,8 ; 0\rangle$ & $\langle 0,64 ; 0,22\rangle$ & $\langle 0,12 ; 0,78\rangle$ & $\langle 0,3 ; 0,3\rangle$ & $\langle 0,95 ; 0\rangle$ & $\langle 0,43 ; 0,43\rangle$ & $\langle 0,35 ; 0,35\rangle$ \\
\hline $\mathrm{N}$ & $\langle 0,6 ; 0\rangle$ & $\langle 0,38 ; 0,38\rangle$ & $\langle 0,55 ; 0\rangle$ & $\langle 0 ; 0,75\rangle$ & $\langle 0,45 ; 0,45\rangle$ & $\langle 0 ; 0,8\rangle$ & $\langle 0,85 ; 0\rangle$ & $\langle 0,23 ; 0,66\rangle$ & $\langle 0,3 ; 0,3\rangle$ & $\langle 0,95 ; 0\rangle$ & $\langle 0 ; 0,85\rangle$ & $\langle 0,7 ; 0\rangle$ \\
\hline 0 & $\langle 0,12 ; 0,47\rangle$ & $\langle 0 ; 0,75\rangle$ & $\langle 0,2 ; 0,35\rangle$ & $\langle 0,38 ; 0,38\rangle$ & $\langle 0,45 ; 0,45\rangle$ & $\langle 0 ; 0,8\rangle$ & $\langle 0,85 ; 0\rangle$ & $\langle 0,45 ; 0,45\rangle$ & $\langle 0,3 ; 0,3\rangle$ & $\langle 0,95 ; 0\rangle$ & $\langle 0,85 ; 0\rangle$ & $\langle 0 ; 0,7\rangle$ \\
\hline $\mathrm{P}$ & $\langle 0,35 ; 0,25\rangle$ & $\langle 0,38 ; 0,38\rangle$ & $\langle 0,17 ; 0,37\rangle$ & $\langle 0,75 ; 0\rangle$ & $\langle 0,45 ; 0,45\rangle$ & $\langle 0 ; 0,8\rangle$ & $\langle 0,85 ; 0\rangle$ & $\langle 0,66 ; 0,23\rangle$ & $\langle 0,3 ; 0,3\rangle$ & $\langle 0,95 ; 0\rangle$ & $\langle 0 ; 0,85\rangle$ & $\langle 0 ; 0,7\rangle$ \\
\hline Q & $\langle 0,6 ; 0\rangle$ & $\langle 0 ; 0,75\rangle$ & $\langle 0,55 ; 0\rangle$ & $\langle 0,38 ; 0,38\rangle$ & $\langle 0,45 ; 0,45\rangle$ & $\langle 0,4 ; 0,4\rangle$ & $\langle 0,85 ; 0\rangle$ & $\langle 0,47 ; 0,43\rangle$ & $\langle 0 ; 0,6\rangle$ & $\langle 0,95 ; 0\rangle$ & $\langle 0,43 ; 0,43\rangle$ & $\langle 0,7 ; 0\rangle$ \\
\hline $\bar{R}$ & $\langle 0,12 ; 0,47\rangle$ & $\langle 0,75 ; 0\rangle$ & $\langle 0,43 ; 0,12\rangle$ & $\langle 0,38 ; 0,38\rangle$ & $\langle 0 ; 0,9\rangle$ & $\langle 0,4 ; 0,4\rangle$ & $\langle 0,85 ; 0\rangle$ & $\langle 0,59 ; 0,31\rangle$ & $\langle 0,6 ; 0\rangle$ & $\langle 0 ; 0,95\rangle$ & $\langle 0 ; 0,85\rangle$ & $\langle 0,35 ; 0,35\rangle$ \\
\hline $\mathrm{s}$ & $\langle 0,28 ; 0,32\rangle$ & $\langle 0,38 ; 0,38\rangle$ & $\langle 0,34 ; 0,21\rangle$ & $\langle 0,75 ; 0\rangle$ & $\langle 0,45 ; 0,45\rangle$ & $\langle 0,4 ; 0,4\rangle$ & $\langle 0,43 ; 0,43\rangle$ & $\langle 0,38 ; 0,53\rangle$ & $\langle 0,1 ; 0,5\rangle$ & $\langle 0 ; 0,95\rangle$ & $\langle 0,43 ; 0,43\rangle$ & $\langle 0,35 ; 0,35\rangle$ \\
\hline
\end{tabular}

Рисунок 8 - Нестрогий формальный контекст

\begin{tabular}{|c|c|c|c|c|c|c|c|c|c|c|c|c|}
\hline & $\mathrm{a}$ & 6 & $B$ & $r$ & A & e & $\ddot{e}$ & * & 3 & n & й & $\mathrm{k}$ \\
\hline A & $\langle 0,6 ; 0\rangle$ & & & & & & & & $\langle 0,6 ; 0\rangle$ & & $\langle 0,85 ; 0\rangle$ & \\
\hline B & & & & $\langle 0,56 ; 0,19\rangle$ & & & & $\langle 0,66 ; 0,23\rangle$ & $\langle 0,6 ; 0\rangle$ & & $\langle 0,64 ; 0,21\rangle$ & \\
\hline C & & $\langle 0,75 ; 0\rangle$ & & & & & & & & & & $\langle 0,7 ; 0\rangle$ \\
\hline D & & $\langle 0,64 ; 0,11\rangle$ & & $\langle 0,56 ; 0,19\rangle$ & & & & & & $\langle 0,63 ; 0,32\rangle$ & & $\langle 0,7 ; 0\rangle$ \\
\hline$E$ & & & & & $\langle 0,9 ; 0\rangle$ & $\langle 0,67 ; 0,13\rangle$ & & & & $\langle 0,59 ; 0,35\rangle$ & & \\
\hline$F$ & & $\langle 0,75 ; 0\rangle$ & & & & $\langle 0,8 ; 0\rangle$ & & $\langle 0,66 ; 0,23\rangle$ & & $\langle 0,95 ; 0\rangle$ & & \\
\hline G & & & & & $\langle 0,9 ; 0\rangle$ & & & $\langle 0,66 ; 0,23\rangle$ & & $\langle 0,95 ; 0\rangle$ & $\langle 0,85 ; 0\rangle$ & \\
\hline $\mathrm{H}$ & & & & $\langle 0,75 ; 0\rangle$ & $\langle 0,9 ; 0\rangle$ & & $\langle 0,85 ; 0\rangle$ & $\langle 0,66 ; 0,23\rangle$ & $\langle 0,6 ; 0\rangle$ & & & \\
\hline 1 & & & & $\langle 0,75 ; 0\rangle$ & & $\langle 0,8 ; 0\rangle$ & & $\langle 0,69 ; 0,22\rangle$ & & $\langle 0,95 ; 0\rangle$ & & \\
\hline J & & & & & & $\langle 0,8 ; 0\rangle$ & $\langle 0,85 ; 0\rangle$ & & $\langle 0,6 ; 0\rangle$ & $\langle 0,95 ; 0\rangle$ & $\langle 0,85 ; 0\rangle$ & $\langle 0,7 ; 0\rangle$ \\
\hline K & & & & & $\langle 0,9 ; 0\rangle$ & $\langle 0,8 ; 0\rangle$ & & $\langle 0,66 ; 0,23\rangle$ & $\langle 0,6 ; 0\rangle$ & $\langle 0,95 ; 0\rangle$ & & $\langle 0,7 ; 0\rangle$ \\
\hline L & & & & & & & & & $\langle 0,6 ; 0\rangle$ & $\langle 0,95 ; 0\rangle$ & $\langle 0,85 ; 0\rangle$ & \\
\hline M & & & & & $\langle 0,9 ; 0\rangle$ & $\langle 0,8 ; 0\rangle$ & $\langle 0,64 ; 0,22\rangle$ & & & $\langle 0,95 ; 0\rangle$ & & \\
\hline $\mathrm{N}$ & $\langle 0,6 ; 0\rangle$ & & $\langle 0,55 ; 0\rangle$ & & & & $\langle 0,85 ; 0\rangle$ & & & $\langle 0,95 ; 0\rangle$ & & $\langle 0,7 ; 0\rangle$ \\
\hline 0 & & & & & & & $\langle 0,85 ; 0\rangle$ & & & $\langle 0,95 ; 0\rangle$ & $\langle 0,85 ; 0\rangle$ & \\
\hline $\mathrm{P}$ & & & & $\langle 0,75 ; 0\rangle$ & & & $\langle 0,85 ; 0\rangle$ & $\langle 0,66 ; 0,23\rangle$ & & $\langle 0,95 ; 0\rangle$ & & \\
\hline Q & $\langle 0,6 ; 0\rangle$ & & $\langle 0,55 ; 0\rangle$ & & & & $\langle 0,85 ; 0\rangle$ & & & $\langle 0,95 ; 0\rangle$ & & $\langle 0,7 ; 0\rangle$ \\
\hline $\mathrm{R}$ & & $\langle 0,75 ; 0\rangle$ & & & & & $\langle 0,85 ; 0\rangle$ & $\langle 0,59 ; 0,31\rangle$ & $\langle 0,6 ; 0\rangle$ & & & \\
\hline$S$ & & & & $\langle 0,75 ; 0\rangle$ & & & & & & & & \\
\hline
\end{tabular}

Рисунок 9 - Стандартная $\alpha$-аппроксимация нестрогого формального контекста при пороге доверия $\langle 0,55 ; 0,5\rangle$

Также следует интерпретировать и рисунок 10, показывающий результат коррекции стандартной $\alpha$-аппроксимации с учётом принятых ОСС (т.е. корректный однозначный формальный контекст), а рисунок 11 приводит использованные для этого пороги доверия, которые обусловили сохранение указанных на рисунке 10 элементов соответствия «объектысвойства» (ранее на рисунке 4 множество этих порогов обозначено как $A$ ).

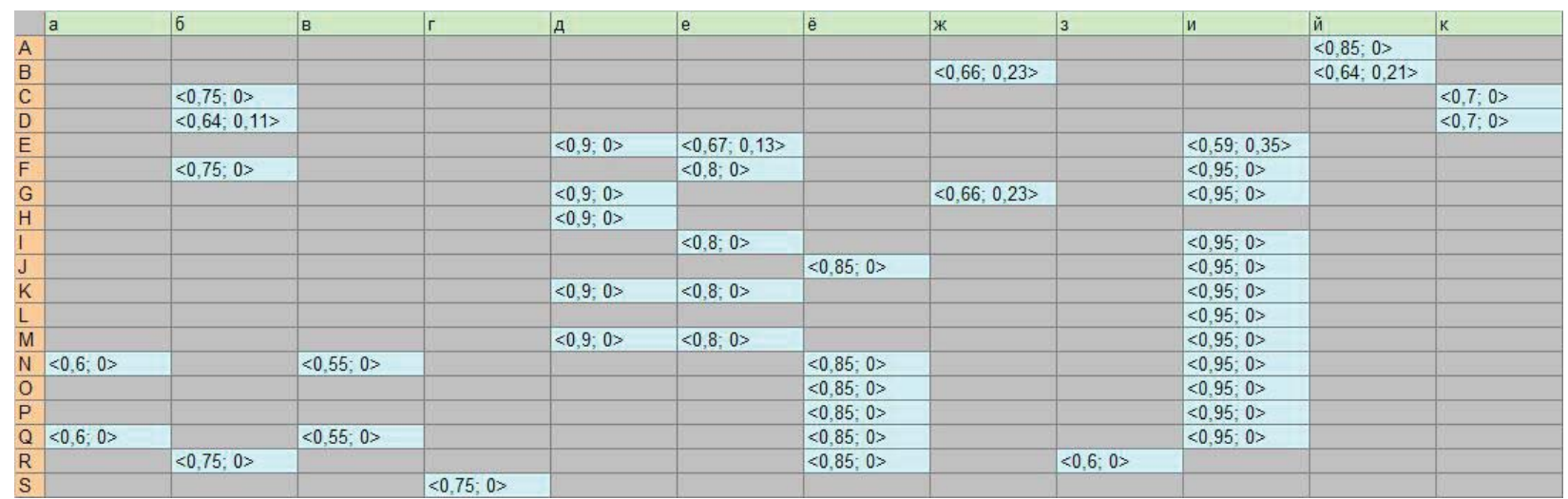

Рисунок 10 - Однозначная аппроксимация нестрогого формального контекста при пороге доверия $\langle 0,55 ; 0,5\rangle$ с учётом ограничений существования свойств

Рисунок 12 представляет все формальные понятия, выведенные из полученного корректного формального контекста, а рисунок 13 - специально размеченную транзитивную редукции решётки этих формальных понятий (т.н. диаграмму Хассе [11-15], где свойство помечает сверху максимальное понятие, заключающее это свойство в своём содержании, а объект помечает снизу минимальное понятие, заключающее этот объект в своём объёме). 


\begin{tabular}{|c|c|c|c|c|c|c|c|c|c|c|c|c|}
\hline & $a$ & 6 & B & $r$ & A & e & ë & * & 3 & n & й & k \\
\hline A & & & & & & & & & & & $\langle 0,6 ; 0,5\rangle$ & \\
\hline$B$ & & & & & & & & $\langle 0,56 ; 0,5\rangle$ & & & $\langle 0,6 ; 0,5\rangle$ & \\
\hline C & & $\langle 0,55 ; 0,5\rangle$ & & & & & & & & & & $\langle 0,55 ; 0,5\rangle$ \\
\hline D & & $\langle 0,56,0,5\rangle$ & & & & & & & & & & $\langle 0,63 ; 0,5\rangle$ \\
\hline $\mathrm{E}$ & & & & & $\langle 0,55 ; 0,5\rangle$ & $\langle 0,55 ; 0,5\rangle$ & & & & $\langle 0,55 ; 0,5\rangle$ & & \\
\hline $\mathrm{F}$ & & $\langle 0,55 ; 0,5\rangle$ & & & & $\langle 0,66 ; 0,5\rangle$ & & & & $\langle 0,55 ; 0,5\rangle$ & & \\
\hline G & & & & & $\langle 0,55 ; 0,5\rangle$ & & & $\langle 0,55,0,5\rangle$ & & $\langle 0,85 ; 0,5\rangle$ & & \\
\hline $\mathrm{H}$ & & & & & $\langle 0,85 ; 0,5\rangle$ & & & & & & & \\
\hline 1 & & & & & & $\langle 0,75 ; 0,5\rangle$ & & & & $\langle 0,75 ; 0,5\rangle$ & & \\
\hline $\mathrm{J}$ & & & & & & & $\langle 0,8 ; 0,5\rangle$ & & & $\langle 0,85 ; 0,5\rangle$ & & \\
\hline K & & & & & $\langle 0,55 ; 0,5\rangle$ & $\langle 0,66 ; 0,5\rangle$ & & & & $\langle 0,7 ; 0,5\rangle$ & & \\
\hline$L$ & & & & & & & & & & $\langle 0,85 ; 0,5\rangle$ & & \\
\hline M & & & & & $\langle 0,55 ; 0,5\rangle$ & $\langle 0,64 ; 0,5\rangle$ & & & & $\langle 0,55 ; 0,5\rangle$ & & \\
\hline $\mathrm{N}$ & $\langle 0,55 ; 0.5\rangle$ & & $\langle 0,55 ; 0,5\rangle$ & & & & $\langle 0,55 ; 0,5\rangle$ & & & $\langle 0,7 ; 0,5\rangle$ & & \\
\hline 0 & & & & & & & $\langle 0,55 ; 0,5\rangle$ & & & $\langle 0,85 ; 0,5\rangle$ & & \\
\hline $\mathrm{P}$ & & & & & & & $\langle 0,75 ; 0,5\rangle$ & & & $\langle 0,75 ; 0,5\rangle$ & & \\
\hline $\mathrm{Q}$ & $\langle 0,55 ; 0,5\rangle$ & & $\langle 0,55 ; 0,5\rangle$ & & & & $\langle 0,55,0,5\rangle$ & & & $\langle 0,7 ; 0,5\rangle$ & & \\
\hline $\bar{R}$ & & $\langle 0,55 ; 0,5\rangle$ & & & & & $\langle 0,59 ; 0,5\rangle$ & & $\langle 0,55 ; 0,5\rangle$ & & & \\
\hline $\mathrm{s}$ & & & & $\langle 0,55 ; 0,5\rangle$ & & & & & & & & \\
\hline & & & & & & & & & & & & \\
\hline
\end{tabular}

Рисунок 11 - Локальные пороги доверия для элементов соответствия нестрого формального контекста, оценкой истинности которых в однозначной аппроксимации является Истина

\begin{tabular}{|c|c|c|}
\hline Имя понятия & Объём & Содержание \\
\hline 1 & & $a, 6, \boldsymbol{B}, r, д, e, \ddot{e}, *, 3, и, \check{и}, \kappa$ \\
\hline 2 & A, B & й \\
\hline 3 & $\mathrm{~B}$ & ж, й \\
\hline 4 & C, D & $6, k$ \\
\hline 5 & A, B, C, D, E, F, G, H, I, J, K, L, M, N, O,P, Q, R, S & \\
\hline 6 & $\mathrm{E}, \mathrm{K}, \mathrm{M}$ & A, e, $и$ \\
\hline 7 & $\mathrm{~F}$ & $6, e, n$ \\
\hline 8 & C, D, F, R & 6 \\
\hline 9 & $\mathrm{E}, \mathrm{F}, \mathrm{I}, \mathrm{K}, \mathrm{M}$ & e, $n$ \\
\hline 10 & G & д, $*, n$ \\
\hline 11 & $B, G$ & ж \\
\hline 12 & $\mathrm{E}, \mathrm{G}, \mathrm{K}, \mathrm{M}$ & д, $и$ \\
\hline 13 & $E, F, G, I, J, K, L, M, N, O, P, Q$ & и \\
\hline 14 & $\mathrm{E}, \mathrm{G}, \mathrm{H}, \mathrm{K}, \mathrm{M}$ & д \\
\hline 15 & $J, N, O, P, Q$ & $\ddot{e}, n$ \\
\hline 16 & $N, Q$ & a, B, ё, и \\
\hline 17 & $\mathrm{R}$ & $6, \ddot{e}, 3$ \\
\hline 18 & $\mathrm{~J}, \mathrm{~N}, \mathrm{O}, \mathrm{P}, \mathrm{Q}, \mathrm{R}$ & ë \\
\hline 19 & $S$ & $r$ \\
\hline
\end{tabular}

Рисунок 12 - Множество формальных понятий

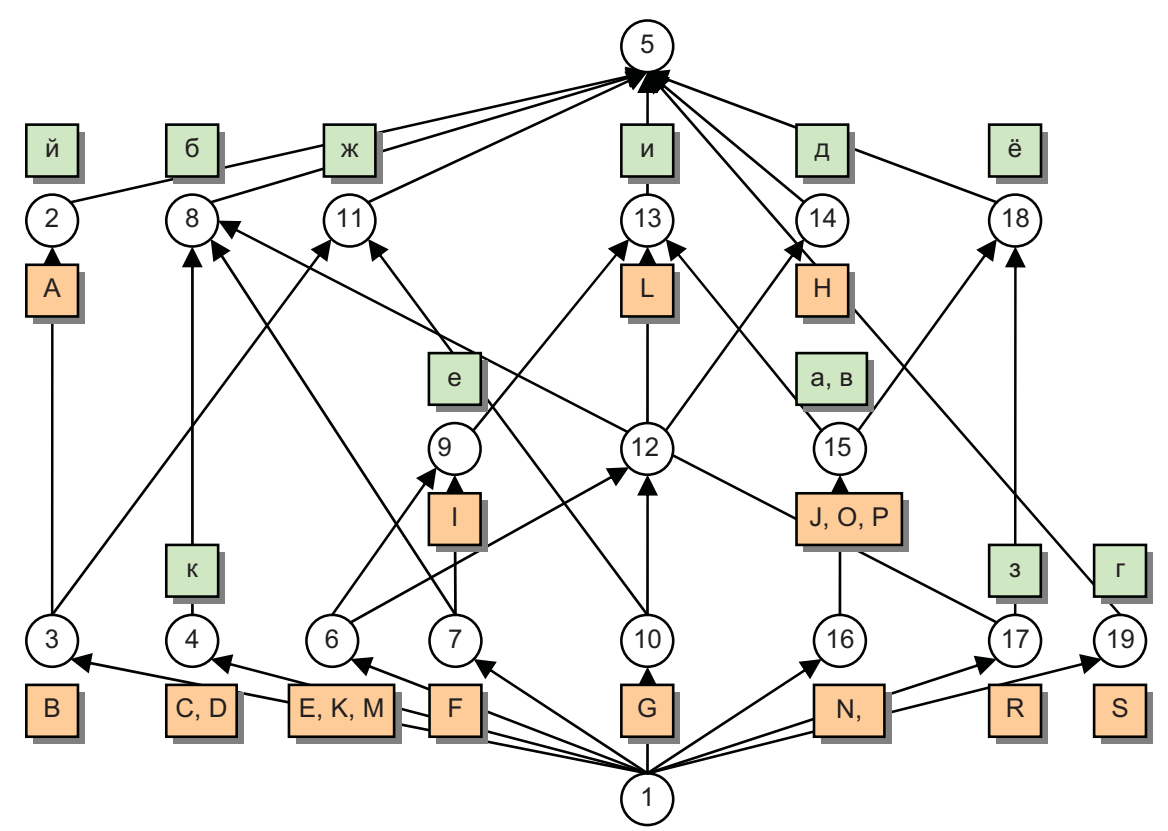

Рисунок 13 - Диаграмма Хассе решётки формальных понятий:

О - формальное понятие; $\boldsymbol{\nabla}$ - обобщение между понятиями; в прямоугольниках - измеряемые свойства и объекты обучающей выборки; 1 и 5 - соответственно наименьшее и наибольшее понятия решётки 
Наконец, рисунок 14 представляет результат трансформации полученной решётки формальных понятий в формальную онтологию ПрО согласно принципам, изложенным в разделе 4. На рисунке 14 идентификаторы сформированных фундаментальных классов имеют префикс «f». Формальному понятию 12 (см. рисунки 11, 12) класс не сопоставлен, т.к. оно не является ни максимальным для какого-либо свойства, ни минимальным для какого-либо понятия в полученной решётке формальных понятий. Криволинейные связующие стрелки на рисунке 14 показывают нетаксономические отношения выведенных формальных понятий. Исток и сток каждой из них определяет соответствующая ПССВ-связь в схеме ОСС (см. рисунок 7) и принадлежность её аргументов-свойств содержанию определённых формальных понятий (см. рисунок 12).

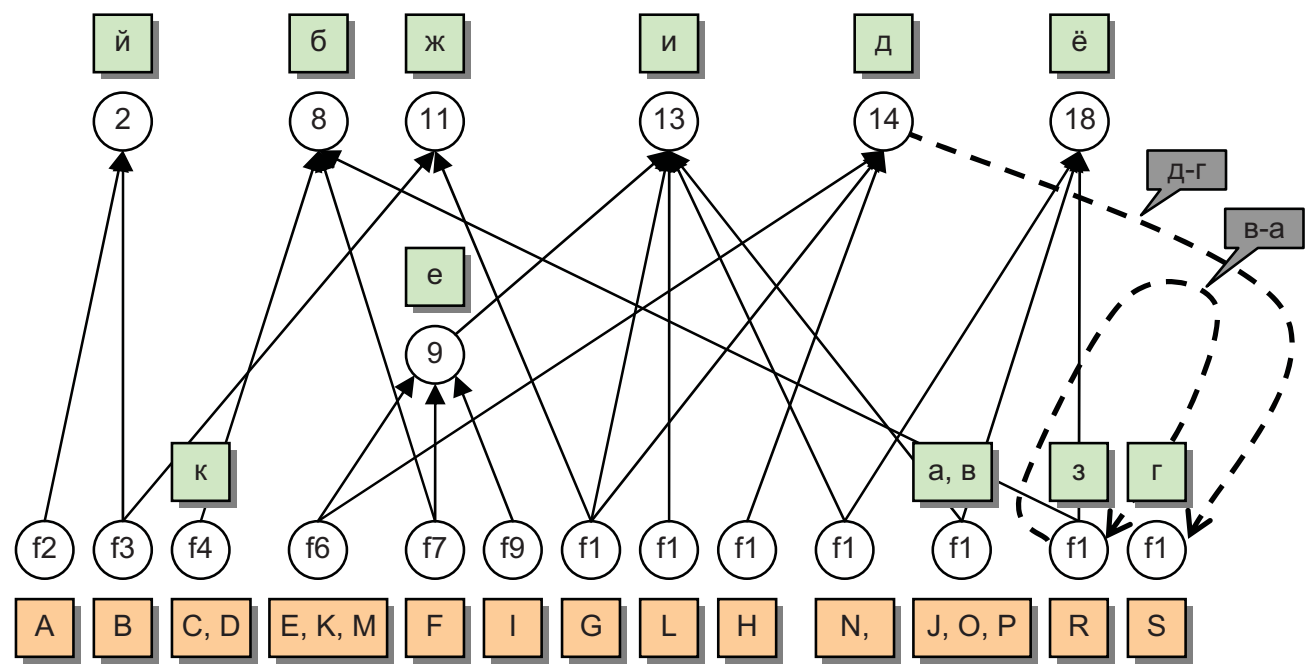

Рисунок 14 - Классы объектов и их связи (формальная онтология):

,-7 - нетаксономические отношения между классами

\section{Заключение}

Представленные в статье модели и методы показывают новый этап развития онтологического анализа данных - методики выявления понятийной структуры и, в конечном счёте, формальной онтологии экспериментально исследуемой ПрО. Основу методики составляет анализ формальных понятий, в котором сохранено классическое понимание понятия как фундаментального смыслового элемента, определяемого объёмом и содержанием.

В центре внимания выполненного исследования находится проблема отражения реалий накопления эмпирической информации о ПрО, определяющих неполноту исходных данных. Для её решения потребовалось обобщить стандартную модель представления объектнопризнаковых данных и применить для её обработки модели и аппарат многозначной векторной логики.

Повышение адекватности моделей исходных данных породило новые задачи онтологического анализа. Потребовалось разработать интеллектуальный метод преобразования исходных данных нового формата в однозначный формальный контекст, для которого известны эффективные алгоритмы вывода формальных понятий. При этом построены модели для учёта априори известных зависимостей между измеряемыми свойствами объектов ПрО.

Наконец, в методику включён ряд прагматических принципов, определивших метод трансформации решетки формальных понятий, выводимой из эмпирических данных, в формальную онтологию ПрО. В полном объёме представленный методический комплекс предполагается внедрить в разрабатываемую в Институте проблем управления сложными систе- 
мами РАН систему семантического моделирования и проектирования на массовой программной платформе.

\section{Список источников}

[1] Искусственный интеллект. - В 3-х кн. Кн. 2. Модели и методы: Справочник / Под ред. Д.А. Поспелова. М.: Радио и связь, 1990. -304 с.

[2] Лукашевич, Н.B. Тезаурусы в задачах информационного поиска / Н.В. Лукашевич. - М.: Изд-во Московского университета, 2011.- $512 \mathrm{c}$.

[3] Мальцев, А.И. Алгебраические системы. - М.: Наука, 1970. - 392 с.

[4] Смирнов, $\boldsymbol{C}$. B. Онтологическое моделирование в ситуационном управлении // Онтология проектирования. - 2012. - №2(4). - C. 16-24.

[5] Гаврилова, T.A. Интеллектуальные технологии в менеджменте: инструменты и системы / Т.А. Гаврилова, Д.И. Муромцев. - СПб.: Изд-во «Высшая школа менеджмента»; Изд. дом СПбГУ, 2008. - 488 с.

[6] Смирнов, A.B. Онтологии в системах искусственного интеллекта: способы построения и организации / А.В. Смирнов, М.П. Пашкин, Н.Г. Шилов, Т.В. Левашова // Новости искусственного интеллекта. - 2002. №1. - С. 3-13 (Часть 1); №2. - С. 3-9 (Часть 2).

[7] Suarez-Figueroa, M.S. The NeOn Methodology for Ontology Engineering / M.S. Suarez-Figueroa, A. GomezPerez, M. Fernandez-Lopez // In: Ontology Engineering in a Networked World. - Berlin-Heidelberg: Springer, 2012. - P. 9-34.

[8] Ломов, П.А. Автоматизация синтеза составных онтологических паттернов содержания // Онтология проектирования. - 2016. - Т. 6, №2(20). - С. 162-172.

[9] Загоруйко, Н.Г. Прикладные методы анализа данных и знаний / Н.Г. Загоруйко. - Новосибирск: Институт математики СО РАН, 1999. - 270 с.

[10] Барсегян, A.A. Анализ данных и процессов / А.А. Барсегян, М.С. Куприянов, И.И. Холод, М.Д. Тесс, С.И. Елизаров. - 3-е изд., перераб. и доп. - СПб.: БХВ-Петербург, 2009. - 512 с.

[11] Ganter, B. Formal Concept Analysis. Mathematical foundations / B. Ganter, R. Wille. - Berlin-Heidelberg: Springer-Verlag, 1999. - 290 p.

[12] Carpineto, C. Concept Data Analysis: Theory and Applications / C. Carpineto, G. Romano. - Wiley, 2004.

[13] Ganter, B. Conceptual Exploration / B. Ganter, S. Obiedkov. - Springer, 2016.

[14] Ignatov, D.I. Introduction to Formal Concept Analysis and Its Applications in Information Retrieval and Related Filds / D.I. Ignatov // In: P. Braslavski, N. Karpov, M. Worring, Y. Volkovich, D.I. Ignatov (Eds.): Information Retrieval. Revised Selected Papers $8^{\text {th }}$ Russian Summer School, RuSSIR 2014 (Nizhniy Novgorod, Russia, August 18-22, 2014). - Springer International Publishing, 2015. - P. 42-141.

[15] Formal Concept Analysis Homepage - http://www.upriss.org.uk/fca/fca.html (дата обращения 20.08.2016).

[16] Пронина, B.A. Использование отношений между атрибутами для построения онтологии предметной области / В.А. Пронина, Л.Б. Шипилина // Проблемы управления. - 2009. - №1. - С. 27-32.

[17] $\boldsymbol{C м и р н о в , ~} \boldsymbol{C} . \boldsymbol{B}$. Построение онтологий предметных областей со структурными отношениями на основе анализа формальных понятий / С.В. Смирнов // Знания - Онтологии - Теории: Материалы Всероссийской конф. с международным участием (3-5 октября 2011 г., Новосибирск, Россия). Т. 2. - Новосибирск: Институт математики СО РАН, 2011. - С. 103-112.

[18] Смирнов, C.B. Онтологический анализ предметных областей моделирования / С.В. Смирнов // Известия Самарского научного центра РАН. - 2001. - Т. 3, № 1. - С. 62-70.

[19] Ganter, B. Conceptual scaling / B. Ganter, R. Wille // In: F. Roberts (Ed.): Applications of Combinatorics and Graph Theory to the Biological and Social Sciences. - New York Springer-Verlag, 1989. - P. 139-167.

[20] Ариинский, Л.В. Векторные логики: основания, концепции, модели / Л.В. Аршинский. - Иркутск: Иркутский гос. ун-т, 2007. -228 с.

[21] Зверев, Г.Н. Неклассические логики в задачах идентификации / Г.Н. Зверев // Идентификация систем и задачи управления: Труды международной конф. SICHRO’2000 (26-28 сентября 2000 г., Москва, Россия). М.: ИПУ РАН, 2000. - С. 1607-1616.

[22] Belohlavek, R. Computing the lattice of all fixpoints of a fuzzy closure operator / R. Belohlavek, B. De Baets, B. Outrata, J. Vychodil // IEEE Trans. on Fuzzy systems. - 2010. - Issue 3, Vol. 18. - P. 546-557.

[23] Tho, Q.T. Automatic Fuzzy Ontology Generation for the Semantic Web / Q.T. Tho, S.C. Hui, A.C.M. Fong, T.H. Cao // IEEE Transactions on Knowledge and Data Engineering. - 2006. - Issue 6, Vol. 18. - P. 842-856.

[24] Yang, K.M. Fuzzy Concept Mining based on Formal Concept Analysis / K.M. Yang, E.H. Kim, S.H. Hwang, S.H. Choi // Int. J. of Computers. - 2008. - Issue 3, Vol. 2. - P. 279-290. 
[25] Lammari, $N$. Building and maintaining ontologies: a set of algorithms / N. Lammari, E. Metais // Data \& Knowledge Engineering. - 2004. - Vol. 48(2). - P. 155-176.

[26] Игнатов, Д.И. Решётки формальных понятий для анализа данных социологических опросов / Д.И. Игнатов, О.Н. Кононыхина // Интегрированные модели и мягкие вычисления в искусственном интеллекте: Труды V-й Международной научно-технической конференции (20-30 мая 2009 г., Коломна, Россия). Т 1. - М.: Физматлит, 2009. - С. 230-240.

[27] Офицеров, В.П. Метод альфа-сечения нестрогих формальных контекстов в анализе формальных понятий / В.П. Офицеров, В.С. Смирнов, С.В. Смирнов // Проблемы управления и моделирования в сложных системах: Труды XVI международной конф. (30 июня - 03 июля 2014 г., Самара, Россия). - Самара: СамНЦ РАН, 2014. - C. 228-244.

[28] Зубцов, P.O. Алгоритмическое и программное обеспечение онтологического анализа данных / Р.О. Зубцов, B.А. Семенова, С.В. Смирнов // Открытые семантические технологии проектирования интеллектуальных систем $=$ Open Semantic Technologies for Intelligent Systems (OSTIS-2016): Материалы VI международной научно-технической конф. (18-20 февраля 2016 г. Минск, Беларусь) / Редкол.: В.В. Голенков (отв. ред.) [и др.]. - Минск: БГУИР, 2016. - С. 83-88.

[29] Kovartsev, A.N. Intelligent Design of Class Structure Model based on Ontological Data Analysis / A.N. Kovartsev, V.S. Smirnov, S.V. Smirnov // Труды ИСП РАН. 2015. Т. 27. Выпуск 3. - с.73-86.

[30] Виноградов, И.Д. Изучение автомобильного рынка на основе онтологий потребительских предпочтений / И.Д. Виноградов, В.А. Виттих, В.М. Карпов, А.Н. Москалюк, С.В. Смирнов // Вестник компьютерных и информационных технологий. - 2005. - №1. - С. 2-7.

\title{
INCOMPLETE DATA ANALYSIS FOR BUILDING FORMAL ONTOLOGIES
}

\author{
D.E. Samoilov ${ }^{1,2}$, V.A. Semenova ${ }^{1,2}$, S.V. Smirnov ${ }^{2}$ \\ ${ }^{1}$ Samara National Research University named after academician S.P. Korolev, Samara, Russia \\ dmitrysam3@gmail.com,queenbfjr@gmail.com \\ ${ }^{2}$ Institute for the Control of Complex Systems of Russian Academy of Sciences, Samara, Russia \\ smirnov@iccs.ru
}

\begin{abstract}
The article considers the problem of automating the formation of ontological specifications subject domains on the basis of measurements. This problem is the pivotal issue of ontological analysis. The article presents models and methods, aimed at identifying conceptual structure and, ultimately, detecting the formal ontology of the considered subject domain. Fundamental realities of accumulation of empirical data (multiple independent measurements for each training sample properties of the object; congruence of the measurement procedures; differentiation of trust to different data sources) are reflected in the "objects-properties" summary table model. Imperfection (inaccuracy, inconsistency, uncertainty) of this information implies the need to use many-valued logic models for its primary processing. The result of this treatment - fuzzy formal context - should be approximated as a unique context, from which the possible conclusion of formal concepts in the framework of applied branch of the lattice theory, known as the "formal concept analysis". The genesis of the "properties' limits of existence" that affect the correctness of the approximation of fuzzy formal context is studied. The models and the method of accounting for this additional information are proposed. Guidelines for conversion of lattice formal concepts into a formal ontology are formulated. A model example of the developed models and ontological data analysis methods is presented.
\end{abstract}

Key words: ontological data analysis, formal ontology, formal concept analysis, multi-valued vector logic, properties existence constraints.

Citation: Samoilov DE., Semenova VA, Smirnov SV. Incomplete data analysis of for building formal ontologies [In Russian]. Ontology of designing. 2016; 6(3): 317-339. DOI: 10.18287/2223-9537-2016-6-3-317-339.

\section{References}

[1] Artificial intelligence Handbook. Vol. 2. Models and methods. Ed.: DA Pospelov [In Russian]. - Moscow: "Radio i svyaz" Publisher, 1990. 
[2] Lukashevch NV. Thesauri in Information Retrieval [In Russian]. - Moscow: Moscow University Publisher, 2011.

[3] Mal'cev AI. Algebraic Systems. - Berlin-Heidelberg New York: Springer-Verlag, 1973.

[4] Smirnov SV. Ontological modeling in situational management [In Russian]. Ontology of Designing, 2012; 2(4): 1624.

[5] Gavrilova TA, Muromtsev DI. Intelligent technologies in management: tools and systems [In Russian]. - St. Petersburg: Management Higher school Publisher, 2008.

[6] Smirnov AV, Pashkin MP, Shilov NG, Levashova TV. Ontologies in Artificial intelligence systems: building and management methods [In Russian]. News of Artificial intelligence, 2002; 1: 3-13 (Part 1); 2: 3-9 (Part 2).

[7] Suárez-Figueroa MC, Gómez-Pérez A, Fernández-López M. The NeOn Methodology for Ontology Engineering. In: Ontology Engineering in a Networked World. Springer Berlin Heidelberg; 2012: 9-34.

[8] Lomov PA. Automation of synthesis of composite content ontology design pattern [In Russian]. Ontology of Designing, 2016; 6(2): 162-172.

[9] Zagoruyko NG. Applied methods of data and knowledge analysis [In Russian]. Novosibirsk: Sobolev Institute of Mathematics, SB RAS, 1999.

[10] Barsegyan AA, Kupriyanov MS, Holod II, Tess MD, Elizarov SI. Data and Process Analysis [In Russian]. - St. Petersburg: BHV- Petersburg, 2009.

[11] Ganter B, Wille R. Formal Concept Analysis. Mathematical foundations. Springer Berlin-Heidelberg, 1999.

[12] Carpineto $C$, Romano G. Concept Data Analysis: Theory and Applications. Wiley, 2004.

[13] Ganter B, Obiedkov S. Conceptual Exploration. Springer, 2016.

[14] Ignatov DI. Introduction to Formal Concept Analysis and Its Applications in Information Retrieval and Related Fields. In: P. Braslavski, N Karpov, M. Worring, Y. Volkovich, D.I. Ignatov (Eds.): Information Retrieval (Revised Selected Papers 8th Russian Summer School, RuSSIR 2014, Nizhniy Novgorod, Russia, 2014, August 18-22,). Springer International Publishing, 2015: 42-141.

[15] Formal Concept Analysis Homepage. Source: http://www.upriss.org.uk/fca/fca.html

[16] Pronina VA, Shipilina LB. Using the relationships between attributes to build domain ontology [In Russian]. Control Science, 2009; 1: 27-32.

[17] Smirnov SV. Building knowledge domain ontologies with structural relationships based on Formal Concept Analysis [In Russian]. Proc. ${ }^{\text {rd }}$ All-Russian Conf. "Knowledge-Ontologies-Theories" (Novosibirsk, Russia, October 3-5, 2011). Vol. 2. Novosibirsk: Sobolev Institute of Mathematics, SB of RAS; 2011: 103-112.

[18] Smirnov SV. Ontological analysis of modeling domain [In Russian]. Bulletin of the Samara Scientific Center of RAS, 2001. 3(1): 62-70.

[19] Ganter B, Wille R. Conceptual scaling. In: F. Roberts (Ed.): Applications of Combinatorics and Graph Theory to the Biological and Social Sciences. Springer-Verlag New York; 1989: 139-167.

[20] Arshinskii LV. Substantial and formal deductions in logics with vector semantics. Automation and Remote Control, 2007; 68(1): 139-148.

[21] Zverev GN. Non-classical logics in identification problems [In Russian]. Proc. of Int. Conf. SICHRO'2000 (Moscow, Russia, 2000, 26-28 September). Moscow: Institute of Control Sciences of RAS; 2000: 1607-1616.

[22] Belohlavek R, De Baets B, Outrata B, Vychodil J. Computing the lattice of all fixpoints of a fuzzy closure operator. IEEE Trans. on Fuzzy systems, 2010; 18(3): 546-557.

[23] Tho QT, Hui SC, Fong ACM, Cao TH. Automatic Fuzzy Ontology Generation for the Semantic Web. IEEE Trans. on Knowledge and Data Engineering, 2006; 18(6): 842-856.

[24] Yang KM, Kim EH, Hwang SH, Choi SH. Fuzzy Concept Mining based on Formal Concept Analysis. Int. J. of Computers, 2008; 2(3): 279-290.

[25] Lammari N, Metais E. Building and maintaining ontologies: a set of algorithms. Data \& Knowledge Engineering, 2004; 48(2): 155-176.

[26] Ignatov DI, Kononychina ON. Formal concept lattices for data analysis in sociological interrogations [In Russian]. Integrated models and soft computation in Artificial Intelligence: Proc. of 5th Int. Conf. (Kolomna, Russia, 2009, May 20-30). Vol. 1. Moscow: "Fizmathlit" Publisher; 2009: 230-240.

[27] Ofitserov VP, Smirnov VS, Smirnov SV. Alpha-section of non-strict formal contexts in Formal Concept Analysis [In Russian]. Proc. of XVI Int. Conf. "Complex systems: Control and Modeling Problems" (Samara, Russia, 2014, June 30 - July 03). Samara: Samara Scientific Center of RAS; 2014: 228-244.

[28] Zubtcov RO, Semenova VA, Smirnov SV. Algorithms and software for ontological data analysis [In Russian]. Proc. of VI Int. Conf. “Open Semantic Technologies for Intelligent Systems (OSTIS-2016)” (Minsk, Belarus, 2016, February 18-20). Minsk: Byelorussian state university for informatics and radio electronics Publisher; 2016: 83-88.

[29] Kovartsev AN, Smirnov VS, Smirnov SV. Intelligent Design of Class Structure Model based on Ontological Data Analysis. Proceedings of the Institute for System Programming of the RAS, 2015; 27(3): 73-86.

[30] Vinogradov ID, Vittikh VA, Karpov VM, Moscalyuk AN, Smirnov SV. Automobile marketing based on ontologies of user's needs. Advances in Concurrent Engineering: Proc. of the 9-th ISPE Int. Conf. on Concurrent Engineering: 
Research and Applications (Cranfield, United Kingdom, 2002, July 27-31). Eds.: R. Gonçales, R. Roy, A. SteigerGarção. Series Editor: B. Prasad. Balkema Pablishers; 2002: 653-659.

\section{Сведения об авторах}

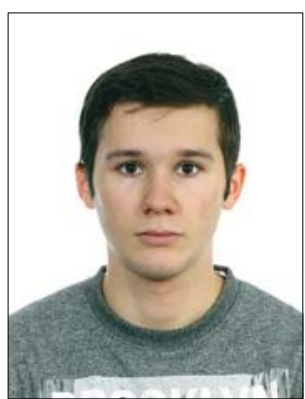

Самойлов Дмитрий Евгеньевич, 1997 г. рождения. Окончил с золотой медалью МБОУ «Лицей авиационного профиля №135» г. Самары (2015). Многократный призёр областных и всероссийских олимпиад по физике, астрономии, математике. Студент второго курса бакалавриата Самарского национального исследовательского университета им. С.П. Королёва по направлению «Прикладная математика и информатика», лаборант Института проблем управления сложными системами РАН. Соавтор двух научных работ по тематике анализа формальных понятий.

Samoilov Dmitry Evgenyevich (b. 1997). He graduated with a gold medal from "Lyceum Profile Aviation №135» (2015). Multiple medalist of regional and All-Russian Olympiads in physics, astronomy and mathematics. Second-year student of the Samara National Research University in "Applied Mathematics and Computer Science", lab assistant of the Institute for the Control of Complex Systems of Russian Academy of Sciences. Co-author of two scientific papers on the subject of formal concept analysis.

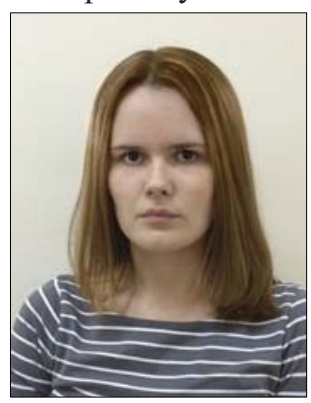

Семенова Валентина Андреевна, 1994 г. рождения. Окончила бакалавриат Самарского государственного аэрокосмического университета им. С.П. Королёва по направлению «Прикладная математика и информатика» (2015). Студентка второго курса магистратуры Самарского национального исследовательского университета им. С.П. Королёва по направлению «Механика и математическое моделирование», инженер Института проблем управления сложными системами РАН. Соавтор пяти научных работ в области интеллектуального анализа данных.

Semyonovna Valentina Andreevna (b. 1994). She graduated from the Bachelor of Samara State Aerospace University, "Applied Mathematics and Computer Science" (2015). A student of the second year master Samara National Research University in the direction of "Mechanics and Mathematical Modeling", engineer of the Institute for the Control of Complex Systems of Russian Academy of Sciences. Co-author of five scientific papers in the field of data mining.

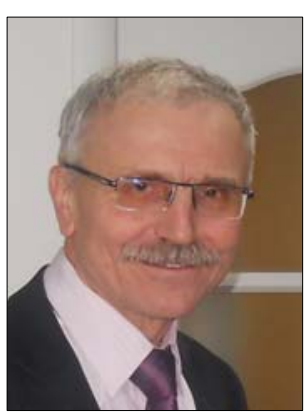

Смирнов Сергей Викторович, 1952 г. рождения. Окончил Куйбышевский авиационный институт им. С.П. Королёва в 1975 г., д.т.н. (2002). Заместитель директора Института проблем управления сложными системами РАН, профессор кафедры «Инженерия знаний» Поволжского государственного университета телекоммуникаций и информатики. Член Российской ассоциации искусственного интеллекта. В списке научных трудов более 150 работ в области прикладной математики, компьютерного моделирования сложных систем, создания интеллектуальных систем поддержки принятия решений в технологических и организационных сферах.

Smirnov Sergei Victorovich (b. 1952) graduated from the Korolyov aviation Institute (Kuibyshev-city) in 1975, D. Sc. Eng. (2002). Deputy director at Institute for the Control of Complex Systems of Russian Academy of Sciences, professor at Povolzhskiy State University of Telecommunication and Informatics (Knowledge engineering sub-department). He is Russian Association of Artificial Intelligence member. He is co-author of more than 150 publications in the field of applied mathematic, complex systems simulation and development of knowledge based decision support systems in control and management. 


\title{
УДК 519.61
}

\section{ДИФФЕРЕНЦИРОВАНИЕ ИНТЕРВАЛЬНЫХ ЭЛЕМЕНТАРНЫХ ФУНКЦИЙ И ПРИНЯТИЕ РЕШЕНИЙ}

\author{
В.И. Левин \\ Пензенский государственный технологический университет, Пенза, Россия \\ vilevin@mail.ru
}

\begin{abstract}
Аннотация
В статье рассмотрены задачи, связанные с вычислением производных от интервально-определённых функций. Эти задачи актуальны при изучении систем с той или иной степенью неопределённости (недетерминированные системы). Рассматриваются простейшие системы, описываемые элементарными интервально-определёнными функциями. Решаются задачи вычисления производных от элементарных интервально-определённых функций. Приведены основные определения, связанные с производными от интервально-определённых функций, и формулы двух типов, которые позволяют вычислять указанные интервальные производные. Формулы первого типа выражают производные в закрытой интервальной форме, которая для вычисления требует использования аппарата интервальной математики. Формулы второго типа выражают производные в открытой интервальной форме, т.е. в форме двух формул, первая из которых выражает нижнюю границу интервала, представляющего производную, а вторая - верхнюю границу интервала. В такой форме вычисление производной от интервально-определённой функции сводится к вычислению двух обычных функций. Получены производные для ряда элементарных интервальных функций: интервальной константы, степенной функции, показательной функции, экспоненциальной функции, логарифмической функции, функции натуральный логарифм, тригонометрических функций, обратных тригонометрических функций. Формулы всех производных представлены в открытой интервальной форме. Показано отличие производных интервальных элементарных функций от производных соответствующих неинтервальных элементарных функций.
\end{abstract}

Ключевые слова: интервал, интервальная функиия, интервальные вычисления, интервальная производная, интервально-дифференциальное исчисление, интервальные элементарные функиии.

Цитирование: Левин, В.И. Дифференциальное исчисление интервальных элементарных функций и принятие решений / В.И. Левин // Онтология проектирования. - 2016. - Т.6, №3(21). - С. 340-354. - DOI: 10.18287/2223-9537-2016-6-3-340-354.

\section{Введение}

Проектирование и анализ свойств разнообразных систем требует соответствующего, адекватного рассматриваемой задаче, математического аппарата. Встречающиеся на практике системы часто характеризуются той или иной степенью неопределённости (недетерминированы). Для исследования и построения таких систем обычно применяют специализированный математический аппарат - теорию вероятностей, нечёткие множества, интервальную математику [1-3].

В работах $[4,5]$ автором был предложен новый математический аппарат для проектирования и исследования недетерминированных систем - недетерминистское (интервальное) дифференциальное исчисление. Этот аппарат является аналогом классического дифференциального исчисления Ньютона-Лейбница [6]. Он позволяет переносить основные идеи классического дифференциального исчисления на неполностью определённые функции, задаваемые с точностью до интервалов возможных значений переменных. Однако, несмотря на сходство основных исходных идей двух исчислений, предложенное интервальное дифференциальное исчисление по форме не похоже на классическое дифференциальное исчисление Ньютона- 
Лейбница, что является следствием неопределённости интервальных функций, обычно фигурирующих в интервальной математике. Кроме того, предложенное интервальное дифференциальное исчисление, по нашему мнению, более адекватно природным явлениям и процессам, чем классическое дифференциальное исчисление [7].

\section{1 Постановка задачи}

Согласно классическому дифференциальному исчислению [6], нахождение производной от любой функции базируется на: 1) представлении этой функции в виде соответствующей суперпозиции так называемых элементарных функций; 2) переходе в полученном представлении от функций к их производным, с использованием для этого основных теорем дифференциального исчисления (производная суммы функций, производная произведения функций и т.д.); 3) подстановке выражений производных элементарных функций.

Процедура, сходная с описанной, может быть полезна и при нахождении производных от интервальных функций, рассматриваемых в интервальном дифференциальном исчислении. При этом необходимо учитывать большое отличие свойств и форм представления обычных и интервальных функций и производных от них. Задачами статьи являются: 1) составление полного набора производных от всех интервальных элементарных функций; 2) выявление различий производных от интервальных элементарных функций и производных от детерминированных элементарных функций.

Интервальное дифференциальное исчисление может быть использовано для исследования поведения неполностью определённых функций, служащих характеристиками недетерминированных систем, при принятии решений на этапе проектирования таких систем. Эта ситуация аналогична использованию классического дифференциального исчисления при исследовании поведения функций, являющихся характеристиками детерминированных систем.

При решении задачи будем использовать в качестве вспомогательных сведений основные математические сведения из алгебры интервальных чисел [3, 4]. В этой алгебре оперируют интервальными числами (операндами), операциями над интервальными числами и интервальными функциями $[4,5,7]$.

\section{2 Математический аппарат}

Базовое для данной статьи понятие интервальной функции $[4,5,7]$ вводится как однозначное отображение множества $\{\tilde{x}\}$ замкнутых вещественных интервалов $\tilde{x}=\left[x_{1}, x_{2}\right]$ на множество $\{\widetilde{y}\}$ замкнутых вещественных интервалов $\tilde{y}=\left[y_{1}, y_{2}\right]$ того же вида. Символически интервальная функция записывается в виде

$$
\tilde{y}=f(\tilde{x}) \text { или } \tilde{y}=\left[y_{1}, y_{2}\right]=\left[f_{1}(\tilde{x}), f_{2}(\widetilde{x})\right] \text {, }
$$

где $\widetilde{x}=\left[x_{1}, x_{2}\right]-$ интервальная независимая переменная, $\tilde{y}=\left[y_{1}, y_{2}\right]-$ интервальная зависимая пе-

ременная, $\widetilde{f}=\left[f_{1}, f_{2}\right]-$ интервальная функция, с её нижней $f_{1}$ и верхней $f_{2}$ граничными функциями. Второе базовое понятие, используемое далее, - понятие предела интервальной функции.

Независимая интервальная переменная $\tilde{x}=\left[x_{1}, x_{2}\right]$ интервальной функции (1) по определению неограниченно приближается к некоторому интервалу (пределу) $\tilde{x}^{\circ}=\left[x_{1}^{\circ}, x_{2}^{\circ}\right]$, если в процессе указанного изменения $x_{1}$ неограниченно приближается к $x_{1}^{\circ}$, а $x_{2}$ к $x_{2}^{\circ}$. Символически это записывается в виде

$$
\tilde{x} \rightarrow \tilde{x}^{\circ} \equiv\left(x_{1} \rightarrow x_{1}^{\circ}, x_{2} \rightarrow x_{2}^{\circ}\right) .
$$


Аналогично определяется неограниченное приближение зависимой интервальной переменной $\tilde{y}=\left[y_{1}, y_{2}\right]$ интервальной функции (1) к интервалу (пределу) $\tilde{y}^{\circ}=\left[y_{1}^{\circ}, y_{2}^{\circ}\right]$ :

$$
\tilde{y} \rightarrow \tilde{y}^{\circ} \equiv\left(y_{1} \rightarrow y_{1}^{\circ}, y_{2} \rightarrow y_{2}^{\circ}\right) .
$$

Если независимая интервальная переменная $\tilde{x}$ своим неограниченным приближением к интервалу-пределу $\tilde{x}^{\circ}$ вызывает неограниченное приближение зависимой интервальной переменной $\tilde{y}$ к интервалу-пределу $\tilde{y}^{\circ}$, то говорим, что предел интервальной функции (1) при $\tilde{x}$, стремящемся к $\tilde{x}^{\circ}$, равен $\tilde{y}^{\circ}$ :

$$
\lim _{\widetilde{x} \rightarrow \widetilde{x}^{\circ}} \tilde{y}=\widetilde{y}^{\circ} \text { или } \lim _{\widetilde{x} \rightarrow \widetilde{x}^{\circ}} \tilde{f}(\widetilde{x})=\tilde{y}^{\circ} .
$$

Если интервальная функция $\widetilde{f}(1)$ непрерывна, т.е. её нижняя $f_{1}$ и верхняя $f_{2}$ граничные функции есть непрерывные функции нижней $x_{1}$ и верхней $x_{2}$ границ независимой переменной $\widetilde{x}=\left[x_{1}, x_{2}\right]$, то предел функции $\widetilde{f}$ равен её значению в предельной точке $\tilde{x}^{\circ}$ аргумента $\tilde{x}$, или символически

$$
\lim _{\widetilde{x} \rightarrow \widetilde{x}^{\circ}} \tilde{f}(\tilde{x})=\tilde{f}\left(\tilde{x}^{\circ}\right) .
$$

Основное понятие интервальной производной вводится аналогично понятию обычной производной функции [6]. Рассмотрим произвольную интервальную функцию $\widetilde{f}$ вида (1). Будем считать её непрерывной. Зафиксируем значение независимой переменной $\widetilde{x}=\widetilde{x}^{\circ}=\left[x_{1}^{\circ}, x_{2}^{\circ}\right]$. Этому значению, в силу непрерывности функции, соответствует фиксированное значение самой функции $\widetilde{y}=\widetilde{f}\left(\widetilde{x}^{\circ}\right)$. Определим приращение независимой и зависимой переменных функции относительно этих фиксированных значений

$$
\Delta \widetilde{x}=\widetilde{x}-\widetilde{x}^{\circ}, \quad \Delta \widetilde{y}=\widetilde{y}-\widetilde{y}^{\circ}=\widetilde{f}(\widetilde{x})-\widetilde{f}\left(\widetilde{x}^{\circ}\right)
$$

и составим отношение второго приращения к первому

$$
\Delta \widetilde{y} / \Delta \widetilde{x}=\left(\widetilde{y}-\widetilde{y}^{\circ}\right) /\left(\widetilde{x}-\widetilde{x}^{\circ}\right)=\left(\widetilde{f}(\widetilde{x})-\widetilde{f}\left(\widetilde{x}^{\circ}\right)\right) /\left(\widetilde{x}-\tilde{x}^{\circ}\right) .
$$

Предел отношения (7) при неограниченном приближении независимой переменной $\tilde{x}$ к её фиксированному предельному значению $\tilde{x}^{\circ}$, если он существует, называется интервальной производной функцией от исходной интервальной функции $\tilde{f}(\widetilde{x})(1)$ в точке $\tilde{x}^{\circ}$ и обозначается $\widetilde{y}_{\widetilde{x}^{\circ}}^{\prime}$ или $\tilde{f}_{\widetilde{x}^{\circ}}^{\prime}(\widetilde{x})$. Таким образом,

$$
\tilde{y}_{\widetilde{x}^{\circ}}^{\prime} \equiv \widetilde{f}_{\widetilde{x}^{\circ}}^{\prime}(\widetilde{x})=\lim _{\widetilde{x} \rightarrow \widetilde{x}^{\circ}} \Delta \widetilde{y} / \Delta \widetilde{x}, \text { где } \Delta \widetilde{x}, \Delta \widetilde{y} \text { из }(6) .
$$

Доказано $[4,5,7]$, что для существования у непрерывной интервальной функции $\tilde{y}=\tilde{f}(\widetilde{x})$ в точке $\tilde{x}^{\circ}$ интервальной производной необходимо и достаточно, чтобы в этой точке и некоторой её окрестности как независимая $\tilde{x}$, так и зависимая $\tilde{y}$ переменные были существенно интервальными (т.е. не вырождались в точку).

Как и в случае обычной производной, понятие интервальной производной можно обобщить путём повторного выполнения операции взятия производной. При этом из интервальной производной 1-го порядка $\tilde{y}_{\widetilde{x}}^{\prime}$ получается интервальная производная 2-го порядка $\tilde{y}_{\tilde{x}}^{\prime \prime}$, а из последней - интервальная производная 3-го порядка $\tilde{y}_{\widetilde{x}}^{\prime \prime \prime}$ и т.д. Согласно введённым определениям интервальной производной любого порядка, все интервальные производные, как и исходная интервальная функция, при любом численном значении аргумента $\tilde{x}$ в виде интерва- 
ла возможных значений $\tilde{x}=\left[x_{1}, x_{2}\right]$ также принимают численные значения в виде интервала возможных значений. Поэтому вычисление интервальной функции и интервальной производной от неё любого порядка состоит в вычислении нижних и верхних граничных функций соответствующих интервальных функций. Вычисление интервальной функции $\widetilde{f}$ выполняется согласно формуле (1), задающей эту функцию в виде пары «нижняя $f_{1}$ и верхняя $f_{2}$ граничные функции». Вычисление интервальной производной любого $n$-го порядка $\tilde{y}_{\tilde{x}}^{(n)}=\widetilde{f}_{\tilde{x}}^{(n)}(\widetilde{x})$ от интервальной функции $\tilde{y}=\widetilde{f}(\widetilde{x})$ выполняется с помощью формулы [7]

$$
\tilde{y}_{\widetilde{x}}^{(n)}=\widetilde{f}_{\widetilde{x}}^{(n)}(\widetilde{x})=\left[\widetilde{f}_{1, \widetilde{x}}^{(n)}(\widetilde{x}), \widetilde{f}_{2, .,}^{(n)}(\widetilde{x})\right],
$$

где $\widetilde{f}_{1, \widetilde{x}}^{(n)}$ и $\widetilde{f}_{2, \widetilde{x}}^{(n)}$ - соответственно нижняя и верхняя граничные функции интервальной производной $\widetilde{f}_{\widetilde{x}}^{(n)} n$-го порядка от исходной интервальной функции $\tilde{y}=\widetilde{f}(\widetilde{x})$. Эти граничные функции в формуле (9) выражаются в виде

$$
\widetilde{f}_{1, \widetilde{x}}^{(n)}(\widetilde{x})=-2^{n-1}\left(y_{2}-y_{1}\right) /\left(x_{2}-x_{1}\right)^{n}, \tilde{f}_{2, \widetilde{x}}^{(n)}(\widetilde{x})=2^{n-1}\left(y_{2}-y_{1}\right) /\left(x_{2}-x_{1}\right)^{n},
$$

при этом $x_{1}, x_{2}$ - нижняя и верхняя границы интервальной независимой переменной $\tilde{x}=\left[x_{1}, x_{2}\right]$ в точке взятия производной от функции $\tilde{y}=\widetilde{f}(\widetilde{x}), y_{1}, y_{2}-$ нижняя и верхняя границы интервальной зависимой переменной $\tilde{y}=\left[y_{1}, y_{2}\right]$ этой функции в той же точке. Как следует из выражений (9), (10), интервальная производная любого порядка имеет вид интервала, симметричного относительно нуля. Это позволяет записать выражение интервальной производной любого $n$-го порядка (9), (10) в более простой форме

$$
\tilde{y}_{\widetilde{x}}^{(n)}(\widetilde{x})=\widetilde{f}_{\widetilde{x}}^{(n)}(\widetilde{x})=\left[-f_{\widetilde{x}}^{(n)}(\widetilde{x}), f_{\widetilde{x}}^{(n)}(\widetilde{x})\right],
$$

где

$$
f_{\widetilde{x}}^{(n)}(\widetilde{x})=2^{n-1}\left(y_{2}-y_{1}\right) /\left(x_{2}-x_{1}\right)^{n},
$$

а значения $x_{1}, x_{2}, y_{1}, y_{2}$ раскрыты в пояснениях к формуле (10).

Формулы (11), (12) позволяют находить интервальные производные любого порядка от любых интервальных функций, в том числе от элементарных интервальных функций.

\section{3 Производные от элементарных интервальных функций}

По определению любая элементарная интервальная функция $\widetilde{y}=\widetilde{f}(\widetilde{x})$ вида (1) получается из соответствующей элементарной вещественной функции $y=f(x)$ путём преобразования в соответствующие интервальные формы независимой переменной $\tilde{x}=\left[x_{1}, x_{2}\right]$, зависимой переменной $\tilde{y}=\left[y_{1}, y_{2}\right]$ и интервальной функции $\tilde{f}=\left[f_{1}, f_{2}\right]$. Определение производных от элементарных интервальных функций начнём с простейшей интервальной функции - интервальной константы.

Функция интервальная константа выражается в виде

$$
\tilde{y} \equiv \widetilde{c}=\left[c_{1}, c_{2}\right], \quad c_{1}=\text { const }, \quad c_{2}=\text { const }, \quad c_{1}<c_{2} .
$$

Из сравнения выражений (13) и (1) видно, что интервальная константа - это интервальная функция, нижняя и верхняя граничные функции которой имеют следующий вид

$$
y_{1}=f_{1}(\widetilde{x})=f_{1}\left(x_{1}, x_{2}\right)=c_{1}, \quad y_{2}=f_{2}(\widetilde{x})=f_{2}\left(x_{1}, x_{2}\right)=c_{2} .
$$

Подставив (14) в общие формулы интервальных производных (11), (12), получим выражение производной любого $n$-го порядка от интервальной константы $\tilde{y}=\widetilde{c}$ в виде

$$
\widetilde{y}^{(n)} \equiv \widetilde{c}^{(n)}=\left[c_{1}, c_{2}\right]=\left[-c_{\widetilde{x}}^{(n)}(\widetilde{x}), c_{\tilde{x}}^{(n)}(\widetilde{x})\right],
$$


где

$$
c_{\widetilde{x}}^{(n)}(\widetilde{x})=2^{n-1}\left(c_{2}-c_{1}\right) /\left(x_{2}-x_{1}\right)^{n} .
$$

Как видно из (15), интервальная производная любого $n$-го порядка от интервальной константы $\widetilde{c}(13)$ не равна нулю (точнее, нулевому интервалу $\widetilde{0}=[0,0]$ ), в отличие от классической производной от вещественной константы, равной нулю. Более того, эта производная не является постоянной величиной, а существенно зависит от аргумента $\tilde{x}=\left[x_{1}, x_{2}\right]$. Согласно формуле (15), она существует во всех точках $\widetilde{x}$, в которых $x_{1} \neq x_{2}$, и монотонно убывает при увеличении разности $x_{2}-x_{1}$.

Интервальная степенная функция выражается в виде

$$
\tilde{y}=\left[y_{1}, y_{2}\right]=\tilde{x}^{m} \equiv\left[x_{1}, x_{2}\right]^{m},
$$

где $\tilde{x}=\left[x_{1}, x_{2}\right]-$ интервальная независимая переменная, $\tilde{y}=\left[y_{1}, y_{2}\right]-$ интервальная зависимая переменная. Будем считать, исходя из физических соображений, что в пределах одной (любой!) решаемой задачи переменная величина $\tilde{x}=\left[x_{1}, x_{2}\right]$ может быть только неотрицательной или только неположительной, т.е. выполняется условие

$$
x_{1}, x_{2} \geq 0 \text { или } x_{1}, x_{2} \leq 0 .
$$

Тогда интервальную степенную функцию (16) можно записать в явном интервальном виде посредством следующей формулы:

$$
\tilde{y}=\left[y_{1}, y_{2}\right]= \begin{cases}{\left[x_{1}^{m}, x_{2}^{m}\right],} & \text { при } x_{1}, x_{2} \geq 0 \text { или } x_{1}, x_{2} \leq 0, m \text { нечётно; } \\ {\left[x_{2}^{m}, x_{1}^{m}\right],} & \text { при } x_{1}, x_{2} \leq 0, m \text { чётно. }\end{cases}
$$

Из сравнения выражения (18) с (1) видно, что интервальная степенная функция есть интервальная функция, нижняя и верхняя граничные функции которой имеют такой вид:

$$
\begin{aligned}
& y_{1}=f_{1}(\widetilde{x})=f_{1}\left(x_{1}, x_{2}\right)= \begin{cases}x_{1}^{m}, & \text { при } x_{1}, x_{2} \geq 0 \text { или } x_{1}, x_{2} \leq 0, m \text { нечётно; } \\
x_{2}^{m}, & \text { при } x_{1}, x_{2} \leq 0, m \text { чётно; }\end{cases} \\
& y_{2}=f_{2}(\widetilde{x})=f_{2}\left(x_{1}, x_{2}\right)= \begin{cases}x_{2}^{m}, & \text { при } x_{1}, x_{2} \geq 0 \text { или } x_{1}, x_{2} \leq 0, m \text { нечётно; } \\
x_{1}^{m}, & \text { при } x_{1}, x_{2} \leq 0, m \text { чётно }\end{cases}
\end{aligned}
$$

Подстановка (19) в (11) и (12) даёт выражение производной любого $n$-го порядка от интервальной степенной функции $\tilde{y}=\widetilde{x}^{m}(16)$ в виде

$$
\tilde{y}^{(n)}=\left(\widetilde{x}^{m}\right)^{(n)}=\left(\left[x_{1}, x_{2}\right]^{m}\right)^{(n)}=\left[-f^{(n)}(\widetilde{x}), f^{(n)}(\widetilde{x})\right],
$$

где

$$
f^{(n)}(\widetilde{x})= \begin{cases}2^{n-1}\left(x_{2}^{m}-x_{1}^{m}\right) /\left(x_{2}-x_{1}\right)^{n}, & \text { при } x_{1}, x_{2} \geq 0 \text { или } x_{1}, x_{2} \leq 0, m \text { нечётно; } \\ 2^{n-1}\left(x_{1}^{m}-x_{2}^{m}\right) /\left(x_{2}-x_{1}\right)^{n}, & \text { при } x_{1}, x_{2} \leq 0, m \text { чётно. }\end{cases}
$$

Как видно из формулы (20), в интервальной производной любого $n$-го порядка $\left(\widetilde{x}^{m}\right)^{(n)}$ от интервальной степенной функции $\widetilde{x}^{m}(16)$ при увеличении $n$ показатель степени $m$ не уменьшается, приближаясь к нулю, в отличие от классической производной от вещественной степенной функции. Интервальная производная $\left(\tilde{x}^{m}\right)^{(n)}$, согласно формуле (20), существует во всех точках $\tilde{x}=\left[x_{1}, x_{2}\right]$, в которых $x_{1} \neq x_{2}$; она монотонно убывает с увеличением разности $x_{2}-x_{1}$.

Интервальная показательная функция выражается в виде

$$
\tilde{y}=\left[y_{1}, y_{2}\right]=a^{\widetilde{x}} \equiv a^{\left[x_{1}, x_{2}\right]}, \quad a>0,
$$


где $\tilde{x}=\left[x_{1}, x_{2}\right]-$ интервальная независимая переменная, $\tilde{y}=\left[y_{1}, y_{2}\right]-$ интервальная зависимая переменная. Согласно $[4,5,7]$ интервальная функция $a^{\tilde{x}}$ определяется в виде

$$
a^{\widetilde{x}}=\left\{a^{x} \mid x \in \widetilde{x}\right\},
$$

здесь $a^{x}$-исходная обычная показательная функция, которая монотонно возрастает. Это позволяет записать интервальную показательную функцию (21) в явном интервальном виде с помощью формулы

$$
\tilde{y} \equiv\left[y_{1}, y_{2}\right]=\left[a^{x_{1}}, a^{x_{2}}\right], \quad a>0 .
$$

Сравнивая (23) с (1), устанавливаем, что интервальная показательная функция есть интервальная функция, нижняя и верхняя граничные функции которой принимают вид:

$$
y_{1}=f_{1}(\widetilde{x})=f_{1}\left(x_{1}, x_{2}\right)=a^{x_{1}}, \quad y_{2}=f_{2}(\widetilde{x})=f_{2}\left(x_{1}, x_{2}\right)=a^{x_{2}}, \quad a>0 .
$$

Подставив (24) в (11) и (12), получим выражение производной любого $n$-го порядка от интервальной показательной функции $\widetilde{y}=a^{\widetilde{x}}(21)$

$$
\tilde{y}^{(n)}=\left(a^{\widetilde{x}}\right)^{(n)}=\left(a^{\left[x_{1}, x_{2}\right]}\right)^{(n)}=\left[-f^{(n)}(\widetilde{x}), f^{(n)}(\widetilde{x})\right],
$$

где

$$
f^{(n)}(\widetilde{x})=2^{n-1}\left(a^{x_{2}}-a^{x_{1}}\right) /\left(x_{2}-x_{1}\right)^{n} .
$$

Из (25) видно, что в интервальной производной любого $n$-го порядка $\left(a^{\widetilde{x}}\right)^{(n)}$ от интервальной показательной функции $a^{\widetilde{x}}(21)$ при увеличении $n$ перед данной функцией не появляются дополнительные множители $\ln a$, в отличие от классической производной от вещественной показательной функции, у которой указанные множители появляются. Интервальная производная $\left(a^{\widetilde{x}}\right)^{(n)}$, согласно (25), существует во всех точках $\tilde{x}=\left[x_{1}, x_{2}\right]$, в которых $x_{1} \neq x_{2}$; она монотонно убывает с увеличением разности $x_{2}-x_{1}$.

Интервальная экспоненциальная функция выражается в виде

$$
\tilde{y}=\left[y_{1}, y_{2}\right]=e^{\widetilde{x}} \equiv e^{\left[x_{1}, x_{2}\right]},
$$

где $\tilde{x}=\left[x_{1}, x_{2}\right]-$ интервальная независимая переменная, $\tilde{y}=\left[y_{1}, y_{2}\right]-$ интервальная зависимая переменная. Из сравнения (21) и (26) видно, что интервальная экспоненциальная функция (26) есть частный случай интервальной показательной функции (21) при $a=e$. Таким образом, из выражения (25) производной любого $n$-го порядка от интервальной показательной функции, положив в нем $a=e$, получим следующее выражение производной любого $n$-го порядка от интервальной экспоненциальной функции

$$
\tilde{y}^{(n)}=\left(e^{\widetilde{x}}\right)^{(n)}=\left(e^{\left[x_{1}, x_{2}\right]}\right)^{(n)}=\left[-f^{(n)}(\widetilde{x}), f^{(n)}(\widetilde{x})\right],
$$

при этом

$$
f^{(n)}(\widetilde{x})=2^{n-1}\left(e^{x_{2}}-e^{x_{1}}\right) /\left(x_{2}-x_{1}\right)^{n} .
$$

Из (27) видно, что в интервальной производной $\left(e^{\widetilde{x}}\right)^{(n)}$ любого $n$-го порядка от интервальной экспоненты $e^{\widetilde{x}}(26)$ при увеличении $n$ изменяется множитель перед экспонентой, равный

$$
M=2^{n-1} /\left(x_{2}-x_{1}\right)^{n},
$$

в отличие от классической производной от вещественной экспоненты, у которой такого множителя нет. Интервальная производная $\left(e^{\widetilde{x}}\right)^{(n)}$, согласно формуле $(27)$, существует во всех точках $\tilde{x}=\left[x_{1}, x_{2}\right]$, в которых $x_{1} \neq x_{2}$. Она монотонно убывает с увеличением разности $x_{2}-x_{1}$.

Интервальная логарифмическая функция выражается в виде

$$
\tilde{y}=\left[y_{1}, y_{2}\right]=\log _{a} \tilde{x}=\log _{a}\left[x_{1}, x_{2}\right] \quad a>0,
$$


где $\tilde{x}=\left[x_{1}, x_{2}\right]-$ интервальная независимая переменная, $\tilde{y}=\left[y_{1}, y_{2}\right]-$ интервальная зависимая переменная. Согласно $[4,5,7]$ интервальная функция $\log _{a} \tilde{x}$ определяется в виде

$$
\log _{a} \tilde{x}=\left\{\log _{a} x \mid x \in \tilde{x}\right\}, \quad a>0, a \neq 1,
$$

при этом $\log { }_{a} x$ - исходная обычная логарифмическая функция, которая монотонно возрастает. Это позволяет записать интервальную логарифмическую функцию (29) в явном интервальном виде посредством формулы

$$
\tilde{y} \equiv\left[y_{1}, y_{2}\right]=\left[\log _{a} x_{1}, \log _{a} x_{2}\right], \quad a>0, a \neq 1 .
$$

Сравнивая (31) с (1), приходим к выводу, что интервальная логарифмическая функция - это интервальная функция, нижняя и верхняя граничные функции которой выглядят как

$$
y_{1}=f_{1}(\widetilde{x})=f_{1}\left(x_{1}, x_{2}\right)=\log _{a} x_{1}, \quad y_{2}=f_{2}(\widetilde{x})=f_{2}\left(x_{1}, x_{2}\right)=\log _{a} x_{2}, \quad a>0, a \neq 1 .
$$

Подставляя выражения (32) в (11) и (12), получим выражение производной любого $n$-го порядка от интервальной логарифмической функции $\tilde{y}=\log _{a} \tilde{x}$ (29) в виде

$$
\tilde{y}^{(n)}=\left(\log _{a} \widetilde{x}\right)^{(n)}=\left(\log _{a}\left[x_{1}, x_{2}\right]\right)^{(n)}=\left[-f^{(n)}(\widetilde{x}), f^{(n)}(\widetilde{x})\right],
$$

где

$$
f^{(n)}(\widetilde{x})=2^{n-1}\left(\log _{a} x_{2}-\log _{a} x_{1}\right) /\left(x_{2}-x_{1}\right)^{n}, \quad a>0, a \neq 1,
$$

или, после потенцирования,

$$
f^{(n)}(\widetilde{x})=2^{n-1} \log _{a}\left(x_{2} / x_{1}\right) /\left(x_{2}-x_{1}\right)^{n}, \quad a>0, a \neq 1 .
$$

Как видно из (33), в интервальной производной $\left(\log _{a} \tilde{x}\right)^{(n)}$ любого $n$-го порядка от интервальной функции логарифм $\log _{a} \widetilde{x}$ исходная логарифмическая функция остаётся логарифмической, в отличие от классической производной от вещественной логарифмической функции $\log _{a} x$, которая равна $1 / x \ln a$, т.е. является рациональной функцией. Интервальная производная $(\log \widetilde{x})^{(n)}$ существует во всех точках $\tilde{x}=\left[x_{1}, x_{2}\right]$, в которых $x_{1} \neq x_{2}$, и монотонно убывает с увеличением разности $x_{2}-x_{1}$.

Интервальная натуральная логарифмическая функция выражается в виде

$$
\tilde{y}=\left[y_{1}, y_{2}\right]=\ln \tilde{x}=\ln \left[x_{1}, x_{2}\right] \text {, }
$$

где $\tilde{x}=\left[x_{1}, x_{2}\right]-$ интервальная независимая переменная, $\tilde{y}=\left[y_{1}, y_{2}\right]-$ интервальная зависимая переменная. Из сравнения (29) и (34) видно, что интервальная натуральная логарифмическая функция (34) есть частный случай интервальной логарифмической функции (29) при $a=e$. Производная любого $n$-го порядка от интервальной натурально-логарифмической функции представляется в виде

$$
\tilde{y}^{(n)}=(\ln \tilde{x})^{(n)}=\left(\ln \left[x_{1}, x_{2}\right]\right)^{(n)}=\left[-f^{(n)}(\widetilde{x}), f^{(n)}(\widetilde{x})\right],
$$

где

$$
f^{(n)}(\widetilde{x})=2^{n-1} \ln \left(x_{2} / x_{1}\right) /\left(x_{2}-x_{1}\right)^{n} .
$$

Как видно из (35), интервальная производная любого $n$-го порядка $(\ln \widetilde{x})^{(n)}$ от интервальной натурально-логарифмической функции $\ln \tilde{x}$ является натурально-логарифмической, в отличие от производной от обычной натурально-логарифмической функции $\ln x$, которая равна $1 / x$ и является рациональной функцией. Найденная интервальная производная $(\ln \tilde{x})^{(n)}$ существует во всех точках $\tilde{x}=\left[x_{1}, x_{2}\right]$, в которых $x_{1} \neq x_{2}$. Она монотонно убывает с увеличением разности $x_{2}-x_{1}$.

Интервальная тригонометрическая функция синус выражается в следующем виде 


$$
\tilde{y}=\left[y_{1}, y_{2}\right]=\sin \tilde{x}=\sin \left[x_{1}, x_{2}\right],
$$

где $\tilde{x}=\left[x_{1}, x_{2}\right]-$ интервальная независимая переменная, $\tilde{y}=\left[y_{1}, y_{2}\right]-$ интервальная зависимая переменная. Согласно $[4,5,7]$ интервальная функция $\sin \tilde{x}$ определяется в виде

$$
\sin \tilde{x}=\{\sin x \mid x \in \widetilde{x}\},
$$

здесь $\sin x$ - исходная обычная тригонометрическая функция синус, которая монотонно возрастает на интервале $-\pi / 2 \leq x \leq \pi / 2$ и принимает все возможные значения от -1 до 1 . Последнее позволяет записать интервальную тригонометрическую функцию синус (37) в явном интервальном виде

$$
\tilde{y} \equiv\left[y_{1}, y_{2}\right]=\sin \tilde{x}=\sin \left[x_{1}, x_{2}\right]=\left[\sin x_{1}, \sin x_{2}\right] .
$$

Сравнивая (38) с (1), заключаем, что интервальная тригонометрическая функция синус есть интервальная функция, нижняя и верхняя граничные функции которой имеют вид

$$
y_{1}=f_{1}(\widetilde{x})=f_{1}\left(x_{1}, x_{2}\right)=\sin x_{1}, \quad y_{2}=f_{2}(\widetilde{x})=f_{2}\left(x_{1}, x_{2}\right)=\sin x_{2} .
$$

Подставляя (39) в (11) и (12), получаем выражение производной любого $n$-го порядка от интервальной тригонометрической функции $\tilde{y}=\sin \tilde{x}$ в виде

$$
\tilde{y}^{(n)}=(\sin \tilde{x})^{(n)}=\left(\sin \left[x_{1}, x_{2}\right]\right)^{(n)}=\left[-f^{(n)}(\widetilde{x}), f^{(n)}(\widetilde{x})\right],
$$

где

$$
f^{(n)}(\widetilde{x})=2^{n-1}\left(\sin x_{2}-\sin x_{1}\right) /\left(x_{2}-x_{1}\right)^{n} .
$$

Из формулы (40) видим, что в интервальной производной любого $n$-го порядка $(\sin \tilde{x})^{(n)}$ от интервальной тригонометрической функции $\sin \tilde{x}$ исходная тригонометрическая функция синус остаётся синусом, в отличие от производной от обычной тригонометрической функции $\sin x$, которая равна $\cos x$. Интервальная производная $(\sin \tilde{x})^{(n)}$ существует во всех точках $\tilde{x}=\left[x_{1}, x_{2}\right]$, в которых $x_{1} \neq x_{2}$. Она монотонно убывает с увеличением разности $x_{2}-x_{1}$.

Интервальная тригонометрическая функция косинус выражается в виде

$$
\tilde{y}=\left[y_{1}, y_{2}\right]=\cos \tilde{x}=\cos \left[x_{1}, x_{2}\right] \text {, }
$$

где $\tilde{x}=\left[x_{1}, x_{2}\right]$ - интервальная независимая переменная, $\tilde{y}=\left[y_{1}, y_{2}\right]-$ интервальная зависимая переменная. Согласно $[4,5,7]$ интервальная функция $\cos \tilde{x}$ определяется в виде

$$
\cos \tilde{x}=\{\cos x \mid x \in \tilde{x}\},
$$

здесь $\cos x$ - исходная обычная тригонометрическая функция косинус, которая монотонно убывает на интервале $0 \leq x \leq \pi$, принимая последовательно все свои возможные значения от 1 до -1. Это позволяет записать интервальную тригонометрическую функцию косинус в виде

$$
\tilde{y} \equiv\left[y_{1}, y_{2}\right]=\cos \tilde{x}=\cos \left[x_{1}, x_{2}\right]=\left[\cos x_{2}, \cos x_{1}\right] .
$$

Сравнивая (43) с (1), получаем, что интервальная тригонометрическая функция косинус является интервальной функцией, нижняя и верхняя граничные функции которой имеют вид

$$
y_{1}=f_{1}(\widetilde{x})=f_{1}\left(x_{1}, x_{2}\right)=\cos x_{2}, \quad y_{2}=f_{2}(\widetilde{x})=f_{2}\left(x_{1}, x_{2}\right)=\cos x_{1} .
$$

Подставляя (44) в (11) и (12), получим выражение производной любого $n$-го порядка от интервальной тригонометрической функции $\tilde{y}=\cos \tilde{x}$ в виде

$$
\tilde{y}^{(n)}=(\cos \widetilde{x})^{(n)}=\left(\cos \left[x_{1}, x_{2}\right]\right)^{(n)}=\left[-f^{(n)}(\widetilde{x}), f^{(n)}(\widetilde{x})\right],
$$

где

$$
f^{(n)}(\widetilde{x})=2^{n-1}\left(\cos x_{1}-\cos x_{2}\right) /\left(x_{2}-x_{1}\right)^{n} .
$$

Согласно (45), в интервальной производной любого $n$-го порядка $(\cos \tilde{x})^{(n)}$ исходная тригонометрическая функция косинус остается косинусом, в отличие от производной от вещественной тригонометрической функции $\cos x$, равной $-\sin x$. Интервальная производная 
$(\cos \tilde{x})^{(n)}$ существует во всех точках $\tilde{x}=\left[x_{1}, x_{2}\right]$, где $x_{1} \neq x_{2}$. Она монотонно убывает с увеличением разности $x_{2}-x_{1}$.

Интервальная тригонометрическая функция тангенс выражается в виде

$$
\tilde{y}=\left[y_{1}, y_{2}\right]=\operatorname{tg} \tilde{x}=\operatorname{tg}\left[x_{1}, x_{2}\right]
$$

где $\tilde{x}=\left[x_{1}, x_{2}\right]-$ интервальная независимая переменная, $\tilde{y}=\left[y_{1}, y_{2}\right]-$ интервальная зависимая переменная. Согласно $[4,5,7]$, интервальная функция $\operatorname{tg} \tilde{x}$ определяется в виде

$$
\operatorname{tg} \tilde{x}=\{\operatorname{tg} x \mid x \in \tilde{x}\},
$$

причём $\operatorname{tg} x$ - исходная обычная тригонометрическая функция тангенс, которая монотонно возрастает на интервале $-\pi / 2 \leq x \leq \pi / 2$, где она последовательно принимает все свои возможные значения от $-\infty$ до $+\infty$. Это позволяет записать интервальную тригонометрическую функцию тангенс (47) в явном интервальном виде

$$
\tilde{y} \equiv\left[y_{1}, y_{2}\right]=\operatorname{tg} \tilde{x}=\operatorname{tg}\left[x_{1}, x_{2}\right]=\left[\operatorname{tg} x_{1}, \operatorname{tg} x_{2}\right] .
$$

Сравнив выражение (48) с (1), устанавливаем, что интервальная тригонометрическая функция тангенс есть интервальная функция, нижняя и верхняя граничные функции которой имеют вид

$$
y_{1}=f_{1}(\widetilde{x})=f_{1}\left(x_{1}, x_{2}\right)=\operatorname{tg} x_{1}, \quad y_{2}=f_{2}(\widetilde{x})=f_{2}\left(x_{1}, x_{2}\right)=\operatorname{tg} x_{2} .
$$

Подставляя (49) в (11) и (12), получим выражение производной любого $n$-го порядка от интервальной тригонометрической функции $\tilde{y}=\operatorname{tg} \tilde{x}$ в виде

$$
\widetilde{y}^{(n)}=(\operatorname{tg} \widetilde{x})^{(n)}=\left(\operatorname{tg}\left[x_{1}, x_{2}\right]\right)^{(n)}=\left[-f^{(n)}(\widetilde{x}), f^{(n)}(\widetilde{x})\right],
$$

где

$$
f^{(n)}(\widetilde{x})=2^{n-1}\left(\operatorname{tg} x_{2}-\operatorname{tg} x_{1}\right) /\left(x_{2}-x_{1}\right)^{n} .
$$

Формула (50) показывает, что в интервальной производной любого $n$-го порядка $(\operatorname{tg} \tilde{x})^{(n)}$ от интервальной тригонометрической функции $\operatorname{tg} \tilde{x}$ исходная тригонометрическая функция тангенс остаётся тангенсом, в отличие от классической производной от вещественной тригонометрической функции $\operatorname{tg} x$, равной $1 / \cos ^{2} x$. Интервальная производная $(\operatorname{tg} \tilde{x})^{(n)}$ существует во всех точках $\tilde{x}=\left[x_{1}, x_{2}\right]$, где $x_{1} \neq x_{2}$. Она монотонно убывает с увеличением разности $x_{2}-x_{1}$.

Интервальная тригонометрическая функция котангенс выражается в виде

$$
\tilde{y}=\left[y_{1}, y_{2}\right]=\operatorname{ctg} \tilde{x}=\operatorname{ctg}\left[x_{1}, x_{2}\right],
$$

где $\tilde{x}=\left[x_{1}, x_{2}\right]-$ интервальная независимая переменная, $\tilde{y}=\left[y_{1}, y_{2}\right]-$ интервальная зависимая переменная. Согласно $[4,5,7]$, интервальная функция $\operatorname{ctg} \tilde{x}$ определяется в виде

$$
\operatorname{ctg} \tilde{x}=\{\operatorname{ctg} x \mid x \in \widetilde{x}\},
$$

здесь $\operatorname{ctg} x$ - исходная обычная тригонометрическая функция котангенс, которая монотонно убывает на интервале $0 \leq x \leq \pi$, где она последовательно принимает все возможные значения от $+\infty$ до $-\infty$. Это позволяет записать интервальную тригонометрическую функцию (52) в явном интервальном виде

$$
\tilde{y} \equiv\left[y_{1}, y_{2}\right]=\operatorname{ctg} \tilde{x}=\operatorname{ctg}\left[x_{1}, x_{2}\right]=\left[\operatorname{ctg} x_{2}, \operatorname{ctg} x_{1}\right] .
$$

Сравнивая (53) с (1), видим, что интервальная тригонометрическая функция котангенс есть интервальная функция, нижняя и верхняя граничные функции которой имеют вид

$$
y_{1}=f_{1}(\widetilde{x})=f_{1}\left(x_{1}, x_{2}\right)=\operatorname{ctg} x_{2}, \quad y_{2}=f_{2}(\widetilde{x})=f_{2}\left(x_{1}, x_{2}\right)=\operatorname{ctg} x_{1} .
$$

Подставляя (54) в (11) и (12), получаем выражение производной любого $n$-го порядка от интервальной тригонометрической функции $\tilde{y}=\operatorname{ctg} \tilde{x}$ в виде

$$
\tilde{y}^{(n)}=(\operatorname{ctg} \widetilde{x})^{(n)}=\left(\operatorname{ctg}\left[x_{1}, x_{2}\right]\right)^{(n)}=\left[-f^{(n)}(\widetilde{x}), f^{(n)}(\widetilde{x})\right],
$$


где

$$
f^{(n)}(\widetilde{x})=2^{n-1}\left(\operatorname{ctg} x_{1}-\operatorname{ctg} x_{2}\right) /\left(x_{2}-x_{1}\right)^{n} .
$$

Выражение (55) показывает, что в интервальной производной любого $n$-го порядка $(\operatorname{ctg} \tilde{x})^{(n)}$ от интервальной тригонометрической функции $\mathrm{ctg} \tilde{x}$ исходная тригонометрическая функция котангенс остаётся котангенсом, в отличие от классической производной от обычной тригонометрической функции $\operatorname{ctg} x$, которая равна $-1 / \sin ^{2} x$. Интервальная производная $(\operatorname{ctg} \widetilde{x})^{(n)}$ существует во всех точках $\tilde{x}=\left[x_{1}, x_{2}\right]$, в которых $x_{1} \neq x_{2}$. Она монотонно убывает с увеличением разности $x_{2}-x_{1}$.

Интервальная обратная тригонометрическая функция арксинус выражается в виде

$$
\tilde{y}=\left[y_{1}, y_{2}\right]=\arcsin \tilde{x}=\arcsin \left[x_{1}, x_{2}\right] \text {, }
$$

где $\tilde{x}=\left[x_{1}, x_{2}\right]-$ интервальная независимая переменная, $\tilde{y}=\left[y_{1}, y_{2}\right]-$ интервальная зависимая переменная. Согласно $[4,5,7]$, интервальная функция $\arcsin \tilde{x}$ определяется в виде

$$
\arcsin \tilde{x}=\{\arcsin x \mid x \in \tilde{x}\},
$$

в котором $\arcsin x$ есть исходная обычная обратная тригонометрическая функция арксинус. Последняя монотонно возрастает на интервале $-1 \leq x \leq 1$, проходя последовательно все возможные значения от $-\pi / 2$ до $\pi / 2$. Это позволяет записать интервальную обратную тригонометрическую функцию (57) в явном интервальном виде следующим образом

$$
\tilde{y} \equiv\left[y_{1}, y_{2}\right]=\arcsin \tilde{x}=\arcsin \left[x_{1}, x_{2}\right]=\left[\arcsin x_{1}, \arcsin x_{2}\right] \text {. }
$$

Сравнивая (58) с (1), устанавливаем, что интервальная обратная тригонометрическая функция арксинус является интервальной функцией, нижняя и верхняя граничные функции которой имеют вид

$$
y_{1}=f_{1}(\widetilde{x})=f_{1}\left(x_{1}, x_{2}\right)=\arcsin x_{1}, \quad y_{2}=f_{2}(\widetilde{x})=f_{2}\left(x_{1}, x_{2}\right)=\arcsin x_{2} .
$$

Подставив (59) в (11) и (12), получим выражение производной любого $n$-го порядка от интервальной обратной тригонометрической функции $\tilde{y}=\arcsin \tilde{x}$ в виде

$$
\tilde{y}^{(n)}=(\arcsin \widetilde{x})^{(n)}=\left(\arcsin \left[x_{1}, x_{2}\right]\right)^{(n)}=\left[-f^{(n)}(\widetilde{x}), f^{(n)}(\widetilde{x})\right],
$$

где

$$
f^{(n)}(\widetilde{x})=2^{n-1}\left(\arcsin x_{2}-\arcsin x_{1}\right) /\left(x_{2}-x_{1}\right)^{n} .
$$

Как видно из формулы (60), в интервальной производной любого $n$-го порядка $(\arcsin \tilde{x})^{(n)}$ от интервальной обратной тригонометрической функции $\arcsin \tilde{x}$ исходная обычная обратная тригонометрическая функция арксинус остаётся арксинусом, в отличие от производной от обычной обратной тригонометрической функции $\arcsin x$, равной $1 / \sqrt{1-x^{2}}$. Производная $(\arcsin \tilde{x})^{(n)}$ существует во всех точках $\tilde{x}=\left[x_{1}, x_{2}\right]$, где $x_{1} \neq x_{2}$ и монотонно убывает с увеличением разности $x_{2}-x_{1}$.

Интервальная обратная тригонометрическая функция арккосинус выражается в виде

$$
\tilde{y}=\left[y_{1}, y_{2}\right]=\arccos \tilde{x}=\arccos \left[x_{1}, x_{2}\right],
$$

где $\widetilde{x}=\left[x_{1}, x_{2}\right]-$ интервальная независимая переменная, $\tilde{y}=\left[y_{1}, y_{2}\right]-$ интервальная зависимая переменная. Согласно $[4,5,7]$, интервальная функция $\arccos \tilde{x}$ определяется в виде

$$
\arccos \tilde{x}=\{\arccos x \mid x \in \tilde{x}\},
$$

при этом $\arccos x$ - исходная обычная обратная тригонометрическая функция арккосинус, которая монотонно убывает на интервале $-1 \leq x \leq 1$, проходя последовательно все возможные значения от $\pi$ до 0 . Это позволяет записать функцию арккосинус (62) в интервальном виде 


$$
\tilde{y} \equiv\left[y_{1}, y_{2}\right]=\arccos \tilde{x}=\arccos \left[x_{1}, x_{2}\right]=\left[\arccos x_{2}, \arccos x_{1}\right] .
$$

Сравнив выражение (63) с (1), видим, что интервальная обратная тригонометрическая функция арккосинус является интервальной функцией, нижняя и верхняя граничные функции которой имеют вид

$$
y_{1}=f_{1}(\widetilde{x})=f_{1}\left(x_{1}, x_{2}\right)=\arccos x_{2}, \quad y_{2}=f_{2}(\widetilde{x})=f_{2}\left(x_{1}, x_{2}\right)=\arccos x_{1} .
$$

Подставив выражения (64) в (11) и (12), получим выражение производной любого $n$-го порядка от интервальной обратной тригонометрической функции $\tilde{y}=\arccos \tilde{x}$ в виде

$$
\tilde{y}^{(n)}=(\arccos \widetilde{x})^{(n)}=\left(\arccos \left[x_{1}, x_{2}\right]\right)^{(n)}=\left[-f^{(n)}(\widetilde{x}), f^{(n)}(\widetilde{x})\right],
$$

где

$$
f^{(n)}(\widetilde{x})=2^{n-1}\left(\arccos x_{1}-\arccos x_{2}\right) /\left(x_{2}-x_{1}\right)^{n} .
$$

Формула (65) показывает, что в интервальной производной любого $n$-го порядка $(\arccos \tilde{x})^{(n)}$ от интервальной обратной тригонометрической функции $\arccos \tilde{x}$ исходная обычная обратная тригонометрическая функция арккосинус остаётся арккосинусом, в отличие от производной от обычной обратной тригонометрической функции $\arccos x$, которая равна $-1 / \sqrt{1-x^{2}}$. Интервальная производная $(\arccos \tilde{x})^{(n)}$ существует во всех точках $\tilde{x}=\left[x_{1}, x_{2}\right]$, в которых $x_{1} \neq x_{2}$. Она монотонно убывает с увеличением разности $x_{2}-x_{1}$.

\section{Интервальная обратная тригонометрическая функция арктангенс выражается в виде}

$$
\tilde{y}=\left[y_{1}, y_{2}\right]=\operatorname{arctg} \tilde{x}=\operatorname{arctg}\left[x_{1}, x_{2}\right] \text {, }
$$

где $\tilde{x}=\left[x_{1}, x_{2}\right]-$ интервальная независимая переменная, $\tilde{y}=\left[y_{1}, y_{2}\right]-$ интервальная зависимая переменная. Согласно $[4,5,7]$ интервальная функция $\operatorname{arctg} \tilde{x}$ определяется в виде

$$
\operatorname{arctg} \tilde{x}=\{\operatorname{arctg} x \mid x \in \widetilde{x}\},
$$

в котором $\operatorname{arctg} x-$ исходная обычная обратная тригонометрическая функция арктангенс. Последняя монотонно возрастает на интервале $-\infty<x<\infty$, проходя последовательно все возможные значения от $-\pi / 2$ до $\pi / 2$, что даёт возможность записать интервальную обратную тригонометрическую функцию арктангенс (67) в виде

$$
\widetilde{y} \equiv\left[y_{1}, y_{2}\right]=\operatorname{arctg} \widetilde{x}=\operatorname{arctg}\left[x_{1}, x_{2}\right]=\left[\operatorname{arctg} x_{1}, \operatorname{arctg} x_{2}\right] \text {. }
$$

Сравнив выражение (68) с (1), увидим, что интервальная обратная тригонометрическая функция арктангенс является интервальной функцией, нижняя и верхняя граничные функции которой имеют вид

$$
y_{1}=f_{1}(\widetilde{x})=f_{1}\left(x_{1}, x_{2}\right)=\operatorname{arctg} x_{1}, \quad y_{2}=f_{2}(\widetilde{x})=f_{2}\left(x_{1}, x_{2}\right)=\operatorname{arctg} x_{2} .
$$

Подставив (69) в (11) и (12), найдём выражение производной любого $n$-го порядка от интервальной обратной тригонометрической функции $\tilde{y}=\operatorname{arctg} \tilde{x}$ в виде

$$
\tilde{y}^{(n)}=(\operatorname{arctg} \tilde{x})^{(n)}=\left(\operatorname{arctg}\left[x_{1}, x_{2}\right]\right)^{(n)}=\left[-f^{(n)}(\widetilde{x}), f^{(n)}(\widetilde{x})\right],
$$

где

$$
f^{(n)}(\widetilde{x})=2^{n-1}\left(\operatorname{arctg} x_{2}-\operatorname{arctg} x_{1}\right) /\left(x_{2}-x_{1}\right)^{n} .
$$

Формула (70) показывает, что в интервальной производной любого $n$-го порядка $(\operatorname{arctg} \widetilde{x})^{(n)}$ от интервальной обратной тригонометрической функции $\operatorname{arctg} \widetilde{x}$ исходная обратная тригонометрическая функция арктангенс остаётся арктангенсом, в отличие от производной от обычной обратной тригонометрической функции $\operatorname{arctg} x$, которая равна $1 /\left(1+x^{2}\right)$. Интервальная производная $(\operatorname{arctg} \tilde{x})^{(n)}$ существует во всех точках $\tilde{x}=\left[x_{1}, x_{2}\right]$, в которых $x_{1} \neq x_{2}$. Она монотонно убывает с увеличением разности $x_{2}-x_{1}$. 
Интервальная обратная тригонометрическая функция арккотангенс выражается в следующем виде

$$
\tilde{y}=\left[y_{1}, y_{2}\right]=\operatorname{arcctg} \tilde{x}=\operatorname{arcctg}\left[x_{1}, x_{2}\right],
$$

где $\tilde{x}=\left[x_{1}, x_{2}\right]-$ интервальная независимая переменная, $\tilde{y}=\left[y_{1}, y_{2}\right]-$ интервальная зависимая переменная. Согласно $[4,5,7]$ интервальная функция $\operatorname{arcctg} \tilde{x}$ определяется в виде $\operatorname{arcctg} \tilde{x}=\{\operatorname{arcctg} x \mid x \in \widetilde{x}\}$,

при этом $\operatorname{arcctg} x$ есть исходная обычная обратная тригонометрическая функция арккотангенс. Последняя монотонно убывает на интервале $-\infty<x<\infty$ и проходит последовательно все возможные значения от $\pi$ до 0 . Это позволяет записать интервальную обратную тригонометрическую функцию арккотангенс (72) в виде

$$
\tilde{y} \equiv\left[y_{1}, y_{2}\right]=\operatorname{arcctg} \tilde{x}=\operatorname{arcctg}\left[x_{1}, x_{2}\right]=\left[\operatorname{arcctg} x_{2}, \operatorname{arcctg} x_{1}\right] \text {. }
$$

Сравнив (73) с (1), видим, что интервальная обратная тригонометрическая функция арккотангенс является интервальной функцией, нижняя и верхняя граничные функции которой имеют вид

$$
y_{1}=f_{1}(\widetilde{x})=f_{1}\left(x_{1}, x_{2}\right)=\operatorname{arcctg} x_{2}, \quad y_{2}=f_{2}(\widetilde{x})=f_{2}\left(x_{1}, x_{2}\right)=\operatorname{arcctg} x_{1} .
$$

Подставив (74) в (11) и (12), получим выражение производной любого $n$-го порядка от интервальной обратной тригонометрической функции $\tilde{y}=\operatorname{arcctg} \tilde{x}$ в виде

$$
\tilde{y}^{(n)}=(\operatorname{arcctg} \tilde{x})^{(n)}=\left(\operatorname{arcctg}\left[x_{1}, x_{2}\right]\right)^{(n)}=\left[-f^{(n)}(\widetilde{x}), f^{(n)}(\widetilde{x})\right],
$$

где

$$
f^{(n)}(\widetilde{x})=2^{n-1}\left(\operatorname{arcctg} x_{1}-\operatorname{arcctg} x_{2}\right) /\left(x_{2}-x_{1}\right)^{n} .
$$

Формула (75) показывает, что в интервальной производной любого $n$-го порядка $(\operatorname{arcctg} \tilde{x})^{(n)}$ от интервальной обратной тригонометрической функции $\operatorname{arcctg} \tilde{x}$ исходная обратная тригонометрическая функция арккотангенс остаётся арккотангенсом, в отличие от производной от обычной обратной тригонометрической функции $\operatorname{arcctg} x$, которая равна $-1 /\left(1+x^{2}\right)$. Интервальная производная $(\operatorname{arcctg} \tilde{x})^{(n)}$ существует во всех точках $\widetilde{x}=\left[x_{1}, x_{2}\right]$, в которых $x_{1} \neq x_{2}$. Она монотонно убывает с увеличением разности $x_{2}-x_{1}$.

\section{4 Обсуждение}

Проблема вычисления производных от интервально-определённых функций существенно отличается от аналогичной проблемы для полностью определённых функций. Это отличие связано с известным отличием процесса вычисления полностью определённой функции от процесса вычисления интервальной функции - во втором случае приходится вычислять параллельно две независимые точно заданные функции - нижнюю и верхнюю граничные функции интервальной функции. В связи с этим отличием вычисление неполностью определённой - интервальной функции оказывается более сложным [8-13]. Эта сложность вычисления распространяется и на производные от интервальных функций, поскольку они также являются интервальными функциями. Поэтому предпринятое в статье детальное изучение производных элементарных функций, сопровождаемое получением простых формул для вычисления этих производных, является важным шагом на пути уменьшения сложности вычисления интервальных функций.

В процессе изучения выявлены различия между интервальными производными от интервальных элементарных функций и классическими производными от детерминированных элементарных функций. Главное различие состоит в том, что производная любого $n$-го 
$(n=1,2, \ldots)$ порядка от любой интервальной функции $\widetilde{P}(\widetilde{x})$, в частности, элементарной функции, всегда представляет собой функцию класса $\widetilde{P}(\widetilde{x}) / \widetilde{x}^{n}$. Поэтому интервальную производную любого $n$-го порядка с полным правом можно интерпретировать как скорость $n$-го порядка изменения функции $P(\widetilde{x})$ относительно её аргумента $\widetilde{x}$. Известно, что классическая производная любого порядка $n$ от любой детерминированной функции $P(x)$ не обязательно представляет собой функцию класса $P(x) / x^{n}$. Поэтому такую производную в общем случае нельзя интерпретировать как скорость $n$-го порядка изменения функции $P(x)$ относительно её аргумента. Это означает, в свою очередь, что классическая производная Ньютона-Лейбница, в отличие от интервальной производной, вообще говоря, не может считаться адекватной моделью динамики большинства природных объектов и процессов.

\section{Заключение}

В работе получен полный набор производных любых порядков от всех элементарных интервальных функций. Выявлены различия между интервальными производными от интервальных элементарных функций и классическими производными от обычных детерминированных элементарных функций. Показано, что учёт неопределённости исходных функций в форме интервальности их возможных значений делает производные от них адекватными моделями динамики природных процессов.

\section{Список источников}

[1] Гнеденко, Б.В. Курс теории вероятностей / Б.В. Гнеденко // - М.: Наука, 2004. - 350 с.

[2] Заде, Л.А. Понятие лингвистической переменной и его применение к принятию приближенных решений / Л.А. Заде // - М.: Мир, 1976. - 160 с.

[3] Алефельд, Г. Введение в интервальные вычисления / Г. Алефельд, Ю. Херцбергер // - М.: Мир, 1987. $356 \mathrm{c}$.

[4] Левин, В.И. Интервальная производная и начала недетерминистского дифференциального исчисления / В.И. Левин // Онтология проектирования. - 2013. - № 4. - С. 72-84.

[5] Левин, В.И. Интервально-дифференциальное исчисление и некоторые его применения / В.И. Левин // Информационные технологии. - 2014. - № 7. - С. 3-10.

[6] Фихтенгольи, Г.М. Курс дифференциального и интегрального исчисления. Т. 1. / Г.М. Фихтенгольц // - М.: Физматлит, 2001. - 616 с.

[7] Левин, В.И. Дифференциальное исчисление для интервально-определенных функций / В.И. Левин // Эвристические алгоритмы и распределенные вычисления. - 2015. Т. 2. - № 2. - С. 8-25.

[8] Вощинин, А.П. Оптимизация в условиях неопределённости / А.П. Вощинин, Г.Р. Сотиров //. - М: Изд-во МЭИ, 1989. - 224 с.

[9] Ащепков, Л.T. Универсальные решения интервальных задач оптимизации и управления / Л.Т. Ащепков, Д.В. Давыдов // - М.: Наука, 2006. - 285 с.

[10] Moore R.E. Interval Analysis. - N.Y.: Prentice-Hall, 1966. - 230 p.

[11] Libura M. Integer Programming Problems with Inexact Objective Function // Control and Cybernetics. - 1980. Vol. 9. - № 4. - P. 189-202.

[12] Куржанский, А.Б. Задача идентификации - теория гарантированных оценок / А.Б. Куржанский // Автоматика и телемеханика. - 1991. - № 4. - С. 447-465.

[13] Hyvonen E. Constraint Reasoning Based on Interval Arithmetic: the Tolerance Propagation Approach // Artificial Intelligence. - 1992. Vol. 58. - P. 19. 


\title{
DIFFERENTIAL CALCULUS OF INTERVAL ELEMENTARY FUNCTIONS AND DECISION-MAKING
}

\author{
V.I. Levin
}

Penza State Technological University, Penza, Russia

vilevin@mail.ru

\begin{abstract}
The article deals with problems, related to calculation of derivatives of interval-specified functions. These problems are relevant in study of systems with any level of uncertainty (nondeterministic systems). Specifically we speak about simple systems described by elementary interval-specific functions. Accordingly we solved the problem of calculating derivatives of elementary interval-specified functions. Previously obtained formulas and methods of finding of derivatives of any intervally defined functions are used. Basic definitions, related to derivatives of the interval-specified functions, are given and formulas of two types allowing calculation of interval derivatives are presented. Formulas of the first type express derivatives in the closed interval form, which requires computation using the apparatus of interval mathematics. But formulas of the second type express derivatives in open interval form, i.e. in form of two formulas. Formulas above expresses the lower and the upper limits of the interval representing the derivative. Here the calculation of the derivative of interval-defined function is reduced to computation of two ordinary certain functions. Using the aforementioned mathematical apparatus we find the derivatives of all elementary interval functions: interval constant, interval power function, interval exponential function, interval logarithmic function, interval natural-logarithmic function, interval trigonometric functions (cosine, sine, tangent, cotangent), interval inverse trigonometric functions. Formulas of all the derivatives are shown in form of an open interval. The difference between derivatives of interval elementary functions and the derivatives of normal (i.e. noninterval) elementary functions is discussed.
\end{abstract}

Keywords: interval value, interval function, interval derivative, interval computations, interval-differential calculus, interval elementary functions.

Citation: Levin VI, Differential calculus of interval elementary functions and decision-making [In Russian]. Ontology of designing. 2016; 6(21): 340-354. DOI: 10.18287/2223-9537-2016-6-3-340-354.

\section{References}

[1] Gnedenko BV. Kurs Teorii Veroyatnostey [In Russian]. - Moscow: Nauka, 2004. - 350 p.

[2] Zadeh LA. The Concept of a Linguistic Variable and its Application to Approximate Reasoning // Information Sciences. - 1975. - № 8; 9. - P. 199-249, 301-357; 43-80.

[3] Alefeld G, Herzberger J. Introduction to Interval Computation. - N.Y.: Academic Press, $1983-352$ p.

[4] Levin VI. The interval derivative and the basis of nondeterministic differential calculus [In Russian]. Ontology of designing. 2013; № 4 (10): 72-84.

[5] Levin VI. Interval-differential calculus and some of its applications [In Russian]. Informacionnye Tehnologii. 2014; № 7: 3-10.

[6] Fihtengolz GM. Differential and integral calculus [In Russian]. V. 1. - M.: Fizmatlit, 2001. - 616 p.

[7] Levin VI. Differential calculus for interval-specific functions [In Russian]. Heuristic algorithms and distributed computing. 2015; 2(2): 8-25.

[8] Voschinin AP, Sotirov GR. Optimization under conditions of uncertainty [In Russian]. - M: MEI Publishers, 1989. $224 \mathrm{p}$.

[9] Aschepkov LT, Davydov DV. Universal solution of interval governance and optimization problems [In Russian]. M.: Nauka, 2006. - 285 p.

[10] Moore RE. Interval Analysis. - N.Y.: Prentice-Hall, 1966. - 230 p.

[11] Libura M. Integer Programming Problems with Inexact Objective Function. Control and Cybernetics. - 1980 . Vol. 9. - № 4. - P. 189-202.

[12] Kurzhanskiy $A B$. Identification Problem - Theory of Guaranteed Estimates [In Russian]. Automation and Remote Control. - 1991. Vol. 52. - № 4. - P. 447-465.

[13] Hyvonen E. Constraint Reasoning Based on Interval Arithmetic: the Tolerance Propagation Approach // Artificial Intelligence. - 1992. Vol. 58. - P. 19. 


\section{Сведения об авторе}

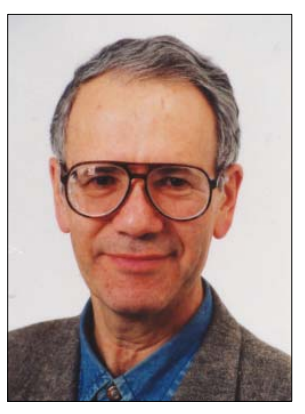

Левин Виталий Ильич окончил Каунасский политехнический ин-т, Открытый ун-т Израиля. Доктор технических наук, професcop, PhD, Full Professor, заведующий кафедрой математики (1975-2000), советник рек-тора по науке (2006-2011) Пензенского гососударственного технологического университетата, профессор Московского университета им. С.Ю. Витте (с 2003 г.). В списке научных трудов сотни работ (в том числе десятки монографий) по логике; математическому моделированию в технике, экономике, социологии, принятию решений; оптимизации; теории надежности; истории науки; проблемам образования. Действительный член МАИ, ЕАИ, МАНЭБ и АСН, заслуженный деятель науки Российской Федерации, лауреат международных премий «Соросовский профессор», Международный эксперт в области социологии конфликта и рейтингования униерситетов.

Vitaly I. Levin graduated from Kaunas Politechnical Institute, Open University of Israel, Doctor of Engineering Science, Professor, PhD, Full Professor. Head of Mathematics Department (1975-2000), the scientific counselor of rector (2006-2011) of Penza State Technological University, professor of Moscow University named after S.J. Vitte (since 2003). He is the autor of hundreds of publications (among them dozens of monographs), in logic; mathematical modelling of engineering, economics, sociology; optimization; reliability; history of science; education problems. The member of IIA, EIA, IAELP, ASS. Honoured scientist of Russia, Laureate of International Prizes "Soros Professor", International Reviewer in Sociology of conflicts and Universiry ranking. 


\title{
КОНЦЕПЦИЯ МНОГОАЛЬТЕРНАТИВНОСТИ В ЖИВЫХ И НЕЖИВЫХ СТРУКТУРАХ
}

\author{
С.Л. Подвальный ${ }^{1}$, Е.М. Васильев ${ }^{2}$ \\ Воронежский государственный технический университет, Воронеж, Россия \\ 1spodvalny@yandex.ru, 22vgtu-aits@yandex.ru
}

\begin{abstract}
Аннотация
В статье рассматриваются механизмы эволюционных процессов, составляющие конструктивноориентированную концепцию существования и развития живого и неживого мира - концепцию многоальтернативности. В рамках этой концепции обсуждаются взаимосвязанные и взаимодополняющие друг друга эволюционные принципы многообразия, дискретности и иерархии процессов и структур. Показано, что возможность эволюции определяется, прежде всего, гетерогенностью форм существования материи, порождающей многообразие их новых свойств. Отмечено, что указанное многообразие необходимо обеспечивается дискретностью элементов физических и биологических систем, образующей комбинаторное множество системных конфигураций и их состояний. Раскрывается взаимосвязь иерархии процессов и структур со свойствами их устойчивости и гомеостазисом. Приведены примеры использования изложенных принципов многоальтернативности в проектировании высоконадёжных систем электроснабжения космических станций и построении эволюционных алгоритмов систем принятия решений.
\end{abstract}

Ключевье слова: открытые системы, эволючия, структура, живая и неживая природа, многоальтернативность.

Цитирование: Подвальный, С.Л. Концепция многоальтернативности в живых и неживых структурах / С.Л. Подвальный, Е.М. Васильев // Онтология проектирования. - 2016. - Т. 6, №3(21). C. 355-367. - DOI: 10.18287/2223-9537-2016-6-3-355-367.

\section{Введение}

Эволюционные процессы в живых и неживых структурах, достаточно долго рассматриваемые в научной картине мира как взаимные противоположности, утратили свой антагонизм с появлением теории открытых диссипативных систем $[1,2]$. Вместе с тем, доказанная непротиворечивость указанных процессов оставляет в стороне вопрос о сходстве этих эволюций, механизмы протекании которых в живой и неживой природе существенно различаются [3]. Онтологическое значение этого вопроса [4-7] дополняется актуальными потребностями теоретических и прикладных исследований в области проектирования структурно сложных открытых систем различного назначения [8-10] и интеллектуальных систем принятия решений [11-13], нуждающихся в практических рекомендациях по управлению такими системами и оценке их возможностей.

Закономерности эволюционных процессов, являющиеся общими для живых и неживых структур, вызывают интерес у широкого круга исследователей, работающих в области биокибернетики и её приложений.

В работе [14] рассматривается теория эволюционного усложнения биологических систем на основе иерархически последовательных метасистемных переходов: существующие биологически устойчивые подсистемы объединяются общим механизмом управления, вследствие чего формируется система нового иерархического уровня, которая, в свою очередь, является 
подсистемой более высокого уровня управления. В $[15,16]$ в качестве одного из общих механизмов эволюции материи описывается блочный принцип формирования новых структур из уже «опробованных», т.е. жизнеспособных (устойчивых) блоков на основе матричной репликации - способности к самоинструктирующему усложнению. С точки зрения эволюции такая способность оказывается более ценной для самоорганизации системы, нежели степень приспособленности к текущим условиям среды. Исследуя возможность самоорганизации искусственных систем Дж. фон Нейман [17] установил существование некоторого критического уровня сложности самовоспроизводящегося автомата, ниже которого воспроизводятся автоматы с более низкой и даже вырождающейся сложностью, а выше этого уровня, названного впоследствии точкой невозврата, сложность автомата, как информационной системы, может возрастать. Критерием указанной сложности для клеточного автомата является комбинаторное многообразие, определяемое числом клеток и количеством состояний каждой из них. Частные случаи такой самоорганизации обнаруживают автоматы Лэнгтона [18] и Кодда [19], самовоспроизведение или упорядоченное движение которых возникает, начиная только с некоторого уровня их сложности.

Работы $[20,21]$ указывают на тесную взаимосвязь физической неоднородности сложных систем с информационным принципом необходимого разнообразия У. Эшби, приводящей, в конечном счёте, к существованию у систем некоторой конечной информационной сложности, достаточной для их устойчивого эволюционного развития и, кроме того, обусловливающей эффективную познаваемость таких систем. Иными словами, идее «неупрощаемой сложности» систем [22] противопоставляется принципиально иная онтологическая предпосылка «неусложняемой простоты» законов построения и функционирования сколь угодно сложной системы.

Указанная предпосылка эволюции развивается в работах [23-27] на основе научного направления «Общая формальная технология» (ОФТ), позволяющего по-новому взглянуть на важность концепции сложности систем в процессах эволюции [24]. В частности, в $[24,25]$, отмечается, что функциональность некоторой сложной конструкции «растёт с ростом числа функциональных объектов в конструкции и неизбежно достигает такого значения, что оказывается достаточной для реализации функциональной сложности процесса собственного воспроизведения». При выполнении ряда условий такая функциональность становится избыточной и возникает «возможность получения бесконечного числа новых конструкций» [25], т.е. возможность протекания эволюционного процесса. На основе ОФТ в настоящее время получены важные практические результаты при построении высоконадёжных гетерогенных электронных схем [26, 27].

Предлагаемая работа лежит в русле указанных исследований общих закономерностей эволюционных процессов. В качестве конструктивной парадигмы, объединяющей эволюцию живого и неживого и отвечающей отмеченным выше необходимым условиям её протекания, рассматривается концепция многоальтернативности, основанная на принципах многообразия, дискретности и иерархии процессов и структур [28-31].

\section{1 Принцип многообразия}

Многообразие неживых форм строения материи, начиная с уровня элементарных частиц, обусловливает эволюционный, лавинообразный рост числа организованных структур, обладающих новыми физическими и химическими свойствами, а значит, и способностью к устойчивому существованию в разных условиях. Поскольку совокупность однородных элементов не порождает новых свойств, то возможность эволюции предопределяется наличием только разнотипного «исходного материала». 
В качестве примера практической реализации принципа многообразия можно привести создание высокоэффективных преобразователей солнечной энергии на основе арсенидгаллиевой гетерогенной структуры AlGaAs-GaAs, в несколько раз превосходящей по своим энергетическим показателям моноструктуры на кремниевой основе [32]. Создание многослойных фотоэлементов из разных сплавов галлия с индием, фосфором, азотом позволяет преобразовывать в электрическую энергию разные диапазоны спектра светового излучения, т.е. наиболее полно использовать его энергию.

Следует заметить, что известный в настоящее время наиболее совершенный биологический механизм хлорофильного фотосинтеза также является гетерогенной структурой, содержащей две фотосистемы с взаимодополняющими функциями [33].

Существенно, что отмеченное выше состояние устойчивости процесса не означает его равновесности. На рисунке 1 показан глобально устойчивый, но неравновесный процесс, происходящий в нелинейной системе второго порядка с внешним гармоническим воздействием [34].

Хаотические фазовые траектории на рисунке 1а несут в себе скрытую упорядоченную фрактальную структуру движения, проявляющуюся в отображениях Пуанкаре (рисунок 1б).
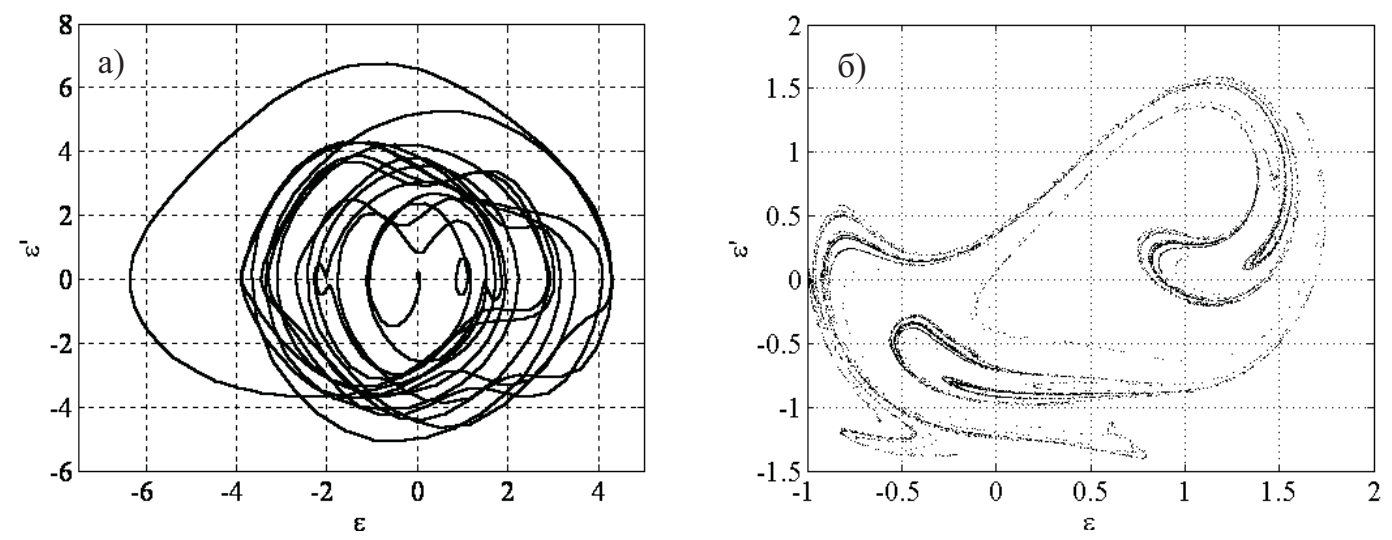

Рисунок 1 - Иллюстрация устойчивого неравновесного процесса

Таким образом, множество устойчивых физических структур включает в себя обширный класс неравновесных, хаотических процессов, обладающих чувствительностью к малым изменениям начальных условий движения и вытекающей из этого высокой порождающей способностью эволюционного многообразия.

Многообразие в биологических системах является достаточно очевидным свойством живой природы, значение которого закреплено конвенцией ООН [35]. Эволюционная необходимость этого многообразия заключается не только в обеспечении непрерывности трофических (пищевых) связей в биосистеме при возникновении условий, неблагоприятных для существования той или иной её части (видовой уровень), но и в поставке генетического материала для механизма естественного отбора, т.е. лежит в основе эволюции живого мира (генетический уровень) [36]. На уровне отдельных организмов многообразие приспособительных механизмов широко проявляется в форме специализации и разделения не только физиологически различных, но и одинаковых функций организма, реализуемых в разных условиях. В качестве примера можно привести результат эволюции зрения животных, в частности, приматов, приведший к формированию цветовосприимчивых, но с низкой светочувствительностью зрительных рецепторов - колбочек, функционирующих в светлое время суток, и высокочувствительных рецепторов - палочек, не воспринимающих цвет и функционирующих при малых уровнях яркости (рисунок 2). 

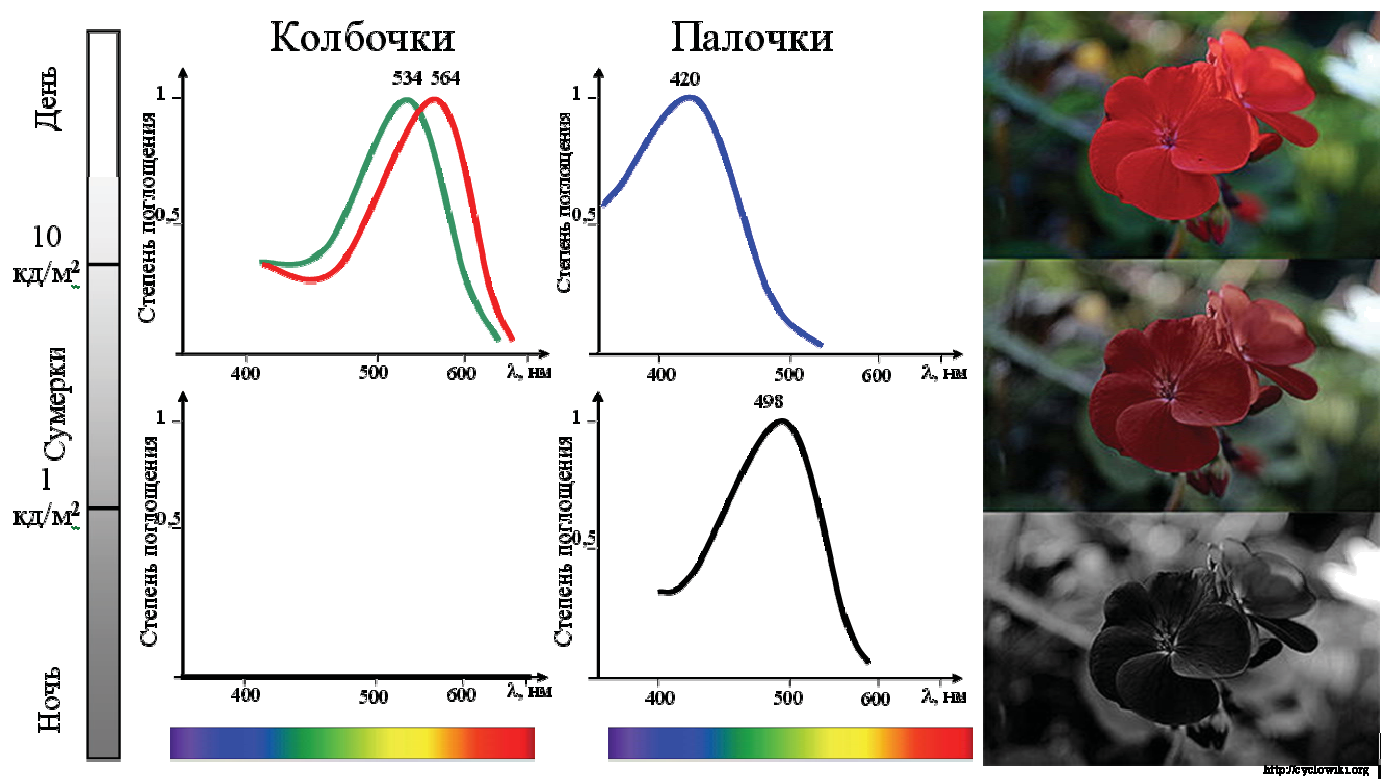

Рисунок 2 - Разделение функций дневного и сумеречного зрения

Ещё более поразительным примером многообразия и разделения функций является наличие у высших млекопитающих так называемых стволовых клеток, которые изначально не являются функционально ориентированными, но способны приобретать узкую функциональную специализацию в зависимости от текущих потребностей организма (рисунок 3 ).

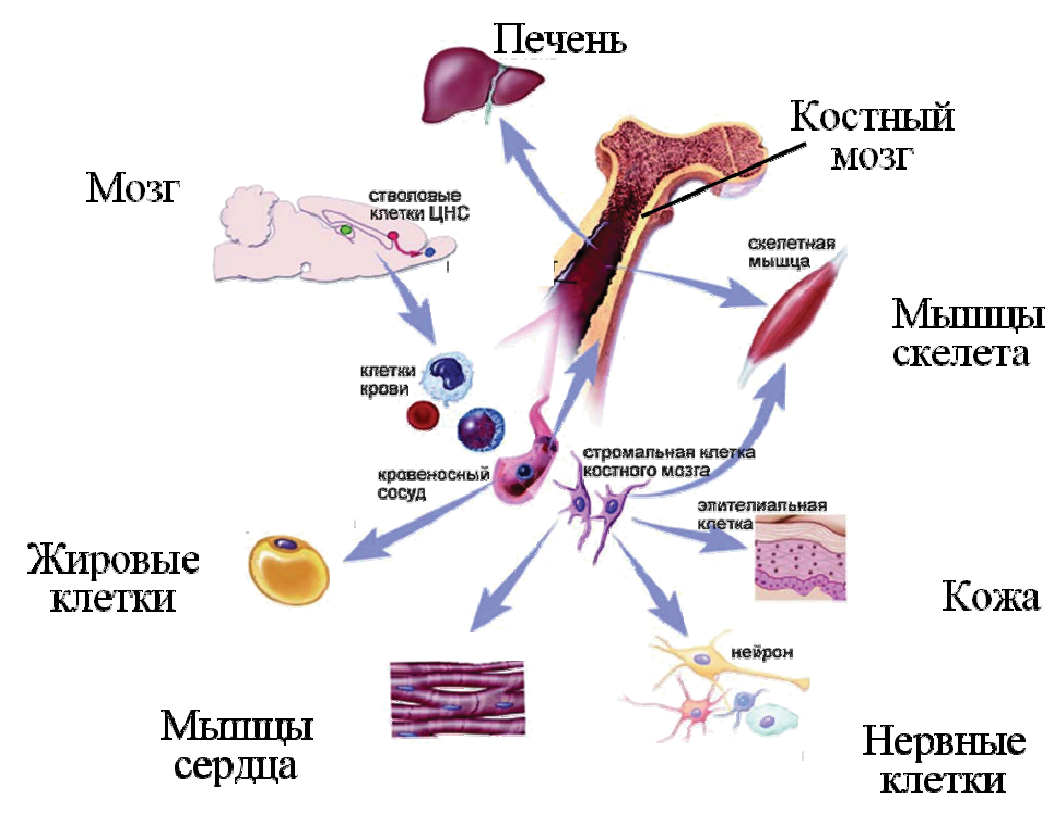

Рисунок 3 - Примеры специализации функций стволовых клеток

Таким образом, источником эволюции живой и неживой материи является многообразие её форм, порождающее качественно новые структуры. В том случае, если указанное многообразие обеспечивается в рамках одной физической или биологической системы, то такая система приобретает эволюционные преимущества: устойчивость существования и эффективное использование энергии внешней среды и внутренних ресурсов. 


\section{2 Принцип иерархии структур}

Иерархия этапов эволюции неживых структур определяется диалектическим законом перехода количественных изменений в качественные и состоит в последовательном количественном усложнении своих форм: элементарные частицы - атомы - химические элементы тела - звёздные системы - галактики, а также видов их взаимодействия, сопровождаемом скачкообразными качественными изменениями в их свойствах.

Следует отметить, что отличия в свойствах различных уровней иерархии физических форм материи возникает не только вследствие различного состава их элементов, но и в результате изменения способов их организации: каждый уровень организации неживых форм возникает в силу качественно других отношений их составляющих (наиболее яркий пример периодический закон химических элементов Д.И. Менделеева).

Известная иерархия живых структур: нуклеотид - ген - клетка - организм - популяция экосистема - биосфера, - очевидно указывает на общность рассматриваемого эволюционного принципа [37]. На каждом уровне структуры биологическая система использует разные способы сохранения своего устойчивого существования:

- на низших уровнях - белковый и нуклеотидный полиморфизм (взаимозаменяемость функций различных белков и нуклеотидов);

- на уровне организмов - гомеостазис, образующий многоуровневую систему защиты, в которой переход к более высоким её уровням затрагивает всё большее число физиологических подсистем организма. На рисунке 4 дана схематическая иллюстрация функционирования такой системы, поддерживающей физиологически нормальный уровень сахара в крови человека;

- на уровне экосистем - разнообразие видов, родов семейств и т.д.

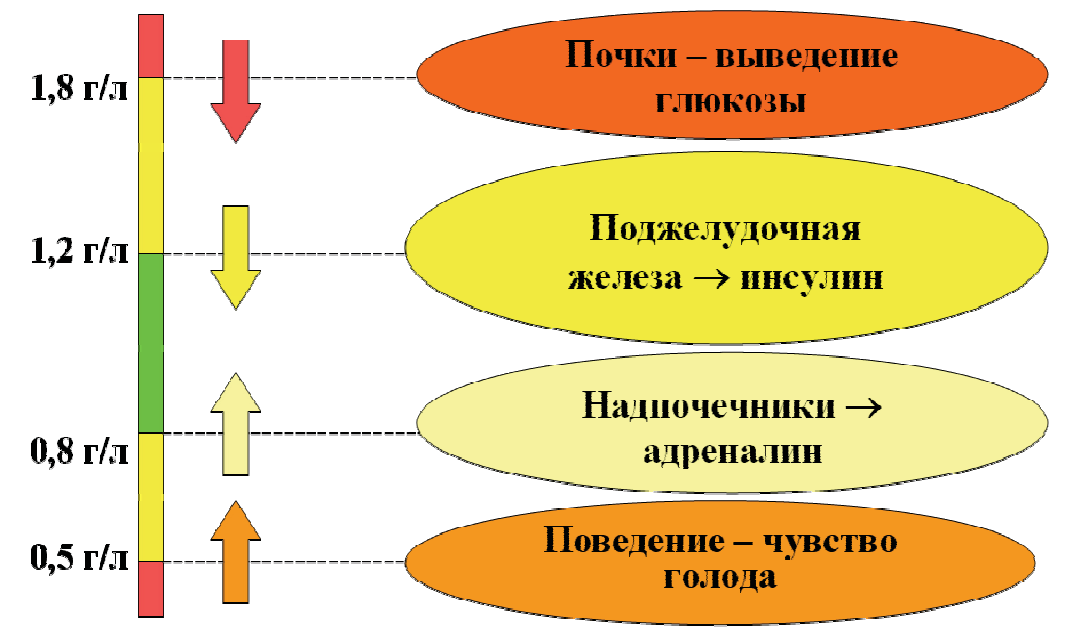

Рисунок 4 - Пример многоуровневого регулирования содержания сахара в крови человека (нормальное содержание $0,8-1,2$ г/л)

Важно отметить, что переход с одного уровня организации или функционирования системы на другой уровень носит дискретный, ступенчатый характер, причина которого раскрывается далее в разделе 3.

Многоуровневость материальных систем, обеспечивая устойчивость процессов (в том числе неравновесных) в неживых структурах, так же, как и гомеостазис в живых организмах, является не только результатом эволюции, но и создаёт условия для накапливания и реализации в этих системах эволюционных изменений на каждом уровне. 


\section{3 Принцип дискретности}

Достижения квантовой теории определили дискретность энергетических параметров элементарных частиц неживой материи и их взаимных состояний - системных конфигураций, или структур [38]. В качестве иллюстрации такой дискретности на макроскопическом уровне на рисунке 5 показаны два состояния плёночной структуры, опорные узлы которой заданы, а дополнительные узлы образуются в зависимости от начальных условий образования плёнки [39].

Обе структуры а) и б) на рисунке 5 являются энергетически локально устойчивыми. В рассматриваемой системе существует несколько вполне определённых устойчивых состояний, т.е. их множество дискретно. Очевидно, что если каждое такое устойчивое состояние охарактеризовать некоторым показателем - критерием качества, то в формальном плане на указанном множестве состояний может быть поставлена задача поиска глобального экстремума.
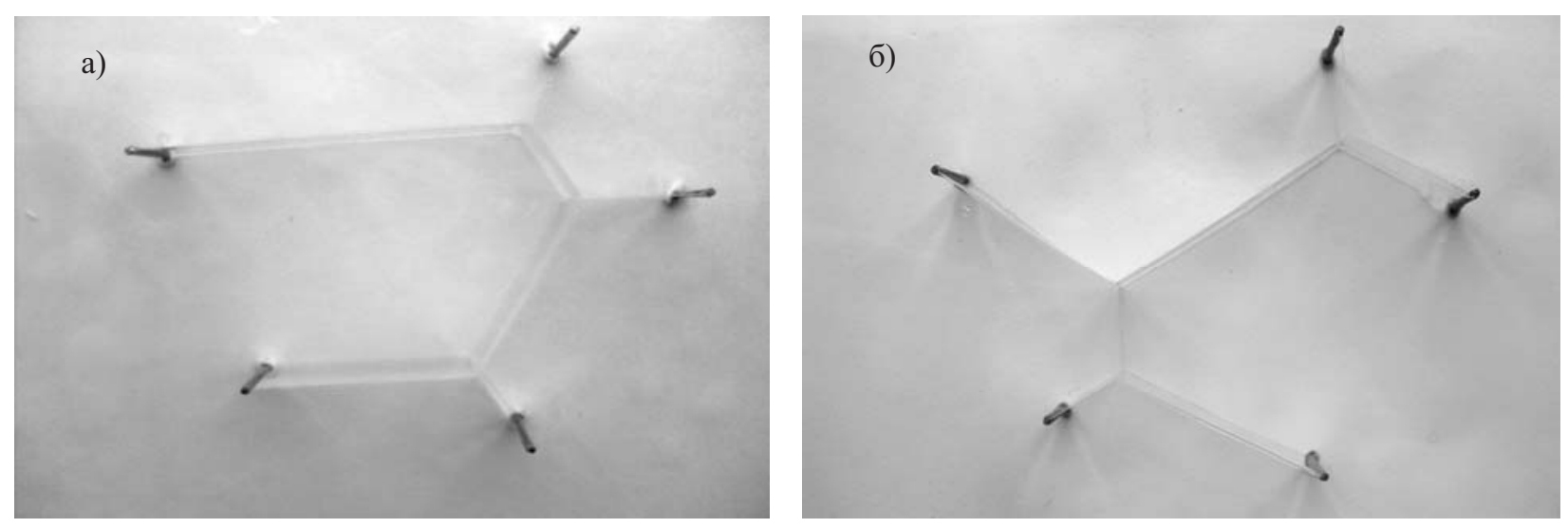

Рисунок 5 - Дискретные состояния плёночной структуры в локальных энергетических минимумах

В биологических структурах дискретность строения определяется, в частности, существованием всего 20-ти основных аминокислот, комбинации которых при средней длине их последовательности в 100 аминокислот определяется числом размещений с повторениями и составляет $20^{100}$ вариантов, что с избытком обеспечивает всё разнообразие известных видов белков (примерно 204).

Дискретность генетических структур обеспечивает элементарным носителям наследственности высокую устойчивость, так как переход из одного дискретного состояния в другое требует преодоления некоторого энергетического порога. Р. Докинз в своей работе [40] подчёркивает, что эволюционная «бессмертность» гена необходимо определяется дискретностью его форм, и что естественный отбор возможен только на дискретном множестве конкурирующих вариантов.

Для иерархически сложных структур наблюдается дискретность поведенческих реакций: в частности, Г. Хакен приводит популярный пример конечного дискретного набора устойчивых естественных аллюров у лошади: шаг, рысь, иноходь, галоп [7].

Обобщая эволюционную роль дискретности форм материи, Э.М. Галимов указывает [41], что «наиболее экономный способ производства низко-энтропийного продукта состоит в комбинировании уже имеющихся низкоэнтропийных структур; эволюция в нашем понимании должна происходить не только и даже не столько путем малых изменений, сколько скачками, обусловленными новыми сочетаниями старых структур».

Отсюда следует, что дискретность живых и неживых структур обеспечивает рассмотренное выше многообразие вариантов форм и является неотъемлемым условием эволюции. 


\section{4 Реализация принципов многоальтернативности в антропогенных системах}

Сформулированные выше эволюционные принципы многоальтернативного построения естественных физических и биологических структур обеспечивают возникновение в этих структурах основного эволюционного свойства - способности устойчивого существования в условиях открытого взаимодействия с непрерывно изменяющейся внешней средой. Осознанное воспроизведение указанных принципов в искусственных системах позволяет реализовать в них элементы адаптивного, приспособительного поведения, характерного для ультрастабильных структур, обладающих высокой живучестью.

В работе [42] приводится пример построения системы электроснабжения космической станции, состав которой представлен на рисунке ба и включает в себя три уровня подсистем:

- подсистему солнечных батарей;

- подсистему источника высокого напряжения, находящегося на внешнем по отношению к космической станции аппарате;

- подсистему электрохимических аккумуляторных батарей (АБ), накапливающих энергию при её избытке в системе и отдающей - при недостатке.

Способ взаимодействия этих подсистем образует иерархическую структуру, в которой передача функций электроснабжения каждому последующему уровню происходит только при полностью исчерпанных энергетических ресурсах предшествующего уровня (рисунок 6).
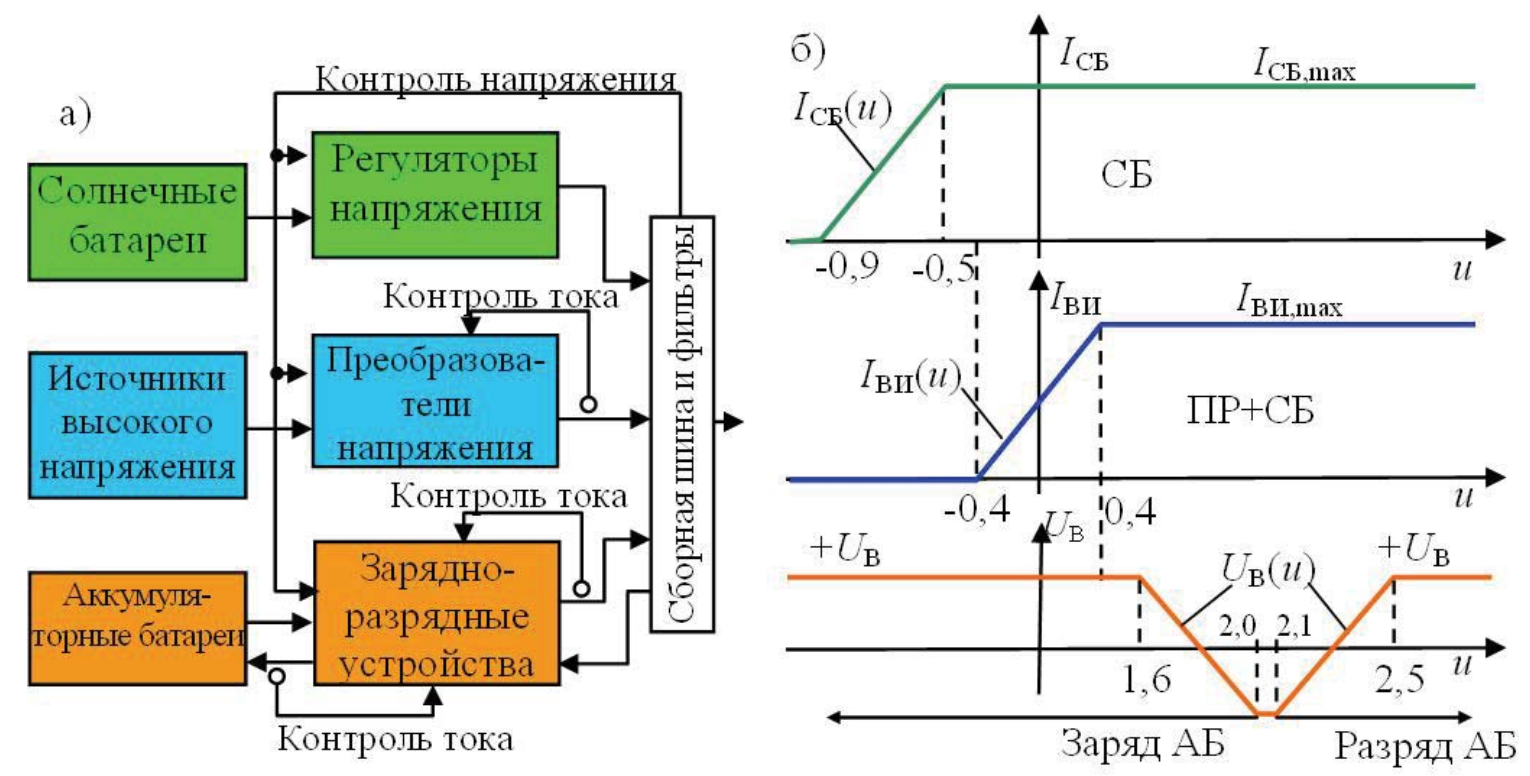

Рисунок 6 - Иллюстрация принципов многоальтернативности в структуре и режимах работы системы электроснабжения космической станции

На рисунке $6 б$ показано, что при выходе управляющего сигнала $u$ за зону регулирования $[-0,9 ;-0,5]$ подсистема солнечных батарей отдаёт в нагрузку свой полный ток $I_{\mathrm{CБ,max}}$, и в работу вступает подсистема внешнего источника (диапазон регулирования $[-0,4 ; 0,4]$ ). При полностью загруженных солнечной батарее и внешнем источнике $\left(I_{\mathrm{Cb}}=I_{\mathrm{CБ}, \max }\right.$ и $\left.I_{\mathrm{B} и}=I_{\mathrm{BИ}, \max }\right)$ начинается отбор энергии от аккумуляторных батарей. Аналогичная передача управления осуществляется в пределах каждой подсистемы, которые содержат большое число идентичных модулей. Модульность и иерархичность строения исключают возможность каскадного (технологически связанного) нарастания отказов в системе, так как при любом токе нагрузки осуществляется активное регулирование не всей отдаваемой потребителям мощности, а только той её части, которая соответствует одному модулю той или иной подсистемы. Все 
остальные модули находятся в нерегулируемом режиме - часть из них отдают полный ток, а неиспользуемая часть отключена. В результате достигается «неусложняемая простота» системы [41], появляется возможность унификации контуров управления и блочного построения подсистем из взаимозаменяемых блоков, что в совокупности обеспечивает надёжное функционирование системы электроснабжения в широком диапазоне изменения её параметров, нагрузок и при отказах отдельных блоков.

Эволюционные принципы функционирования ультрастабильных биофизических структур, сохраняющих своё в некотором смысле экстремальное состояние, успешно применяются также в информационных системах для поиска оптимальных решений в сложных NP-полных задачах высокой размерности (рисунок 7).

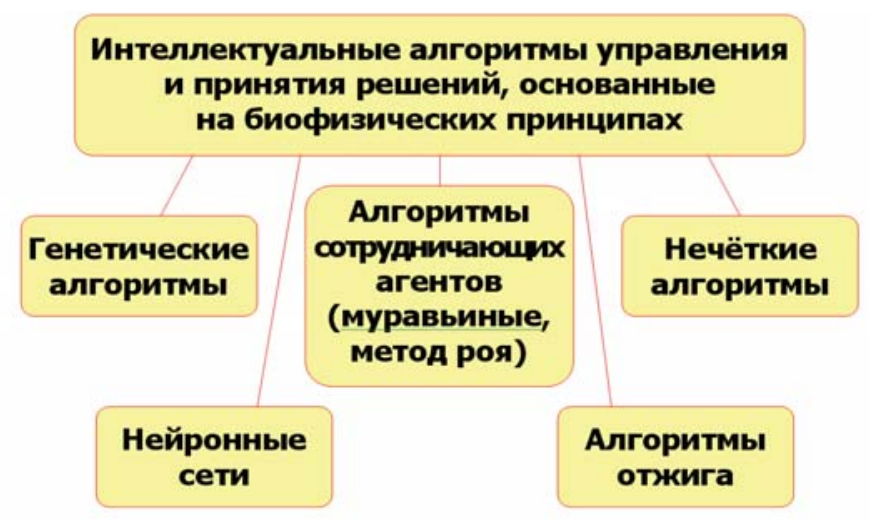

Рисунок 7 - Алгоритмы управления и принятия решений, построенные на биофизических принципах

Из перечисленных на рисунке 7 примеров отметим обширный класс хорошо разработанных генетических алгоритмов [11], использующих, в частности, не только механизмы расщепления родительских признаков, но и матричную репликацию изначально известного набора модулей, многообразие которых с помощью самоинструктирования мутаций (прообраза эволюционной памяти) порождает множество альтернативных вариантов решений $[31,43,44]$. На рисунке 8 показан результат применения такого алгоритма для решения задачи Штейнера с размерностями $n=100$ и $n=75$.

a) $n=100$

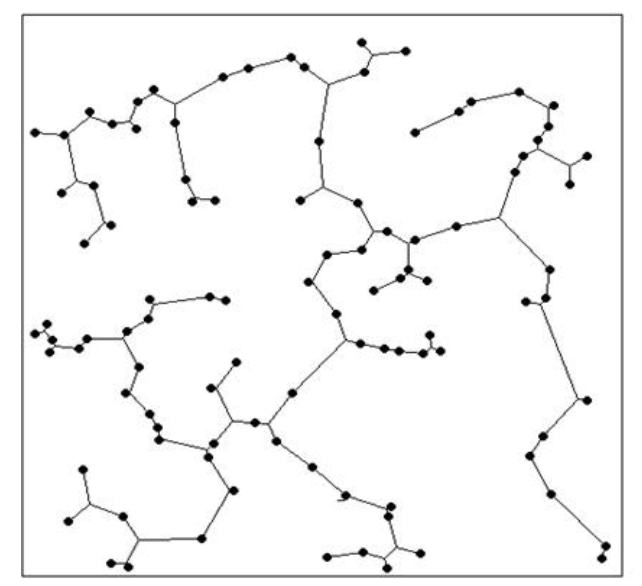

б) $n=75$

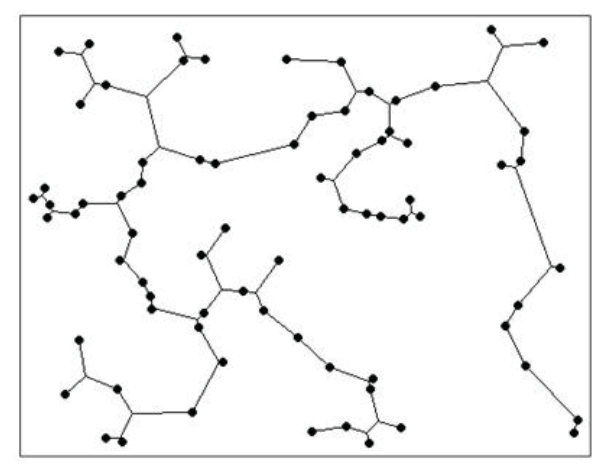

Рисунок 8 - Примеры кратчайших сетей Штейнера, построенных генетическим алгоритмом с эволюционной памятью 
Исходные опорные узлы сети Штейнера на рисунке 86 совпадают с соответствующим фрагментом на рисунке 8а, однако топологии этих фрагментов сетей на рисунках 8а и 86 отличаются в силу системного влияния различного общего числа $n$ опорных узлов.

\section{Заключение}

Единство законов эволюции живых и неживых систем может быть установлено на основе объединяющей концепции многоальтернативности, постулирующей принципы многообразия, дискретности и иерархии структур.

Принцип многообразия отражает исходную онтологическую предпосылку о возможности возникновения и стабилизации новых - эволюционных - изменений в природе только на основе множественных вариаций имеющихся структур. В информационном плане этот тезис близок к известному кибернетическому принципу необходимого разнообразия У. Эшби: "Variety can destroy variety".

Дискретность строения и состояний живых и неживых структур является необходимым условием комбинаторного многообразия физических и биологических форм существования материи, определяя характер протекания эволюционных процессов в виде скачкообразных, качественных переходов.

Иерархическое, многоуровневое строение сложных природных систем обеспечивает возникновение в этих системах феноменологического свойства «неусложняемой простоты», выражающегося в их гомеостатизе и ультрастабильности, которые возрастают с увеличением разнообразия входящих в системы подсистем.

Конструктивное содержание этих принципов заключается в их целенаправленном использовании при проектировании высоконадёжных систем критического назначения и построении интеллектуальных систем принятия решений.

Эволюционная общность концепции многоальтернативности открывает перспективы её практического применения для прикладного анализа и управления сложными развивающимися системами как естественного, так и антропогенного происхождения.

\section{Список источников}

[1] Шрёдингер, Э. Что такое жизнь? Физический аспект живой клетки / Э. Шрёдингер. - Москва-Ижевск: НИЦ «Регулярная и хаотическая динамика», 2002. - 92 с.

[2] Пригожин, И. Порядок из хаоса / И. Пригожин, И. Стенгерс. - M.: URSS, 2008. - 296 с.

[3] Васильев, А.Н. Эволюция Вселенной / А.Н. Васильев. // Современное естествознание: Энциклопедия. Т. 4. Физика элементарных частиц. Астрофизика. - М.: Магистр-Пресс, 2000. - С. 261-266.

[4] Боргест, Н.M. Научный базис онтологии проектирования / Н.М. Боргест // Онтология проектирования. 2013. - №1(7). - С. 7-25.

[5] Смирнов, С.В. Онтологии как смысловые модели / С.В. Смирнов // Онтология проектирования. - 2013. №2(8). - С. 12-19.

[6] Князева, E.H. Законы эволюции и самоорганизации сложных систем / Е.Н. Князева, С.П. Курдюмов. - М.: Наука, 1994. - 236 с.

[7] Хакен, Г. Информация и самоорганизация / Г. Хакен. - M.: URSS, 2014. - 320 с.

[8] Bummux, B.A. Пролегомены к эвергетике / В.А. Виттих // Онтология проектирования. - 2015. - Т. 5 , №2(16). - C. 135-148.

[9] Арпентьева, М.P. Эвергетика и онтологии управления / М.Р. Арпентьева // Онтология проектирования. 2016. - Т. 6, №1(19). - С. 106-124.

[10] Bummux, B.A. Ситуационное управление с позиций постнеклассической науки / В.А. Виттих // Онтология проектирования. - 2012. - №2(4). - С. 7-15.

[11] Курейчик, В.В. Анализ и обзор моделей эволюции / В.В. Курейчик, В.М. Курейчик, П.В. Сороколетов // Известия РАН. Теория и системы управления. - 2007. - №5. - С. 114-126. 
[12] Малышев, В.В. Метод принятия решений в условиях многообразия способов учёта неопределённости / В.В. Малышев, Б.С. Пиявский, С.А. Пиявский // Известия РАН. Теория и системы управления. - 2010. №1. - C. 46-61.

[13] Bummux, B.A. Принятие решений на основе консенсуса с применением мультиагентных технологий / В.А. Виттих, Т.В. Моисеева, П.О. Скобелев // Онтология проектирования. - 2013. - №2(8). - С. 20-25.

[14] Турчин, В.Ф. Феномен науки. Кибернетический подход к эволюции / В.Ф. Турчин. - М.: ЭТС, 2000. $368 \mathrm{c.}$

[15] Ратнер, В.A. Блочно-модульный принцип организации и эволюции молекулярно-генетических систем управления / В.А. Ратнер // Генетика. - 1992. - №2. - С. 5-23.

[16] Эйген, М. Самоорганизация материи и эволюция биологических макромолекул / М. Эйген. - М.: Мир, 1973. $-224 \mathrm{c}$.

[17] Нейман, Джс. Теория самовоспроизводящихся автоматов / Дж. фон Нейман. - M.: URSS, 2010. - 384 с.

[18] Langton, C.G. Self-reproduction in cellular automata / C.G. Langton // Physica 10D. - 1984. - V.10. - P.135-144.

[19] Codd, E.F. Cellular Automata / E.F. Codd. - N.Y.: Academic Press, 1968. - 122 p.

[20] Chaitin, G.J. Information-Theoretic Computational Complexity / G.J. Chaitin // IEEE Transactions on Information Theory IT-20. - 1974. - P. 10-15.

[21] Гуревич, И.М. Законы информатики - основа строения и познания сложных систем / И.М. Гуревич. - М.: Торус Пресс, 2007. - 400 c.

[22] Behe, M.J. Darwin's Black Box / M.J. Behe // The Biochemical Challenge to Evolution. - N.Y.: Simon \& Shuster, 1998. -307 p.

[23] Крылов, С.М. Метаматематические основы науки будущего / С.М. Крылов. - Самара: Самарский государственный технический ун-т, 2014. - 247 с.

[24] Крылов, С.М. Перспективы метаматематических структур в науке / С.М. Крылов // Вестник Самарского государственного технического ун-та. Сер. Физ.-мат. науки. - 2013. - №2(31). - С. 101-110.

[25] Крылов, С.M. Онтология метанауки. Аксиомы, технологии, алгоримы, эволюция / C.M. Крылов. - Saarbrücken: LAP LAMBERT Academic Publ., 2012. - 408 c.

[26] Крылов, С.М. Математические основы онтологии проектирования бинарных систем обработки информации / С.М. Крылов // Онтология проектирования. - 2016. - Т.6, №1(19). - С. 29-38.

[27] Крылов, С.M. Онтология проектирования гетерогенных электронных систем / С.М. Крылов, Е.Н. Гребенщиков // Онтология проектирования. - 2012. - №1(3). - С. 65-72.

[28] Подвальный, С.Л. Многоальтернативные системы: обзор и классификация / С.Л. Подвальный // Системы управления и информационные технологии. - 2012. - Т.48, №2. - С. 4-13.

[29] Подвальный, С.Л. Многоальтернативные системы с переменной структурой автоматического управления процессами непрерывной полимеризации / С.Л. Подвальный // Системы управления и информационные технологии. - 2011. - Т. 46, №4.1. - С. 175-178.

[30] Podvalny, S.L. Evolutionary principles for construction of intellectual systems of multi-alternative control / S.L. Podvalny, E.M. Vasiljev // Automation and Remote Control. - 2015. - Vol. 76, No. 2. - P. 311-317.

[31] Podvalny, S.L. A Multi-Alternative Approach to Control in Open Systems: Origins, Current State, and Future Prospects / S.L. Podvalny, E.M. Vasiljev // Automation and Remote Control. - 2015. - Vol. 76, No. 8. - P. 1471-1499.

[32] Алфёров, Ж.И. Тенденции и перспективы развития солнечной фотоэнергетики / Ж.И. Алфёров, В.М. Андреев, В.Д. Румянцев // Физика и техника полупроводников. - 2004. - Т. 38, вып. 8. - С. 937-948.

[33] Физиология растений / Ред. И.П. Ермаков. - М.: Академия, 2007. - 640 с.

[34] Васильев, E.M. Хаотические движения в системах низкого порядка / Е.М. Васильев // Вестник Воронежского государственного технического ун-та. - 2012. - Т. 8, №6. - С. 104-108.

[35] Convention on Biological Diversity / Treaty Series. New York: United Nations, 2001. - V. 1760. I. Nos. 30690. P. 79-307.

[36] Тимофеев-Ресовский, Н.В. Краткий очерк теории эволюции / Н.В. Тимофеев-Ресовский, Н.Н. Воронцов, А.В. Яблоков. - М.: Наука, 1977. - 303 с.

[37] Подвальный, С.Л. Интеллектуальные системы многоальтернативного управления: принципы построения и пути реализации / С.Л. Подвальный, Е.М. Васильев // Труды ХІІ Всероссийского совещания по проблемам управления ВСПУ-2014 (16-19 июня 2014 г., Москва, Россия). - М.: ИПУ РАН, 2014. - С. 996-1007.

[38] Окунь, Л.Б. Физика элементарных частиц / Л.Б. Окунь. - M.: URSS, 2013. - 218 с.

[39] Васильев, E.M. Исследование топологий сетей Штейнера на физических моделях тонких пленок / Е.М. Васильев, И.В. Крутских // Вестник Воронежского государственного технического университета. 2010. - Т. 6, №12. - С. 125-129.

[40] Докинз, Р. Эгоистичный ген / Р. Докинз. - М.: Изд. АСТ, 2013. - 512 с.

[41] Галимов, Э.М. Феномен жизни: между равновесием и нелинейностью. Происхождение и принципы эволюции / Э.М. Галимов. - М.: Едиториал УРСС, 2006. - 256 с. 
[42] Тищенко, A.K. Многоальтернативное управление критическими режимами системы электроснабжения космической станции / А.К. Тищенко, Е.М. Васильев, А.О. Тищенко // Вестник Воронежского государственного технического университета. - 2015. - Т. 11, №2. - С. 101-106.

[43] Podvalny, S.L. Models of Multi-Alternative Control and Decision-Making in Complex System / S.L. Podvalny, E.M. Vasiljev, V.F. Barabanov // Automation and Remote Control. - 2014. - Vol. 75, No. 10. - P. 1886-1891.

[44] Васильев, E.M. Эволюционные алгоритмы с матричной репликацией / Е.М. Васильев, И.В. Крутских // Вестник Воронежского государственного технического университета. - 2011. - Т. 7, №2. - С. 21-23.

\title{
THE CONCEPT OF MULTI-ALTERNATIVE IN THE ANIMATE AND INANIMATE STRUCTURES
}

\author{
S.L. Podvalny ${ }^{1}$, E.M. Vasiljev ${ }^{2}$ \\ Voronezh State Technical University, Voronezh, Russia \\ 1spodvalny@yandex.ru, 2vgtu-aits@yandex.ru
}

\begin{abstract}
The paper concentrates on some mechanisms of evolution that forms the constructive-oriented approach to the existence and development process of both wildlife and inanimate nature. This approach, also known as multi-alternative concept, is taken as a basis for the discussion of some interrelated and complementary principles of the diversity, discreteness and hierarchy in evolutionary processes and structures. First of all, it is demonstrated, that the possibility of evolution depends mainly on the heterogeneity of matter forms that implicates the diversity of its acquired characteristics. It can also be shown that the specified diversity is essentially enabled with discreteness of elements, which constitutes the combinatorial manifold of patterns and modes in physical and biological systems. Special attention is given to the issue of correlation between process hierarchy and structures, on one side, and its stability and homeostasis on the other. Finally, there are some examples provided to demonstrate the application of the considered principles in solving different technological problems, such as development of high-reliable power systems for space stations or designing evolutionary algorithms for decision-making systems. It is shown that the evolutionary concept of community multi-alternative opens prospects for its practical appliance to application analysis and control of complex systems, both of natural and anthropogenic origin.
\end{abstract}

Key words: open systems, evolution in the animate and inanimate nature, concept multi-alternative.

Citation: Podvalny SL, Vasiljev EM. The concept of multi-alternative in the animate and inanimate structures [in Russian]. Ontology of designing. 2016; v.6, 3(21): 355-367. DOI: 10.18287/2223-9537-2016-6-3-355-367.

\section{References}

[1] Schrödinger E. What is Life? The physical aspect of the living cell [in Russian]. - Moscow-Izhevsk: NIC Regular and Chaotic Dynamics; 2002.

[2] Prigogine I, Stengers I. Order out of chaos [in Russian]. - Moscow: URSS; 2008.

[3] Vasilyev AN. Evolution of the Universe [in Russian]. Modern science: Encyclopedia. V. 4. Elementary Particle Physics. Astrophysics. - Moscow: Magistr-Press; 2000.

[4] Borgest NM. The scientific basis of ontology of designing [in Russian]. Ontology of designing. 2013; 1(7): 7-25.

[5] Smirnov SV. Ontologies as a semantic model [in Russian]. Ontology of designing. 2013; 2(8): 12-19.

[6] Knjazeva EN, Kurdjumov SP. The laws of evolution and self-organization of complex systems [in Russian]. Moscow: Nauka; 1994.

[7] Haken H. Information and self-organization [in Russian]. - Moscow: URSS; 2014.

[8] Vittikh VA. Prolegomena to evergetics [in Russian]. Ontology of designing. 2015; 5(2): 135-148.

[9] Arpentieva MR. Evergetic and ontologies of management [in Russian]. Ontology of designing. 2016; 6(1): 106-124.

[10] Vittikh VA. Situational management from the perspective of postnonclassical science [in Russian]. Ontology of designing. 2012; 2(4): 7-15.

[11] Kureichik VV, Kureichik VM, Sorokoletov PV. Analysis and a survey of evolutionary models. Journal of Computer and Systems Sciences International. 2007; 46(5): 779-791. 
[12] Malyshev VV, Piyavsky BS, Piyavsky SA. A decision making method under conditions of diversity of means of reducing uncertainty. Journal of Computer and Systems Sciences International 2010; 49(1): 44-58.

[13] Vittikh VA, Moiseeva TV, Skobelev PO. A decision on the basis of consensus with the use of multi-agent technologies [in Russian]. Ontology of designing. 2013; 2(8): 20-25.

[14] Turchin VF. The phenomenon of science. The cybernetic approach to evolution [in Russian]. - Moscow: ETS; 2000.

[15] Ratner VA. Block-modular principle of organization and evolution of the molecular genetic control systems [in Russian]. Genetics. 1992; 2: 5-23.

[16] Eigen M. The self-organization of matter and the evolution of biological macromolecules [in Russian]. - Moscow: Mir; 1973.

[17] Neumann J. The theory of self-reproducing automata [in Russian]. - Moscow: URSS; 2010.

[18] Langton CG. Self-reproduction in cellular automata. Physica 10D 1984; 10: 134-144.

[19] Codd EF. Cellular Automata. - N.Y.: Academic Press; 1968.

[20] Chaitin GJ. Information-Theoretic Computational Complexity. IEEE Transactions on Information Theory IT-20. 1974. - P. 10-15.

[21] Gurevich IM. Informatics laws - the basis of the structure and knowledge of complex systems [in Russian]. - Moscow: Torus Press; 2007.

[22] Behe MJ. Darwin's Black Box. The Biochemical Challenge to Evolution. - N.Y.: Simon \& Shuster; 1998.

[23] Krylov SM. Metamathematical foundations of the science of the future [in Russian]. - Samara: Samara State Technical University; 2014.

[24] Krylov SM. Prospects of metamathematical structures in science [in Russian]. Bulletin of Samara State Technical University 2013; 2: 101-110.

[25] Krylov SM. Ontology of Meta-Science. Axioms, Technologies, Algorithms, Evolution [in Russian]. - Saarbrücken: LAP LAMBERT Academic Publ;; 2012.

[26] Krylov SM. Mathematical foundation of binary system ontology for data processing [in Russian]. Ontology of designing. 2016; 6(1): 29-38.

[27] Krylov SM, Grebenschikov EN. Ontology of heterogenious electronics systems design [in Russian]. Ontology of designing. 2012; 1: 65-72.

[28] Podvalny SL. Multi-alternative system: A review and classification [in Russian]. Control systems and information technologies. 2012; 48(2): 4-13.

[29] Podvalny SL. Multiple-variable structure system with automatic process control continuous polymerization [in Russian]. Control systems and information technologies. 2011; 46(4.1): 175-178.

[30] Podvalny SL, Vasiljev EM. Evolutionary principles for construction of intellectual systems of multi-alternative control. Automation and Remote Control. 2015; 76(2): 311-317.

[31] Podvalny SL, Vasiljev EM. A Multi-Alternative Approach to Control in Open Systems: Origins, Current State, and Future Prospects. Automation and Remote Control. 2015; 76(8): 1471-1499.

[32] Alfjorov ZhI, Andreev VM, Rumjancev VD. Trends and prospects for the development of solar photovoltaic [in Russian]. Semiconductor Physics and Technology. 2004; 38(8): 937-948.

[33] Plant Physiology [in Russian]. Red. Ermakov IP. - Moscow: Akademija; 2007.

[34] Vasiljev EM. Chaotic motion in the low-order [in Russian]. Bulletin of Voronezh State Technical University. 2012; 8(6): 104-108.

[35] Convention on Biological Diversity. Treaty Series. N.Y.: United Nations, 2001; 1760(I. Nos. 30690): $79-307$.

[36] Timofeev-Resovskij NV, Voroncov NN, Jablokov AV. A brief outline of the theory of evolution [in Russian]. - Moscow: Nauka; 1977.

[37] Podvalny SL, Vasiljev EM. Intelligent multialternative control: principles and ways to implement [in Russian]. Proc. XII All-Russian conference on Control (16-19 June 2014, Moscow, Russia). - Moscow: Institute of Control Sciences of a name V.A. Trapeznikov RAS, 2014. - P. 996-1007.

[38] Okun' LB. Physics of Elementary Particles [in Russian]. - Moscow: URSS; 2013.

[39] Vasiljev EM, Krutskih IV. Research topologies Steiner networks on physical models of thin films [in Russian]. Bulletin of Voronezh State Technical University. 2010; 6(12): 125-129.

[40] Dawkins R. The Selfish Gene [in Russian]. - Moscow: AST; 2013.

[41] Galimov JeM. The phenomenon of life: between equilibrium and non-linearity. Origin and evolution of the principles [in Russian]. - Moscow: Editorial URSS; 2006.

[42] Tishhenko AK, Vasiljev EM, Tishhenko AO. Multialternative critical control mode power supply system space station [in Russian]. Bulletin of Voronezh State Technical University. 2015; 11(2): 101-106.

[43] Podvalny SL, Vasiljev EM, Barabanov VF. Models of Multi-Alternative Control and Decision-Making in Complex System. Automation and Remote Control. 2014; 75(10): 1886-1891. 
[44] Vasiljev EM, Krutskikh IV. Evolutionary algorithms with matrix replication [in Russian]. Bulletin of Voronezh State Technical University. 2011; 7(2): 21-23.

\section{Сведения об авторах}

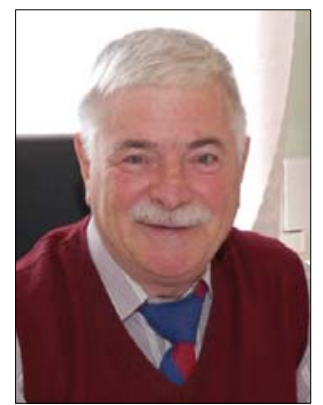

Подвальный Семён Леонидович, 1938 г. рождения. Окончил Одесский политехнический институт (химико-технологический факультет) в 1961 г., к.т.н. (1968), д.т.н. (1982), проф. (1985). Заведующий кафедрой Воронежского государственного технического университета. Заслуженный деятель науки Российской Федерации. Главный редактор журнала «Системы управления и информационные технологии» и член редколлегий нескольких других журналов. Автор свыше 500 научных работ в области математического моделирования динамических объектов и систем нефтехимического производства, алгоритмизации управления технологическими процессами и создания специализированных вычислительных систем.

Podvalny Semen Leonidovich (b. 1938), graduated from the Odessa polytechnic university, faculty of chemical technology in 1961. PhD (1968), D.Sc.Eng. (1982), professor (1985). Head of department of Voronezh state technical university. Merited Scientist of the Russian Federation. Chief Editor of "Control Systems and Information Technologies" journal. He is author of more than 500 publications in the field of mathematical modeling of dynamic objects and systems.

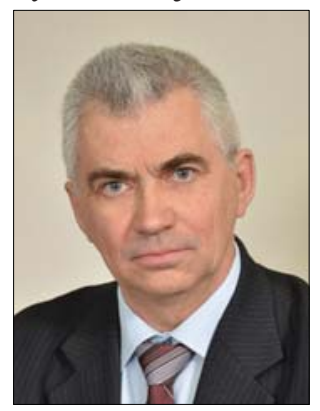

Васильев Евгений Михайлович, 1949 г. рождения. Окончил Воронежский политехнический институт в 1971 г., к.т.н. (1983). Доцент Воронежского государственного технического университета. В списке научных трудов более 300 публикаций в области математического моделирования и управления динамическими объектами.

Vasiljev Eugene Mikhailovich, (b. 1949), graduated from the Voronezh polytechnic institute in 1971, PhD (1983). Associate Professor of Voronezh state technical university. He is co-author of more than 300 publications in the field of mathematical modeling of dynamic objects. 


\title{
КОГНИТИВНЫЕ ПРОБЛЕМЫ ПРОЕКТИРОВАНИЯ НА ОСНОВЕ КОМПЬЮТЕРНЫХ МОДЕЛЕЙ: ТЕХНИЧЕСКИЙ И СОЦИО-ГУМАНИТАРНЫЙ АСПЕКТЫ"
}

\author{
С.В. Шалагин ${ }^{1}$, Г.Э. Шалагина ${ }^{2}$ \\ ${ }^{1}$ Казанский национальный исследовательский технический университет им. А.Н.Туполева, Казань, Россия \\ sshalagin@mail.ru \\ ${ }^{2}$ Казанский национальный исследовательский технологический университет, Казань, Россия \\ galanova@fromru.com
}

\begin{abstract}
Аннотация
Рассмотрены когнитивные проблемы, возникающие при выполнении проектирования сложных систем на основе компьютерных моделей: когнитивный барьер и аберрация когнитивного процесса. Определены причины указанных проблем, которые носят как технический, так и социогуманитарный характер. В неолибералистском капитализме повысилась значимость финансового сектора. Сменяемость поколений технических устройств вызвана экономической, а не научнотехнической задачей или потребностями человека. Инновационная экономика порождает дискурс изменений человека с целью создать потребителя, соразмерного темпам технического прогресса. Вызванный экономикой темп технических изменений не антропомерен, не соответствует темпу «счастливой жизни». Динамизация базиса приводит к динамизации морально-нравственной сферы, возникает транзиторная этика. Латентность когнитивных проблем проектирования следствие потребности получить инновационный продукт в жёстких временных рамках. При главенстве техницизма в науке и неизбежности внедрения результатов проектирования в жизнь проектная деятельность должна сопровождаться философской рефлексией.
\end{abstract}

Ключевые слова: когнитивные проблемы, проектирование, транзиторная этика, счастье, информачионное общество.

Цитирование: Шалагин, С.В. Когнитивные проблемы проектирования на основе компьютерных моделей: технический и социо-гуманитарный аспекты / С.В. Шалагин, Г.Э. Шалагина // Онтология проектирования. - 2016. - Т. 6, №3(21). - С. 368-376. - DOI: 10.18287/2223-9537-2016-6-3-368-376.

\section{Введение}

В настоящее время программно-аппаратные системы автоматизированного проектирования (САПР) находят своё применение при создании как технических, так и естественнонаучных, аналогичных природным, объектов. Вместе с тем, применение САПР для проектирования определённых классов объектов либо затруднительно, либо не целесообразно. При проектировании сложных технических объектов требуется оперировать данными, различными по своей природе [1]. Трудности при проектировании возникают при взаимодействии между специалистами из различных областей, что приводит к трудно устранимым коллизиям. Данное обстоятельство является фактором ограничения сложности объекта проектирования (ОП). Причины такого рода ограничений кроются в том, что

\footnotetext{
Статья и её авторы - наглядный пример взаимного стремления к интеграции «разделённого» технического и гуманитарного знания. Актуальность «стыковых» исследований важна для нашего журнала, и об этом мы неоднократно писали, стимулируя тем самым приток такого рода работ. Публикуемая статья вызвала неоднозначную оценку в редакции в силу неточности или неполноты ряда формулировок исследуемых понятий. Тем не менее, с учётом актуальности рассматриваемой темы, мы надеемся на продолжение её обсуждения нашими неравнодушными читателями, которые восполнят этот пробел. Прим.ред.
} 
компьютерные модели (КМ) ОП в определённых случаях, во-первых, оказываются не адекватными, а во-вторых, сложными для создания и/или интерпретации [2]. На первое обстоятельство уже указывалось исследователями в работе [3] применительно к КМ ОП из области химии. Второе обстоятельство указано в работе [4]: САПР программных комплексов применимы на практике не столько как «помощники», сколько как средство для документирования промежуточных и итоговых результатов.

В чём же заключается причины подобного рода ограничений? Какие последствия, в том числе - социальные, могут возникнуть при недооценке и/или игнорировании сложившейся ситуации? Какие способы разрешения сложившейся проблемы могут быть приемлемы?

Цель настоящей работы - ответы на указанные вопросы.

\section{1 Основные понятия и определения}

Рассмотрим базовые понятия и определения, служащие отправной точкой для исследования.

Проектирование [5, с. 1061] - процесс создания проекта - прототипа, прообраза предполагаемого или возможного объекта, состояния.

Проект [5, с. 1061] - 1) замысел, план; 2) совокупность документов (расчётов, чертежей и др.) для создания какого-либо сооружения или изделия.

То есть проект есть образ, воплощённый в форму описания, обоснования, расчётов, чертежей, раскрывающих сущность замысла и возможность его практической реализации. Обращает на себя внимание тот факт, что в определении проекта наблюдается некоторая двойственность. С одной стороны, проект должен раскрывать замысел, идею, образ будущего объекта проектирования. С другой стороны, проект немыслим без раскрытия технологии реализации ОП. По мере усложнения ОП, что стало возможным во второй половине XX века в результате широкого применения компьютерных моделей, в проектировании прослеживается двойственная тенденция, нашедшая свое отражения в определении подходов к проектированию на основе компьютерных моделей. Различают два подхода к проектированию: функциональный и оптимизационный [6].

При функциональном подходе к проектированию на первый план выступает функция, которую должен выполнять объект. Оно нацелено, прежде всего, на создание эффективно работающего объекта. Выполнение требуемой функции - главная цель и основа разработки ОП. Во внимание принимаются, прежде всего, функциональные показатели качества и показатели надёжности.

При оптимизационном (критериальном, вариантном) подходе к проектированию осуществляется не только поиск функционально эффективных решений, но и удовлетворение разных, порой противоречивых потребностей людей. Производится обоснованный выбор окончательного варианта. Активно оптимизационное проектирование начало применяться со второй половины XX века благодаря достижениям теории принятия решений, теории исследования операций, а также благодаря широкому распространению вычислительной техники. Указанные обстоятельства позволили разработать методы, позволяющие в обозримые сроки просчитывать многочисленные варианты и решать сложные математические задачи.

Оптимизационный подход усилился в конце XX, в начале XXI веков. Возросшая актуальность указанного подхода напрямую связана с интенсификацией модернистской идеологии: создатели ОП требуют, чтобы новое поколение проектируемых объектов было дешевле по себестоимости и в большей степени удовлетворяло современной структуре спроса. Модернистская идеология, в свою очередь, напрямую связана с логикой 
капитализма, при рассмотрении которой мы переходим к социо-гуманитарным аспектам когнитивных проблем проектирования. Базовое понятие здесь - транзиторная этика. Транзиторная этика - это система норм нравственного поведения человека или социальной группы, предполагающая в качестве базовой моральной ценности инновационизм (идеологию готовности человека к переменам).

\section{2 Когнитивные проблемы проектирования: социо-гуманитарный аспект}

Модернистская идеология вписана в логику капитализма в его неолиберальной версии. Повысилась значимость финансового сектора и главной целью инноваций стало увеличение объёма оборота денежных средств. Поэтому сменяемость поколений технических устройств зачастую продиктована внешней экономической, нежели внутренней научно-технической задачей, тем более не витальными или экзистенциальными потребностями человека. Рабочие айфоны, непригодные для использования в связи с невозможностью скачать «устаревшее» программное обеспечение, зарядное устройство, выходящее из строя не по физическим причинам, а из-за несовместимости с новым ПО - это примеры «выкачивания денег» из потребителя технологий.

Быстрая смена технологий способна обескуражить рабочую силу, выбить почву из-под ног работников в нашем нестабильном, транзиторном мире, вселить чувство неопределённости. Люди вынуждены без объективной необходимости перестраивать свои трудовые навыки под новое оборудование и новые информационные технологии. Сказанное актуально и в отношение, например, бухгалтеров, каждый раз отвлекающих свою экзистенциальную энергию на освоение новой версии ПО для налоговых органов, и для профессорско-преподавательского состава ВУЗов, отвлекающего свои силы и время на освоение всё новых и новых информационно-технических средств для формализации своего труда.

Техническое творчество сегодня регулируется авторским правом, порождая уже масштабную практику «жизни на ренту» не только для изобретателя технологии, но и для всего штата сотрудников технических организаций. Владельцы патентов устанавливают экономические «правила» игры», препятствуя развитию альтернативных технологий. Казалось бы, ни что иное, как конкуренция инспирирует инновации, заставляет инженеров придумывать новые устройства. Однако, на практике оказывается, что отрасли, занятые созданием технологий, создают устройства, для которых ещё только предстоит создать рынок сбыта. Поэтому «львиную долю» в разработках составляет реклама с её маркетинговыми технологиями. Определяя инновационные товары, работы, услуги как «товары, работы, услуги, новые или подвергавшиеся в течение последних трёх лет разной степени технологическим изменениям», Росстат косвенно устанавливает общий для всех видов техники срок новизны инновационной продукции - не более 3 лет [7]. Чтобы быть «инновационным», производитель должен не реже трёх лет изменять технические параметры продукции, вынуждая потребителей покупать именно новые товары. Навязчивость дискурса «изменений себя и других», для того, чтобы соответствовать «инновационному духу времени», идеи о перевоспитании, переубеждении, постоянной социализации и ресоциализации взрослых фактически являются маркетинговым ходом, попыткой создать человека, соответствующего темпам технического прогресса, воспринимающего необходимость изменений некритически, как норму.

Результаты технического творчества сегодня быстро внедряются в повседневность через различные технические и программные устройства. Вопрос: насколько такой темп изменений социально значимых показателей технического оснащения жизни антропомерен, 
соответствует темпу осмысленной и «счастливой» человеческой жизни? Счастливая жизнь предполагает стабильность и неизменность значимых социальных показателей, к которым относятся и моральные установки. Когда счастлив, время летит незаметно, жизнь пробегает, как миг именно потому, что замечаемая единица социального времени - это промежуток между новыми жизненно значимыми событиями. Изменения в жизни нужны, но они антропомерны только тогда, когда органично вытекают из биографических поворотов жизни человека, а не навязаны внешней по отношению к нему борьбой инвесторов за потребительский рынок инновационной продукции. При измерении человеческой жизни сроками инноваций, когда скорость трансформации базиса, вещной составляющей высока в угоду модернистской идеологии, происходит искусственная динамизация моральнонравственной сферы, что приводит к возникновению моральной транзиторности (транзиторной этики). Моральная транзиторность как принцип, предполагающий готовность человека к изменениям - одна из причин морально-нравственного релятивизма, который традиционно осмысливается как черта постмодернизма.

Таким образом, техника сегодня рискует оказаться в числе средств увода человека в сторону от его витальных и экзистенциальных целей. Очевидно, что последующее использование спроектированных технических и программных устройств уже не является полем ответственности инженера, наступает ответственность экономиста, политика, правоприменителя, социума в целом. Однако, в условиях главенства техницистского мышления в науке, в условиях неизбежного внедрения в общественную практику в обязательной форме информационной компетентности, вторжения результатов компьютерного моделирования в повседневность в форме обилия всевозможных «гаджетов», «Интернета вещей» и «Интернета всего», деятельность проектировщиков должна сопровождаться философской рефлексией ответственности за последствия своей деятельности. Ведь внедренный сегодня в общественную практику результат проектирования зачастую может оказаться витальной и/или экзистенциальной ловушкой для человека, как для пользователя, так и для проектировщика инновационной продукции.

\section{3 Структурная схема процесса автоматизированного проектирования}

Процесс автоматизированного проектирования представим следующей структурной схемой (рисунок 1). Далее объект проектирования на этапе замысла будем обозначать как ОП, а объект проектирования, реализованный в физической среде - как ОПр. С одной стороны имеет место замысел проектировщика (или группы проектировщиков), которые проявляется в виде конечного множества идеальных ОП. Для каждого идеального ОП создаётся своя КМ при использовании САПР различного назначения. На основе множества КМ в определённой физической среде как естественного (например, область химии), так и искусственного (например, область техники) происхождения создаётся ОПр. Параметры физической среды накладывают ограничения как на множества идеальных ОП, отображающих замысел проектировщиков, так и на множества создаваемых КМ.

Обозначим следующие когнитивные проблемы автоматизированного проектирования. Во-первых, при создании сложных идеальных ОП группой проектировщиков - специалистов из разных областей, требуется обеспечить их взаимодействие в определённой нотации, на заданном метаязыке. Во-вторых, множество КМ, описывающих ОП, требуется создавать при использовании общей компьютерной среды.

Трудности разрешения указанных проблемных вопросов на практике были определены в [1]: 1) в каждой проектной организации существуют десятки различных САПР, а на стыках между ними возникает немало вопросов, некоторые из которых остаются не решёнными; 
2) сложность, разнообразность и многочисленность проектных данных сегодня не позволяет проектировщику-руководителю ознакомиться с множеством идеальных ОП; 3) разбить проект на фрагменты данных не всегда удаётся.

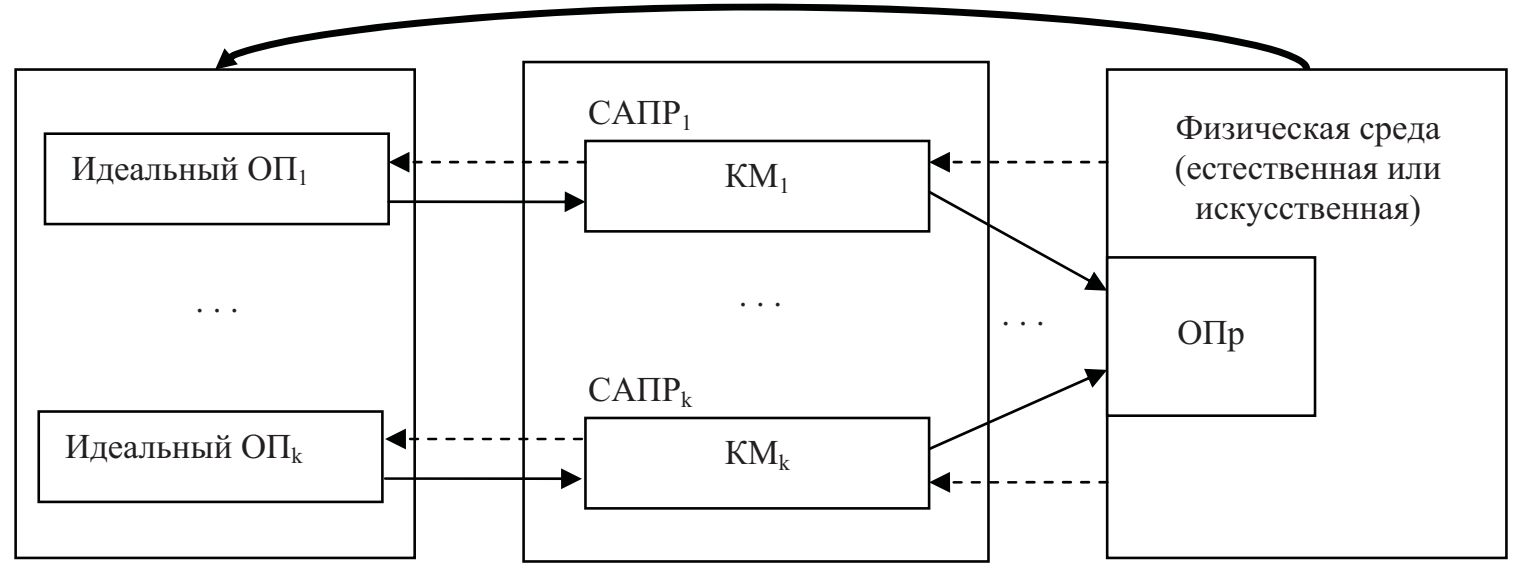

Рисунок 1 - Структурная схема процесса автоматизированного проектирования

Представленная структурная схема процесса автоматизированного проектирования позволяет определить следующие подходы, применяемые в современных САПР сложных ОП.

Подход 1. Множество идеальных ОП $\left(\mathrm{OП}_{1}, \ldots, \mathrm{OП}_{k}\right)$ описывается в общей нотации, на одном метаязыке, позволяя определить единственный идеальный ОП, для которого строится одна КМ. Согласно данной КМ определяется ОПр, существующий в заданной физической среде.

Подход 2. Для каждого идеального ОП ${ }_{i}$ в единой компьютерной среде строится КМ $i=\overline{1, k}$, при этом на основе множества $\left(\mathrm{KM}_{1}, \ldots, \mathrm{KM}_{k}\right)$ определяется единая КМ, на основе которой строится ОП.

Подход 3. Для каждого ОП $і$ строится $\mathrm{KM}_{i}$, на основе которой, в свою очередь, строится $\mathrm{OПр}_{i}, i=\overline{1, k}$, при этом применяются две и более компьютерные среды; совокупность ОПр представляет собой ОПр.

Возможность выбора того или иного подхода определяется свойствами ОПр. Первый подход требует наличия общей нотации, метаязыка, которые бы адекватно описывали идеальный ОП в целом, а также его компоненты. Второй подход, помимо требований, предъявляемых к первому подходу, требует наличия общей среды для компьютерного моделирования, позволяющей в автоматизированном режиме объединить множество $\left(\mathrm{KM}_{1}\right.$, $\ldots, \mathrm{KM}_{k}$ ) в единую $\mathrm{KM}$, отображающую ОПр. Третий подход предъявляет повышенные требования к ОПр: наличие возможности разбиения на отдельные элементы ОПр $i, i=\overline{1, k}$, ограниченно связанные друг с другом. В этом случае каждый элемент ОПр проектируется отдельно, с использованием отдельной компьютерной среды, базирующейся на заданной нотации, метаязыке.

Третий подход, безусловно, позволяет существенно увеличить сложность ОПр путём увеличения количества его элементов - ОПр,$i=\overline{1, k}$. Вместе с тем, сложности возникают в том случае, если группой проектировщиков не учтено и/или не полностью определено всё многообразие связей между элементами ОПр ${ }_{i}, i=\overline{1, k}$. Примером подобного подхода может служить проектирование и разработка сложных объектно-ориентированных программ для 
ЭВМ. Указанные программные комплексы сложно верифицировать. Каждый компонент в отдельности верифицируется относительно нетрудно. Тогда как поверить всю совокупность взаимодействий между многочисленными программными компонентами за приемлемый срок не представляется возможным. В данной связи, на практике нашёл широкое применение подход, связанный с поставкой пользователю частично отлаженного программного обеспечения с сервисной системой. Сведения об ошибках в работе программного комплекса, направляемые пользователями разработчикам, систематизируются, ошибки исправляются, и пользователям рассылаются так называемые Service Packs (пакеты обновлений). В настоящее время указанный подход интенсивно развивается применительно к проектированию сложных программно-аппаратных комплексов. Например, к проектированию систем на кристалле и встроенных систем.

Однако, указанный подход в принципе не применим к системам, требующим перед применением 100 \% отладки. Например, к системам информационной безопасности.

Возникает вопрос о применимости такого рода подходов к проектированию сложных объектов естественного происхождения. Естественная физическая среда по определению не разбиваема на отдельные участки. В данной связи, к проектированию объектов в среде естественного происхождения, например, в области химии, применимы только первые два подхода. Данное обстоятельство предъявляет более высокие требования к адекватности КМ ОП в естественной среде, по сравнению с КМ объектами, проектируемыми в искусственной среде.

\section{4 Компьютерные модели в автоматизированном проектировании}

При автоматизированном проектировании создаётся электронный образ, КМ ещё не существующего объекта, который требуется создать. Вместе с тем, по мере развития КМ актуализируется проблема когнитивного барьера, обозначаемая следующим образом [2].

С одной стороны, производится абстрагирование от определённых характеристик ОП, которые, по мнению исследователя, являются несущественными. При этом исследователь руководствуется собственной интуицией, опирающейся на постановку прикладной задачи и понимание природы объекта моделирования [8, стр. 42]. Кроме того, имеет место упрощение характера связей между характеристиками объекта. Например, линеаризация связей между параметрами КМ с целью упрощения описания зависимостей между ними, при наличии у исследователя информации о нелинейном характере указанных связей. Следствием подобного абстрагирования и упрощения является создание идеального образа моделируемого объекта. Подобная идеализация неизбежно влечёт за собой ограничения на область адекватности создаваемой КМ. Внутренние и выходные характеристики моделируемого объекта отображаются с приемлемой точностью только на ограниченной области адекватности в пространстве входных параметров КМ.

С другой стороны, учёт всех параметров объекта моделирования и нелинейного характера связей между ними ведёт к существенному усложнению процессов верификации и валидации создаваемой КМ. Определение области адекватности КМ требует существенных вычислительных затрат. Указанные затраты экспоненциально возрастают при росте количества отображаемых параметров моделируемого объекта с нелинейными связями между ними [9].

В результате совокупные вычислительные затраты, направленные на определение области адекватности создаваемой КМ, становятся существенно выше, чем затраты на выполнение экспериментов на КМ ОП. Хотя при компьютерном моделировании первая задача практически не отделима от второй $[8,10]$. 
Проблема аберраџии когнитивного процесса при построении КМ ОП, обозначенная в [2, 11], в данном случае сводится к проблеме когнитивного барьера. Проектировщику, пользователю САПР следует установить область адекватности КМ ОП. В противном случае, из-за объективизации и натурализации результатов, полученных на КМ с не идентифицированной областью адекватности, и «давления» указанных результатов на понимание исследователей, имеет место опасность аберрации когнитивного процесса при проектировании сложных систем. Например, согласно [3], отдельные КМ позволяют описывать с заданной степенью точности только строго определённое химическое вещество в заданном агрегатном состоянии.

\section{Заключение}

Таким образом, при проектировании сложных объектов возникает проблема когнитивного барьера. При этом ключевую роль играет физическая среда, элементом которой является указанный объект. Среда искусственного происхождения позволяет определять сложный ОП как совокупность элементов, каждый из которых возможно проектировать отдельно, с применением КМ и САПР. Что касается сложных объектов, являющихся частью естественной среды, то их проектирование должно быть произведено на основе единой КМ.

При увеличении сложности КМ и аппаратных средств моделирования необходимо уделить пристальное внимание среде проектирования и метаязыку, допускающему формальное описание сложного ОП.

Ключевую роль при проектировании сложных объектов играет верификация проекта и синтезированного объекта. Латентность когнитивных проблем проектирования указанного класса объектов зачастую является следствием того, что в современном информационном обществе существует устойчивая потребность в получении результата при наличии жёстких временных ограничений. В условиях внедрения в общественную практику результатов компьютерного моделирования проектная деятельность должна сопровождаться философской рефлексией ответственности за социальные последствия.

\section{Список источников}

[1] Храпкин П.Л. Системы автоматизированного проектирования: роль человека и компьютерной среды / П.Л. Храпкин // Развитие вычислительной техники и ее программного обеспечения в России и странах бывшего CCCP: история и перспективы (SoRuCom-2014): труды III Междунар. конф. - Казань: Изд-во КГТУ им. А.Н.Туполева, 2014. - с. 385 - 388.

[2] Галанова Г.Э. Когнитивные проблемы компьютерного моделирования в контексте культуры постмодерна / Г.Э.Галанова, С.В.Шалагин // Вестник КГТУ им. А.Н.Туполева. - 2014. - № 1.- С. 178 - 182.

[3] Клинов А.B. Моделирование многокомпонентного массопереноса при ректификации в насадочных колоннах на основе потенциалов межмолекулярного взаимодействия / А.В. Клинов, А.И. Разинов, В.В. Никешин и др. // Вестник Казанского технологического университета. - 2002. - № 1-2. - c. 382-388.

[4] Богzс У. UML и Rational Rose / У.Боггс, М.Боггс. - М: Лори, 2008. - 600 с.

[5] Советский энциклопедический словарь / Гл. ред. А.М. Прохоров 2-е изд. - М.: Сов. энциклопедия, 1983. - $1600 \mathrm{c}$.

[6] Норенков И. П. Основы автоматизированного проектирования: учеб. для вузов / И.П.Норенков. - 4-е изд., перераб. и доп. - М.: Изд-во МГТУ им. Н. Э. Баумана, 2009. - 430 с.

[7] Объем инновационных товаров, работ, услуг / Федеральная служба государственной статистики. 1999 2016. - http://www.gks.ru/free_doc/new_site/business/nauka/minnov-3.htm

[8] Бусленко Н.П. Моделирование сложных систем / Н.П.Бусленко. - М.: Наука, 1968. - 356 с.

[9] Советов Б.Я. Моделирование систем: Учеб. для бакалавров / Б.Я.Советов, С.А.Яковлев. - 7-е изд. - М.: «Юрайт», 2012. - 343 с. 
[10] Шеннон Р. Имитационное моделирование систем - искусство и наука: пер. с англ. / Р.Шеннон. - М.: Мир, 1978. - 424 с.

[11] Шалагин C.B. Когнитивные проблемы компьютерного моделирования в информационной химии: технический и гуманитарный аспекты / С.В. Шалагин, Г.Э. Шалагина // Вестник Казанского технологического университета. 2014. Т. 17. Вып. 19. - С. 435 - 437.

\title{
COGNITIVE PROBLEMS OF DESIGNING BASED ON COMPUTER MODELS: TECHNICAL AND SOCIO-HUMANITARIAN ASPECTS
}

\author{
S.V. Shalagin ${ }^{1}$, G.E. Shalagina ${ }^{2}$ \\ ${ }^{1}$ Kazan national research technical university named after A.N.Tupolev, ${ }^{1}$ Kazan, Russia \\ sshalagin@mail.ru \\ ${ }^{2}$ Kazan national research technological university, ${ }^{1}$ Kazan, Russia \\ galanova@fromru.com
}

\begin{abstract}
Cognitive problems resulting from the implementation of the designing of complex systems based on computer models are considered, including cognitive barrier and aberration of cognitive process. The reasons of these problems are both technical and socio-humanitarian. In neoliberalist capitalism the importance of the financial sector has increased. Turnover of generations of technical equipment is caused by economic rather than technical science problems or human needs. Innovative economy generates discourse of human changes to create a consumer, commensurate with the pace of technological progress. Economies-driven pace of technical change corresponds neither to human-dimension nor the tempo of a happy life. Dynamizing of basis leads to a dynamizing of moral sphere leads to transitory ethics. The latency of cognitive problems of design is a consequence of the need to get an innovative product in a strict time frame. In the context of the rule of technicism in science and the inevitable adoption of the results of design activity to the life, design activity must be accompanied by a philosophical reflection.
\end{abstract}

Key words: cognitive problems, designing, transitory ethics, happiness, information society.

Citation: Shalagin S.V, Salagina G.E. Cognitive problems of designing based on computer models: technical and sociohumanitarian aspects [In Russian]. Ontology of designing. 2016; 6(21): 368-376. DOI: 10.18287/2223-9537-2016-6-3368-376.

\section{References}

[1] Hrapkin PL. Computer-aided design: the role of human and computer environment. The development of computer technology and software in Russia and the former Soviet Union: History and Perspectives (SoRuCom-2014): Proceedings of the III International. conf. [In Russian]. Kazan: Izd-vo KGTU im. A.N.Tupoleva, 2014. P. 385 388.

[2] Galanova GE, Shalagin SV. Cognitive problems of computer modeling in a context of postmodern culture [In Russian]. Vestnik KGTU im. A.N.Tupoleva. 2014. № 1. P.178 - 182.

[3] Klinov AV, Razinov AI, Nikeshin VV. and others. Modeling of multicomponent mass transfer during rectification in packed columns based on the potentials of intermolecular forces [In Russian]. Herald of Kazan Technological University. 2002. № 1-2. P. 382 - 388.

[4] Boggs U., Boggs M. UML and Rational Rose [In Russian]. Moscow: Lory, 2008.

[5] Soviet encyclopedic dictionary. (ed. 2-d ed. [In Russian]. Moscow: Sov. enciklopedia, 1983.

[6] Norenkov IP. Fundamentals of computer-aided design: a textbook for high school. 4-th ed. [In Russian]. Moscow: Izd-vo MGTU im. N.E.Baumana, 2009.

[7] The volume of innovative products, works and services / Federal State Statistics Service. 1999 - 2016. [In Russian]. URL: http://www.gks.ru/free_doc/new_site/business/nauka/minnov-3.htm

[8] Buslenko NP. Modeling of Complex Systems [In Russian]. Moscow: Nauka, 1968.

[9] Sovetov BY. Modeling of Systems: a textbook for bachelors. 7-th ed. [In Russian]. Moscow: "Iurait”, 2012. 
[10] Shennon R. Simulation modeling of systems - the art and science: trans. from engl. [In Russian]. Moscow: Mir, 1978.

[11] Shalagin SV., Shalagina GE. Cognitive problems of computer modeling in infochemistry: technical and humanitarian aspects [In Russian]. Herald of Kazan Technological University. 2014. Vol. 17. № 19. P. 435 - 437.

\section{Сведения об авторах}

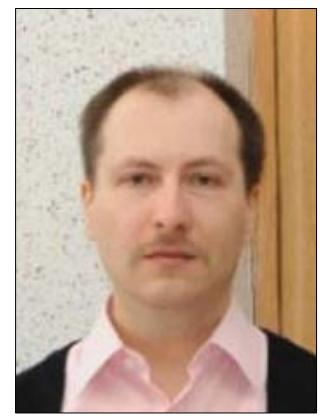

Шалагин Сергей Викторович, 1975 г. рождения. Окончил Казанский государственный технический университет им. А.Н.Туполева в 1998 г., д.т.н. (2013). Профессор кафедры компьютерных систем Казанского национального исследовательского технического университета им. А.Н.Туполева (КАИ). В списке научных трудов более 100 работ в области компьютерного моделирования и САПР.

Shalagin Sergei Victorovich (b. 1975) graduated from Kazan state technical university named after A.N.Tupolev in 1998, Doctor of Technical Science degree holder (2013). He is Professor at Kazan national research technical university named after A.N.Tupolev (Computer Systems department). He is author of about 100 scientific articles and abstracts in the field of Computer simulation and CAD.

Шалагина Гульнара Эдуардовна, 1974 г. рождения. Окончила Казанскую

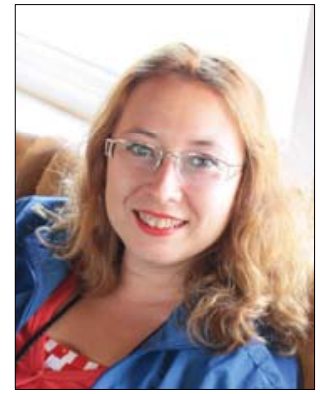
государственную консерваторию им. Н.Г. Жиганова в 1998 г., к.ф.н. (2001). Доцент кафедры философии и истории науки Казанского национального исследовательского технологического университета. В списке научных трудов более 80 работ в области социальной философии, этики, философии науки и культурологии.

Shalagina Gulnara Eduardovna (b. 1974) graduated from Kazan state conservatoire named after N.Zhiganov in 1998, "kandidatskaya" degree in philosophy holder. She is docent at Kazan national research technological university (Philosophy and History of Science department). She is author of more than 80 publications in the field of social philosophy, ethics, philosophy of science and culturology. 


\title{
УДК 1:62
}

\section{ЭПИСТЕМОЛОГИЧЕСКИЕ И ОНТОЛОГИЧЕСКИЕ ПРОБЛЕМЫ ФИЛОСОФИИ ТЕХНИКИ: «ЧЕТВЁРТОЕ ЦАРСТВО» Ф. ДЕССАУЭРА}

\author{
А.Ю. Нестеров \\ Самарский национальный исследовательский университет им. академика С.П. Королева, Самара, Россия \\ phil@ssau.ru
}

\begin{abstract}
Аннотация
В статье рассматриваются понятие и проблема техники в работах Фридриха Дессауэра «Философия техники» (1927) и «Спор о технике» (1959). Анализируются способы постановки эпистемологических и онтологических вопросов, специфических для техники. Показывается, что концепция «четвёртого царства» является областью правил проективной, материально выраженной рефлексии, понимаемой в качестве техники в собственном смысле. Обосновывается тезис о том, что «четвёртое царство» выполняет для проективной деятельности те же функции, что и «мир идей» Платона - для традиционно исследуемой в истории философии рецептивной деятельности; тем самым платонистская философия техники демонстрируется в качестве перспективной области исследований в рамках анализа проективных правил с позиций трансцендентализма и общей семиотики.
\end{abstract}

Ключевые слова: платонизм в философии техники, четвёртое иарство, проективный семиозис, предустановленные формы решений, искусственное и естественное.

Цитирование: Нестеров, А.Ю. Эпистемологические и онтологические проблемы философии техники: «четвёртое царство» Ф. Дессауэра / А.Ю. Нестеров // Онтология проектирования. - 2016. - T. 6, №3(21). - C. 377-389. - DOI: 10.18287/2223-9537-2016-6-3-377-389.

\section{Постановка проблемы. Техника и философия}

Некоторые проблемы в аналитической философии и в целом в рациональных моделях философствования XX-XXI вв. могут быть прояснены на примере философии техники. Это относительно молодое направление исследований: «Философия техники» Э. Каппа была опубликована в 1877 году [1], а первые попытки исследования сущности техники предпринимаются только в первые десятилетия XX в. (П.К. Энгельмейер [2], Э. фон Майер [3], М. Айт [4], Э. Цшиммер [5]). Фундаментальное отличие философии техники от подавляющего большинства направлений современной философии определяется её предметом: техника не только рецептивна, но и проективна, её природа заключается не только и не столько в восприятии и анализе, сколько в деятельности. Если мы хотим понять, перефразируя известное выражение К. Маркса, как именно философы изменяют мир, как должна пониматься философия, чтобы она оказалась способна к изменению «мира», техника является едва ли не самым удобным и очевидным предметом исследования.

Философия в XX в., после ранних работ Р. Карнапа [6], тождественна методологии, отвечает на вопрос «как?» и осуществляется в форме логического анализа языка, деятельности, мировоззрения, тех или иных систем. В том или ином виде философия для любой эпохи является анализом предельных оснований, тех граничных условий, которые обеспечивают конкретное осуществление человеческого в человеке в конкретных исторических обстоятельствах. Ф. Дессауэр отмечал, что «философствовать - значит ставить вопросы о сущности и смысле и, насколько это удаётся, прояснять их» [7, с.59]. Уже в наши 
дни В.П. Горан предложил убедительное и исчерпывающее определение философии в качестве «рефлексивной метамировоззренческой теории» $[8,9]$.

Философствование в любом виде задаётся исходным пониманием человеческого и человека. Ответ на вопрос, что есть человек, является исходной предпосылкой любого философского построения. Прояснить этот вопрос довольно просто через оппозицию «человек - природа»; в ней человек - это либо сугубо воспринимающее существо, либо существо действующее, соответственно человеческое определено либо только рецептивными процедурами, либо рецептивные процедуры дополняются проективными, деятельностью того или иного рода. Эту оппозицию вполне удачно показывает популярная в последней трети XX в. и в начале XXI в. литература, иллюстрирующая быт и мировосприятие примитивного, доисторического человека: К. Кастанеда, например, рисует образ «нагваля», воспринимающего мир особенным, сверхчеловеческим способом и отличающегося от человека как такового сложностью восприятия; В. Сёркин, напротив, показывает образ «шамана», действующего в условиях первобытной природы и отличающегося от среднего человека навыком, способностью к определённого рода деятельности [10]. В соответствии с этой оппозицией философствовать - значит извлекать предпосылки либо восприятия, либо навыков практического действия, так что и любое из приведённых определений философии может быть развёрнуто либо в одну, либо в другую сторону.

Техника на фоне оппозиции действующего и воспринимающего человека представляет собой своего рода общую территорию, в которой объединены и переплетены навыки восприятия и деятельности, которая имеет вполне конкретное отношение к сущему (реальности как она есть сама по себе), определённый порядок отношений своих элементов, определённые механизмы развития и деградации. Как говорит Ф. Дессауэр, «техникой называется создание и стремительно увеличивающийся инвентарь таких ${ }^{1}$ предметов и технологий» [7, с.109]. Техника, будучи объективацией человеческих способностей и навыков, позволяет многое прояснить в философском знании, показать практическую применимость или же, наоборот, абсурдность тех или иных построений.

Классические проблемы философского знания, на фоне которых философия с момента своего возникновения показывает границы (и расширение границ) человеческого, это воля, истина, красота, добро, польза (включая ценность). Этот список использует, например, П.К. Энгельмейер, чтобы показать возможности определения технической воли и технического мировоззрения [2, с.92-96], до него подобный перечень был предложен В. Виндельбандом. Ценность техники в качестве предмета философского исследования заключается в том, что здесь впервые появляется возможность исследовать процессы, происходящие в человеке, как вызванные не некоторыми природными данностями, то есть естественными, не обусловленными человеческим разумом и волей событиями, но их искусственными субститутами, созданными и определёнными посредством разума и воли человека. Например, в области эстетики именно техника впервые позволяет сравнить переживание прекрасного, как оно вызывается закатом, рассветом, пейзажем, физической данностью какого-то природного объекта, с переживанием, которое возникает при созерцании статуи, собора, чтении поэтического произведения и т.п. В области этики - это направление становится всё более популярным в последние годы - сравнивается долженствование (системы ценностей), как оно реализуется в естественных человеческих сообществах, и искусственно заданные правила поведения агентов в мультиагентных системах [11-13] и т.П. В области логики - это наиболее хорошо исследованная в последнее столетие область - актуальным является анализ осуществления естественных законов

${ }^{1}$ Созданных и создаваемых человеком. Прим. автора. 
логики, синтаксических правил естественных языков, тех натуральных форм мышления, которые оказываются непротиворечивыми в силу природы мышления как такового на фоне обусловленного «новой логикой» в смысле Венского кружка математического и кибернетического построения искусственных языков, в которых используются искусственные алфавиты, искусственные правила вывода, за счёт которых создаются неприродные программные системы и среды. Примером расширения логического исследования за счёт техники является соотношение корреспондентской и когерентной теорий истины: если применение корреспондентской теории ограничивается для индивидуального субъекта принципом привилегированного доступа к объектам собственного сознания, то когерентная теория, выражая системы межсубъектных синтаксических правил, абстрагируется от конкретного субъекта, показывает объективность истинностного отношения и подтверждается осуществлением этого отношения в артефактах. Здесь, как и в областях онтологии, теории познания и праксиологии, техника впервые позволяет добиться объективности, общезначимости, ясности и воспроизводимости человеческого знания как такового.

Одно из наиболее удачных определений техники предложено Ф. Дессауэром в 1959 г. в работе «Спор о технике»: «Техника есть реальное бытие из идей посредством финалистского формирования и обработки из данного природой инвентаря» [7, с. 115]. Анализ этого определения позволяет прояснить не только общефилософский контекст исследования техники как мира искусственных объектов, располагающегося между естественным, природой и внутренним, описываемым в терминах res cogitans, интенциональности, квалиа, души и духа, но и некоторые проблемы аналитической философии техники [14, 15], в частности, проблему значения, проблему существования и применения правил. Сам Ф. Дессауэр характеризует это определение с онтологической, эпистемологической и праксиологической точек зрения и показывает его потенциал в контексте аксиологии и эстетики.

\section{1 Техника в контексте онтологии и эпистемологии}

Онтология техники включает в себя большое число вопросов. Собственный вопрос онтологии - это вопрос о существовании реальности безотносительно к какому-либо способу учёта, фиксации или восприятия этой реальности каким-либо субъектом. Самая короткая формулировка онтологического вопроса предложена У. Куайном: «Что есть?» [16]. В аналитической философии он формулируется методологически: «Что значит быть?», «Что значит существовать?», «Что значит быть реальным?». Применительно к аналитической философии техники список онтологических вопросов формулируется следующим образом: «Что значит быть техническим объектом?», «Что значит быть технической средой?», «Каковы способы существования технического объекта и технической среды?», «Чем технический, искусственный способ существования объектов и сред отличается от природного, естественного, с одной стороны, и от фантазии, вымысла, инобытия, с другой стороны?».

Уникальность техники на фоне традиционного контекста онтологии легко увидеть, если сформулировать известные ответы на вопрос о существовании. Существовать - значить быть воспринимаемым, значением переменной, учитываемым тем или иным способом [17]. Наблюдаемый объект, с одной стороны, правило (математические или логические объекты) с другой и фантазия (художественный образ в творческом сознании поэта или читателя поэтического текста) - с третьей, существуют различными способами. Наиболее «сильный» критерий существования - это наблюдаемость, именно наблюдаемость свидетельствует о 
подлинности существования, начиная с Дж. Беркли [18] и вплоть до современной материалистической науки. Наиболее «слабый» - «учитываемость» вымыслом и фантазией: он был высмеян еще у Платона [19] и оказывается попросту запрещённым в любого рода проработанном религиозном сознании, от индуизма до ислама и христианского протестантизма. «Средняя» область существования правил трактуется после Платона либо в качестве исходного мира божественного бытия, в качестве мира математических объектов, материальное осуществление которых создаёт те или иные наблюдаемые объекты, - эту точку зрения легко перенимает экспериментальная наука с Г. Галилеем, либо после И. Канта [20] - в качестве способа организации человеческого познания, объективирующего и опредмечивающего реальное на основе трансцендентальных форм, то есть существующих особым внутренним образом правил.

Специфика технического на фоне сугубо фантазии или наблюдения сугубо естественных объектов (заката, рассвета, дерева, ручья) заключается в практическом соединении всех областей существующего, доступных человеку: фантазии, рассудка и восприятия. Критерий существования технического объекта - это последовательная реализация известных критериев существования с самого слабого вплоть до самого сильного. Например, самолёт как фантазия - это представление человеком себя в управляемом полёте над землёй. Самолёт как логическая форма - это чертёж или конструкция, изобретение формы, способной выполнить полёт. Самолёт как воспринимаемый объект - это материальная реализация чертежа в производственном цикле. Технический объект возникает, последовательно «усиливая» способ своего существования от вымысла к наблюдению.

Технический объект - изначально не наблюдаемый объект. Технический объект должен быть осуществлён (человеком), чтобы он существовал. Он должен быть изобретён, то есть оформлен средствами фантазии и вымысла, затем приведён к некоторой логической форме, имеющейся в распоряжении изобретателя, а затем обработан руками и инструментами. Ф. Дессауэр связывает осуществление технического объекта с тремя фундаментальными способностями человека: человек изобретающий (investigator), человек внедряющий (inventor), человек обрабатывающий (faber): изобретение, внедрение и обработка позволяют техническому объекту существовать [7, с.68-70]. Таким образом, онтология технического объекта в аналитической части, при реконструкции значения вопроса «что значит существовать?» оказывается более сложной, нежели исследование бытия естественных объектов и процессов, вынуждает использовать весь наработанный философами потенциал для фиксации сущности технического. Если же последовать за Ф. Дессауэром в том, что наука становится наукой тогда и только тогда, когда начинает использовать технику для измерительного эксперимента, то можно утверждать, что всякое научное знание последних трёх веков является техническим знанием и способно показать реальный мир ровно в той мере, в какой этот мир технически осуществим человеком.

Отдельный вопрос онтологии техники - это существование технических сред или искусственной природы, технически созданной человеком. Ф. Дессауэр подробно останавливается на том, что всякий технический объект, будь то медикамент или деталь машины, осуществляясь в реальном мире, привносит в него свою специфическую «силу»: медикамент останавливает болезнь или смерть, деталь машины позволяет функционировать производству и т.д.; «сила» в данном случае - это некоторое изменение, нарушение естественного порядка вещей, влекущее, в том числе, и трансформацию горизонтов фантазии, которые, в свою очередь, показывают возможности для новых технических объектов. Важно, что сложение сил отдельных технических объектов позволяет технике в целом изменять человеческий мир. Общий смысл техники, как говорит Ф. Дессауэр, заключается в построении человеческой среды, накладывающейся на естественную, 
природную среду и позволяющей человеку реализовать свой собственно человеческий потенциал [7, с.105-108]. Жизненный мир человека - это искусственная, технически построенная самим человеком среда. Сумма трансформаций, вносимых отдельными техническими объектами в естественную среду, перерастает в новое качество среды: из естественной она становится искусственной. Следовательно, практическое осуществление созданных вымыслом форм сначала в структурах рассудка, а затем путём обработки, то есть в материи, доступной чувственному восприятию, позволяет реализоваться новому качеству среды обитания человека, изменить «мир».

Рассуждение Ф. Дессауэра о смысле техники (в контексте аналитической философии правильнее было бы говорить «о цели техники») хорошо коррелирует с рассуждением П.К. Энгельмейера о неприменимости теории эволюции Ч. Дарвина к описанию человека и человеческой истории [2, с.91-92]. Человек не приспосабливается к среде, человек изменяет среду таким образом, чтобы она соответствовала его потребностям. Это верно в отношении человеческого вида в целом, поскольку индивид по определению не может являться ни объектом, ни субъектом эволюции в дарвиновском смысле. Практическое изменение среды есть следствие саморазвития человека посредством техники. Действительно, то новое, которое фиксируется человеком в практике естественнонаучного, художественного и исторического познания, создаётся самим человеком: новые предметы, новые художественные и математические языки, новые системы ценностей, - причём во всех случаях речь идёт о технике как месте появления нового. Ещё один взгляд на ситуацию появления новой искусственной среды за счёт технического развития даёт оригинальное рассуждение Ю.М. Лотмана о сущности автокоммуникации [21, с.168-177]. Если представить себе время как канал осуществления коммуникации, а человечество, человеческий вид - в качестве глобального субъекта коммуникации, то окажется, что человечество коммуницирует только с самим собой, постоянно оставляет самому себе сообщение во времени, само его принимает как сообщение, расшифровывает и изменяет себя под влиянием отправленного самому себе сообщения. Человечество создаёт новые технические объекты из самого себя в оппозиции естественной природе, последовательно подменяя последнюю искусственной природой. Сложение сил технических объектов создаёт новую сверхъестественную среду, и в этой новой среде возникают новые механизмы осуществления человеческого, новые способы построения технических объектов, новые формы художественного, науки, этики и т.д. Этот вопрос довольно подробно рассмотрен [22, 23] в рамках анализа эволюции техники от первой естественной природы ко второй и третьей искусственной природе. Сейчас подчеркнём, что в рамках онтологии техники искусственная среда, понятая через сумму нарушений, внесённых каждым отдельным техническим объектом в мир естественной природы, - это то, что меняет, в том числе, и способ самопонимания человека, характер его рефлексии относительно восприятия и деятельности, характер этического долженствования. То, что немецкие, а затем советские школы философии исследуют в качестве мировоззрения, фактически есть техническая среда человека, формирующая и ограничивающая его горизонты. Соотношение исторической трансформации мировоззрения, например, в смысле В. Дильтея [24], и эволюции технических сред с их предельно конкретной онтологией, выраженной в границах фантазии, рассудочных структур, материально осуществимого, еще предстоит проработать: Ф. Дессауэр сходным образом предложил посмотреть на науку как на деятельность, опосредованную и ставшую возможной благодаря технике; в значительной степени этот подход реализуется сейчас в терминах социологии науки, в историческом методе технологической реконструкции, в математическом моделировании истории науки (и даже классической политической истории) на фоне истории техники. 
Эпистемология техники, как и эпистемология в целом, - это наиболее ясная из всех возможных философских дисциплин. Она включает в себя ответы на вопросы об определении акта познания, о доступе познающего субъекта к реальности, об определении знания, о причинах и способах расширения познания и знания. Ф. Дессауэр подчёркивает, что техника - технические объекты и среды - своим существованием снимает предмет классической дискуссии о доступе индивида к реальности. Сущность этого спора заключается в вопросе, имеет ли человек доступ к реальности как она есть сама по себе в акте познания, если познание определено в виде интериоризации «внешнего мира». Технический объект всегда осуществляется на основе знания о реальном, как оно доступно человеку: чем выше уровень этого знания, тем сложнее объекты, которые могут быть построены на его основе; технический объект всегда исполняет законы природы. Нюанс в том, что всякий технический объект, будучи однажды изобретённым, в дальнейшем функционирует как элемент воспринимаемого мира, наряду с естественными объектами. Это означает, что человек имеет доступ к реальности в той мере, в какой он способен создавать не просто субституты естественных объектов, но новые объекты, «существующие» для его систем восприятия ровно тем же способом, что и нетехнические, природные объекты: наблюдаемый полевой цветок растёт сам по себе, является природным объектом, вместе с тем, колесо или лопата воспринимаются точно так же, как и полевой цветок, хотя и являются искусственными объектами. Этот пример (Ф. Дессауэр говорит о микроскопе на фоне растения или фрукта [7, с.104]) с эпистемологической точки зрения показывает ряд крайне значимых моментов. Во-первых, человек обладает знанием как системой обоснованных истинных убеждений о чём-то тогда и только тогда, когда он в состоянии это нечто воспроизвести в качестве технического объекта - в этом смысле наше знание природы на фоне знания технических искусственных объектов и процессов по определению неполно и будет таковым всегда при любых обстоятельствах. Человек может сейчас промоделировать многие природные и исторические процессы, однако отнюдь не все модели могут быть осуществлены в виде технических объектов. Во-вторых, объективное знание о естественном, о природе ограничено техникой. Наука, понимаемая в качестве соединения чувственного восприятия и логического анализа [25], становится наукой благодаря техническому измерительному эксперименту, легитимирующему индуктивный метод познания. В-третьих, об истории мы знаем только то, что было технически осуществлено нашими предками и только в той мере, в какой их технические методы эквиваленты сегодняшним методам, то есть понятны представителям нашей эпохи. Последний момент раскрывает крайне продуктивное применение методов герменевтики в истории техники и истории как таковой.

Наиболее важный для эпистемологии техники вопрос заключается в том, откуда человек собственно черпает сведения о конкретных технических формах, посредством которых может быть удовлетворена его потребность, желание или фантазия. Что собой представляют «идеи», позволяющие техническому объекту стать реальностью в определении техники Ф. Дессауэра? Аналогичный вопрос в общей эпистемологии - откуда вообще берётся форма индуктивного обобщения в случае индуктивного вывода, или что такое гипотеза, как она возможна, что является её основанием?

С точки зрения определения рецептивного, нетехнического познания ответ на этот вопрос демонстрируется уже Платоном и с тех пор практически не претерпевает серьёзных изменений, составляя классический предмет истории онтологии, эпистемологии и философии языка через спор номинализма и реализма, рождение семиотики в качестве общей теории интерпретации, формирование собственно теории познания на фоне Лейбнице-Вольфовской метафизики и т.д. Когда обнаруживается, что способ мышления об объекте - логическая форма, в которую включён предмет в индивидуальном мышлении, или 
языковая форма, посредством которой объект оказывается обозначен в той или иной ситуации коммуникации, - не совпадает ни с объектом, ни с порядком обнаружения этого объекта чувственным восприятием (проф. М.В. Лебедев ${ }^{2}$ любил на своих лекциях задавать вопрос, отчего такое большое животное как слон, обозначается таким коротким словом «слон»?), возникает онтологическая проблема существования правил мышления и языка и эпистемологическая проблема соотношения мышления и языка, с одной стороны, и фиксируемых чувственным восприятием объектов, с другой стороны; кроме того, и соединение онтологии и эпистемологии заставляет задать метафизический вопрос о том, есть ли, например, в слоне что-то реальное, такое, которое находится за пределами его восприятия, мышления и говорения о нём.

Решение Платоном этого списка проблем сформулировано в его учении об идеях. Человек живёт в неподлинном мире, подобном пещере, и воспринимает чувственным восприятием лишь тени, то есть материальные осуществления действительно существующих нематериальных вещей. Подлинный же мир - это идеи, расположенные за пределами нашего неподлинного мира. Выйти из мира теней можно, изучая математику: многолетняя концентрация внимания на арифметике, геометрии и астрономии позволяет «стражу» перейти от неподлинного и иллюзорного к подлинному, реальному [19]. История этой платоновой метафоры по большому счёту совпадает с историей философии как таковой, включая ранние доплатоновы версии индуизма. Сейчас важно отметить, что Платон в теории идей открывает сферу рассудка, область правил, существование которых заключается не в наблюдаемости, но в непротиворечивости, область, которая фиксируется не восприятием, но отличным от восприятия умом. Серьёзные трансформации это учение претерпевает сначала в трансцендентальной философии И. Канта, а затем, уже в XX в., - в концепции «третьего мира» К.Р. Поппера [26]. Подлинно существующие «идеи» Платона в «Критике чистого разума» И. Канта [20] обнаруживаются не в качестве неких самостоятельных сущностей, подобных наблюдаемым объектам, но в качестве преднаходимых правил деятельности человеческого ума, «трансцендентального сознания». Оказывается, что человеческая деятельность во всех её аспектах и направлениях есть осуществление систем априорных и апостериорных правил восприятия, рассудка и разума. Еще до И. Канта Д. Беркли [18] вполне убедительно показал, что проблема применения и трансформации априорных правил является наиболее существенной проблемой как онтологии, так и гносеологии: например, именно неспособность конкретного человека, конкретного субъекта познания изменить то или иное правило, как-то существенно повлиять на порядок его осуществления является наиболее сильным аргументом против солипсизма (против отсутствия у человека доступа к «реальности», чем бы она ни была).

Превращение самостоятельно существующего мира идей, постижимых средствами логики и математики, в систему трансцендентальных правил деятельности позволило поновому поставить вопрос о человеке, о его отношении к реальности, о материи. Обсуждение этого вопроса в целом вывело бы слишком далеко за пределы вопроса о технике. Отметим, что влиятельным развитием платонизма в XX в. является плюралистическая онтология К.Р. Поппера [26], выделяющая отдельно мир физических объектов, мир ментальных состояний и третий мир языка. Эквивалентом мира Платоновых идей, мира математических объектов или правил является мир языка. В отличие от Платона, множество элементов третьего мира Поппера бесконечно и может увеличиваться посредством деятельности человека. Важно, что и здесь - на материале научных теорий, процедур установления их истинности и ложности, эволюции научного знания - показана невыводимость одного мира из другого,

\footnotetext{
2 Лебедев Максим Владимирович (1959-2012) видный российский философ, логик и лингвист, доктор философских наук, член научного совета РАН по методологии искусственного интеллекта, главный редактор журнала «Analytica». Прим.ред.
}

Онтология проектирования, том 6, №3(21)/2016 
самостоятельный характер различных способов существования в виде физических объектов, эмоциональных состояний и переживаний и научных теорий. Фундаментальный вопрос теории познания формулируется и здесь: «как осуществляется познание?», «как взаимодействуют различные миры?», «как они отображаются друг в друге?».

Решение фундаментальной проблемы познания в классической рецептивной эпистемологии связано с концепцией отображения форм одного мира на формах другого мира: для Античности математическая идея отпечатывается в материи, отображая в ней свою форму; для средневековой и во многом новоевропейской философии фигура «бога» опосредует в том или ином виде соотнесение чувственного и умопостигаемого; для аналитической философии в версии Л. Витгенштейна грамматика изоморфна структурам наблюдения и т.п. Ф. Дессауэр также ссылается на концепцию отображения или «отражения» реального мира в духе [7, с.100-105.]. Представление о познании как отображении одной системы на другой - один из наиболее значимых результатов европейской философии. Это отображение может мыслиться как «внешнее» и как «внутреннее». Если оно берётся как внешнее отношение, то «реальным миром», отображаемым во «внутреннем мире», оказывается более сложная, содержащая большее количество элементов система, отображающаяся на более простой, содержащей меньшее количество элементов системе: в качестве такого рода реальности выступает, в зависимости от автора концепции и от эпохи, либо мир физических объектов, либо мир правил (божественный). Если же отображение берётся как внутреннее, внутрисистемное отношение, то «реальным миром» оказывается бесконечно большое количество правил, выражаемое и показываемое каждой из систем, участвующих в познании, а «внутренним миром» - та сумма правил, которая известна человеку в рецептивном и проективном смысле. Модель в истории философии, которая показывает указанное отображение миров друг в друге в акте познания в качестве внутрисистемного отношения, - это трансцендентализм. С точки зрения трансцендентализма в его рецептивном выражении проблема доступа к реальности, равно как и проблема материи, остаются метафизическими проблемами, неразрешимыми до тех пор, пока рецептивное направление познания не будет рассмотрено на фоне проективного, конструктивного познания. Именно техника как материально выраженная проективная рефлексия позволяет в данном случае создать набор проверяемых следствий, подтверждающих онтологические предпосылки трансцендентализма. Трансцендентальная философия, которую исторически возводят к И. Канту, фактически осуществляется в истории философии, начиная с А. Августина, как семиотика, общая теория знаков, претендующая на единообразное описание процедур познания, коммуникации и понимания в терминах синтаксических, семантических, прагматических правил и способов их взаимодействия в реальных, выраженных в той или иной материи сущностях.

До тех пор, пока познание рассматривается сугубо рецептивно, проблемы формы отображения одной системы на другой довольно трудно увидеть в качестве проблемы, и эта трудность приводила в истории философии к метафизике, умножению сущностей и трудно воспроизводимым онтологическим конструкциям. Когда познание рассматривается проективно, в качестве процедуры создания технического объекта - а любой создаваемый человеком «объект» является техническим объектом, изобретённым в фантазии, воплощённым сначала в логическую форму, а затем выраженным в материи физического мира - проблема отображения друг в друге слоёв сознания в смысле немецкого идеализма или взаимодействия миров в смысле К.Р. Поппера становится предельно ясной и открытой. Ф. Дессауэр во многих местах подчёркивает, что в идеале каждой фантазии должно соответствовать только одно техническое решение, и это решение, по его мнению, принадлежит не человеку, но космосу, порядку мироздания. Это соответствие он 
формулирует в концепции «четвёртого царства», названного им так в продолжение трёх «царств» И. Канта: «царства опытного познания», «царства воли и нравственного закона», «царства эстетического и целесообразного [des Zweckmaessigen]» [27, с.50]: «Тройного деления мира по Канту недостаточно. В четвёртом царстве мы вступаем в новый мир, заключающийся в технике» [27, с.57].

\section{2 «Четвёртое царство» Ф. Дессауэра}

Что это значит, что техника составляет новый мир? Можно ли проследить его новизну, его открытие человеком не в доисторических временах, а в процессах взросления, воспитания, то есть в процессах роста самосознания, духовного роста? Если уже понятно, что техника как деятельность - это материально выраженная рефлексия, осуществляемая человеком процедура самопознания, то ответ очевиден. Человек за пределами некоторых частных случаев автоматического восприятия и рефлекторной неосознаваемой деятельности является рефлексирующим существом. Открытие осознанной и управляемой рефлексии как механизма становления человека человеком маркирует переход от мифологического, архаического мировоззрения к религиозному. Открытие возможностей внетелесной (К.Р. Поппер сказал бы «экзосоматической») рефлексии - и есть открытие техники «как мировой силы», которое прокладывает путь к научному, а с середины XX в. - к инженернотехническому мировоззрению (в смысле П.К. Энгельмейера).

Рефлексия в её материальном, физическом выражении - это наиболее сложный уровень самосознания, которого добился человек на настоящий момент. Одно дело - интуитивное прозрение, показывающее несовпадение разума с рассудком и восприятием, другое фантазия или вымысел, возникающий в переживании такого несовпадения, третье воплощение фантазии и вымысла в логической форме, выражение в структурах языка и только четвёртое - техника, материальное воплощение объекта, его (вос)создание. Концепция четвёртого царства Ф. Дессауэра как некоего предданого любой технической деятельности инвентаря «предустановленных образов решений» выполняет функцию мира идей Платона, только не для рецептивного, а для проективного разума. В терминах трансцендентальной философии её следует понимать как область специфических правил проективной рефлексии, начинающуюся с присущих разуму правил созерцания и конструирования, о которых И. Кант говорит в «Трансцендентальном учении о методе», опускающуюся затем на уровень рассудочных категорий, чтобы в конечном итоге воплотиться в пространстве и времени как формах восприятия. На языке общей семиотики «четвёртое царство» может быть представлено как набор правил последовательного отображения синтаксиса разумной деятельности в синтаксисе рассудочной, языковой деятельности и затем - в синтаксисе восприятия, или, другими словами, как набор правил согласования прагматических правил разных типов семиозиса. Отметим, что ту конструкцию, которую Ф. Дессауэр фиксирует и предлагает исследовать в виде «четвёртого царства», в Новое время Дж. Беркли [18] в том же проективном ключе (для Беркли само восприятие - по сути проективная, а не рецептивная деятельность) определил в виде «доброго бога», такой фигуры, которая отвечает за самотождественность мироздания (аналогичной фигурой является «универсальный наблюдатель» в физике XX в.), а $Г$. Лейбниц [28] - в виде предустановленной гармонии, позволяющей взаимодействовать различным типа сущего. В наши дни А.Н. Павленко справедливо связывает проективную концепцию техники Ф. Дессауэра с «антропным космологическим принципом» [29, §6]. 
В работе «Спор о технике» Ф. Дессауэр [7, с.83-85] предлагает шесть тезисов относительно «четвёртого царства» ${ }^{3}$.

Современные критики, презрительно или недоумённо отмежёвывающиеся от концепции «четвёртого царства», большей частью просто не знакомы с текстом Ф. Дессауэра (или не способны изложить его так, чтобы это знакомство стало очевидным для информированного читателя). Тезисы Ф. Дессауэра и приведённые рассуждения показывают, что философия техники за счёт специфического соединения онтологии и теории познания позволяет не только прояснить классический спор о реальности и действительности, но и в значительной степени прояснить фундаментальную проблему этики, заключающуюся в несоответствии сущего (действительного) и должного (возможного). Если искать адекватные параллели для проблем, пробным решением которых является концепция «четвёртого царства», то они обнаруживаются в целом в философии творчества, как с филологической или в целом историко-художественной стороны, так и с психологической. Анализ «предустановленных форм решений» в технике следует сопоставлять с анализом тех грамматических и стилистических норм, которые тот или иной язык предоставляет поэту, с анализом соответствий цветовой палитры и геометрии фантазии художника, с анализом звуковых рядов, частотных характеристик, посредством которых выражает свои образы композитор или музыкант-импровизатор, с анализом логических структур, формул и правил, которые позволяют учёному сформулировать абдуктивную гипотезу. Этот анализ по большому счёту должен начинаться с припоминания того конкретного способа, которым каждый студент решал, решает и будет решать проблему «чистого листа» у хорошего профессора, проблему начала собственного текста, первый для каждого и оттого самый важный способ осуществления общей проблемы выражения.

\section{Заключение. Проблема человека в философии техники}

В настоящем рассуждении без внимания осталась проблема эволюции технических сред, её влияние на человека, вопросы о нечеловеческих субъектах деятельности, возникающие при обсуждении т.н. «технологической сингулярности» [30]. Платонистское понимание техники Ф. Дессауэром позволяет достаточно внятно поставить эти проблемы и вопросы, выразив их в моделях трансцендентального описания на языке общей семиотики. Очевидно, что в XXI веке человечество вступает в состояние «третьей природы», выстраивая новую искусственную среду поверх искусственной среды, созданной в XIX и XX веках, и у философского сообщества пока нет обобщающих глобальных моделей, которые могли бы описать взаимодействие природного и искусственного, показать глобальный горизонт прогноза. Оформленное Ф. Дессауэром платонистское понимание техники как проективной, материально выраженной рефлексии, формирующей специфическую среду со своими нормами существования и эволюции, позволяет, по меньшей мере, увидеть этот круг проблем.

Платонистский подход Ф. Дессауэра к пониманию техники в онтологической и эпистемологической перспективах выявляет существенную область в исследованиях философии техники, а именно область правил проективной рефлексии, которая вскрывает сущность технического на фоне проблемы человека. Техника - область, в которой сталкиваются человеческие проблемы, то есть знание человека о собственном незнании, со способами их решения, то есть с формами и правилами человеческой деятельности в отношении естественной природы, самого себя и других людей. Каждое конкретное решение

\footnotetext{
${ }^{3}$ Перевод на русский язык второй главы «К философии техники. Что есть техника? - Термин и сущность» монографии Ф. Дессауэра «Спор о технике», в которой приведены эти тезисы, публикуется впервые в этом номере журнала. Прим.ред.
} 
в области техники, будь то логически корректная теория по поводу объекта или процесса или созданный технический объект, оказывает специфическое, присущее только ему воздействие на всю область техники и через неё - на человека и на среду его обитания. Эти изменения, накапливаясь, влекут изменения в научной, политической, экономической сферах, прямо влияют на понимание целей и содержание образования.

Соответственно исследование области техники, техносферы может и должно ориентироваться на анализ правил проективной рефлексии, заданных «четвёртым царством» Ф. Дессауэра, научиться делить их в смысле общей семиотики на группы семантических, синтаксических, прагматических правил, находить корреляции этих правил с общими правилами выражения и теориями творчества, исследуемыми философами, историками, филологами, психологами и социологами.

\section{Благодарности}

Работа выполнена при поддержке Совета по грантам Президента Российской Федерации, проект МД-6200.2016.6 «Семиотические основания техники и технического сознания».

\section{Список источников}

[1] Kapp, E. Grundlinien einer Philosophie der Technik. Zur Entstehungsgeschichte der Cultur aus neuen Gesichtspunkten / E. Kapp. - Braunschweig: «Verlag von George Westermann», 1877.

[2] Энгельмейер, П.К. Философия техники / П.К.Энгельмейер. - СПб.: «Лань», 2013.

[3] Mayer, E. Technik und Kultur. Gedanken ueber die Verstaatlichung des Menschen / E. Mayer. - Berlin: «Huepeden \& Merzyn Verlag», 1906.

[4] Eyth, M. Lebendige Kraefte. Sieben Vortraege aus dem Gebiete der Technik / M. Eyth. - Berlin: «Springer», 1905.

[5] Zschimmer, E. Philosophie der Technik: vom Sinn der Technik und Kritik des Unsinns über die Technik / E. Zschimmer . - Jena: «Diedrichs», 1914.

[6] Carnap, R. Scheinprobleme in der Philosophie und andere metaphysikkritische Schriften / R. Carnap. - Hamburg: «Meiner», 2004.

[7] Dessauer, F. Streit um die Technik / F. Dessauer. - Freiburg in Breslau: «Verlag Herder», 1959.

[8] Горан, В.П. Философия. Что это такое? (начало статьи) / В.П. Горан //Философия науки. - 1996. - № 1 (2).

[9] Горан, В.П. Философия. Что это такое? (завершение статьи) / В.П. Горан //Философия науки. $-1997 .-$ № 1 (3).

[10] Сёркин, В. Шаманский лес / В. Сёркин. - Магадан: «Северный междунар. ун-т», 2007.

[11] Редько, В.Г. Будущее России, будущее человечества / В.Г. Редько // Вторые Лемовские чтения: сб. материалов Всероссийской научной конференции с международным участием памяти Станислава Лема / отв. ред. А.Ю. Нестеров. - Самара: «Изд-во Самар. гос. аэрокосм. ун-та», 2014. - С.161-179.

[12] Боргест, Н.M. Научный базис онтологии проектирования / Н.М. Боргест // Онтология проектирования. 2013. - № 1. - C.7-25.

[13] Боргест, Н.М. Онтологии: современное состояние, краткий обзор / Н.М. Боргест, М.Д. Коровин // Онтология проектирования. - 2013. - №2. - С.49-55.

[14] Ястреб, Н.A. Аналитический подход в философии техники / Н.А. Ястреб // Вестник Московского государственного областного университета. - 2016. - № 1. - С. 102-107.

[15] Ястреб, Н.A. Проблема двойной демаркации технического знания в аналитической философии техники / Н.А. Ястреб // Вестник Томского государственного университета. Философия, социология, политология. 2016. - № 2. - C. 129-136.

[16] Quine, W. From a logical point of view. 9 logico-philosoph. Essays / W. Quine. - New York: «Harper \& Row», 1963.

[17] Нестеров, А.Ю. Существование и значение: проблема субстрата знаковой функции / А.Ю. Нестеров // Вестник Томского государственного университета. Философия, социология, политология. - 2014. - № 4 (28). - C.56-63.

[18] Berkeley, G. A treatise concerning the principles of human knowledge / G. Berkeley. - Oxford: «Oxford Univ. Press»), 1998. 
[19] Платон. Государство // Собрание сочинений в 4т. Т.3. - М.: «Мысль», 1994.

[20] Kant, I. Kritik der reinen Vernunft / I. Kant / Wekausgabe in 12 Bänden. Bd. III. - F.a.M.: «Suhrkamp», 1956.

[21] Лотман, Ю.М. Внутри мыслящих миров / Ю.М. Лотман // Семиосфера. - СПб.: «Культура - СПБ», 2010.

[22] Нестеров, А.Ю. Вопрос о сущности техники в рамках семиотического подхода / А.Ю. Нестеров // Вестник СГАУ. - Т. 14, № 1, 2015. - С.235-246.

[23] Нестеров, А.Ю. Техническое сознание как семиозис. Постановка задач / А.Ю. Нестеров // Вестник Вологодского государственного университета. Серия: Гуманитарные, общественные, педагогические науки. - 2016. - № 2 (2). - С. 22-28.

[24] Dilthey, $\boldsymbol{W}$. Weltanschauung und Analyse des Menschen seit Renaissance und Reformation Abhandlungen zur Geschichte der Philosophie und Religion / W. Dilthey. - Leipzig: «Teubner», 1914.

[25] Verein Ernst Mach. Wissenschaftliche Weltauffassung. Der Wiener Kreis // Wiener Kreis. Texte zur wissenschaftlichen Weltauffassung von Rudolf Carnap, Otto Neurath, Moritz Schlick, Philipp Frank, Hans Hahn, Karl Menger, Edgar Zilsel und Gustav Bergmann. - Hamburg: «Meiner», 2006.

[26] Popper, K.R. Objective Knowledge: An Evolutionary Approach / K.R. Popper. - Oxford: «Clarendon Press», 1995.

[27] Dessauer, F. Philosophie der Technik: das Problem der Realisierung / F. Dessauer. - Bonn: «Cohen», 1928.

[28] Leibniz, G. W. Monadologie und andere metaphysische Schriften / G.W. Leibniz. - Hamburg: «Meiner», 2002.

[29] Павленко, А.Н. Возможность техники. Часть III. Технический проект Фридриха Дессауэра / А.Н. Павленко // Историко-философский ежегодник, 2007. - М.: «ИФ РАН», С. 325-351.

[30] Глобальное будущее 2045. Конвергентные технологии (НБИКС) и трансгуманистическая эволюция. - Под ред. проф. Д.И. Дубровского. - М.: ООО «Издательство МБА», 2013.

\title{
EPISTEMOLOGICAL AND ONTOLOGICAL PROBLEMS OF THE PHILOSOPHY OF TECHNOLOGY: "THE FOURTH KINGDOM” OF F. DESSAUER
}

\author{
A.Y. Nesterov \\ Samara National Research University named after academician S.P. Korolev, Samara, Russia \\ phil@ssau.ru
}

\begin{abstract}
This article considers the concept and a problem of technology in Friedrich Dessauer's works "Philosophy of technology" (1927) and "Dispute on technology" (1959). Ways of statement of the epistemological and ontological questions specific to technology are analyzed. The article shows that the concept of "the fourth kingdom" is an area of rules of the projective, materially expressed reflection which is understood as technology in the true sense. The author proves the thesis that "the fourth kingdom" carries out for projective activity the same functions, as "the world of ideas" of Plato - for the philosophy of receptive activity which has been traditionally investigated in the history. Thereby the platonic philosophy of technology is shown as a perspective area of research within the analysis of projective rules from positions of transcendentalism and the general semiotics.
\end{abstract}

Key words: Platonism in the philosophy of technology, the fourth kingdom, projective semiosis, the preset forms of decisions, artificial and natural.

Citation: Nesterov AY. Epistemological and ontological problems of the philosophy of technology: "the fourth kingdom" of F. Dessauer [In Russian]. Ontology of designing. 2016; 6(21): 377-389. DOI: 10.18287/2223-9537-20166-3-377-389.

\section{References}

[1] Kapp E. Grundlinien einer Philosophie der Technik. Zur Entstehungsgeschichte der Cultur aus neuen Gesichtspunkten [In German]. - Braunschweig: Verlag von George Westermann; 1877.

[2] Engelmeier PK. The Philosophy of technique [In Russian]. - St. Petersburg: Lanj; 2013. 
[3] Mayer E. Technik und Kultur. Gedanken ueber die Verstaatlichung des Menschen [In German]. - Berlin: Huepeden \& Merzyn Verlag; 1906.

[4] Eyth M. Lebendige Kraefte. Sieben Vortraege aus dem Gebiete der Technik [In German]. - Berlin: Springer; 1905.

[5] Zschimmer E. Philosophie der Technik: vom Sinn der Technik und Kritik des Unsinns über die Technik [In German]. - Jena: Diedrichs; 1914.

[6] Carnap R. Scheinprobleme in der Philosophie und andere metaphysikkritische Schriften [In German]. - Hamburg: Meiner; 2004.

[7] Dessauer F. Streit um die Technik [In German]. - Freiburg in Breslau: Verlag Herder; 1959.

[8] Goran VP. Philosophy. What is it? (The beginning) [In Russian]. Philosophy of science 1996; 1 (2).

[9] Goran VP. Philosophy. What is it? (The ending) [In Russian]. Philosophy of science 1997; 1 (3).

[10] Syorkin V. Shaman wood [In Russian]. - Magadan: North international university; 2007.

[11] Redko VG. The future of Russia, the future of humanity [In Russian]. The Second Lem's readings. - Samara: SSAU publ.; 2014:161-179.

[12] Borgest NM. Scientific basis for the Ontology of designing [In Russian]. Ontology of Designing. 2013; 1: 7-25.

[13] Borgest NM, Korovin MD. Ontologies: current state, short review [In Russian]. Ontology of Designing. 2013; 2: 49-55.

[14] Yastreb NA. Analitical approach in philosophy of technology [In Russian]. Bulletin of MSRU. Series Philosophy (Vestnik Moskovskogo gosudarstvennogo oblastnogo universiteta. Seriâ Filosofskie nauki). 2016. № 1. P. 102107.

[15] Yastreb NA. The Problem of double Demarcation in analytic Philosophy of Technology [In Russian]. Tomsk State University Journal of Philosophy, Sociology and Political Science 2016; 2: 129-136.

[16] Quine W. From a logical point of view. 9 logico-philosoph. Essays. - New York: Harper \& Row; 1963.

[17] Nesterov AY. Existence and meaning: the matter of semiosis [In Russian]. Tomsk State University Journal of Philosophy, Sociology and Political Science 2014; 4 (28): 56-63.

[18] Berkeley G. A treatise concerning the principles of human knowledge. - Oxford: Oxford Univ. Press; 1998.

[19] Plato Republic [In Russian]. Sobranije sochinenij v 4 tomah. Tom 3. Moscow; 1994.

[20] Kant I. Kritik der reinen Vernunft [In German]. Wekausgabe in 12 Bänden. Bd. III. - F.a.M.: Suhrkamp; 1956.

[21] Lotman YM. In the conceiving worlds. Semiosfera [In Russian]. St. Petersburg: Culture - St.P.; 2010.

[22] Nesterov $A Y$. The essence of technical consciousness within the frame of the semiotic approach [In Russian]. Vestnik SSAU 2015; V. 14, № 1: 235-246.

[23] Nesterov AY. Technical consciousness as semiosis: goals setting [In Russian]. Vestnik VoGU. Humanitarian, social, pedagogical sciences 2016; 2 (2): 22-28.

[24] Dilthey $W$. Weltanschauung und Analyse des Menschen seit Renaissance und Reformation Abhandlungen zur Geschichte der Philosophie und Religion [In German]. - Leipzig: Teubner; 1914.

[25] Verein Ernst Mach. Wissenschaftliche Weltauffassung. Der Wiener Kreis [In German]. Wiener Kreis. Texte zur wissenschaftlichen Weltauffassung von Rudolf Carnap, Otto Neurath, Moritz Schlick, Philipp Frank, Hans Hahn, Karl Menger, Edgar Zilsel und Gustav Bergmann. - Hamburg: Meiner; 2006.

[26] Popper KR. Objective Knowledge: An Evolutionary Approach. - Oxford: Clarendon Press; 1995.

[27] Dessauer F. Philosophie der Technik: das Problem der Realisierung [In German]. - Bonn: Cohen; 1928.

[28] Leibniz GW. Monadologie und andere metaphysische Schriften [In German]. - Hamburg: Meiner; 2002.

[29] Pavlenko AN. Technological Possibility. Part III. Friedrich Dessauer's views on technology (In Russian). Istorikophilosophskij eshegodmik 2007. Moscow: IPH RAS. P. 325-351.

[30] The Global future 2045[In Russian]. Moscow: MBA publ.; 2013.

\section{Сведения об авторе}

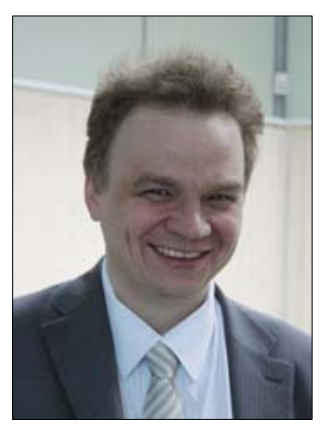

Нестеров Александр Юрьевич, 1978 г. рождения. Кандидат филологических наук, доктор философских наук. Заведующий кафедрой философии Самарского национального исследовательского университета имени академика С.П. Королева. Область научных интересов: общая семиотика и герменевтика, философия науки и техники, теория значения.

Nesterov Alexander Yurjewitsch (b. 1978). PhD in philology, Doctor (hab.) of philosophy, chief of the department of philosophy, Samara University. Area of research: semiotics and hermeneutics, philosophy of science and technology, theory of meaning. 


\title{
К ФИЛОСОФИИ ТЕХНИКИ.
}

\section{ЧТО ЕСТЬ ТЕХНИКА? - ТЕРМИН И СУЩНОСТЬ ${ }^{1}$}

\author{
Ф. Дессауэр ${ }^{2}$
}

\section{Задача философии техники}

В 1926-27 годах, когда вышла моя «Философия техники», было две книги с таким же названием. Первая, вышедшая в 1877 году, принадлежит Эрнсту Каппу и толкует технику виталистски, в духе своего времени. Техника представляет собой «органопроекцию», повторение того, что организует и осуществляет сама природа. Критика этой односторонней концепции сформулирована уже у Макса Айта. Однако в ней есть зерно истины, и к ней мы вернёмся при обсуждении кибернетики. Вторая книга, вышедшая в 1913 году, принадлежит Эберхарду Цшиммеру. [...]

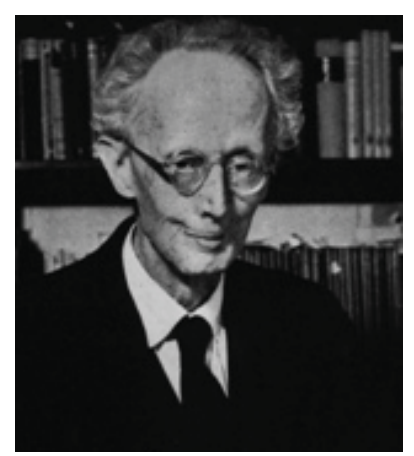

\section{1 Происхождение термина - «техне» Сократа - Платон - Кант}

[...] Человек с момента своего появления на Земле сразу был техником, и... всякий человек, которого судьба например, в результате кораблекрушения - оставляет в естественной неизменённой природе одного и без средств к существованию, становится техником. Это означает, что человек на основании своего, пусть ещё очень малого знания о природе, по необходимости и по своему желанию выдумывает и представляет приборы и методы, которые могли бы ему помочь, а затем путём обработки с помощью сначала рук, а затем и инструментов воплощает их в опытном мире, извлекая из пространства мысли, из представленного.

Посредством потребности пробуждается, выдумывается, «изобретается» и формируется всегда нечто единичное. Вещи и методы не только крайне могущественны, но и разнообразны, поскольку и потребности разнообразны, к тому же они умножаются до бесконечности в ходе тысячелетий.

Но, как и в любой предметной области, сначала всегда речь идёт о единичностях: о клине, скребке, каменном ноже, плетении, одежде, столбе, лопате, оружии, украшении, месте для сна, очаге, плите, а с течением времени - о тысячах единичностей такого рода.

То, что все эти вещи и методы связаны между собой, обладают единым характером, что здесь - пользуясь известной пословицей - речь идёт не только об отдельных деревьях, но и о лесе, было подмечено за 400 лет до нашей эры Сократом и его учениками, сократиками. У них мы встречаем, причём на удивительно высоком уровне, рефлексивную позицию, которая не останавливается на отдельных объектах и не удовлетворяется их формированием и использованием, но стремится выяснить, что в целом происходит, почему это происходит и как, то есть стремится знать общее, ставит вопросы о бытии и сущности, исходные вопросы философии, онто-

\footnotetext{
${ }^{1}$ Впервые на русском языке представлен перевод второй главы монографии Фридриха Дессауэра «Спор о технике» 1959 года [Dessauer F. Streit Um Die Technik. - Freiburg In Breslau: «HERDER», 1959. Zweites Kapitel «Zur Philosophie Der Technik. Was Ist Technik? - Wort Und Wesen». P. 59-115], посвящённый сущности техники и концепции «четвёртого царства». В целях сокращения объёма текста опущены повторы, большая часть примеров, рассуждения об эпистемологических и аксиологических аспектах техники. Перевод выполнен при поддержке Совета по грантам Президента Российской Федерации, проект МД-6200.2016.6 "Семиотические основания техники и технического сознания". Пер. с нем. А.Ю. Нестерова. Самарский национальный исследовательский университет им. академика С.П. Королева (phil@ssau.ru). Прим.nерев.

Рекомендуемое цитирование: Дессауэр, Ф. К философии техники. Что есть техника? - Термин и сущность. / Ф. Дессауэр. Пер. с нем. А.Ю. Нестерова // Онтология проектирования. - 2016. - Т. 6, №3(21). - С. 390-406. - DOI: 10.18287/2223-95372016-6-3-390-406. Прим.ред.

${ }_{2}^{2}$ Фридрих Дессауэр родился 19 июля 1881 года в Ашаффенбурге, Германия. В 1920 году - профессор университета Франкфурта на Майне. С 1921 по 1933 ординаруис и директор университетского института физических основ медицины, первого биофизического института в высшей школе. С 1924 по 1933 - член Рейхстага. В 1933-34 преследовался националсоциалистами. С 1934 - ординариус университета Стамбула по радиологии и биофизике. С 1937 по 1953 - ординариус и директор физического института университета Фрайбурга (Швейцария). С 1946 - профессор университета Франкфурта на Майне им. Иоганна Вольфганга Гёте. Умер 16 февраля 1963 года во Франкфурте на Майне. Радиолог, физик, политик и публицист. Основоположник квантовой биологии, классик философии техники. Автор работ «Философия техники. Проблема реализации» (1927), «Освобождение техники» (1931), «Естественнонаучное познание. Доклады по философии природы» (1951), «Квантовая биология: введение в новую отрасль знания»(1954), «Спор о технике» (1956) и др. Справка издательства «Гердер». Прим.перев.

Фото Friedrich Dessauer из Википедии - https://ru.wikipedia.org/wiki/Дессауэр,_Фридрих.
} 
логические вопросы. Предмет обсуждается, сначала под руководством Сократа, в повторяющихся итерациях, выясняются обстоятельства, связанные с «техне», «технитес» или «техникос», ремесленником, мастеровым, художником, мастером. Отсюда до нас дошло слово «техника», и не только слово, но и глубокий анализ его смысла. Сократический анализ техники у зрелого Платона стал одним из основных элементов его (не совсем корректно) обозначаемой в качестве учения об идеях философии, которая тысячелетиями оказывала влияние на западноевропейское мышление и продолжает звучать в произведениях современных мыслителей. [...]

Сократ исследует две фундаментальные темы: истину (знание) и благо (ценность). Это два исходных вопроса философии, встающих во все времена, как, например, через две тысячи лет у И. Канта, среди четырёх знаменитых вопросов (в его логике). Сократ борется против философских безобразий софистов, этих диалектических болтунов и краснобаев, которые за деньги или за почести практиковали искусство «говорением сделать слабейшую вещь сильнейшей». Сократ был серьёзен: что я знаю на самом деле, как человек приходит к подлинному, надёжному знанию? Что есть благо, что есть собственно ценное, как оно достигается, что я должен делать?

Чтобы найти ответы, он исследует опыт, а именно свой опыт в своём жизненном окружении, в ремесле, в «технических» профессиях своего времени. В диалоге «Горгий» Платона и в других местах Сократа упрекают: «Ты всё время говоришь о сапожниках, кожевниках, поварах, врачах». То есть о техниках, ведь врачи считались тогда ремесленниками.

Сократ в диалогах поступает так, потому что он привлекает ремесленников в качестве примеров для ответа на свои вопросы. Именно здесь, в области «техне», возникает «мастерство» [Koennen], осуществление, произведение на основе «знания», понимания ремесла. Ведь мы и сегодня еще говорим: «Он понимает своё ремесло», - это означает, что он с ним доподлинно знаком, у него есть истинное знание о нём! Здесь уже видно, что такое знание, и как оно связано с мастерством, осуществлением, с изготовленной вещью и её ценностью в качестве товара. Платоновский Сократ знает о возникновении из образца (эйдоса), предвосхищаемого в представлении образа того, что должно быть оформлено или сделано; он знает и о непроизвольности не только мысленного образа, но и пути, способа изготовления, и, наконец, о ценности как исполнении задачи, пригодности к чему-то. В диалоге «Кратил», когда речь заходит об изготовлении инструмента, например, ткацкого челнока, Сократ говорит, что определяющим для этого является мысленный образ, эйдос, идея, и что этот мысленный образ не произволен, он определяется целью человека. Имя, сущность, природа, образец задаются предназначением, а вместе с ними и эргон, произведение, взятое как само по себе, так и в его пригодности к чему-то, в его «добродетели».

Здесь выявлено то, что мы в дальнейшем будем называть «полем» [Fuehrungsfeld], в котором работает техник. Выявлено, что исполнение задачи в технике является основой ценности, в дальнейшем мы будем это называть «служебной ценностью», в отличие от прочих порядков ценностей, таких как обменная ценность (денежная стоимость) в экономике. В любом случае, согласно Сократу, ценность заключена в природе предмета; в диалоге «Евтидем» ситуация, в которой о чём-то говорится «это хорошо» без указания на то, для чего это хорошо, обозначается как бессмысленная. Сократ ясно понимает мысль о «финалистском» или «телеологическом», то есть о господстве цели (если говорить со стороны человека) или задачи (если говорить со стороны вещи).

Продвигаясь в этом направлении, в диалоге «Хармид» он приходит к отождествлению мастерства и знания. Мастерство техника есть знание и оттого правильно, хорошо, то есть имеет ценность. Знание, сущность и ценность растворяются в единстве техне. Это верно для любой человеческой деятельности (согласно диалогу «Ион»): в случаях рулевого, художника, музыканта, каменотёса, врача, возничего, рыбака, пастуха, полководца, ткача, спортсмена речь идёт о «техне», о понимании, знании и тем самым о мастерстве в своём деле, то есть о том, что философ И. Гейзер назвал теоретико-практическим знанием.

Такое общее понятие технического, применимое к любой возможной деятельности, можно встретить и сегодня в повседневной речи. «Техника» виолончелиста, или управления, или еще чего-то подобного подразумевает иногда нечто такое, что можно освоить путём упражнений (игра на виолончели), а иногда внешний рутинный процесс. Это понятие техники не совпадает с темой настоящей книги, с техникой в более точном смысле. Вскоре мы определим отличительные признаки. Пока очевидно, что подобное полное вхождение формотворческой деятельности (мастерства) в знание, которое постоянно повторяется в разъяснениях Сократа и Платона, не соответствует сегодняшнему понятию техники, которая является чем-то существенно большим, нежели просто знание, большим, нежели просто «прикладное естествознание», поскольку несёт в себе творческоформообразующее, «изобретательское» начало.

В сократической философии модель техне, в которой растворено покоящееся на знании мастерство, используется для прояснения фундаментального вопроса о благе, ценности, добродетели. Это ведёт к тезису Сократа о познаваемости добродетели, о том, что она основывается на понимании и знании. Таким образом, в рамках техне изучение, то есть добывание знания, одновременно означает освоение истины и тем самым освоение мастерства. Например, всадник или каменщик путём изучения и упражнения осваивает знание и ма- 
стерство и тем самым становится всадником или каменщиком, практикуя эти виды деятельности на основе своего знания; так и тот, кто изучил справедливость, становится справедливым. Мужество, дружба, скромность сводятся по аналогии с техне к знанию, то есть осваиваются путём изучения, исходят из фронезиса, из понимания, как и всякое правильное действие (orthos prattein). Кто поступает так, поступает хорошо - это перенос техне с её полезностью («хорошо для чего-то») на благо в смысле нравственности. В диалоге «Менон» Сократ учит, что всякое благо полезно, а всякое зло вредно, и только мудрость, софия, знание, понимание делают такие блага, как богатство, здоровье, честь, власть, настоящими благами. Так добродетель отождествляется со знанием. Мудрый добродетелен. (Диалоги «Лахет», первая книга «Государства», «Протагор»).

Что бросается в глаза мыслителю нашего времени: техне берётся в тесной связи с этикой, с нравственностью, техне с его компонентом полезности («хорош для...») является моделью метафизического блага, которое в свою очередь обосновывается полезностью (оно также «хорошо для...»). В современных дискуссиях о технике многие авторы обозначают технику как этически нейтральную. [...]

Для нас в истории Сократа и его техне важно следующее: однажды Сократ задал вопрос о пути познания. Его называют первым теоретиком познания. Но его исходные посылки глубже. Его заботит судьба человека, его поиски и заблуждения. Его исходные посылки, говоря сегодняшним языком, носят экзистенциальнофилософский характер. И он использует в соответствии со своим происхождением ремесленно-техническое творчество и то, что представляется ему в этом ключе аналогичным, в качестве пути познания истины (знания) и блага. Это его цель. Он не задаёт вопросов о сущности и смысле ремесленно-технической деятельности, но берёт её как нечто известное и само собой разумеющееся и использует в качестве модели.

При этом ему приходится показывать то, что он сам знает о ремесленно-технической деятельности, что он имеет в виду под своим «техне». И ему действительно есть, что о нём сказать, гораздо больше, нежели некоторым современным авторам в спорах о технике. Сократ знает: во-первых, любому техническому процессу предшествует знание о предмете. Без опоры на пусть ещё даже преднаучно-примитивное знание о природе не бывает никакой техники. Чем выше уровень знаний, тем больше возможность совершенствования технических произведений. Во-вторых, Сократ знает, что все технические предметы исходят из целей человека. Финалистская предпосылка ему ясна. Отсюда, в-третьих, возникает представляемая картина произведения, эйдос, фиксируемый духом образец, «идея» творимого предмета. В-четвёртых, когда выполнена первая предпосылка, когда есть знание и понимание, тогда посредством действия в соответствии с целью возникает произведение, эргон, выполняющее свою задачу в качестве органона. При выполнении этой предпосылки понимания (как фронезиса), в-пятых, произведение создаётся не произвольно, не случайно, но в соответствии со знанием. И оно, в-шестых, будет выполнять задачу, которую техник («технитес», «техникос») имел перед глазами в качестве цели, оно будет хорошим для этой задачи, будет обладать ценностью, и за счёт этого произведение попадёт в мир ценностей, блага, согласно сократическому учению. Сократ далёк от распространённой ошибки наших дней, заключающейся в смешении или вообще в замене местами техники и экономики.

Мы познакомились с шестью чертами технического, значимыми и сегодня. От той ранней эпохи нельзя требовать понимания сущности техники в сегодняшнем смысле: базис был не только слишком мал, но и не очень ясно выделен на фоне прочих видов человеческой деятельности, приводимых Сократом, таких как верховая езда или игра на флейте. Впоследствии зрелый Платон показывает, что сократического техне, взятого в виде модели мышления, недостаточно для обоснования истины и блага, и разрабатывает своё грандиозное учение об идеях. Техне же сохраняется как мышление с телеологическим уклоном.

Перепрыгнем через 2200 лет. В 470 году до н.э. родился Сократ. В 399 он вынужден был осушить кубок с ядом. В 1724 году родился Иммануил Кант, подобно Сократу, в семье ремесленника, в 1804 он умер там же, где и родился, в Кёнигсберге. Он оставил после себя потрясающее произведение мысли. Сейчас мы подробнее рассмотрим, что он, мысливший и писавший о столь многих вещах, говорит о технике.

Кант не обращал внимания на технику, которая в его время едва шевелилась, пока еще не создавая ощущения проблемного всемирного явления. Он пришёл в философию под сильным впечатлением физики. В его произведениях, наряду с тремя критиками, рассматриваются космологические вопросы, фундаментальные проблемы естествознания, происхождение человеческого вида, проблема теодицеи, вечный мир, спор факультетов, логика, религия, антропология и многое другое. Слово «техника» у него встречается, но не в смысле нашей темы. Кант в «Критике способности суждения», своей третьей великой критике, говорит о технике природы. Эта третья (и наименее понятная) критика занимается «идеями» по ту сторону опытного познания. Однако эти идеи рассматриваются так, как если бы они были опытными. Идеей в этом смысле является представление Гёте об исходном растении (разговор Гёте с Шиллером в июле 1794 года), но не тот опыт, который Гёте, по его словам, получил в ботаническом саду в Палермо собственными глазами. Гений, мастерски схватывающий ситуацию, ясно изображает силу суждения. Ведущей идеей является соответствие задачам ${ }^{3}$; возвышенность, красота суть

${ }^{3}$ В русских переводах редко различаются «Zweck» и «Ziel». В рамках традиции переводов Канта правильно было бы передавать «Zweckmaessigkeit» словом «целесообразность» (и именно этот термин используется далее в прямых цитатах из Кан- 
соответствие задачам без задачи, темой является «свобода в явлении». Возникающее изначально из способности суждения понятие есть понятие о природе как искусстве, другими словами, о технике природы. Эту точку зрения можно соотнести с сократическим техне: природа обладает определённым техне организации, которое мы видим задачесообразным и похожим на художественное формообразование. [...]

\section{2 Начало техники и экономики}

Тема всемирной дискуссии не подразумевает «техне» в общем смысле, который включал бы технику верховой езды, технику игры на струнных инструментах и т.п. Мы имеем дело не с тем, что изучается посредством упражнений, не с рутиной и не с внешними процессами типа тематического вечера, но с техникой как судьбоносной силой, с историческим, трансформирующим человека и человечество, изменяющим Землю фактором культуры (в самом общем смысле слова). [...]

Мы углубимся в исходные основания настолько, насколько это возможно. Вместе с объектами исследования древнейшей истории, в раскопках остатков скелетов, отстоящих от нас, возможно, на 1000000 лет, обнаруживаются предметы, изготовленные человеческими руками. Эти находки чрезвычайно важны для исследований, потому что их наличие подтверждает, что находка имеет дело с homo sapiens, а не с его предками. Клинья, наконечники, украшения из кремния или костей, следы огневищ служат тому примером. Эти находки указывают на индивидуальное использование и на индивидуальное изготовление артефактов. Здесь мы затрагиваем неразрешимый вопрос о технике животных. Пауки, пчёлы, бобры, муравьи и другие животные создают удивительные постройки, которые, с человеческой точки зрения, производят впечатление форм, которые за счёт своей высокой задачесообразности на фоне данного им естественного окружения принципиально могут быть приравнены к объектам, являющимся техническими изделиями человека. В этой книге мы не рассматриваем вопрос о «технике животных» и ограничимся тем, что укажем на одно отчётливое отличие. Постройки животных демонстрируют коллективный и фиксированный характер. В настоящее время нам неизвестны примеры отдельных особей животных, которые осуществляли бы изобретательскую деятельность: паука, который изобретал бы новый вид сети, пчелы, которая выдумывала и изготавливала бы улучшенную систему сот. Пробел в наших знаниях обозначается словом «инстинкт», однако он им не исчерпывается. Под ним понимают готовность к задачесообразному поступку и реакцию на факторы среды, допуская, что «инстинкт» есть нечто психическое, однако не осознаваемое, (внерефлексивное). В случае человека, осуществляющего техническую формообразующую, «изобретательскую» деятельность, доподлинно известно, что формы задачесообразной активности опираются на осознанную, индивидуальную разумную деятельность личности. Мы не занимаемся в этой книге ни животной техникой, ни тем, что иногда называют биологической техникой. Наш предмет - техника, осуществляемая человеком, и мы приступаем к исследованию её сущности.

То, что показывают древнейшие находки, подтверждается последующими периодами. Артефактов становится больше, они разнообразнее и лучшего качества. Камень и кремний сменяются металлом. Бронзовому веку наследует железный. Они, как и переход от древнейшей истории к историческому времени, демонстрируют всё большее разнообразие нужных, полезных и красивых вещей. По этому вопросу достаточно специальной литературы. Нам необходимо лишь констатировать, что человек с первого появления на планете сквозь все тысячелетия своего развития вплоть до настоящего момента был творцом, что он с самого начала медленно, затем во всё более ускоряющемся движении вперёд открывал, изобретал и изготавливал, что он в этом смысле всегда был «техником».

Наглядным примером, пусть и не имеющим строгой доказательной силы, являются известные рассказы, как, например, история о Робинзоне Крузо, где предметом изображения оказывается судьба человека, который, будучи выброшенным на неизвестный берег после кораблекрушения, один противостоит природе и защищает своё существование. Роман о Робинзоне, в своё время написанный Даниелем Дефо (около 1700 года), бестселлер и образец для подражания многим похожим текстам, опирается на реальные события. Матроса по имени Селкрик выбросило на необитаемый берег в Карибском море, он был вынужден бороться с природой в одиночку, пока его, спустя годы, не нашли и не вернули в Англию. Его рассказ послужил автору основанием, а его переживания стали темой этого и многих похожих приключенческих романов в последующее время. Эта тема заключается в следующем: что делает человек, если он оказывается вырван из человеческого общества и в одиночку противопоставлен девственной природе? Внимательному читателю все эти книги дают один и тот же ответ: такой человек становится техником. Он должен открывать, изобретать и изготавливать, организовывать. Он становится плетельщиком, гончаром, изготавливает заступ, молоток, корзину, одежду, оружие. В этих историях потерпевшие кораблекрушение повторяют (с некоторыми романтическими вариациями) в течение нескольких лет или десятилетий то, чего древнейшие люди добивались тысячелетиями, исходя из нужды и жела-

та в переводе М.И. Левиной). Однако для Ф. Дессауэра различие «Zweck» и «Ziel» является принципиальным, поэтому в данном переводе «Zweck» передаётся как «задача», а «Ziel»-как «цель». Прим. перев. 
ний: изобретали и выдумывали приборы, технологии, инструменты, вещи, которые им помогали побороть в окружающей среде враждебное и поддержать полезное. Герои робинзонад были техниками.

В романе Дефо и других подобных книгах с течением времени происходит нечто новое. Появляется слуга Пятница, добавляются другие люди. Это означает зарождение общественного устройства, множественность ведёт к разделению труда, к обмену товарами и услугами, к элементарному рынку, что в свою очередь означает: к технике добавляется экономика. Мы констатируем, что техника первична, она - вместе с единичным человеком в мире, предпосылкой же экономики является множественность людей в обществе, экономика вторична по своему способу бытия. Отсюда уже с самого начала ясно различие в порядках ценностей: техническая ценность есть служебная ценность отдельной созданной человеком вещи или технологии, экономическая же ценность есть обменная ценность в обществе, среди множества людей, на «рынке», соразмерно разделению товаров и услуг. Это различие прослеживается от первого скребка древнейшего человека вплоть до электронных вычислительных машин, до атомной энергии сегодняшнего дня и космических полётов дня завтрашнего.

Изначальным является то, что человек, в отличие от растения и животного, не склоняется и не сдаётся окружающей среде, вместо этого - атакует, дополняет, обогащает её настолько, чтобы жить в уже самостоятельно созданной окружающей среде, как мы делаем это сегодня. Вопросы связаны с тем, что заставляет человека перестраивать природу и как он способен это делать?

\section{3 Формообразующие силы человеческой техники - Homo investigator, inventor, faber - Формы пространства и времени - Техническое воздействие}

Обзорная ретроспектива начальных условий позволяет увидеть формообразующие силы техники. Человек, как и всякое другое живое существо, оказавшись в природных условиях, реагирует на окружающую среду человеческим образом, иначе, нежели растение или животное. Он не просто воспринимает и приспосабливается, но спрашивает «что?», «как?», «почему?» и «зачем?». Он хочет знать, он по своей природе - homo investigator, человек исследующий, который изучает причину и следствие, пользу и вред; он оценивает. Он распознаёт взаимосвязи, отношения и зависимости. У него с самого начала есть «сознание». Латинское слово для «сознания», «conscientia», обозначает сопровождающее (со-) знание, переживание собственных духовных и душевных процессов, внимание к собственной «самости» или же готовность к такому вниманию. Животное познаёт с помощью чувств, в том числе и своих врагов, свои жертвы, но, предположительно, это происходит без рефлексивного сопровождения такой соотнесённости с собой. Созданный таким, человек сохраняет впечатления от своих восприятий в качестве представлений, над которыми он может работать, - «раз»-мышлять [«nach»-denken]. Он «осмысливает» себя через них, то есть он спрашивает «что?», «как?», «почему?» и «зачем?». Способность к представлению, фантазия комбинирует затем материал, состоящий из впечатлений от воспоминаний, из энграмм (энграммата, греч. «отпечаток») воспоминаний, чтобы передать его второй исходной способности человека, коренящейся в самой его сущности, - способности к формообразованию, организации, творчеству.

Человек в своей сущности - homo inventor, изобретающее, организующее существо. Он несёт в себе, наряду с изначальной потребностью в знании (потребностью в истине), потребность в комбинаторном формообразовании, организации, пробуждаемую и поддерживаемую факторами окружающей среды, природой и обстоятельствами, страхами и желаниями. Это даёт ему способность творить в рамках его собственного знания природы, то есть осмысленно и целесообразно создавать то, что отсутствует в природе в пределах его досягаемости. Это творчество всегда финально, нацелено, то есть заранее подразумевает конечный результат в предварительном представлении. Это - серьёзная работа для духа. Интраментальные, то есть внутренние образы, возникающие таким способом, осуществляются фантазией; вначале размытые и туманные, они - путём постепенного «раз-мышления» под контролем знания о природе - становятся яснее и конкретнее, так что с ними уже может работать третья исходная способность человека.

Человек - это homo faber, обрабатывающий человек. Он способен, преимущественно с помощью рук (и инструментов), перенести, трансцендировать представленное из интраментального пространства, из мира представлений во внешний мир, в окружающую среду своего восприятия. На стадии подготовки это происходит уже в тот момент, когда человек создаёт подготовительный набросок или рисунок, а человек этим занимался ещё в каменном веке. На стадии осуществления - тогда, когда он как homo faber делает из кремния скребок, нож, сверло, наконечник копья, клин, и делает его именно так, как он его выдумал, - медленно, со многими ошибками и повторами. И случается так, что он в союзе с другими согласно чертежу, перечню деталей и руководству строит современный прибор, микроскоп, телевизор, атомную электростанцию. Всегда речь идёт о комбинации трёх изначальных способностей человека: Investigator, Inventor, Faber. Постоянно в рамках закона природы, насколько он познан, но за пределы природной данности; всегда финалистски, нацеленно, всегда вначале имманентно или интраментально, в мире мышления и представления рефлексирующих духа и души, и лишь затем путём обработки (духовной и ручной) - перенос в опытно данный мир. Благодаря первой изначальной способности, потребности в познании, технические предметы обладают каузальными (причинными) свойствами. Тех- 
ническое образование «функционирует», исполняя законы природы, сущностный причинный порядок. Формообразующая способность человека, его (ограниченная) способность к творению придаёт техническим предметам финалистские, телеологические («телос» - цель) свойства. Сфера homo faber подводит их под меру физических и биологических способностей человека, под возможности и ограничения того, что может быть построено непосредственно с помощью человеческой органики, рук или с помощью приборов (инструментов, станков, технологий).

Анализ техники в качестве выражения и продукта исходных человеческих способностей нуждается в некотором разъяснении. То, что возникает таким образом, может быть некоторым строением, прибором, химикатом, станком и т.п., то есть пространственной формой. Но оно может представлять собой и некоторый метод, технологию, то есть временную форму. Обе, взятые вместе, образуют технические объекты. Технологии, например, разведения, поддержания и тушения огня или изготовления серной кислоты, равно как и приборы, например, необходимые для этого ёмкости, соединения, насосы, - все они носят триединый характер. Все они однажды были впервые созданы (изобретение), превосходят тем самым всё, что преднаходится в качестве созданного самой природой, все они исторически перешли от небытия к бытию и, тем не менее, строго привязаны к исполнению законов природы.

Второе дополнение заключается в том, что технические формы пространства и времени вследствие их финалистского характера способны оказывать воздействие за пределами технической предметной области. Так обстоят дела не только в технике, это в целом общая характеристика человеческого творчества. Закон не остаётся в сфере юридического, но по своему смыслу и предназначению (финалистски) оказывает воздействие на человеческое общество. Лекарство не остаётся в сфере фармакологии, но воздействует на поддержание и восстановление здоровья; музыкальное произведение не остаётся в своей сфере, но финалистским образом воздействует на сложно познаваемую и сложно выражаемую человеческую потребность. Так везде, не только в технике. Книга в своей пространственной форме - технический объект, но она посредством своего содержания воздействует сквозь технику как таковую. Это положение вещей, в котором решительно всё, принадлежащее некоторой предметной области, финалистски воздействует сквозь свой предмет, необходимо постоянно держать в уме при оценке порядка ценностей.

\section{4 Техника как исполнение человеческого целеполагания посредством организации задач}

Анализ внутренних человеческих формообразующих сил, ведущих к технике, подводит нас к таинству техники, к тому нерастворимому остатку, который сохраняется при всех усилиях по прояснению, толкованию, определению техники. Чтобы это показать, полезно прояснить два понятия, неточное определение и употребление которых в прошлом (в том числе и у очень хороших авторов) создало сумятицу.

Речь идёт о понятиях «цель» и «задача». Они не тождественны. Нацеливание, обладание целью подразумевает некоторое сознание. Человек может иметь цель, стремиться к цели. Но прибор - нет. Он может исполнять свою задачу. Микроскоп выполняет свою задачу, если он делает видимыми в хорошем разрешении очень маленькие объекты. Но добиться этого - изначально было целью изобретателя, конструктора, изготовителя микроскопа. Цель предшествует. Именно она приводит к представляемым картинам, затем к трансцендированию, к изобретению и к изготовлению. Задачесообразное построение - позднее.

Таинство сущности техники скрывается в вопросе: как это возможно, чтобы из интраментальных, то есть представляемых и желаемых целей в конце концов выходили пространственно-временные формы (приборы и технологии), несущие в себе посредством своих свойств (естественно-научного и финалистского способа построения, структуры) в качестве подлежащей исполнению задачи то, что человек внутри своего сознания созерцал в качестве цели? Фундаментальная проблема заключается в превращении идей, собственно представлений о цели, в оформленные объекты внешнего мира, исполняющие задачи. Попытки приблизиться к решению приводят не только к психологическим и в общем смысле антропологическим, но и к метафизическим основаниям. Очевидно, что способу существования человека в качестве исследователя, первооткрывателя, обработчика должен по аналогии соответствовать космический способ бытия, не исполненный, не организованный, не наличествующий, но содержащий в себе возможность, потенцию, «так-бытие» решений (их свойства, их сущность); иначе эти решения нельзя было найти, «изобрести». В смысле древнего философского различения (так называемой реальной дистинкции между высказываниями о существовании, банальном наличии чего-то и высказываниями о сущностном свойстве, о «чтойности», о так-бытии, о quidditas) это можно сформулировать так: Все технические объекты, которые были изобретены, до этого не «существовали», до этого не наличествовали. До изобретения микроскопа не было микроскопа. Но «чтойность», так-бытие объектов, например, микроскопа, уже была в космосе, - иначе он не смог бы оказаться изобретённым. 


\section{5 Признаки технического объекта}

Формообразующие силы человека, из которых исходит «техника», соответствуют характеристикам, признакам технических предметов. Всякое техническое образование несёт на себе эти признаки, а когда они объединены, речь всегда идёт о техническом образовании, будь это форма пространства, некоторый прибор или химикат, или нечто подобное, или будь это форма времени, некоторый метод или технология.

Первый признак заключается в строгой связи объектов. Они выполняют свои задачи, исполняя законы приpodbl. Не бывает технических образований, противоречащих законам природы или находящихся вне их. Микроскоп, лекарство, самолёт, радар, электронная трубка, конкретные примеры здесь не важны, «функционируют», то есть исполняют свои задачи посредством процессов, сообразных законам природы, каузально.

Но эти сообразные законам природы причинные процессы управляются, они организованы для исполнения задачи, они заданы финалистски или телеологически («телос», греч. - «задача», «конец»). В неорганическом естествознании (физика, химия) финализм не является определяющим. Исследователь здесь выявляет причинность и вероятность. В биологическом естествознании финализм, ориентация клеток и органов растений и животных на целостность живого существа, неоспорим, он повсюду используется в качестве определяющей исследовательской линии, однако эти исследования не всегда прозрачны. Кант говорил о technica naturalis живых существ ввиду «сходства задач». Он склонялся к тому, чтобы видеть в этом перенос человеческих форм мышления и представления на объекты, и многие биологи следуют ему в этом мнении. Однако в случае технических образований финализм объективен, исполняющая задачу форма отпечатывается в предмете человеческим «творцом» на основании его представления о цели. Вне финализма как сущностного признака невозможно говорить о технике. Технический предмет является техническим лишь в той мере, в какой он исполняет свою задачу. В этом коренится обоснование объективного порядка ценностей (порядка служебных ценностей) техники. Средства, строительные или технологические элементы технического объекта определяются смыслом задачи. Усматриваемая «творцом» цель выбирает их, упорядочивает, организует в единую, несущую задачу форму, например, в часы, в телескоп. Становление технического предмета осуществляется во всех фазах как формирование, структурирование, управление, актуализация материалов и энергий в реально существующее, обладающее бытием и силой единство.

Множество человеческих потребностей, желаний и забот создаёт целевые причины для технического формообразования и применения. При этом цели техники не ограничиваются ею самой. Цель строительства дома не дом, но проживание в нём, цель книгопечатания - не книга, но сообщение. Так обстоят дела не только с техникой, как выше уже было показано. Но и здесь целеполагание, человеческое осознание, отделяется от задач, заключённых и реализованных в формах. Микроскоп увеличивает, но цель - гораздо больше: познать мир мельчайших объектов. Цели больше, выше, шире, нежели задачи.

К первым двум признакам соответствия законам природы и финализма добавляется и третий признак - обработка руками человека, осуществляемая непосредственно или посредством инструментов, станков, приборов. Этот признак отчётливо виден и в случаях самого современного автоматического массового производства товаров, ведь автомат как таковой возник благодаря обработке человеком, из его головы и его руками.

Общность этих трёх признаков в одном объекте характеризует его как принадлежащего области техники. Это не подразумевает, что он принадлежит только технике. Церковь, например, в качестве строения является техническим объектом. Но её смысл выходит далеко за этот предел, она должна быть местом служения богу. Это долженствование в качестве цели первично. Затем следует сообразное задаче формообразование путём планирования и обработки, и, наконец, перед нами стоит готовое здание. В каждой фазе своего возникновения путём рациональных действий и контроля долженствование плана переводится в бытие исполнения. Приведём в качестве следующего примера нечто обыденное, дверной замок. Его задачу легко увидеть, она заключается в обеспечении разделения и соединения помещений. Каждая деталь замка соотнесена с этой задачей, финалистски сформирована и скомбинирована с другими деталями. Но цель, которой он подчинён, предшествует задаче и выходит за её пределы, заключаясь в проживании в некотором сегменте строения. Существует целая иерархия задачесообразных конструктивных элементов, вместе составляющих единство, например, пассажирского теплохода, который в свою очередь служит цели морских путешествий. Все члены, как и целое, несут на себе черты технического образования и одновременно оказывают внешнее воздействие через себя.

О возникающем здесь возражении, согласно которому техника не обладает собственной ценностью, профессия техника не образует собственной жизненной формы, оставаясь лишь функционализмом, сервитутом, опосредованием для любых заданий, одним лишь осуществлением чужих приказов, об этом мы поговорим позже. Такое можно сказать против многих профессий, также получающих свои, часто крайне гетерогенные, задачи снаружи. 


\section{6 Техника как реальное бытие из идей - Исторический характер - Пребывание и сила техники}

Предыдущий анализ подводит нас к сущности «техники», являющейся как осуществлением, действием на основании человеческих формообразующих сил, так и мощным, ежедневно растущим множеством пространственных и временных форм, предметов и технологий, объединённых одними и теми же признаками. Прежде чем мы предпримем попытку определения понятия техники (а попытки такого рода всегда содержат элемент произвольности), необходимо прояснить ещё некоторые основания.

Должно быть понятно, что понятие техники не имеет такого широкого и произвольного объёма, как понятие сократического техне, являющегося воплощением всякого основанного на знании мастерства, само состоящее, как учил Сократ, из знания, то есть включающее в себя, наряду с ремесленным делом, верховую езду, музицирование, управление повозкой, рыболовство, выпас овец, руководство битвой, бег наперегонки.

Различие заключается в том, что техне при верховой езде, выпасе овец, рыболовстве и т.п. означает формирование и обладание индивидуальной способностью, которая изучается путём упражнений и регулярно практикуется. Техника же в рассматриваемом нами смысле подразумевает объективные формы, предметы и технологии, сами по себе являющиеся носителями некоторой силы, такие как лекарство, микроскоп, часы, самолёт, станок, производство соды, метод изготовления плексигласа и других искусственных материалов типа полимеров или поликонденсатов. Способности (техне) всадника, пастуха или музыканта исчезают с его смертью. Технический прибор, музыкальный инструмент, технология изготовления каучука остаются и продолжают своё действие, когда изобретателя и первых изготовителей уже нет. Локомотив - технический объект. Управление локомотивом в качестве объективного метода, набора предписаний является техническим в нашем смысле. Большая или меньшая сноровка и опыт водителя локомотива являются в смысле Сократа техне; мы не затрагиваем техне, когда говорим о технике как исторической мировой силе.

Сократ был прав в том, что всякий технический предмет (как, например, ткацкий челнок) происходит из идеи (эйдоса), из представленной картины. Он происходит и отсюда тоже, но не только отсюда. В случае технического осуществления речь идёт о «становлении из идей». Представляемая картина, идея является предпосылкой формообразования как для кремниевого украшения, так и для радиоастрономического приёмника, исключая те особые случаи, когда речь идёт об изобретении впервые, о своего рода открытии изобретения, когда изобретатель на своём пути неожиданно сталкивается с чем-то решительно новым.

Происхождение из идей показывает исторический характер техники. Никакого технического предмета не было, пока он не был изобретён. До изобретения колеса - в неизвестное доисторическое время - не было никаких колёс. Всякий раз это переход из «бытия, которого еще нет», но которое возможно, в действительность чувственного мира. Он происходит в конкретном месте пространства и времени и в историческом смысле характеризуется тем, что не исчезает, как многие конвенциональные общественные данности (границы, династии, власти, обычаи, привилегии и т.п.), но, наоборот, сохраняется и совершенствуется в рамках исполнения своих задач. Колесо, будучи однажды изобретённым, по сей день здесь. Людей, которые его изобрели, равно как и формы общественной организации, при которой они жили, давно уже нет. И если бы колесо у человечества исчезло - мы бы проснулись однажды утром, а никаких колёс вдруг не стало бы, то есть никаких средств транспорта, никаких фабрик, - то большей части цивилизованного человечества пришлось бы вымереть, а остаток вернулся бы к той примитивной жизни, которую ведут племена пигмеев в центральной Африке.

Резюмируем: техническому предмету свойственны становление реальным из идеи, историческое появление и пребывание среди человечества.

Это появление и пребывание технического предмета есть возникновение и действие силы. Технические объекты обладают силой, они сами, а не те, кто их изобретает, изготовляет и использует. Эту силу показывает мысленный эксперимент «если бы вдруг исчезло колесо». Микроскоп обладает силой раскрывать микромир и он передаёт её тому, кто его использует. Лекарство обеспечивает сон, обезболивание, часто предупреждает смерть, - лекарство, а отнюдь не исследователь и изобретатель, который его создал. И сила атомного оружия присуща ему самому, а не конструкторам. Технические объекты и технологии становятся из идей, появляются исторически, однажды появившись, настойчиво пребывают и обладают каждый своей, свойственной ему специфической силой. Наконец, сила технического объекта способна соединяться с силами прочих технических объектов. Так существует общая сила технического, насколько бы ни отличались объекты и их возможности. Эта общая сила судьбоносно велика. Она изменяет облик Земли.

\section{7 Изобретение как источник техники - Поздние стадии не так прозрачны - Происхождение изобретения как напряжение между действительным и возможным}

Попытка приблизиться к сущности техники привела нас к её истоку, к «открытию». Здесь техника является сама собой, не столь сильно перемешана и затемнена другими факторами человеческого общества. То, с чем 
сталкивается наблюдатель в ремесленном производстве, в промышленности, на предприятиях, на транспорте, сформировано многими источниками; в нём смешан иерархический порядок, на него, часто определяющим образом, оказывают влияние экономические, социальные, политические, гигиенические, правовые моменты. Когда идёшь по фабрике, всё это вместе создаёт общую картину. Если это устаревшее предприятие, то посетитель получает впечатления механизации, унижения и лишения достоинства человеческой личности узкими помещениями, загрязнённым воздухом, шумом, спешкой, монотонностью, однообразностью, скудностью. Скоропалительный вывод из всего этого делается в виде тезиса о «порабощении человека техникой». Обычное, непродуманное суждение не различает, что здесь исходит из сущңности техники как таковой, а что - из стремления к прибыли, незнания, экономического давления, социального непонимания, правовой отсталости, халатности, злоупотреблений и т.п. Это то основание, которое заставляет нас в исследовании сущности техники обращаться к её истоку, к изобретению. В этой области накоплен большой опытный материал, имеется очень большое число самостоятельных работ, особенно в литературе, посвящённой защите изобретений, много подходов к прояснению понятия изобретения, есть попытки разбора психологии изобретения. Глубокое исследование и здесь приводит к основополагающим проблемам метафизики (онтологии).

Часто утверждалось, что техническое изобретение и техническое творчество исходят в основном из экономических интересов, из стремления к прибыли или к власти. Такого рода обобщения ложны. Стремление к власти, к прибыли играет иногда свою роль, однако не оно одно, и очень редко оно является основным мотивом. Наши древнейшие предки оказались изобретателями, как говорится, по нужде. Стремление к изобретательству, и точно не в меньше мере, нежели жаждой власти и прибыли, было пробуждено нуждой, опасностями, тоской по свободе, по преодолению животных условий жизни, по далям, ширям и высотам, по победе над пространством и временем, этими великими разделителями людей и обществ, по теплу и свету, по познанию, по красоте.

В этой ситуации справедливо, пользуясь словами Дональда Бринкмана, говорить о тоске по спасению, которая просвечивает сквозь все манифестации народов от древнейших времён вплоть до наших дней и которая в Новое время заменила религиозное ожидание поворотом к мирскому самоспасению. Достаточно мотивов к техническому творчеству даёт экономика. Если, например, рассмотреть проблему производства макромолекулярного искусственного материала, который дешевле и лучше изготавливать не под высоким давлением и большой температурой, а с помощью катализаторов при нормальных параметрах, то оправданно и социально значимо именно более дешёвое и более качественное изготовление. Однако само по себе увеличение прибыли для технического химика в его длительных и самоотверженных усилиях является, как правило, сопроводительным мотивом, а не основным. Это становится очевидным при изучении истории изобретений и изобретателей, в этом заставляет убедиться внимательная прогулка по Немецкому музею.

Существует, на самом деле, изначальное стремление к «формированию нового», к созданию вещей, которые могут больше, нежели те, что есть, к методам, осуществляющим то, что до них было невозможным, например, полёт, излечение болезней, обеспечение энергией, телевидение. Это подлинное стремление к творчеству, сродни потребности к художественному выражению, только менее свободное в своём осуществлении. Оно обнаруживается в некоторых случаях доведённым до фанатизма, довольно часто приводит к трагедиям, к мученичеству. Случалось и случается, что оно растрачивает себя в неразрешимых задачах, как например, показывает это история создания perpetuum mobile, вечного двигателя.

Большей ясности мы добьёмся, если будем исходить из следующего общего рассуждения. Человек живёт в напряжении между действительныл, тем, что дано и что видится ему всегда несовершенным, требующим улучшений - потому что всё земное имеет изъяны, - и возможныл, тем, что лучше, что он представляет себе как «заданное». Так обстоят дела повсюду. Например, в политике все усилия происходят из сравнения того, что есть, с тем, что могло бы быть. Очевидно невозможное, конечно, не обсуждается, однако улучшение политических, социальных, правовых, транспортных, гигиенических порядков жизни всегда видится как возможное, даже в хорошо организованных странах. Это напряжение между действительностью и возможностью является источником всё новых человеческих устремлений, источником прогресса в самых разных областях. Продолжительность жизни сейчас в два раза больше, нежели у наших предков, но мы могли бы жить и дольше. Это возможно. И человек к этому стремится, вступая в борьбу с укорачивающими жизнь факторами. Мы знаем, очевидно, больше, нежели древние, но возможно знать и много больше, и человек прикладывает колоссальные усилия в этом направлении.

Источник технических новообразований точно так же кроется в этом напряжении между жизнью, воспринимаемой в качестве несовершенной, и созерцанием возможных усовершенствований. Всякий момент времени определяется попыткой приведения существующего, того, что есть, к тому, чем оно должно быть или могло бы быть. Так пробуждается и поддерживается в пробуждённом состоянии латентная творческая сила. Другой вопрос заключается в исполнении этого стремления, это проблема того, как человек на самом деле способен создавать новое в пространстве техники, отливать свои цели в соответствующие задачам формы, так, чтобы они исполняли задуманное им. [...] 


\section{8 Сфера потребностей и сфера природного порядка сталкиваются в технике - «Изобрете- ние», пример - Область покрытия возможного - Пример обнаружения предустановленной формы решения - Изобретение как открытие}

Как возможна техника? Есть безграничное царство человеческих потребностей, бед, желаний. Оно постоянно растёт, потому что всякое исполнение порождает новое желание. Есть царство природных данностей, материалов, энергий, законов. И оно безгранично. Каждый год случаются новые удивительные открытия. В начале нашего столетия и не подозревали о космическом излучении, устройстве атомного ядра, эквивалентности материи и энергии. Утверждения прошлых эпох, принадлежащие, в том числе, и авторитетам, вроде «в космосе всё важное познано» или «физика, по сути, завершена» всякий раз опровергались фактами.

Два бесконечных царства очень различны. Для их изображения нужны разные языки, разные системы понятий. Но в технике они сталкиваются. Исполнение техникой неизмеримо разнообразных потребностей происходит, так сказать, из сокровищницы природных данностей, законов природы. Однако это исполнение не обнаруживается в природе в готовом виде, как например, в ней можно обнаружить и с некоторыми трудозатратами собрать готовые для утоления голода фрукты.

Технические решения заданий, поставленных человеческими потребностями, должны быть «изобретены». Это больше, нежели просто «разработаны». Этому предшествует поиск, и не в области наличествующего, а в области не наличествующего, но возможного.

Природа сама по себе не сформировала колеса, и не может, как в этом легко убедиться, производить никаких колёс. Колесо есть подлинно техническое изобретение, сделанное неизвестным человеком в доисторическое время. На нём строится транспорт, работа большинства станков и многих приборов в ремесле и промышленности. Оно «может», таким образом, очень многое, обладает очень большой силой. Способ действия колеса строго определён законами природы, это означает, что законы природы (и материал для постройки) всегда имели своё место. Но и потребность человека в облегчении передвижений существовала всегда. Природная данность и потребность впервые сталкиваются друг с другом в творческом формообразовании, в колесе, объединяются в нём в форму решения, которое не произвольно, но однозначно. Эта однозначность решения в виде жёсткой круговой формы колеса, сущностное свойство колеса, его «так-бытие» или, как говорили древние философы, его «quidditas» (дословно «чтойность»), была, следовательно, предусмотрена, так сказать, «ждала» изобретателя. Это «так-бытие», форма решения, было предопределено, уже «имело своё место» без того, чтобы быть осуществлённым. То, что никаким образом не наличествует, не может быть изобретено. Где же была эта форма решения? Не в сфере существующего, но в сфере возможного. И здесь она не была произвольной или хаотично-неопределённой, но уже зафиксированной в своих бытийных определениях, сущностных свойствах.

Этот пример может производить впечатление пространного описания некоей банальности, чего-то само собой разумеющегося. Но часто это «само собой разумеющееся» и есть то, о чём не думают, и что впоследствии оказывается проблематичным, глубоким. «Само собой разумеется», что предмет, если его отпустить, упадёт вниз. Однако, несмотря на общую теорию относительности Эйнштейна, притяжение масс, гравитация остаются в нашем представлении глубокой тайной. Так и здесь. Кроме готовых, оформленных, прямо или косвенно доступных чувству «действительных» вещей космос содержит необозримый запас определённых в ux свойствах, но (ещё) не существующих объектов, корреспондирующих с человеческими потребностями. Следует показать, что первоначальное техническое формообразование, «изобретение», есть мысленное извлечение и разработка посредством рук и инструментов таких форм решений, которые «предустановлены». Для абсолютно однозначно (включая дополнительные условия) поставленного технического задания в идеале есть лишь одно совершенное решение, а не набор случайных. Практические решения являются вследствие этого подлинными настолько, насколько они к нему приближаются. Это показывают многие примеры развития технических решений. Велосипед вначале появился в многообразных, сегодня выглядящих причудливыми формах. Сегодня для каждой задачи (пол, размер, нагрузка, местность и т.п.) есть практически единственная, варьируемая лишь в несущественных деталях (особые пожелания или специфические задачи) форма решения. Каждый конструирующий техник знает это асимптотическое приближение к «идеальной» форме решения, которая накладывается на конструкцию, нормализует и стандартизирует её. [...]

\section{9 Зона столкновения между потребностью и порядком природы - «Четвёртое царство» - Нечёткие границы исполнимости - Расширение творения - Динамика творения - Соответствие областей}

Анализ процесса изобретения показал, что между сферами человеческих потребностей и природного порядка есть общая область, в которой эти две сферы могут быть соотнесены друг с другом. Современным примером такого соотнесения является хемотерапевтический медикамент Эрлиха, древним - колесо. Они относятся к человеческим нуждам $и$ являются сообразнылм законам природы образованиями. В такого рода формах 
потребности исполняются в соответствии с законами природы. В этом выражается сущность техники. Но предпосылкой является возможность исполнения. Возможность есть не для каждого человеческого желания. Например, такого технического предмета, который бы мыслил осознанно в подлинном смысле слова, выбирал, принимал решения, осуществлял целеполагание, не существует; такого предмета нельзя ожидать и от самой совершенной кибернетики. Царство возможного в природе, тем не менее, намного больше, нежели царство наличных, существующих форм природы. «Изобретённое» переносится оттуда в опытный мир, делается «действительным», но всякая искомая и обнаруженная там форма оказывается предустановленной. Она может быть реализована лишь тогда, когда она познана в достаточном приближении. Такое положение дел важно в свете онтологии.

Воплощение всех готовых образов решений, не порождаемых, но извлекаемых человеком в изобретении, я в первом издании этой книги назвал «царством», намеренно обозначив его в соответствии с восходящим к Канту делением в качестве «четвёртого царства». То, что здесь возникнут возражения, я ожидал. Однако возражения не были достаточно весомыми. В свете изложенного само выражение не должно быть непонятным, полагаю, оно облегчает дальнейшую дискуссию. Относительно «четвёртого царства» я сформулировал несколько тезисов. Важнейшими из них являются следующие.

1. Царство предустановленных образов решений обосновывает и ограничивает технику, которая определяется через него. В отношении человеческих потребностей часто невозможно предсказать, являются ли они техническими исполнимыми. Это верно и для древних времён, и для сегодняшнего дня. Возможно ли настоящее космическое путешествие, то есть посещение других планет? Возможно ли излечение любой болезни? Насколько можно продлить жизнь? Может ли человек управлять погодой? Возможен ли синтез белка из синтетических аминокислот? Позволит ли макромолекулярное исследование выйти за границы жизни? Ответить сегодня на такие вопросы «да» или «нет» - значит высказать мнение, но не знание. Как смог бы ответить греческий натурфилософ или средневековый мыслитель на вопрос о том, можно ли принимать, сохранять и в любых количествах воспроизводить звук и речь; или о том, можно ли друг друга видеть, говорить друг с другом через страны и континенты. Он ответил бы в соответствии со своим временем: «Немыслимо, следовательно, невозможно», - и обосновал бы это общими, полагаемыми в качестве истинных высказываниями. Мы знаем, что тождество «немыслимо = невозможно» не верно. Есть многое в багаже наших сегодняшних знаний, что ранее было немыслимым, а есть и такое, что и сегодня немыслимо, однако реально существует. Поэтому и для техники должно быть верным то, что в отношении возможности и невозможности обнаружения и реализации образов решений нет никакой определённости, если только задание не располагается в близкой, обозримой области, или если оно противоречит известному порядку природы.

Можно с достаточной уверенностью ожидать - я выбираю весьма скромный пример, - что возможно изобрести менее шумный пневматический молоток, вероятно, будут реализованы средства против артроза, полиомиелита, туберкулёза, рака. Исследователи и изобретатели верят в разрешимость своих проблем, иначе у них не было бы сил, чтобы вкладывать в их решение свои жизни. С аподиктической достоверностью можно утверждать, что в «четвёртом царстве» не пребывает в ожидании изобретателя образ реализации вечного двигателя. В случае техники речь идёт лишь о тех возможностях, которые соответствуют законам природы. Здесь граница техники. Эта граница постоянно раздвигается соразмерно нашему знанию о природе, однако она никогда не исчезает.

2. Когда мы в целях упрощения языка обсуждения заимствуем из теологически ориентированной метафизики выражение «творение» и подразумеваем под ним всю полноту космического, всё, прямо или косвенно доступное органам чувств, тогда творение предстаёт в несколько изменённой конфигурации: оно содержит не только объекты, «телесные субстанции», как говорили древние, от звёзд до частиц пыли, не только всё одушевлённое и неодушевлённое, но и существенно большую сферу латентных, то есть скрытых, еще не реализованных образов, которые посредством человеческой деятельности переносятся, «высвобождаются» к реальному существованию. Потенциальная часть космоса необозримо велика, и именно она обеспечивает для нас динамический характер творения. Поэт, чей антропоморфный язык свободнее, нежели язык техника или философа, мог бы сказать, что миллионы и миллионы обладающих силой упорядоченных образов стремятся к воплощению, взывают к технику, призывая его найти их в их так-бытии, перевести из сокрытости в видимый мир, освободить от оков и дать свободу действия. Он смог бы изобразить, как они завлекают и просят, чтобы выйти из вневременного пребывания в область действительного, как пробуждают и поддерживают в талантливой душе стремление к изобретательству. Призванная таким образом, собирается всё растущая армия, напрягает все силы, скрытые образы обнаруживаются, они входят в историю, принося с собой силы, каждая - свою, а вместе - силу, изменяющую мир. Поэт смог бы лучше выразить то, что было сформулировано в первом издании этой книги вот так: «Творение осуществляется ежедневно, проникая в видимый мир тысячами путей. Мы причастны ему и превращаемся вместе с ним. Мы созерцаем, как поверхность Земли ежедневно обогащается новыми формами, как стирается старое (устаревшие формы не возвращаются). Мы - посреди дня творения. Через созерцание, содействие, испытание мы постигаем и изменяем себя». 
3. Динамический характер творения чувствовали уже древние. Анаксимандр, чей образ возвышается на заре древнегреческой философии (Ницше назвал его главной фигурой среди натурфилософов), живший за 600 лет до н.э., был исполнен динамическим характером мироздания, но в другом смысле. Он задавался вопросом о первооснове (архе) существующего мира, который тогда виделся как множество телесно оформленного: всякий предмет в нём оформлен, ограничен. Он учил, что первоосновой является безграничное (апейрон), то, что само будучи неоформленным, из себя порождает, разворачивает и забирает в вечном повторении оформленное, миры. Динамический характер космоса, как он для нас раскрывается в технике, исходит из человеческой деятельности. Именно человек, носитель формообразующих сил, которые делают необходимым, заставляют исследовать, оформлять и обрабатывать, источник беспокойства как таковой, он извлекает образы силы из потенциального космоса, помогает им приступить к действию. Изобретающий человек - используем аналогию с фотограммой - приводит латентные картины к «развитию», раскрывает их, продолжает определённым и ограниченным образом творение, является одним из источников этой динамики ${ }^{4}$.

4. Тем самым мы можем обобщить: изначальные формообразующие способности человека являются основанием технического исторического прочесса, латентное наличие в «четвёртом царстве» предустановленных, подлежащих исполнению форм является основанием возможности техники. Динамика, неугомонность и неостановимость продолжающегося формообразования с её следствием в виде поразительной трансформации общества есть беспокойство человека, который не чувствует себя дома, который ищет родину, которому природы не достаточно.

5. Мышление человека, его направленные на познание усилия имеют в познаваемом родственный объект, в случае естествознания это предданная природа. Если бы не было такого рода эквивалентности, то не было бы и познания или, словами древних, отражения в духе. Это сродство было ясно грекам за 500 лет до н.э., и это была, так сказать, заря Европы. Должно быть и сродство между человеческими потребностями и латентными образами творения, пребывающими формами «четвёртого царства», корреспонденция в том же смысле, в каком она для других случаев точно показана теорией групп. Должны быть однозначные соответствия между потребностью и образом решения в потенциальном царстве природы. Насколько эти соответствия двух сфер можно прояснить в понятиях соответствия корреспондирующих структур, таких как «инвариантность», «трансформация», «гомо- и изоморфность», пока неизвестно. Работы такого рода нам неизвестны. Но именно в этом направлении лежит ответ на исходный вопрос этой книги: как возможна техника? Она возможна только за счёт структурной аналогии. В идеале словарю языка человеческих бед и желаний должен быть противопоставлен словарь форм исполнения с лежащим в основе взаимно-однозначным соответствием терминов обоих. [...]

6. Сформированное таким путём противопоставление области желаний, которая происходит из человеческой природы, с областью исполнений, которые становятся возможными благодаря силам природы, приводит к выводу о том, что не все потребности могут быть удовлетворены таким путём; потому что человек - не только природное, но и духовное существо. Но так как все духовные и душевные функции человека привязаны к природным процессам, следует понимать, что формы «четвёртого царства», то есть технические проблемы, являются значимыми предпосылками для исполнения таких потребностей, которые обусловлены его духовной природой, сформированы его сознанием. Это подтверждается тем фактом, что объективные предметы культуры в своём воплощении суть технические предметы.

\section{0 Изобретение - больше, нежели прикладное естествознание - Изобретательское творче- ство - Пионерские изобретения, развивающие изобретения - Конструкция, обработка}

Акт «изобретения» для познания технического обладает особенной важностью. Всякий, даже простейший предмет некогда еще не наличествовал, вступив затем посредством деятельности духа и рук в опытный мир на своём месте и в своё время, и оставшись в нём, возможно, в улучшенном и изменённом виде. Этот акт изобретения наделяет предмет историей. Этим актом начинается сила предмета. После изобретения начинается распространение предмета, его тиражирование на производстве, его сбыт на рынке. Однажды изобретённое лекарство распространяется в миллионах драже, пилюль, флаконов. Производство тоже имеет дело с техникой, однако, уже не только с ней одной...

Мы уже говорили о том, что подлинное изобретение предметов и технологий есть нечто большее, нежели «прикладное естествознание», больше, нежели просто соединение элементов, больше, нежели просто комбинация. Исполнение поставленного задания в случае каждого, даже самого мелкого изобретения имеет признак «быть удивительным образом больше». Часы есть нечто большее, нежели просто комбинация, соединение

\footnotetext{
${ }^{4}$ Здесь рекомендуем ознакомиться со статьей, опубликованной в нашем журнале: Боргест Н.M. Распознавание образов при создании артефактов как метафора и как прикладные технологии онтологии проектирования / Н.М. Боргест // Онтология проектирования. - 2015. - Т. 5, №1(15). - С. 19-29. Прим.ред.
} 
стрелок, маятников, шестерёнок, пружин. Они являются часами тогда и только тогда, когда они верно измеряют время; детали оказываются к этому способы лишь тогда, когда они стали членами осмысленного целого, так что это целое исполняет задачу, способно на большее, нежели его части, которые сами по себе в свете цели этого изобретения не способы ни к чему. Измерение времени - это удивительное «больше, нежели сумма» частей. Часы становятся часами благодаря целостной структуре, благодаря финалистской упорядоченности этого единства.

Изобретения исполняют свои задачи в рамках соответствующего законам природы порядка. Но они больше, нежели только «прикладное естествознание». Они возникают благодаря творческому началу нового формообразования. У слова «прикладной» нет такого значения. Знание о природе постоянно «прикладывается», применяется и животными, и людьми, часто неосознанно, но при этом еще не возникает новый, обладающий силой предмет техники. «Приложение», применение знания о природе должно быть дополнено финалистски оформленным стремлением $u$ исполняющим обнаружением, чтобы возникло новое. [...]

Среди множества разнообразных изобретений выделяются две основные группы: пионерские изобретения и развивающие изобретения. В первой группе признак человечески-творческого выражен с особенной ясностью. Наши примеры (колесо, сальварсан) это показывают. Когда речь идёт о столь важных объектах, пионерские изобретения такого рода могут влечь за собой новые эпохи, как это часто и происходило (паровая машина, литерная печать, телескопы, фотография, текстильные станки, телеграф, телефон и многое другое). Пионер опирается на самого себя, часто гениален, опережает своё время. Но речь не обязательно должна идти о великих вещах, решающим является личностный акт предвосхищающей своё время деятельности.

Развивающее изобретение, напротив, лишено этого уникального, взрывного, тесно связанного с отдельной личностью характера. Оно возникает из определённых временем условий, из знания, опыта, потребности. Если бы оно не было сделано данным конкретным изобретателем, то оно было бы сделано другим, потому что само время созрело. Такие изобретения довольно часто делаются почти одновременно разными людьми - и тут можно спорить о первенстве. Изобретатель возникает «как продукт своего времени, как производитель духовных сил своей эпохи»... Однако и здесь верно утверждение, что изобретениями они являются тогда и только тогда, когда содержат в себе момент нового качества, творческого начала, чего-то большего, нежели простая комбинаторика.

Чёткой границы между этими двумя видами изобретений и тем, что называют конструированием, нет. Исключительно важная деятельность конструирования в пространстве техники заключается в планомерной, систематической, финалистской разработке и построении. Конструирование точно так же является объединением формообразующих сил человека в качестве Investigator, Inventor, Faber.

Однако в противоположность полноценному изобретению результат конструирования известен заранее, определён, если только не допущена профессиональная ошибка. Момент неожиданности и удивления, уникальности здесь не подчёркнут или подчёркнут не так сильно. Конструктор остаётся в области известного, изученного, методически-систематического. Это необязательно должно означать, что конструирование не является высокодуховной деятельностью. Однако часто это так.

Римляне оставили пословицу: «Роeta nascitur, orator fit - поэт рождается, оратор учится». По аналогии можно было бы сказать: изобретатель рождается, конструктор же, с учётом необходимых для этой деятельности способностей, - воспитывается, формируется, обучается 5 .

В живой деятельности изобретение и конструкция проникают друг в друга. Многие конструкции содержат компоненты изобретения, многие изобретения - компоненты конструкции. Но и в конструировании роль һото faber, который должен сделать мысленную вещь «вещью в себе», предметом внешнего мира, характеризуется постоянным «внутренним» управлением. Такое внутреннее управление представлением позволяет с помощью рук и инструментов приблизить построение к идеальной форме решения, в повторяющихся усилиях привести должное к сущему. Однако для преодоления невероятного количества внешних трудностей необходимо управлять и материалами, инструментами, затратами экономических средств, пространства и времени. Трансцендирование изнутри наружу идёт сквозь компромиссы, ошибки, опыт, которые со своей стороны вынуждают изменять картину представлений. Если верно то, что посредством «homo faber», посредством «обработки» делается шаг наружу, то не менее верно и то, что на этой стадии осуществления происходит небыстрый (длящийся часто годы и десятилетия), кропотливый, угрожающий полным провалом процесс взаимодействия и взаимовлияния между представлением и опытом внешнего мира. Следует понимать, что оценка удачного решения формирует-

\footnotetext{
${ }^{5}$ Макс Айт 9 декабря 1903 года сделал доклад с названием «К философии изобретения», который нельзя не упомянуть. Он говорит, что вся культурная жизнь строится на открытиях, классифицирует открытия, отграничивает их от исследования, описывает творческий порыв (как основной источник изобретательской деятельности, как «озарение», творческое прозрение, как начало) и терпеливую, преодолевающую сопротивление проработку в качестве процессов изобретения, сопровождая их примерами. См. «Живые силы» Макса Айта, 1924. Прим. автора.
} 
ся «снаружи»: лишь апробирование позволяет решить, «функционирует оно» или нет, является ли решение «подлинным», достаточно ли оно приближено к идеальному образу решения.

\section{1 Роль техники в экспериментальном естествознании}

Поскольку техника всегда основывается на знании о природе, пусть оно даже столь примитивно, как в каменный или бронзовый век, решающим для неё стало новое основание естествознания около 350 лет назад. [...]

На что до настоящего момента практически не обращали внимания, так это на роль техники в экспериментальном естествознании. Поворот Галилея можно охарактеризовать, собственно говоря, как введение техники, её методов, её форм в исследование природы. Лишь за счёт неё возник мощный прогресс.

Экспериментирование, например, в физике, означает буквально следующее. Исследователь формирует для себя некоторое мнение, некоторую гипотезу. Далёкий от того, чтобы выдавать её за знание, он передаёт её, так сказать, «божественному суду» эксперимента. Это означает, что он измышляет в представлении некоторую постановку и некоторый метод, некоторое финалистское построение на основе законов природы, которое часто имеет изобретательский, как минимум, конструкторский характер. Наклонные плоскости Галилея со скатывающимися бронзовыми шарами и автоматическим измерением времени с помощью равномерно вытекающей воды для обоснования законов падения имеют признаки сделанного ad hoc изобретения. Наши измерительные инструменты, счётчики Гейгера, счётчики люминесценции, электронные микроскопы - это технические прибоpbl. Лаборатории оснащены ими, и без них не было бы сегодняшнего уровня знаний о природе. Хорошая постановка эксперимента сама по себе часто является подлинным изобретением, как минимум конструкцией, только не непосредственно для массового производства, а для единичного случая. Часто из этого рождается промышленный продукт, как, например, в случае счётчика Гейгера-Мюллера или многих приборов химической техники, которые вначале продумывались, строились и применялись в исследовательских целях, а затем оказались применимыми для экспериментального исследования, для контроля производственных процессов. Многие из наших сегодняшних измерительных приборов и измерительных инструментов возникли таким путём, потому что в наших областях если нечто заработало, то оно всегда будет работать при соответствующих условиях.

Часто и по праву развитие техники анализируют в связи с влиянием прогрессирующего естествознания. Фарадей, Максвелл, Герц привели к появлению электротехники. Но, насколько мне известно, еще никто не предпринимал попытки систематического исследования рождения и роста естествознания под влиянием прогрессирующей техники. Это определённо была бы очень богатая тема. Тогда отчётливее, нежели сейчас, проявилось бы то, в какой степени исследователь в самых разных областях естествознания должен быть техником в подлинном смысле слова, изобретательным, вдохновенным творцом. Исследователи и являются ими - но обычно это не замечается. Однако то, чем исследование обязано технике, неисчислимо велико, и настало время обратить на это внимание.

\section{2 Сила технических объектов основывается на «порядке» - Сущность этого порядка - Происхождение силы}

Мы уже много раз отмечали, что в момент исторического появления техники, а именно при открытии, в человеческое распоряжение поступает сила, которой раньше не было. Часто речь идёт об очень значительной силе, как например, в случае изобретения колеса, поставляющих энергию машин, действующих лекарств, книгопечатания, динамита, динамического крыла, прядильных и ткацких станков, производящих энергию атомных реакторов. Примеры такого рода бесконечны. Вопрос заключается в следующем: где размещается эта сила, в предмете или в методе? Ответ может быть обнаружен посредством анализа одного примера, и он оказывается верным и для других случаев. Для лучшего понимания мы возьмём такой пример не из области машиностроения (хотя можно было бы это показать на примере автоматической бумагоделательной машины, линотипа и т.п.), но из области действующих химических веществ, пусть таким примером будет синтетическое лекарство, сульфонамид, которое во многих случаях действительно предотвращает смерть. Что заставляет смерть отступить, когда несколько грамм, несколько кубических сантиметров сульфонамида вводятся в больной организм? Где размещена эта сила, которая способна на большее, нежели любой уход, любое сочувствие и стремление помочь, на большее, нежели сила всех армий, всех государств, всех моторов и станков мира?

Очевидно, что это специфическая сила определяется материальной структурой «лекарства». Это структура из молекул, которые построены из атомов. Она не может задавать виды атомов. Ведь это известные, широко распространённые атомы: водород, кислород, углерод, сера, фосфор и т.П., из которых состоят очень многие объекты. Однако атомы здесь совершенно конкретным образом упорядочены в единства, в молекулы. В органической химии бывают молекулы из сотен, тысяч и десятков тысяч атомов, химически (валентность и побочная валентность), пространственно и энергетически (в качестве квантовых построений) встроенных в молекулу. 
Такие молекулы являются микро-архитектурами крайне интересного устройства. Изменение порядка при сохранении атомного числа и вида атомов может изменить, снять характер молекулы, её способ действия. Часто для этого достаточно пространственного перемещения одного единственного атома углерода.

Ясно, что сила медикамента располагается в его структуре, то есть в совершенно конкретном порядке организации материальных и энергетических элементов в единство и целостность. Этот порядок делает так, что целое оказывается больше и способно к большему, нежели сумма его частей. Перед этим конкретным порядком отступает смерть в нашем примере. И часы - упорядоченное единство и целостность, и только поэтому они способны измерять время. Сумма их частей не способна к этому. И так повсюду, пример верен в случае самолёта, телескопа, дизельного мотора, микроскопа: порядок финалистски связанных элементов в единство системы есть место расположения силы технических предметов и технологий. [...]

Мы констатируем, таким образом, что носителем свойственной техническим объектам силы является структурный, определённый высшим единством финалистский порядок. Вытекающий отсюда следующий вопрос о происхождении силы не содержит больших сложностей. Это не человеческая сила, она происходит из космоса. Носителями силы являются не Нобель, но гремучий желатин, не конструкторы атомной бомбы, но энергия расщепления или в случае термоядерной бомбы - энергия, высвобождающаяся при синтезе лёгких атомов в тяжёлые, не Стивенсон и Левенгук, но локомотив и микроскоп. Люди обнаружили эти несущие силу образы и тем самым позволили, используя выражение Сократа, «родиться» этой силе в опытный мир. Она происходит из космоса, она - сила природы. В час, когда Отто Ган, Штрассман и Лиза Майтнер открыли расщепление атома и высвобождаемую им энергию, она была передана в руки человека, став доступной благодаря деятельности изобретающих и конструирующих техников. Космос содержит много больше того, о чём человек может мечтать.

\section{3 Разнообразие и смысловое единство техники - Построение человеческой среды - Инструментальная и электронная музыка в качестве примера}

Область техники необозримо многообразна, во многих отношениях. Техника повсюду проникла в человеческую деятельность. Ничто в пространстве цивилизации не происходит без неё. И представители, казалось бы, крайне далёких от техники профессий - философы, историки, деятели искусства, теологи, исследователи древностей, юристы - ежедневно её используют; им необходимы пишущие машинки, бумага, книги, журналы, средства передвижения, одежда и обувь, телефон, вода, отопление, свет, лекарства. Техника - это не только множество предметов (форм пространства) и методов (форм времени), техника - это познание, воля, стремление, действие, осуществление, применение, употребление. Видеть сущность технического только в употреблении объектов - ошибка. Если бы Шпенглер был прав, то техником был бы не химик, синтезирующий медикаменты, а тот, кто их принимает. [...]

Мы видели это единство в сочетании исходных способностей человека в качестве Investigator, Inventor, Faber. Мы его вновь обнаружили в учении о трёх признаках. Тем самым мы уже в некотором роде в состоянии различить, что относится к технике, а что нет. «В некотором роде» по той причине, что здесь, как и повсюду, встречаются пограничные случаи. Однако сейчас мы задаёмся вопросом о единстве в этом многообразии в другом плане. Исчисляющиеся миллионами различные технические объекты возникли из самых разных целей. Есть ли некое единство этих целей, есть ли некий единый смысл?

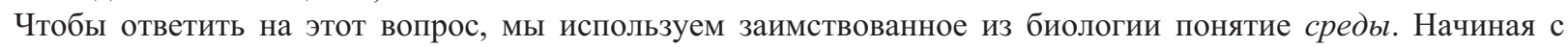
Якоба фон Икскюля (не перенимая, однако, его кантианских эпистемологических интенций), исследуют «среду» живых существ, растений и животных. Она дана и ограничена для живого существа тем, что имеет для него значение. Всё остальное это живое существо не замечает и не включает в поле своего действия. Растения и животные включены таким образом в их специфическую среду, которая у примитивных живых существ крайне мала, но увеличивается с повышением уровня развития. Они не могут из неё выйти - их среда есть для них своего рода жизненная оболочка, их тюрьма. Человеку Икскюль такой среды не приписывает. Человек лишён мира [sei weltlos] ${ }^{6}$. Это мнение мы не разделяем. Собственно человек как существо, которое не растворяется в природе, самостоятельно строит свою собственную среду, свой «мир внимания» и «мир действия». Неизменённая природа предлагает человеческому телу ровно то же, что она предлагает и животному. Но человек беспрестанно с помощью «внимания» и «действия» расширяет свою среду. И он встраивает в неё всё, что соответствует потребностям и способностям его одухотворённой души, а именно то, что обозначается широким понятием «культура». Культура есть то, что выходит за пределы природы, превосходит физическое, растительное, животное, то, что происходит из человеческой «заботы» [«Pflege»] (colere = «заботиться», «ухаживать» [pflegen]). У культуры есть субъективная сторона; мы говорим о культурном человеке, культурном народе. Объективная культура - это наличие, создание и использование объектов культуры, которые остаются тысячами после ухода

${ }^{6}$ Ср. Т. фон Икскюль «Человек и природа», 1953. Прим. автора. 
людей в виде книг, построек, статуй, картин, инструментов. Все объекты культуры носят одежды техники, придуманы и изготовлены техниками, даже если они по своим задачам выходят далеко за пределы техники.

Собор, надгробный крест или кубок - тоже произведения техники («тоже», не «только»). Библия и хорал, всё, что хранится в библиотеках, музеях, собраниях, предлагается и демонстрируется на уроках, концертах и лекциях, служит образованию, воспитанию, художественному вкусу, - носит одежды техники, не существовало бы без неё. Об ушедших культурах нам известно ровно столько, сколько их носители смогли запечатлеть в камне, на папирусе, в обнаруженных приборах. Если бы техники не было, культура исчезла бы вместе с народами. [...]

Единый смысл техники заключается в построении человеческой среды, в восхождении к духу сквозь данное природой, к определению, к становлению человеком. [...]

\section{7 Обобщённо о сущности техники - Приложение: примеры попыток определения}

Сущность техники с очевидностью обнаруживается при анализе её происхождения... В исследовании промышленности, ремесла, транспорта и многого другого техника повсюду обнаруживается как участник, как компонента. При анализе тех или иных обстоятельств, особенно неудачных, следует выяснить, что в них относится к социологии, что к экономике, а что - к технике...

Тема была ограничена только человеческой техникой. Она берёт начало с наших древнейших предков, которые тысячелетия назад изготовляли и использовали «артефакты» (искусственные предметы): украшения и инструменты, оружие и огневища. В такой превосходящей возможности животных деятельности выражаются исходные способности, формообразующие силы человеческой сущности, дух и душа которой превосходят растительно-животные зоны.

С изначальным стремлением к знанию (познание), к финалистскому, творческому формированию в представлении (изобретение) и к переносу (трансцендирование) вымышленного из имманентности во внешнюю действительность «вещей в себе» (обработка) (Investigator, Inventor, Faber) человек выстраивает собственную среду, метакосмос, соответствующий его сущности, в котором он может обитать, который даёт ему свободу от многих бед и опасностей, свободу к развитию, к становлению человеком, даёт ему силу, преодолевающую пространство и время.

Создаваемые таким образом предметы и технологии (формы пространства и времени), при всём своём разнообразии, имеют общие признаки, обусловленные формообразующими силами: соответствующий законам природы порядок, финалистская структура, обработка посредством рук (и инструментов). Создание и стремительно увеличивающийся инвентарь таких предметов и технологий называется «техникой». Их использование часто выводит за пределы технического пространства (книга, лекарство), как и их задача, отлитая из человеческой цели в форму предмета, часто осуществляется за пределами собственно технического (художественные произведения, научные, религиозные объекты).

Техника по праву может быть названа бытием реального и становлением реального из идей, переходом форм задач из имманентности в опытный мир, который за счёт этого перехода становится с течением времени богаче. Это положение вещей поставило вопрос о собственной силе технических объектов, о происхождении этой силы и об основаниях возможности технического творчества. В технике сущность («еssentia», «такбытие») предшествует существованию, наличному бытию. Лишь то, что обнаружено в своём образе решения, может быть осуществлено.

В это определение техники не входит (в противоположность сократическому «техне») личная способность, навык (верховой езды, игры на флейте, ремесленной деятельности), который умирает вместе с его носителем. Имеется в виду объективный набор предметов и технологий, то, что остаётся или может остаться, то, что действует на основе собственной упорядоченности. Изобретательская деятельность человека приводится в движение напряжением между действительностью, постоянно воспринимаемой в качестве неудовлетворительной, и лучшей возможностью, подразумеваемой в фантазии. Глубокое различие между этими областями, столкновение в реализации техники, а именно в предустановленных формах исполнения, человеческой потребности с данностью законов природы приводит к онтологическим проблемам.

Техника тем самым оказывается продолжением творения, которое несёт в себе, кроме набора собственных форм, возможность необозримо большого числа осмысленных форм. Отсюда динамический характер целого и исторический - отдельного изобретения. Отсюда смысловое единство техники как «идеального субъекта», как судьбоносной силы с собственным порядком ценностей и вытекающей из её общего предназначения этикой.

Мощное воздействие техники на мировую историю осуществляется за счёт её включения в исследование природы в форме человеческого эксперимента во времена Френсиса Бэкона, Галилея, Кеплера. Сегодняшнее впечатляющее развитие атомной техники - одно из многих следствий этого. Этим определяется современное европейское (и североамериканское) мышление. Многие из методов точных исследований и методических действий проникли в другие области. Планирование, разработка, исследование, действие осуществляются не толь- 
ко more geometrico, но и more technico, рационально и эффективно, с меньшим количеством эмоций, более реалистично - и более действенно. С этой поры техника во всё большей мере даёт свободу, время, средства для культуры, обеспечивает доступ к культуре для всё большего количества людей, которого они раньше были лишены. Мировоззрение Европы, Северной Америки и, под их влиянием, - всего человечества приобретает более рациональные и прагматичные черты. На этом пути были устранены причины многих бед, было получено невероятное количество действительно полезных результатов.

Разумеется, не обходится без опасностей, односторонности, перегибов. Ещё ничто великое не приходило к человеку без этих тёмных спутников. И всегда, как и сейчас в споре о технике, находятся люди, которые из-за этих слишком человеческих слабостей не способы более увидеть сам предмет. Многие не видят культурную миссию, подъём масс, которым впервые в мировой истории был открыт широкий доступ к участию в обладании культурой и в культурных процессах. Этот факт тем более значителен, что с начала истории за счёт тирании, классового господства, кабалы, злоупотребления властью миллионы людей унижались в их достоинстве, «превращались в массу» (уравнивались по низшим стандартам). Такое иногда случается и в пространстве истории техники, когда имеет место злоупотребление экономическими или политическими интересами, социальной отсталостью техники. По своей сущности техника не превращает человека «в массу», наоборот, она освобождает его и помогает, связывает людей в сообщество взаимного служения и отдачи. Однако - слишком многие судили о ней, не зная её или зная очень слабо - незнание некоторой вещи не является достаточным оправданием для суждения о ней. [...]

\section{Техника есть реальное бытие из идей посредством финалистского формирования и обработки из данного природой инвентаря. [Technik ist reales Sein aus Ideen durch finale Gestaltung und Bearbeitung aus naturgegebenen Bestaenden.]}

Первая строчка даёт онтологическое (бытийное) определение: реальное бытие вышло из «идей» в смысле творческих картин представления человека, которые в рамках способности к представлению антиципируют (предвосхищают) образы пространства и времени (предметы или методы) в их сущностных свойствах (их такбытии), что означает «essentia praecedit existentiam - сущность (сущностное свойство) предшествует реальному бытию».

Вторая строчка задаёт вид осуществления: телеологическое человеческое сознание духовно и с помощью рук и инструментов формирует строительные элементы таким образом, что они в их связности (целостности) в качестве задачи исполняют то, что для сознания являлось целью.

Третья строчка даёт основание возможности техники: материалы, энергии и законы природы являются сокровищницей и ограничением технического формообразования. 


\section{Рекомендуемые издания 2016-2017 года по тематике журнала}

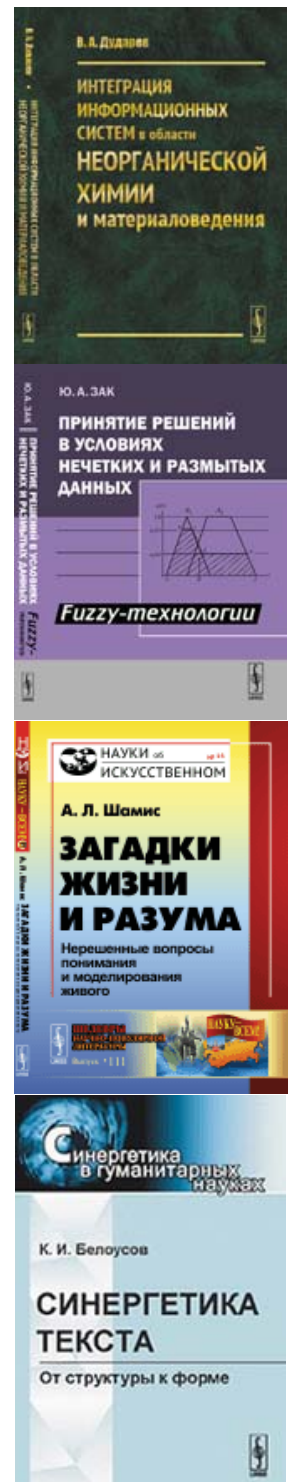

Дударев В.А. Интеграция информационных систем в области неорганической химии и материаловедения. - M: URSS. 2017. 320 с.

Книга посвящена вопросам создания интегрированных информационных систем в области неорганической химии. Приведен краткий обзор фактографических баз данных по свойствам неорганических веществ, созданных в мире, выполнен анализ архитектуры современных информационных систем в области материаловедения. Рассмотрены основные методы создания интегрированных систем, и на их основе предложена комплексная методология интеграции материаловедческой информации, учитывающая требования пользователей и программ анализа данных. Рассмотрены примеры использования консолидированной информации для поиска закономерностей в данных и компьютерного конструирования новых неорганических соединений.

Зак Ю.А. Принятие решений в условиях нечётких и размытых данных: Fuzzyтехнологии. Изд.2. - М: URSS. 2016. - 352 с.

Книга посвящена применению нечётких множеств и Fuzzy-технологий в задачах управления техническими и экономическими системами, в проблемах многокритериального выбора, в кластерном и регрессионном анализе, в задачах технической и медицинской диагностики, а также в оценке риска при принятии сложных решений в финансовой и производственной сфере. Рассматриваются формы представления нечётких множеств, свойства функций принадлежности, лингвистических переменных, операторов Fuzzy-логики и Fuzzy-арифметики. Приводятся модели и алгоритмы решения прикладных задач принятия решений в условиях нечётких и размытых данных.

Шамис А.Л. Загадки жсизни и разума: Нерешённые вопросы понимания и моделирования жсивого. - M: URSS. 2016. - 200 с

В книге рассматриваются нерешённые проблемы, связанные с конструктивным объяснением и моделированием живого, эволюции, поведения, восприятия и мышления. Для решения этих проблем необходимо выделение особенностей живого, его специфики и определение различий между живым и неживым, поиск возможности формализации этих различий и их реализации в искусственных системах. Особенности живого являются следствием активной неравновесности живой материи. Кроме активности и неравновесности требуют объяснения сознание, воля, целенаправленность, эмоции, ощущения, творчество и другие свойства живого.

Белоусов К.И. Синергетика текста: от структуры к форме. - M: URSS. 2016. - 248 c.

В монографии осуществляется описание текста в аспекте его онтологических качеств: пространственновременной протяженности, полионтологичности, сукцессивно-симультанной организации, функциональности и целостности. В работе широко используются аппаратурные методы исследования, моделирование, методы и методики психолингвистического эксперимента и квазиэксперимента, методы вероятностно-статистической обработки данных, в том числе факторный и кластерный анализ. Представленная исследовательская программа открывает возможность перехода от предмодельного состояния к модельным исследованиям в области общей теории текста.

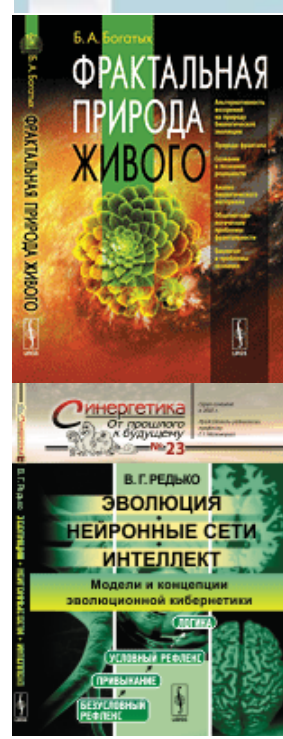

Богатых Б.А. Фрактальная природа живого: Системное исследование биологической эволюичи и природы сознания. - M: URSS. 2017. - 256 с

В книге рассматривается ряд ключевых проблем системного исследования биологической эволюции и природы сознания в рамках постнеклассического этапа познания, синергетической интерпретации, концепции фракталов, фрактальности. Фрактальные структуры живого рассматриваются в аспекте направленности, запрограммированности эволюционного процесса. Для обоснования этих положений анализируется альтернативность воззрений, с одной стороны, дарвинизма, синтетической теории эволюции, a c другой - номогенеза, а также ряда других теорий эволюции в рамках концепции фракталов. С этих позиций рассмотрен ряд спорных проблем и проявлений эволюции органического мира.

Редько В.Г. Эволюиия, нейронные сети, интеллект: Модели и концепџии эволюиионной кибернетики. - M: URSS. 2017. - 224 с

Книга посвящена обзору исследований эволюции биологических кибернетических систем. В работе проанализированы математические и компьютерные модели простейших кибернетических молекулярно-генетических систем, которые могли возникнуть в процессе происхождения жизни, а также общие модели биокибернетической эволюции; рассмотрены прикладные эволюционные алгоритмы. Обсуждаются философские вопросы, связанные с эволюционной кибернетикой, намечены проблемы для дальнейших исследований. Впервые в отечественной литературе представлены направления исследований - «искусственная жизнь» и «адаптивное поведение». 


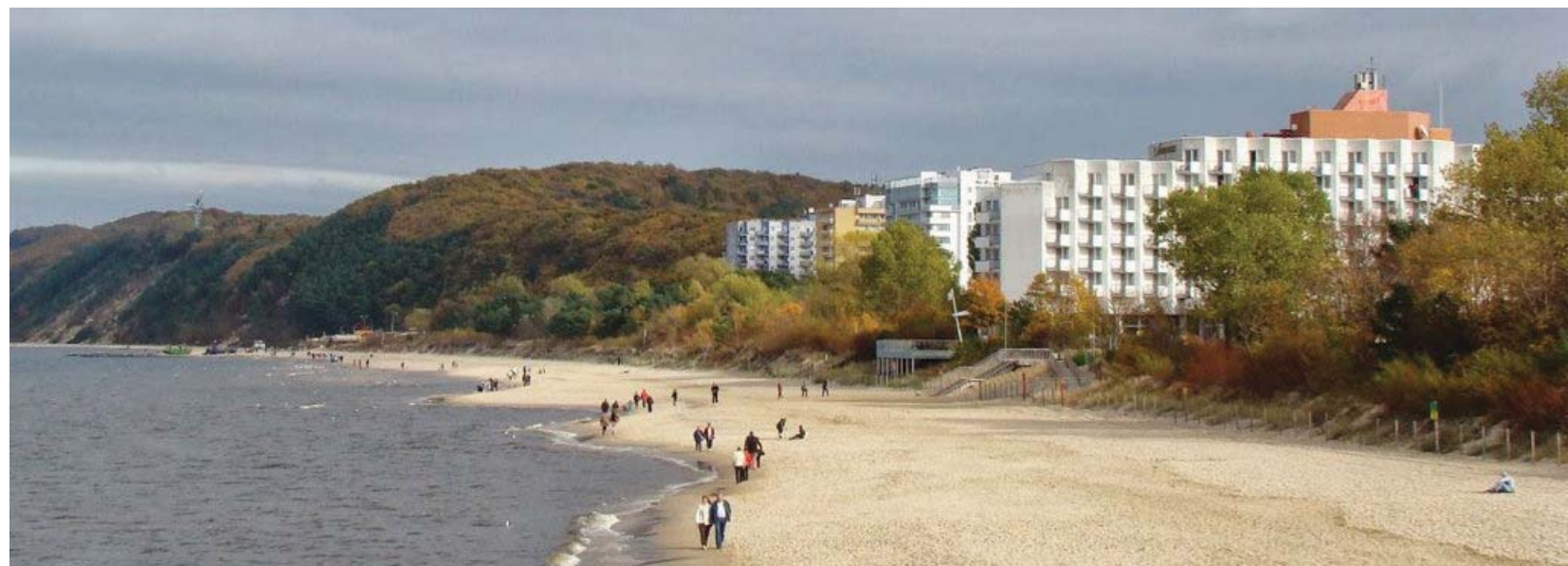

THE TWENTIETH INTERNATIONAL MULTI-CONFERENCE ON ADVANCED COMPUTER SYSTEMS

\section{ACS 2016}

\section{Międzyzdroje, Poland, October 19-21, 2016 ORGANIZED BY}

West Pomeranian University of Technology, Faculty of Computer Science, Poland IN COOPERATION WITH

Warsaw University of Technology, Faculty of Mathematics and Information Science AGH University of Science and Technology, Faculty of Physics and Applied Computer Science, Poland Ehime University, Japan

Polish Academy of Sciences IPIPAN, Poland

Kuban State University of Technology, Institute of Information Technology and Safety, Russia

\section{PURPOSE OF CONFERENCE}

Artificial intelligence, software technologies, biometrics and IT security are established fields of computer science of both theoretical and practical significance.

The aim of ACS 2016 Multi-Conference is to bring artificial intelligence, software technologies, biometrics, IT security and open and distance learning researchers in contact with the ACS community, and to give ACS attendees an opportunity to exchange some significant knowledge according to this areas of interest. Industrial and systems presentations bearing new ideas and solution paradigms are welcome as well.

The primary focus is on high-quality original unpublished research, case studies, and implementation experiences. Papers should have practical relevance to the construction, evaluation, application or operation of the systems. Theoretical papers must make convincing argument for the practical significance of the results.

Any other information details as committees, instructions for authors, invitation session (plenary papers) and payment details see the ACS web site: http://acs.zut.edu.pl.

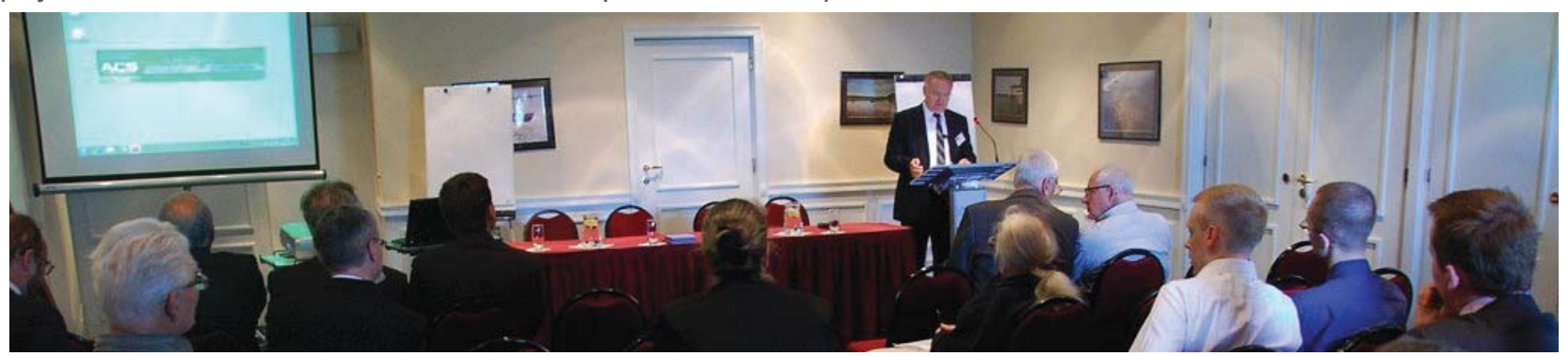

SECRETARIAT ADDRESS FOR CONTACTS

Sylwia Hardej, Miss

Faculty of Computer Science \& Information Systems

West Pomeranian University of Technology, Poland

Zolnierska 52, 71-210 Szczecin, Poland, tel. (+4891) 44956 62, shardej@zut.edu.pl 


\section{Индекс 29151}

В следуюших номерах журнала готовятся к публикации уже присланные в редакиию статьи авторов из Москвы, Ижевска, Уфы, Магнитогорска, Иркутска и других городов России, а также из Украины, Белоруссии, Армении и других стран ближнего и дальнего зарубежья. Высокая степень готовности статей из Самары, Москвы, Уфы, Иркутска, Магнитогорска и др. мест.

\section{ХОЛОНИЧЕСКИЙ ПОДХОД К УПРАВЛЕНИЮ}

\section{ИНТЕЛЛЕКТУАЛЬНЫМ РАЗВИТИЕМ ОБУЧАЕМЫХ}

Е.А. Самойлов (Самарский государственный социально-педагогический университет)

КАК «НУМЕРИЗОВАТЬ» ПОНЯТИЕ «ВАЖНЕЕ»

С.А. Пиявский (Самарский государственный архитектурно-строительный университет)

ОНТОГНОСЕОЛОГИЧЕСКИЙ ПОТЕНЦИАЛ ПРОБЛЕМЫ КОНСТРУКТИВНОЙ УСЛОВНОСТИ

А.Н. Огнев (Самарский университет)

\section{ОНТО-ЛОГИКА ЭКОУСТОЙЧИВОЙ АРХИТЕКТУРЫ}

А.Н. Ремизов (Некоммерческое партнерство «Совет по «зеленому» строительству»)

\section{ИСПОЛЬЗОВАНИЕ ОНТОЛОГИЙ}

\section{ДЛЯ УПРАВЛЕНИЯ ЗНАНИЯМИ ОРГАНИЗАЦИИ}

И.А. Савичев (Российский экономический университет им. Плеханова)

ОЦЕНИВАНИЕ ЗНАЧИМОСТИ ДЕФЕКТОВ НА РАННИХ СТАДИЯХ ПРОЕКТИРОВАНИЯ АППАРАТНО-ПРОГРАММНЫХ КОМПЛЕКСОВ НА ОСНОВЕ ПОЛОЖЕНИЙ ТЕОРИИ ИНТЕРСУБЪЕКТИВНОГО УПРАВЛЕНИЯ

В.Е. Гвоздев и др. (Уфимский государственный авиационный технический университет)

ОНТОЛОГИЯ ПОНЯТИЙНОГО АППАРАТА

ДЛЯ ОБРАБОТКИ БИБЛИОГРАФИЧЕСКОЙ ИНФОРМАЦИИ

О.С. Логунова и др. (Магнитогорский государственный технический университет)

ОНТОЛОГИЧЕСКИЙ ИНЖИНИРИНГ ИНДИКАТИВНОГО АНАЛИЗА

УРОВНЯ ЭНЕРГЕТИЧЕСКОЙ БЕЗОПАСНОСТИ

Е.В. Носырева (Иркутский национальный исследовательский технический университет)

Флажками на карте России представлена география авторов статей номера журнала, который Bы, уважаемый читатель, держите в руках.

Присоединяйтесь и Вык кам!

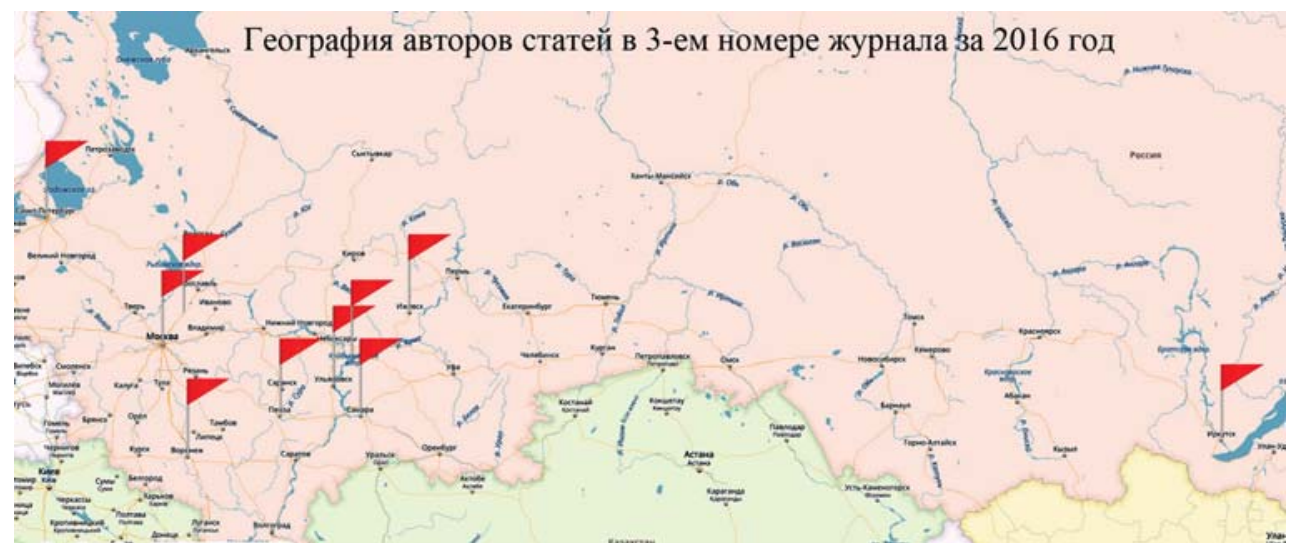

Ontologists and designers of all countries and subject areas, join us!

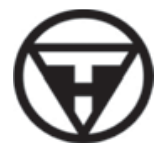

Издательство “Новая техника" - Publisher «New Engineering» Ltd Россия, 443010, Самара, ул.Фрунзе 145 - 145, Frunze Str., Samara, 443010, Russia 